\title{
ORTHOPAEDIC SURGERY IN THE UNITED STATES OF AMERICA
}

\author{
Leo Mayer, New York, N.Y. \\ I-THE EARLY YEARS
}

Forty years ago an interne on one of the services of a large New York City hospital, when discussing his ambition of specializing in orthopaedic surgery with a leading neurologist of the city, a man well versed in the actualities of medical practice, was given this advice: "Don't! You'll be wasting your surgical talent. Flat feet, crooked backs, and a few cases of joint tuberculosis: that's what you may expect." Though, as we shall see shortly, orthopaedic surgery at that time actually embraced much more, the neurologist was expressing truthfully the dominant concept of the speciality. What has occurred during the past half-century to change the accepted status of orthopaedic surgery from one of scant, grudging recognition to that of one of the major surgical specialities? That is the subject of this paper.

The modern era of orthopaedic surgery in America begins in January 1887 when at the instigation of Dr Virgil P. Gibney and Dr Newton M. Shaffer, both of New York City, a group was called together to consider the advisability of organizing an orthopaedic association. When after discussion a vote was taken, ten were in favor, two were opposed and two cast blank ballots. Following the opinion of the majority, a rule of democratic procedure to which the Association has steadfastly adhered, the first meeting of the new society was scheduled for June of that year at the New York Academy of Medicine. It was to be called "The American Orthopaedic Association." Its purpose was "the advancement of orthopaedic science and art." Gibney was elected chairman; Robert Lovett of Boston served as temporary secretary and was replaced in June by Lewis H. Sayre. Thirty-five men were invited to become members; they may well be known as the "founding fathers." For the next fifteen years the proceedings were published in a yearly volume known as The Transactions. These publications reflect accurately the thought and the achievements of this early period. They show clearly the struggle between two concepts: the old, emphasizing the importance of braces and the mechanical phases of therapy; the new, insisting on the inclusion of surgery and stressing the necessity for more accurate knowledge of the etiology and pathology of disease. This, the modern view, was well expressed by A. M. Phelps, who in his presidential address (1894) said: " The orthopaedic surgeon of the future will be a man who has been thoroughly schooled in all the departments of medicine, who will have a perfect knowledge of pathology, surgical bacteriology and anatomy." And by De Forest Willard (1890) of Philadelphia who wrote: "The true orthopaedic surgeon should be ready to treat, care for and carry a case through all stages, no matter whether the treatment requires the application of apparatus or whether it necessitates a serious surgical operation." And by A. J. Steele (1890) of St Louis who maintained: "The orthopaedist should first be a general surgeon." The opposition nevertheless fought a stubborn battle, which actually lasted in some quarters until the end of the first world war. A. B. Judson, president in 1891, insisted that when an amputation was indicated in an orthopaedic case, a general surgeon should be called in to do the surgery. Newton Shaffer pleaded for the orthopaedic surgeon to "specialize in mechanical therapy.... To mingle surgery and mechanics is to endanger both." Gradually, however, the new concept gained control as evidenced by the replacement of Dr Shaffer as chief of the New York Orthopaedic Hospital in 1898 by a rising young surgeon, Russell Hibbs, who proved conclusively that surgery and mechanics could be "mingled" with great advantage to both.

This insistence on surgery as an integral part of the speciality precipitated an inevitable fight with the general surgeon. Not that this was anything new: "The orthopaedist was 
always at war with the general surgeon," said Phelps in 1894 . "There never was a time when they could lie peacefully together in the same bed excepting like the lion and the lamb-one inside the other, and the poor orthopede was always inside." The conflict continued to be long and bitter; the orthopaedic surgeons have had to show their mettle and prove their case by the superiority of their results. Said Phelps: "The specialists won the battle in a fair fight upon the field of thought and the profession of medicine awarded them the victory." Gradually, almost imperceptibly, the scope of the speciality has widened by what might be termed the pragmatic method- "If you can do the job, it's yours to do." As early as 1891, Gibney quoted the remark of a prominent general surgeon, "the next work on orthopaedic surgery will likewise tell us all about fractures and dislocations." But though the scope has widened, the original intent of orthopaedic surgery has remained constant. This intent was phrased with particular felicity by Royal Whitman in his presidential address in 1896: "Orthopaedic surgery is that division of surgery which treats of disabilities and diseases of the locomotor apparatus, and of the prevention and treatment of deformities of the framework of the body."

What were actually the "disabilities and diseases of the locomotor apparatus" which claimed the attention of " the founding fathers" during this early period ? Dr Samuel Ketch, the president in 1897, has given us an enlightening summary of the papers of its first ten years. Of 292 papers, 114 dealt with tuberculosis of the bones and joints. Of these, forty-nine were concerned with Pott's disease, thirty-five with coxitis and nineteen with the knee. Club feet came next in frequency with forty-three papers, then scoliosis with twenty and congenital dislocation of the hip with fourteen. There were nine dealing with rickets, seven with spastic paralysis, six with poliomyelitis and six with torticollis. There were seventy-nine unclassified, including outstanding contributions by Dr Whitman on flat feet $(1889,1895)$ and juvenile coxa vara (1894), by Townsend (1889) on acute arthritis of infants, by Brackett (1891) on atrophy in joint disease, by Goldthwait (1892) on joint lesions due to spinal disease, by Hodgen (1892) on neuritis involving the serratus magnus and rhomboids, by Robert Lovett (1897) on spondylolisthesis, by Taylor (1894) on infantile scorbutus, and by Park (1895) on acute infections of the bone. Certainly the range of topics is extensive, with only a few striking omissions: fractures, backache and bone neoplasms are scarcely mentioned. In 1897, however, appeared Whitman's paper "Fracture of the Neck of the Femur in Childhood," a signpost indicating the direction in which orthopaedic surgeons were to advance. In this study of ten cases, in none of which the diagnosis had been made at the time of injury, Whitman expressed the germ of his subsequent abduction method by this statement: "[reduction of this fracture] might best be accomplished by abducting the leg to the full." Even more significant is the comparative lack of attention to the X-ray. A number of skiagraphs were presented, but the vital importance of the discovery for orthopaedic surgeons seems not to have been fully appreciated. Even as thoughtful a student as Robert Lovett, in his presidential address in 1898 dealing with " Pathology in its Relation to Orthopaedic Surgeons," does not once mention the work of Röntgen, nor did he seem to. envisage its meaning for the pathological knowledge he considered so important to orthopaedic advance. In his remarkable paper of 1900 dealing with the mechanics of lateral curvature he employed a variety of ingenious methods of investigation, but not the $\mathrm{X}$-ray. The omission is all the more significant since Lovett was already thinking in terms of the X-ray in 1898, when with Cotton he employed roentgenology in his study of "The Anatomy of the Foot." No doubt the apparatus then available was so incapable of demonstrating fine bone detail that even the far-seeing Lovett failed to realize that the X-ray would help the development of orthopaedic surgery more than any other single discovery of the next half-century. The only orthopaedic surgeon of the day to stress its significance was Louis A. Weigel of Buffalo. He presented a paper in 1899 dealing with the diagnostic value of radiography. X-ray films. were, he asserted, " not as fallacious as had been claimed." It is interesting to note that his paper did not elicit any discussion. 
Returning to Dr Ketch's summary, it is obvious that the major interest of the Association centered in tuberculosis of the joints. The treatment was predominantly conservative. A fierce controversy raged between the adherents of the traction method, which was considered the "American way" (though according to Mr H. O. Thomas of Liverpool it originated with Mr James of Exeter in 1839), and the rigid fixation advocated by Thomas and by Robert Jones. There was also a clash of opinion regarding the treatment of abscesses, which occurred with great frequency (in 25 to 50 per cent of cases of coxitis). John Ridlon maintained with conviction: "Leave them alone. Not one in a hundred will cause trouble, if you just fix the joint." Others believed in aspiration, or, if this was not effectual, in open operation, excision of the abscess wall, and drainage. In cases of progressive coxitis, excision of the hip-an operation first performed by Lewis Sayre in 1854-was permissible. Some successes were reported, but according to Lovett their records showed a mortality close to 50 per cent and, of those who survived the operation, the functional results were bad. Only a few bold surgeons, like Harry Sherman of San Francisco, essayed the operation in the earlier stages of the disease, when the prognosis was more favorable. Attempts were made after mechanical excision of obvious pathological tissue to sterilize the field either with pure carbolic acid, left in place one minute, then neutralized with alcohol, or with 10 per cent iodoform in glycerin, or with iodoform gauze. None of these methods gained popularity, since a fatality was reported due to carbolic acid poisoning and the iodoform did not prove effective. Far more encouraging were the results in excision of the knee. These were in reality fusions of the joint. Joseph Bryant reported ten cases in 1891, all with good results except one, in which death ensued from Bright's disease. He urged therefore that the operation be done early, before kidney damage had occurred. The following year James Moore reported six cases, three of them complicated by extensive abscess formation; these patients recovered with ankylosed knees in good position. He concluded his excellent article with this illuminating statement: "It would be morally wrong under ordinary circumstances to operate at any early stage, because by proper orthopaedic treatment a movable joint could be secured." Phelps, Plimpton (1895) and Willard (1893) also reported cures by excision of the knee, but the concept of fusion as the treatment for a tuberculous joint had to germinate for many years before fruition. The idea of internal fixation in Pott's disease was suggested as early as 1891 by B. E. Hadra, who, having successfully wired the spinous processes for fracture of the cervical spine, advised the application of this method to prevent the deformity of Pott's disease. This, however, seemed to Reginald Sayre " such a novel departure that no one could pronounce judgment upon it at once." A good idea of the results of treatment can be gained from the paper of Lovett and Goldthwait (1889) dealing with " abscesses of hip disease." They found that during the five-year period 1884-88 inclusive, of 320 cases treated at the Children's Hospital, abscesses developed in seventy ( 23 per cent). Of these seventy, sixteen were dead and four dying; in seven cases the result was unknown. Approximately the same mortality was found by Gibney's five-year study of 150 cases of coxitis at the Hospital for the Ruptured and Crippled. Of these, 107 were classed as cured, eleven as dead, twenty-five as still under treatment, and in seven readmission had been advised. The adduction-flexion deformity which was evidently a frequent end-result was corrected by the Gant or the Adams subcutaneous osteotomy of the femur. Of this operation Ap Morgan Vance said in 1887: "I freely confess that I will break a man's femur subcutaneously with as little misgiving as to the outcome as I would divide his tendo Achillis." The first man to suggest the value of climatic treatment was George Packard of Denver, Colorado, who in 1898 reported the rarity of suppuration in his cases, which he attributed not to his treatment, but to " sunshine (320 clear days a year), pure air, rarity of the atmosphere, and the dry sandy soil." But the greatest impetus to the rational therapy of tuberculosis came from the pathological laboratory. Edward H. Nichols of Harvard, probably at the instigation of the Boston orthopaedic group, studied 107 tuberculous joints secured at the operating table or in the post-mortem room,

Vol. 32 B, No. 4, NOVember 1950 
and in 1898 reported his findings to the Association in its longest communication (fifty-three pages). The occasion was dignified by the presence of Professor J. Collins Warren, head of the surgical department of Harvard, and of Professor William J. Councilman, head of the department of pathology. Both of them, as well as Gibney and Bradford representing the Association, expressed their appreciation of the significance of Nichol's study, which in reality laid the ground-work for our modern knowledge of the pathology of joint tuberculosis.

If the results in tuberculosis did not measure up to modern standards, the same cannot be said of club feet, the second in point of number of Dr Ketch's list of publications. Beginning with Bradford's paper in 1889, it is evident that the surgeons of that epoch thoroughly understood the pathology and treatment of the deformity, and that their results in all grades of deformity were excellent. Bradford's exposition could be used to-day as a lecture for medical students, so modern is it in every respect. The treatment of congenital dislocation of the hip, however, was in its earliest transition stage. Hoffa and Lorenz both attended meetings of the Orthopaedic Association. Lorenz's first paper in 1894 dealt with open reduction and explained his method. His second in 1896 gave a lucid description of the pathology and the "bloodless" method of reduction. Undoubtedly attempts were made to follow his technique, but according to Bradford's exhaustive paper in 1900 the technique by both the closed and the open method "lacked precision." He found that in all of his cases done by the "bloodless" method redislocation occurred; that the earlier cases treated by open operation were failures, but of the last group done in 1899 and 1900, six out of nine were successful. In 1902 he pointed out the danger of reluxation due to anteversion and advised a rotational osteotomy of the femur to overcome this element of the deformity.

The problem of scoliosis, according to Phelps, " rises before us each year like a spectre." He went on to say that despite all the claims made for sundry methods "I have yet to see (1900) the first case of lateral curvature of the spine, in which bone changes had taken place, cured by any plan of treatment known to the scientific world." Right he certainly was thensome think so even now-but our understanding of the mechanics of scoliosis was given a mighty forward surge in 1900 by the unusual research of Robert Lovett. Working on cadavers by the insertion of long needles into the vertebrae, and confirming his observations on living models, he was able to prove that "lateral flexion and torsion are associated parts of one compound movement and neither can exist without the other. That, however, in side-bending from the flexed position the torsion is diametrically opposite from what it is in the extended position, and that the spine follows the laws governing flexible rods in this regard." Again, "In flexion the bodies rotate toward the convexity of the curve, the spinous processes toward the concavity. In extension, however, the bodies rotate toward the concavity, the spinous processes toward the convexity of the curve." Lovett's observations still hold good. In the application of his results, however, to therapy he was not able to disprove the dictum of Phelps just quoted. The cure of scoliosis had to be handed down to future generations of orthopaedic surgeons.

In overcoming the deformities of infantile and spastic paralysis, Goldthwait (1895) and others employed tendon transfers, tenotomies and fusion operations, frequently with some measure of success. Dane and Townsend in 1903 were able to trace thirty-six out of fifty cases done at the Children's Hospital, Boston, and concluded that most of the tendon transplants gave poor results except where the tibialis anterior was transferred to the outer side of the foot for the correction of paralytic varus. Astragalectomy and fusion of the " tibio-astragaloid" joint, on the contrary, gave strong, useful feet.

The orthopaedic surgeons of this period varied markedly in their surgical prowess. Some of the leaders, like Newton Shaffer, did not even attempt major surgery, Others like Harry Sherman, Bradford, A. J. Steele, Royal Whitman, Phelps, James Moore, Joseph Bryant and De Forest Willard must have been expert operators, some of them with a remarkable flair for originality. Goldthwait (1900) reported thirty-eight operations for internal derangement 
of the knee with a failure in only one case. Reginald Sayre (1893) demonstrated satisfactory correction of a club hand, due to an absent radius, by a shift of the ulna to the middle of the carpus. Phelps (1894, reported by D. Brown) secured normal motion by operating on an ankylosed jaw; and on three cases of posterior congenital dislocation of the humerus due to fracture of the posterior lip of the glenoid. De Forest Willard (1889) performed as many as six osteotomies at one time to correct rachitic deformities. Moore (1892), Bryant (1891) and others could resect a knee with accuracy and speed. Moore (1895) corrected severe "pigeon-toe" by a rotational osteotomy of the tibia. Bradford (1895) cured recurrent dislocation of the patella by an operation corresponding exactly to modern methods. Steele (1898) corrected a very severe hallux valgus by resecting part of the proximal phalanx of the big toe, exactly as in the Keller-Brandes procedure. Gillette (1898), G. G. Davis (1900) and Charles Thomson (1901) had the courage to operate on ununited fractures of the femoral neck and, after freshening the bone ends, to hold them in anatomical alignment by ivory pegs, nails or screws.

These men were accurate observers. Without the aid of X-ray, Royal Whitman (1894) worked out the pathology and symptomatology of adolescent coxa vara and slipping epiphysis. His papers on weak foot $(1889,1895)$, Morton's toe (1898) and congenital torticollis (1891) are classics which should be read and re-read by every orthopaedic student. Goldthwait (1894) made a fine study of the anterior arch by means of frozen sections. H. L. Taylor (1899) reported two cases of enlargement of the tibial tubercle (later called Osgood-Schlatter's disease). Without knowing anything about vitamins, they understood the dietetic causes of rickets (Charles N. Dixon Jones 1889) and infantile scurvy (Taylor 1894). Townsend made a masterly study of "Acute Arthritis of Infants" (1889) and urged early incision as the one hope. Brackett diagnosed subgluteal bursitis (1897) and cured it in three cases by excision of the bursa. Harry Sherman gave a good description of cleidocranial dysostosis. and McKenzie (Toronto) showed an amazing knowledge of psycho-somatic medicine (1901).

They were men of great industry as evidenced by their writings. Between 1887 and 1902 the fellows of the Association published 1,951 papers (H. A. Wilson, presidential address 1902); 583 of them appeared in The Transactions. Bradford wrote 105 papers, two text-books and numerous articles on the progress of orthopaedic surgery in the Boston Medical and Surgical Journal. Virgil Gibney wrote ninety-six papers, Roswell Park 100 papers and twenty-five clinical lectures, De Forest Willard 105 papers. Besides they gave much time to their hospital services as well as to private practice. They were enthusiastic about orthopaedic surgery and at times optimistic to the point of betraying an adolescent sentimentality. Said Steele in his presidential address (1893): "Had the infant Byron or the child Pope been born in our day, the club foot of the one would have been corrected, and the boss of the other prevented, and mighty genius which gave itself to satire and immorality would have sung ennobling verse and virtue's sweet refrain."

Of preventive medicine there was a faint beginning. Bradford tried to get shoes made according to anatomical designs; he also wrote an excellent paper on the seating of school children, and helped devise a good-posture chair. Of social service and rehabilitation there were no evidences in the publications available to the author. A sharp line apparently was drawn between the dispensary clientele and private practice. In 1891 Foster of Cambridge wrote: "I am not writing this article ('Extension in Bed in Spinal Caries ') with reference to tenement house cases but a very different class-those who will meet us later in society and be known as our cases; also those people of means who come from a distance. For such the best is none too good." No voice was raised in protest: evidently further evolution was necessary before the sociological responsibilities of orthopaedic surgery were to be realized.

From the foregoing pages it is obvious that the American Orthopaedic Association represented a group of hard-hitting intelligent physicians who were determined to advance their speciality. Yet they were given only scant recognition in the medical world. In 1889 the members of the Association included four full professors, two clinical professors, one associate

Vol. $32 \mathrm{~B}$, No. 4, November 1950 


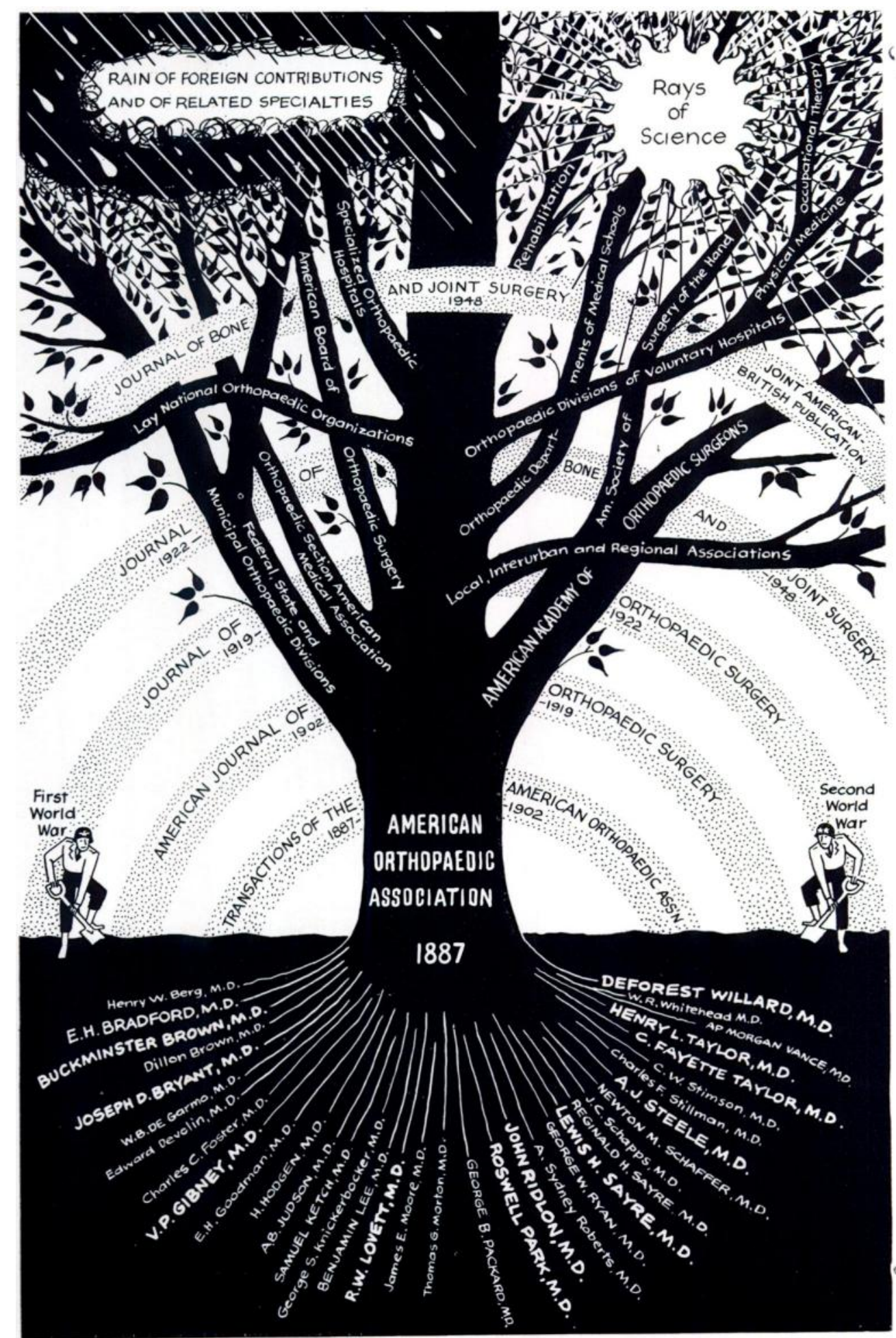

GROWTH OF ORTHOPAEDIC SURGERY IN THE UNITED STATES, 1887-1950 
professor, two lecturers and a few " assistants." Twelve universities were represented. In 1900 Harry Sherman devoted his presidential address to the topic of orthopaedic instruction in the medical schools. He discovered that of seventy-six universities only thirty-eight mentioned teaching orthopaedic surgery (just 50 per cent), whereas sixty had courses in gynecology, fifty-nine in pediatrics and fifty-eight in neurology. In only five colleges was the instruction both didactic and clinical. The Association was evidently doing its fair share of education, for of fifty-one active members twenty-six were engaged in teaching at twenty-three medical schools. Only slowly and by dint of education of the lay public as well as their brother physicians has orthopaedic surgery been able to attain its present status in the medical schools; and even now, as Dr LeRoy Abbot has pointed out, it is still unable to achieve universal recognition.

\section{II-A BIRD'S-EYE VIEW}

The period 1887-1902 came to an end when, at the urging of their president, H. Augustus Wilson, the members of the Association voted to discontinue The Transactions and instead to publish an American Journal of Orthopaedic Surgery. This step meant a radical transition from a self-centered and more or less provincial type of publication to one of world-wide significance. As early as 1893 Steele had advised publishing abstracts of all orthopaedic papers irrespective of their national origin. This method of imparting orthopaedic information was begun in 1902 in the pages of the Journal and kept up for many years. Through the change in the form of their publication, the inclusion of contributions from non-members and the printing of abstracts, not only the Journal but orthopaedic surgery in America took on new stature. Growth since then has been phenomenal. To its extraordinary development many factors have contributed: the development of roentgenology; improvement in surgical technique particularly in the field of bone-grafting, tendon-plasties, fusion operations and arthroplasties; increased interest in fractures, treatment of which has come more and more into the hands of orthopaedic surgeons; rapid advance in the knowledge of bone pathology, particularly of neoplasms; the successive development of numerous organizations all designed to further the advance of orthopaedic surgery; an increasing popular interest in the crippled child and the disabled adult; finally, two world wars and the obvious economic necessity for rehabilitation-these are but a few of the factors which come to mind. The development of orthopaedic surgery in the United States may be likened to that of a giant oak tree. The simile is not to be taken too literally; it serves only to characterise the unity, the complexity and the growth of American orthopaedic surgery. The roots, representing the thirty-five " founding fathers," spring deep from the soil of native mechanical ingenuity and surgical skill. From the great trunk-the first Association, founded in 1887-have sprung numerous branches, some of them, like the American Academy of Orthopaedic Surgeons, matching the parent trunk in importance. Other branches are seen representing the American Board of Orthopaedic Surgery, the orthopaedic section of the American Medical Association, the local, inter-urban and regional associations, and the American Society for Surgery of the Hand. Still other branches indicate the hospital development: the orthopaedic departments of the general hospitals, the specialized orthopaedic hospitals and crippled children's homes, the veterans' hospitals, the departments of physical medicine and occupational therapy, and the institutes for rehabilitation. There are branches to represent the national lay organizations such as The National Foundation for Infantile Paralysis, The Shriners' Hospitals, The International Society for Crippled Children, The National Association for Cerebral Palsy. Note also a most important branch-the orthopaedic departments of the university medical schools. The branch labelled federal, state, and municipal orthopaedic divisions includes the Army, the Veterans, the Children's Bureau, the State and City Departments of Health, hospitals and schools, above all, the great organization instituted by the Compensation Acts which have been so helpful to the injured workman, and brought a wealth of material to many important surgeons. Note the men in uniform who are cultivating the soil about the

vol. 32 B, No. 4, NoveMBer 1950 
tree. They signify the stimulating effect of the two world wars on the growth of the speciality. The figure on the left is in colonel's uniform to typify the activity of the two colonels who were at the head of the orthopaedic departments of the Army during World War I: Colonel E. G. Brackett in the Surgeon-General's office, and Colonel Joel Goldthwait overseas. The figure on the right wears a two-star cap to represent Major-General Norman Kirk, SurgeonGeneral of the Army during World War II, the only American orthopaedic surgeon to hold such a high rank. In both wars the high percentage of injuries of the extremities presented an enormous mass of material which the orthopaedic surgeon was better able to take care of than any other specialist. New problems were presented and solved: a host of younger men became enthused with the ambition to become orthopaedic surgeons. This led, as will be told later, to a great expansion after World War II of the system of orthopaedic residencies. In the upper left corner are visible the "life-giving rain of foreign contributions and of other specialities" such as neurology, pharmacology and pediatrics. From the outset The American Orthopaedic Association has invited foreign surgeons to attend their meetings and to contribute of their experience. Robert Jones, William Adams, Howard Marsh, Professor Hoffa of Berlin, Adolf Lorenz of Vienna are only a few of the distinguished men whose names appear in The Transactions. Through the years American orthopaedic surgeons have drawn knowledge and enthusiasm from colleagues in every part of the world. The debt of orthopaedic surgeons to the other branches of medicine is so great and self-evident that it does not require exposition here. In the right upper corner appear the rays of science shedding light upon the tree: from Lovett's early demonstration of the analogy between flexible rods and the spine with respect to the mechanical laws affecting both, from the epoch-making discovery of Röntgen, through the dramatic revelations of modern chemistry, physiology, bacteriology and pathology, down to the discovery of atomic fission, orthopaedic surgery has derived light and inspiration from science. In the background are seen five arcs, resembling rainbows, which represent the five periods in the development of our Journal:

1. The Transactions-from 1887 to 1902.

2. The American Journal of Orthopaedic Surgery-from 1902 to 1919.

3. The Journal of Orthopaedic Surgery-from 1919 to 1922.

4. The Journal of Bone and Joint Surgery-from 1922 to 1948.

5. The Journal of Bone and Joint Surgery, published jointly by the American and British Boards of Editors-from 1948 to the present.

The term "American" which has been used so frequently thus far has developed a peculiar connotation in connection with the phrase "American Orthopaedic Association." In reality it includes the orthopaedic representatives of Canada as well as of the United States, with a happy admixture during recent years of representatives of Cuba and Mexico. It is hard to differentiate between the activities of the Canadian members of the Association and those from the United States. Some of the most distinguished presidents of the Association have been Canadians and some of the most inspiring meetings have occurred in Canada. In deference, however, to the separate article on progress of orthopaedic surgery in Canada, I have endeavoured so far as possible to remain "south of the border" in my report of orthopaedic advances.

\section{III-THE TRANSITION PERIOD}

The years from 1903 to the end of the first world war may well be considered the transition period in the development of American orthopaedic surgery. During this time it acquired the general recognition which had at first been denied it. The period was characterized by: 1) great technical advances, based largely on more exact knowledge of pathology and of the anatomy and physiology of the musculoskeletal system;2) increasing sense of responsibility to the community evidenced by the founding of large numbers of hospital-schools for crippled children, by the formation of hospital social service, by the growth 
of the rehabilitation concept and by the development of compensation acts in many states; 3) the founding of numerous orthopaedic societies to instruct and to stimulate; 4) closer contact with foreign orthopaedic surgery through the medium of "exchange articles" and an extensive abstract system in The American Journal of Orthopaedic Surgery; 5) the expansion of orthopaedic teaching; 6 ) finally, and most important, by the inculcation of restoration of function as the essential purpose of orthopaedic surgery.

The period came to a dramatic climax with the advent of the first world war, when as John Porter said in his presidential address (1918): "I believe that a new era has begun for our speciality through the impetus given it by the demands of war." Overnight the medical profession, including the surgeon-general's office, realized that " the orthopaedic surgeon ... from his peculiar training and experience ... was specially qualified to deal with a large group of casualties, to conserve limbs and restore function, so as to return to civil life a multitude of soldiers who would be otherwise hopeless pensioners." (C. L. Starr 1918.) Had the war occurred fifteen years sooner, orthopaedic surgery could not possibly have played the important role which it did. What happened during these years to create the amazing development of the speciality?

Probably no factor was more important than the extension of orthopaedic surgery to adults. E. G. Brackett in 1905, commenting on the enlargement of the orthopaedic field, said: "It is within the remembrance of even most of the younger men when the orthopaedic work was almost entirely confined to children. Now a large, if not the larger, part is devoted to adults, and in the work with them there has come relief to one of the most helpless forms of cripples." In the same year Virgil Gibney (1905) reported on the work of the adult orthopaedic ward of the Hospital for the Ruptured and Crippled over a two-year period; during this time 154 cases had been treated. He ended with a "plea for hospitals in which the adult cripple, male or female, may receive the same scientific treatment that has so long been meted out to the children." The inclusion of adults led to the study of new fields, hitherto unexplored by the orthopaedic surgeon: backache, fractures of the femoral neck, neoplasms, circulatory disturbances of the extremities, stiff painful shoulders, chronic arthritis, and the problem of mobilizing ankylosed joints.

Until the early years of the twentieth century cases of low back-pain had been considered under the vague category "lumbago." Goldthwait and Osgood in 1905 and John Dunlop in 1907 published papers emphasizing the pathological changes in the sacro-iliac joint and its ligaments as a cause of back pain. There followed papers by Meisenbach (1911), Freiberg (1913), Bucholz (1914) and many others dealing with the anatomy of the lumbo-sacral region, the pathological abnormalities and the clinical syndromes associated with them. Although the treatment was chiefly conservative and relied on rest, adhesive strapping, posture exercises and braces, Painter in 1908 advocated arthrodesis of the sacro-iliac synchondrosis. Blanchard and Parker in 1915 resected an impinging transverse process of the fifth lumbar vertebra with relief of pain; Roberts (1916) stressed gluteal myositis as an etiological factor. In 1916 Arnold of New Haven described his methods of fusion of the sacro-iliac and lumbo-sacral articulations. The gynecologist, the genito-urinary surgeon and the neurologist became interested in back-pain and indicated the frequency with which displacements of the uterus, or renal neoplasms or spinal-cord tumors caused back pain.

It is notable that some lines of therapy begun during this period-for example, fusiondeveloped more and more significance and became more and more popular, whereas the test of time resulted in less and less resections of transverse processes and fewer diagnoses of gluteal myositis. The development of bone-graft surgery by Fred Albee (1911) and by Russell Hibbs (1911) led to marked improvements in the technique of fusion which has now become so important in the operative treatment of low back pain.

Although previous to 1902 a few isolated articles on fractures had appeared and Whitman had written an important paper on fractures of the femoral neck in childhood suggesting the

VOL. $32 \mathrm{~B}$, No. 4, NOVEMBER 1950 
feasibility of the abduction treatment, the great wave of orthopaedic interest in fractures began in 1902 with Whitman's description of his method of treatment by abduction combined with internal rotation and traction. His success in treating by this means fractures which had hitherto defied cure brought the orthopaedic surgeon into the field of fracture treatment. This was commented on by H. L. Taylor in his presidential address in 1908. Numerous articles then began to appear dealing with fractures of all the bones of the body from the atlas and axis down to the metacarpals. G. G. Davis of Philadelphia, Ryerson of Chicago, Mixter and Osgood, A. R. Shands, Packer, and Hammond of Providence, Hawley of Bridgeport and many others made contributions. Of particular importance were the papers of Albee and Henderson in 1914, the first dealing with treatment of acute fractures by the inlay bone graft, second, the treatment of ununited fractures by the same method. Hartwell in 1916 published eleven cases of fracture of the spine without paraplegia and was therefore one of the first to substantiate the views of Gillette presented in his presidential address of 1901 . Cotton stressed the importance of reduction of os calcis fractures and published his well-known method in 1916. Cotton also made his own contribution to the treatment of fractures of the femoral neck by urging that they be impacted with a heavy mallet. Of particular orthopaedic significance was the paper of Robert Jones in 1913, "The Orthopaedic View of the Treatment of Fractures." "Every fracture," he said, " is potentially a deformity and if it becomes a deformity will lead to impairment of function." He concluded this article with these sentences: "The question for the modern surgeon is not whether operative treatment is to supersede manipulative... The problem before each of us is how we can improve our skill and technique in both manipulative and operative treatment and what means must we adopt in each individual case to give to our patients the surest, safest and most complete restoration of function." The quotation is of significance as emphasizing the concept of function which more and more has become a characteristic of orthopaedic surgery.

Typical of the expansion of the scope of orthopaedic surgery is the interest in circulatory disturbances of the extremities. Lovett's paper in 1906 on intermittent limping was followed in 1908 by Wilson's on Raynaud's disease, and in 1913 by Stern's on spontaneous gangrene in orthopaedic surgery. Further interest was stimulated by the pathological studies of $\mathrm{Dr}$ Leo Buerger, whose work on thrombo-angiitis-obliterans marked the beginning of an exact knowledge of the pathological changes.

The study of stiff painful shoulders owes much to Dr Codman of Boston, who as early as 1906 described the anatomy of the subdeltoid bursa, its relation to the supraspinatus tendon and its great significance in the etiology of pain about the shoulder joint. Walter Brickner's paper in 1912 contributed the idea of the abduction treatment as an important phase of therapy.

In many of the presidential addresses reference was made to the importance of arthritis; in the meeting of the American Orthopaedic Association in 1912 a symposium was held on the subject. Elliott of the Montefiore Hospital told about gastro-intestinal causes of arthritis. Nathan wrote of the treatment of toxic arthritis, Peckham on the importance of the abdomen as a factor in arthritis, Preiser of Hamburg voiced his theory of the incongruence of the joint surfaces as a cause of arthritis deformans. Leonard Ely brought out the fact that actually very little was known about the etiology of chronic arthritis. The treatment continued to be largely conservative and empirical, but in $1915 \mathrm{E}$. G. Brackett published his paper on the operative treatment of arthritis in which fusion was reported as a valuable method of cure, particularly in osteoarthritis of the hip.

Even more significant is the attempt to mobilize ankylosed joints. One of the pioneers was Dr William Baer of Baltimore who in 1909 published his preliminary report on the insertion of chromicized pig's bladder as an interposition material in performing arthroplasty. In 1918 sufficient advance had been made to warrant a symposium on the subject with fascinating papers by Baer, Henderson and Allison. The method had been applied to the 
hip, the knee and the elbow with particular success. From the ranks of the general surgeons, Dr John B. Murphy of Chicago popularized arthroplasty and presented his methods at meetings of the American Medical Association as well as in numerous publications.

In the first part of this paper dealing with the early years, the strong interest of orthopaedic surgeons in tuberculosis was emphasized by the great number of papers devoted to this subject. During the period now under consideration occurred a remarkable advance. This was preceded by attempts to influence disease by the use of tuberculins, vaccines and serums. Ridlon in 1907 reported on the use of tuberculin, Freiberg in the same year on Marmorek's serum, Taylor on vaccines using the opsonic index as a means of control. Ogilvie, Mixter and Hastings, Plummer, Painter all reported their attempts, but without too much success. Leonard Ely in 1911 was the first orthopaedic surgeon to voice the inadequacy of the treatment of tuberculosis. He wrote: "This entire subject forms a reproach on surgery . . Here is a frequent disease whose cause we have known for many years and whose effects we have had ample opportunity to observe. . . Surely one might expect to find in regard to it among intelligent medical men a practical consensus of opinion, a weight of scientific opinion to which one may resort for light. . . . No such scientific opinion exists as to any phase of the disease." He stressed two main principles: immobilization of the joint and avoidance of secondary infection. Further: "The erection of hospitals in the affected cities for children with tubercular joints is an anachronism; glass sun parlors and closed wards are an abomination."

In the same year and within several months of one another Russell Hibbs of New York Orthopaedic Hospital and Fred Albee of the Post Graduate Hospital both published articles on fusion of the spine for Pott's disease. The concept of fusion which had been dormant for so many years finally became alive. Although the methods proposed by these two surgeons were quite different in technique, the purpose was the same, namely, to prevent deformity and aid in healing by a physiological method of internal fixation. This differed radically from Lange's method of implanting steel rods, published in 1910. Ryerson in 1914 characterized the Albee operation as " the acme of conservative treatment." In 1916 Albee was able to report on 539 cases of Pott's disease treated by the insertion of a tibial graft, with an arrest of the disease in 460 , improvement in fifty-nine, unimproved in twenty, and deaths in nine cases-a great advance over previous statistics. In the same year Rugh reported twenty-six excellent results of the Albee operation in a series of forty cases. Rogers (1914) extended the idea of fusion to the knee and strongly urged early operation in the adult as the best means of stopping the progress of the disease. Ryerson (1914) favored ankylosis of the hip, but at that time there was still considerable difference of opinion on this problem by competent orthopaedic surgeons, Allison (1915) adhering to the view that healing with motion could be secured. Willis Campbell (1917) in two papers urged heliotherapy as an important adjuvant.

To perfect the technique of his spine operation Albee had developed an electric motor-saw for the removal of the tibial graft. Thanks to this effective instrument, bone-graft surgery became increasingly popular. Mention has already been made of its use in the treatment of fresh and ununited fractures; soon the method was extended to all forms of bone plastics. In 1916 Albee published his first book on Bone Graft Surgery detailing the numerous uses to which the bone graft could be put. This clinical application of bone grafting was based on important experimental work which preceded it. In 1912 appeared Macewen's book The Growth of Bone. The great Scottish surgeon presented a series of convincing experiments to prove that the periosteum acted simply as a limiting membrane and that bone growth occurred through the functional activity of the osteoblast. Albee published an experimental study of bone growth in 1913. Gallie in 1914 wrote on the "History of a Bone Graft." His contention was that all bone cells of the graft die and that the graft acts simply as a scaffolding. Mayer and Wehner in 1914 published their paper on " Experimental Study of Osteogenesis." These authors came to a conclusion opposed to that of Macewen. They excluded the periosteal activity by applying a small metal or glass cap to the surface of a rabbit's tibia and found

VOL. $32 \mathrm{~B}$, No. 4 , NOVEMBER 1950 
that under those conditions there was no evidence of activity of the osteoblasts: that on the contrary wherever the periosteum regenerated, abundant bone growth occurred. These authors were also able to show that in transplants of young spongy bone not all of the bone cells had the appearance of being dead; a number of them showed definite evidences of cell division, indicating their viability.

The experimental method of investigation became more important during this transition period and was applied by many orthopaedic surgeons to aid in the solution of practical problems of treatment. In 1906 Silver of Pittsburg studied the extent of necrosis caused by tendon suture. In 1907 Osgood, using a clever spring-balance device, studied the comparative strength of the foot muscles. The next year Legg (1908) wrote his thesis for admission to the American Orthopaedic Association on experimental study of atrophy in joint disease. Nathan in 1909 studied the effects of injecting staphylococci into the joints of rabbits. Meisenbach tried to stimulate bone-growth by the injection of formalin or alcohol into the region of the epiphysis. Stern (1910) studied the circulation of club feet by injection of the vessels. Thomas (1914) ankylosed the spine of kittens in order to observe whether this caused any retardation of growth. Erlacher of Graz (1915) reported to the Association his experiments on the direct neurotization of paralyzed muscles. Lovett (1916) elaborated on the spring-balance test begun by Osgood so as to check the relative strength of normal and paralyzed muscles. Haas of San Francisco (1917) made a fascinating study of the relationship of blood supply to the longitudinal growth of bones and was able to show that the nutrient artery was of no significance, whereas the vessels in the region of the epiphysis were of the greatest importance. Steindler (1917) studied the nutrition and vitality of tendons after transplantation.

Largely because of these experimental studies, technical advances occurred in almost every field of orthopaedic surgery. Methods of improving the residual deformities of poliomyelitis engaged the attention of many orthopaedic surgeons. Lange in 1910 as the guest of honor of the American Orthopaedic Association gave an exhaustive paper on the subject. His particular contribution was the utilization of silk to prolong tendons so as to insert them directly into bone. The silk was impregnated with paraffin and sterilized with sublimate of mercury. By means of these silk tendons he claimed satisfactory correction of deformity in many hundreds of cases. Bartow of Buffalo used silk to form supporting ligaments of the joints: with Plummer in 1911 he published his first article. In 1913 and 1916 there were additional papers in the last of which operations on 152 joints were reported. G. G. Davis of Philadelphia expressed himself as strongly opposed to the use of silk ligaments which gave, in his opinion, only temporary improvement. Of more permanent benefit were the astragalectomy operation of Whitman for the correction of calcaneus deformity first published in 1901, and the horizontal transverse section for cavus deformity published by G. G. Davis in 1913. The correction of calcaneus by the two-stage operation of Robert Jones (1907) gave excellent permanent results. In 1916 appeared three papers by Mayer on the physiological method of tendon transplantation. They were the outgrowth of experimental and clinical work done with Biesalski of Berlin; in the method described each step of the operation was made to conform with the known facts of tendon anatomy and physiology. They furnished the basis for the subsequent brilliant advances in tendon surgery by Dr Sterling Bunnell. Gallie (1922), instead of using silk ligaments to fix joints, performed a tenodesis operation. He was able in 1916 to report 90 per cent of successes in 150 cases.

In the field of nerve surgery attempts were made to employ the direct neurotization method which Erlacher had demonstrated as effective in animals. Steindler (1915) found that there was a slight regeneration in clinical cases but not enough to be of clinical significance. In the field of cerebral palsy, Allison and Schwab in 1910 injected alcohol into the nerves of overactive muscles so as to produce temporary paralysis. With a similar idea in mind Stoffel of Mannheim reported in 1913 his method of severing portions of the nerves of spastic muscles. His technique involved an accurate knowledge of the internal architecture of the nerves. 
Still another approach to the problem was that of Foerster of Breslau; utilizing laminectomy as an approach he severed some of the posterior nerve roots of the spastic lower extremities so as to interrupt the reflex arc. Hunkin (1913) reported his results in eighteen operations by this method; his results were fairly good.

Scoliosis during this period witnessed two vigorous attacks-the first in 1906 and 1907 by Henry $\mathrm{O}$. Feiss of Cleveland who published an exhaustive series of papers dealing with the etiology of the condition, the second by Dr E. G. Abbott of Portland, Maine, in August 1913. Abbott placed his patients in a hammock in a flexed position and instituted rotational and lateral compression to force the vertebrae to return to the normal position through the same path by which they had progressed to deformity. His results aroused great interest not only in America where they furnished the subject for a symposium, but also abroad. In 1913 he demonstrated his method in Berlin before the Deutsche Orthopädische Gesellschaft, and also in France. The enthusiastic reception which first greeted his work was somewhat tempered by the reports $(1914,1915,1916)$ of a committee on scoliosis (Freiberg, Silver, Osgood) appointed by the American Orthopaedic Association; they concluded that though some cases actually showed correction the force employed was so great as to be dangerous. Abbott replied to the Committee in five papers (1917) which presented a mass of clinical material substantiating his claim that structural scoliosis could be completely corrected. Why has the method fallen into disrepute ? Probably because, despite the correction, patients developed other unsightly deformities of the ribs and pressure wounds of such a degree as to make the aesthetic end-result distasteful to them.

The contributions of Dr Michael Hoke of Atlanta deserve special recognition. In 1903 he essayed the difficult feat of correcting a severe scoliosis by extensive rib resections on both the convex and concave sides. His patient survived the two operations and was apparently benefited by them. Of more significance was his paper in 1911 on the pathology and operative treatment of severe recurrent club feet. This masterly presentation showed Hoke to be an authority on the anatomy and function of the foot. His operative methods were precise, ingenious and so effective that practically normal function was secured. This study of club feet led to his development of a special operation to reshape and stabilize paralysed feet, by combining subtalar arthrodesis with temporary resection of the head of the talus and replacement in such a position as to balance the foot. Although not published in the Journal until 1921, the operation was devised at a much earlier date and is therefore included in the period with which we are now dealing.

Frank Ober also made an important contribution to the operative correction of club feet by his procedure, reported in 1916, in which he divided the deltoid ligament and any other restraining bands on the medial side of the foot.

The idea of lengthening short legs by osteotomy and traction was first advanced by Codivilla in 1903 . His idea was elaborated in 1916 by R. T. Taylor who combined the lengthening of the short leg with a shortening of the long leg. This idea was later to lead to important developments.

In 1917 appeared an article of particular significance by Smith-Petersen on a new "supra-articular subperiosteal approach to the hip joint." This was the first of a series of important contributions by an orthopaedic surgeon who has always based his work on most precise anatomical knowledge.

While these practical improvements in operative therapy were being made, pathological knowledge was advancing rapidly. The value of the Roentgen ray as a means of study and diagnosis began to be more generally appreciated, and Osgood in 1903 wrote: "As in the evolution of any new discovery applicable to medicine, the opinion of the profession in regard to the value of the Roentgen rays has passed through certain stages. These may be described as the stage of enthusiasm, the stage of disappointment, and finally the stage in which the true value is admitted and the limitations recognized." He then proceeded to point out the

vol. $32 \mathrm{~B}$, No. 4 , NOVEMBer 1950 
limitations and the positive value of the X-rays. Blanchard (1906) made a contribution to the pathology of rickets by X-ray studies, Painter and Rogers in the next year to the diagnosis of neoplasms whose presence "might give rise to confusion in the minds of orthopaedists." R. T. Taylor pointed out its value in the detection of tuberculous coxitis (1903). In 1915 Percy W. Roberts of New York described nine cases of " juxta-articular sarcoma." That some of those cases eventually proved to be myeloma, not sarcoma, does not detract from the historical value of the paper; by post-mortem studies and the examination of museum material much was learnt. Allison (1905) wrote a most illuminating account of the pathology of congenital hip dislocation as the result of the post-mortem dissection of a seven-year-old Navajo Indian girl who died four months after reduction. Brackett (1910) added greatly to our knowledge of the pathology of spinal tuberculosis by a study of the specimens in the Warren Museum of the Harvard Medical School. Elliott (Montefiore Hospital, New York) performed autopsies in five cases of rigid spine (Marie-Strumpell) and published his observations (1905). Mayer (1913) described a specimen of congenital anterior subluxation of the tibia on the femur, and suggested an operative method for curing the condition. Ely (1913) described the pathological changes in two cases of tabetic arthropathy which came to post-mortem examination. By combining clinical observation with $\mathrm{X}$-ray study and occasional observations at the operating table, numerous advances were made. In January 1903 Osgood published a thorough study - anatomical, clinical and pathological—of the adolescent tibial tubercle; and in October of the same year Schlatter published a similar paper. Freiberg (1905) wrote on coxa vara adolescentium in its relation to arthritis deformans, Napier (1905) on two cases of spondylolisthesis, G. G. Davis (1905) on multiple exostoses, Blodgett on congenital dislocation of the head of the radius, Geist (1907) on chondrodystrophy, Yaegar on exostoses of the os calcis which he considered gonorrheal in origin, Painter and Clark (1908) on myositis ossificans, Horwitz (1909) on adolescent rickets, Freiberg (1910) on osteochondritis dissecans, S. Fosdick Jones (1911) on Madelung's deformity, Dunlop (1911) on the adolescent tibial tubercle, Silver (1911) on benign cysts of bones, Coon (1911) on dyschondroplasia, Hammond (1911) on brittle bones, Gaenslen (1915) on Paget's disease, Allison and Moody (1915) on osteochondritis deformans juvenilis which $\mathrm{H}$. L. Taylor characterized in the same year as " Quiet Hip Disease," now usually termed Legg-Calvé-Perthes disease.

Of special note is the study of Sprengel's deformity published by Alexander E. Horwitz in 1908. Carried on under the supervision of Bradford, Lovett and Brackett, it illustrates what can be learned by combining the historical viewpoint with clinical and pathological study. Aside from a few improvements in operative technique little has been added to Horwitz's paper during the past forty-two years. Another pathological-clinical paper of great importance was Sever's (1916) on obstetrical paralysis. He demonstrated the site of the pathological lesion, classified the paralysis, disproved the theory of T. Turner Thomas that the essential pathology was in the shoulder, and worked out an excellent method of operative correction. Fisher (1916) published a paper on torticollis, Brackett and Hall (1917) on osteochondritis dissecans, Henderson (1917) on osteochondromatosis of the knee, Freiberg (1914) on infraction of the second and third metatarsals, Honeiz (1917) on bone changes of leprosy, Barrie (1918) on haemorrhagic osteomyelitis and bone sarcoma.

Another method of study has already been alluded to under the topic of backache-the anatomical approach applied to clinical problems. Goldthwait has been the most brilliant exponent of this method. He applied it not only to the lumbo-sacral and sacro-iliac regions, but also to the shoulder. His paper in May 1909 on "An Anatomic and Mechanical Study of the Shoulder Joint, explaining many of the cases of painful shoulder, many of the recurrent dislocations and many of the cases of brachial neuralgias or neuritis" should be read by every orthopaedic student, not because all of Goldthwait's conclusions have stood the test of time, but because it is such a beautiful application of the scientific methods of accurate observation, deduction and induction. Goldthwait extended these studies to "relation of posture to 
human efficiency" (1909) and to the "influence of poise upon the support and function of the viscera." He considered good posture as essential to good health. To support his thesis he not only studied anatomical sections to illustrate the effects of visceroptosis but also turned " to the direct study of the human family" as portrayed in sculpture; from the period of the early Greeks down to St. Gaudens's figure of Lincoln he found "the chest high, the shoulders erect, the trunk so in balance that no group of muscles or part is strained, but action with the minimum of waste is possible, while the visceral support and function is maintained with the least effort." Swaim continued in the footsteps of his teacher Goldthwait and elaborated the theme in his paper "The Mechanically Unfit" (1915).

In the field of preventive medicine, Goldthwait (1916) maintained that " the orthopaedist had a much larger place than is commonly held." He wrote: "The time to stop the functionally weak back is in childhood by teaching the child how to use its spine. The time to prevent pulmonary disease is in childhood through training so that the body will be so developed that the lungs can be used rightly and gain the strength with which to throw off disease. The time to correct visceroptosis is in childhood, when the body can be so trained that the postural habits of weakness which lead to the harmful displacements cannot develop." Previous to this paper, the American Posture League had been formed in April 1914 with Miss Jessie H. Bancroft, assistant director of physical training in the New York City Board of Education, as president. Its activities were the direct result of the teaching of orthopaedic surgeons, beginning with Bradford and Reginald Sayre; the latter in his presidential address (1904) urged that the orthopaedic surgeon " teach our teachers what kind of desks the pupils should use in our schools. He must also impress on our public educators that there is very little use in developing the mind if it is done at the expense of so much wear and tear of the nervous system that the body which is to be controlled by this mind becomes a physical wreck." The Posture League hoped "by systematic education to establish a demand for healthful standards in what may be termed posture engineering." It assisted " with expert advice the engineers of the Brooklyn Rapid Transit Company, the seats of whose new subway cars are being constructed in accordance with the League's specifications." It was " in touch with several large organizations of workers engaged in the standing occupations-such as motormen and shop-girls-and proposes issuing official bulletins for their benefit illustrating the correct standing postures both for work and rest."

In other ways too one is conscious of a growing sense of responsibility of the orthopaedic surgeon to the community. E. G. Brackett (1905) urged that young orthopaedic surgeons should settle in communities where they were needed. Charlton Wallace made a special study in 1907 of the effects of imperfect hygiene on the production of bone tuberculosis, and urged that steps be taken to improve conditions in the tenements. Henry L. Taylor in his presidential address (1908) urged the importance of organizing the home, so as to "make it an integral part of the orthopaedic service. . . . The school should also be brought into helpful relation with the home, hospital and clinic. . . . Many children unable to attend public schools may advantageously attend special schools or classes for crippled children, or special classes in the hospital, or may receive instruction at their homes." Thus began the special classes for handicapped children, which are now a feature of the public school systems of most of our cities.

More and more what I)r Albert Freiberg (1937) has characterised as "The Social Point of View" has played an important part in orthopaedic surgery. "From the time when the identity of the orthopaedic surgeon became recognised, the care and the rehabilitation of the cripple has been his particular province. This is true of both the child and the adult cripple. . . . In every country which has developed facilities for the aid of indigent cripples, the orthopaedic surgeon will be found in the background, first winning respect by excellent professional accomplishment." The state care of crippled children was begun in the same year as the founding of the American Orthopaedic Association, and by one of its members, Arthur J. Gillette of St Paul. He persuaded the legislature of the State of Minnesota to

vol. $32 \mathrm{~B}$, vo. 4 , NOVEMBer 1950 
establish a hospital for crippled children: this was actually opened in 1897. His example, however praiseworthy, was not followed with the rapidity which it deserved; there were not many orthopaedic surgeons so persuasive as Arthur Gillette. Twelve years later (1909) in an editorial in the Journal he wrote of the sad plight of orthopaedic patients who in a large city with extensive hospital facilities had to return to their homes untreated because there were no vacancies. He continued: "After fifteen years of observation ... it is quite difficult for one to refrain from making a simple and impassioned argument setting forth the necessity for state care of the crippled and deformed. When one reads the various letters of inquiry [to the Minnesota State Hospital for Crippled and Deformed Children] one cannot but wonder what becomes of these children living in states or cities where no institution whatever exists for their care and treatment; yet there are in the United States to-day forty-seven states and territories that have no provision for this class of unfortunates." Despite the slow response of state legislatures, private charity did something to make good the deficiency. In 1911 Douglas McMurtrie, a young man who ran a printing establishment in New York, wrote the leading article for the May issue of the Journal; it was entitled " The Care of Crippled Children in the United States." He, too, concluded his paper with a plea for state support. " From a national standpoint the situation is most unsatisfactory, all the institutions being grouped around four or five cities. The gravest defect is that immense sections, notably the West and South, are without any provision whatever."

H. Winnett Orr of Lincoln, Nebraska (1911), also favoured state support, and cited the example of the Nebraska Orthopaedic Hospital, whose increasing usefulness during the five years of its existence had been met by "increasing appropriations by the legislature." The argument between those favoring state and those favoring private care is still being hotly contested, but the " grave defect " emphasized by Gillette and McMurtrie has gradually been eliminated thanks to the constant hammering of social-minded orthopaedic surgeons and public-spirited laymen.

A most significant advance in the "social point of view" was the development of the so-called " compensation acts." These were state legislative enactments to assure an injured workman adequate medical treatment, partial financial reimbursement for loss of salary and, in case of permanent injury, financial compensation for loss of earning power. They have been passed in all the states except Mississippi. These laws are of such importance to orthopaedic surgery that, at the author's request, Dr Michael Burman, associate orthopaedic surgeon of the Hospital for Joint diseases, has written the following summary of compensation law and practice in the United States. (This carries the reader through the transition period. 1902-19, down to the present time.)

\section{Compensation Law and Practice in the United States}

The passage of such laws was protested by certain groups as an invasion of the property rights of the employer and hence contrary to the letter and spirit of the Fourteenth Amendment of the Constitution of the United States. Both the Maryland law of 1902 and the Montana law of 1909 were declared unconstitutional. The original compensation act of New York of 1910 was likewise declared unconstitutional (Ives vs. So. Buffalo Ry. Co., 201 N.Y. 271), a legal hurdle surmounted by the passage of an amendment to the State Constitution in 1913. In 1917 The United States Supreme Court passed favorably on the constitutionality of the legislation. Two weeks after this decision Idaho and Utah passed compulsory compensation laws.

The essence of all compensation law is the assumption of liability on the part of the employer except in the unusual circumstances of wilful disobedience of rules of safety or drunkenness on the job. The definition of "injury" is usually made sufficiently broad so that the injury need not be acute. Reasonable notice of the accident must be given to a responsible officer of the employer. Hearings are held before an official of the commission or body administering the law. The hearings are informal with minimal but reasonable observance of the rules of evidence. The workman may be represented by a lawyer or a licensed claims representative. A decision is made and, if compensability is established, a money award given which, even in the event of total disability, 
is less than the workman's wages. This sum does not exceed $\$ 32.00$ a week in New York. In Alaska and in six states, the laws are administered by courts.

The right of the workman to choose his own doctor is limited in most states. Medical care is usually given by a physician of the employer's choosing or by the carrier insuring the employer. The logical extension of compensation insurance is disability insurance. New York, following the example of Rhode Island, made such a law effective on July 1, 1950. A workman, ill of a malady not associated with his work, receives a maximum of $\$ 26.00$ a week for thirteen weeks. The employee pays thirty cents a week, the employer a similar sum for each of his employees.

The Federal Government has several compensation laws. "Compensation is compulsory for all or some private employments . . . in the District of Columbia and compulsory for all or some public employments . . . in the District" (Koontz). The Federal Employers' Liability Act gives to railroad employees the right of action for injuries sustained by negligence of the railway carrier. The Longshoremen's and Harbor Workers' Compensation Act covers the limited category of employees injured in the navigable waters of the United States, including any dry dock. The Jones Act (Merchant Marine Act of 1920) does the same for seamen on both land and sea and regardless of the nature of the errand taking him ashore.

This brief review can hardly hope to encompass all the details of the various compensation laws.

In the conduct of the hospitals, the "social point of view" invaded the orthopaedic clinic and transformed the patients from mere numbers unto living beings whose social needs required attention just as much as their crippled bodies. Dr Harry Low in 1914 reported his study of the orthopaedic out-patient clinic of the Massachusetts General Hospital in which he credited the social service department " for helping us in many ways in carrying out the treatment." A few years later (1918) Miss Edith Baker, head of the social Service Department spoke for herself. She wrote: "We are all familiar with the advice given to tuberculous patients, 'good food, rest, fresh air and sunshine,' but these are not commodities which can be delivered like drugs. We may order them, but they do not get there unless personally conducted all the way ... Through frequent home visits these patients have been encouraged to persevere in the treatment (heliotherapy) and some very good results have been obtained." Dr E. G. Brackett in commenting on this report attested to the great value of the Social Service Department. He said it filled a particular need and by way of making his point told about the old darky who when advised by his doctor to " take this medicine after each meal," replied, "Yes, but I would like to know where the meal is coming from." Dr J. Archer O'Reilly of St Louis told of the successful work of the social service department of Washington University which organized a volunteer system of transportation. This method has since been developed by the Red Cross and by organizations for the care of crippled children.

No one has phrased the peculiar responsibility of the orthopaedic surgeon to his patient more vigorously than G. G. Davis in his presidential address of 1914. "It is not fair, it is not just," he said, " that we as orthopaedic surgeons should confine our work and efforts to solely the medical care of our patients: we can do more and we should do more. ... We are not solely the medical attendants of these cripples but also to a certain extent their guardians. We are the ones who, better even than the parents, can decide to what extent training can go hand-in-hand with treatment."

In this same year Dr Michael Hoke of Atlanta began a series of conferences with the officials of the Order of the Mystic Shrine of the Free and Independent Order of Masons (the "Shriners ") which resulted in a vote at the Portland, Oregon, meeting of 1920 to contribute to the support of hospitals for crippled children. The first " Shriners' Hospital " was opened at Shreveport, Louisiana, in 1922 and has been followed by others in San Francisco, Chicago, Springfield (Mass.), Minneapolis, Portland (Oregon), Philadelphia, Salt Lake City, Spokane, Greenville (South Carolina), Honolulu and Montreal.

Lay organizations for the care of crippled children developed: in New York City the Association for the Aid of Crippled Children, and in Elyria, Ohio, the Ohio Society for Crippled Children, later called The International Society for Crippled Children. Founded by Edgar Allen, the Society "seeks to co-ordinate the various social, nursing and medical agencies

VOL. $32 \mathrm{~B}$, No. 4 , NOVEMBER 1950 


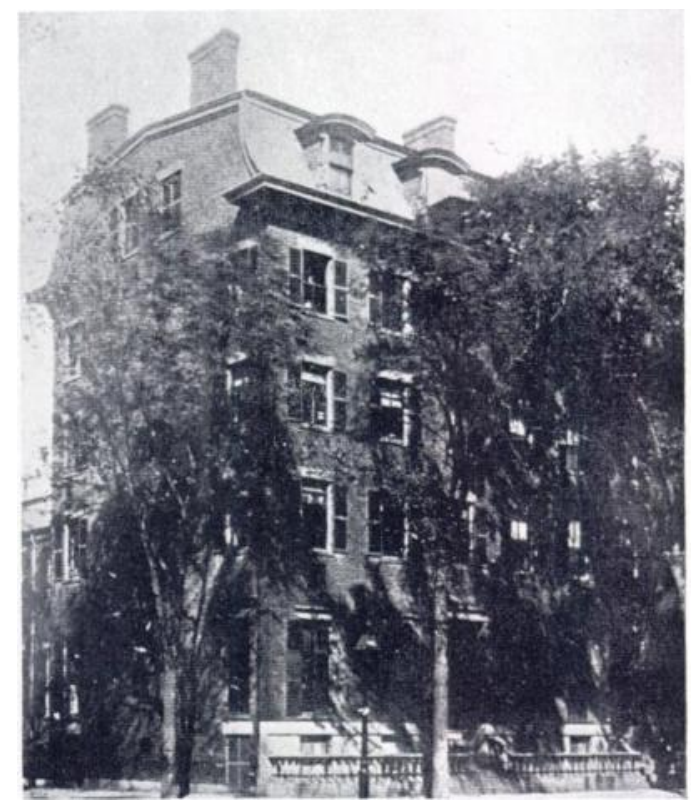

The original Children's Hospital building, Rutland Street, Boston, Massachusetts-built in 1869 to accommodate twenty patients. Here Dr Edward Bradford became chief of the Orthopaedic Service in 1878, and here under him served Drs Robert Lovett, Elliot ( $\mathrm{x}$. Brackett, Joel Goldthwait, Robert Osgood, Arthur Legg, James Sever and many other distinguished orthopedic surgeons; from here emanated most of the 105 articles credited to Bradford during the years 1887-1902; here he taught as the first John Ball and Buckminster Brown Professor of Orthopedic Surgery of the Harvard Nedical School. Retiring in 1912 he was succeeded by Dr Robert Lovett, who continued to be as productive as his great predecessor. In 1914 the first summer course in physical therapy was given here under the direction of I)r James Sever.

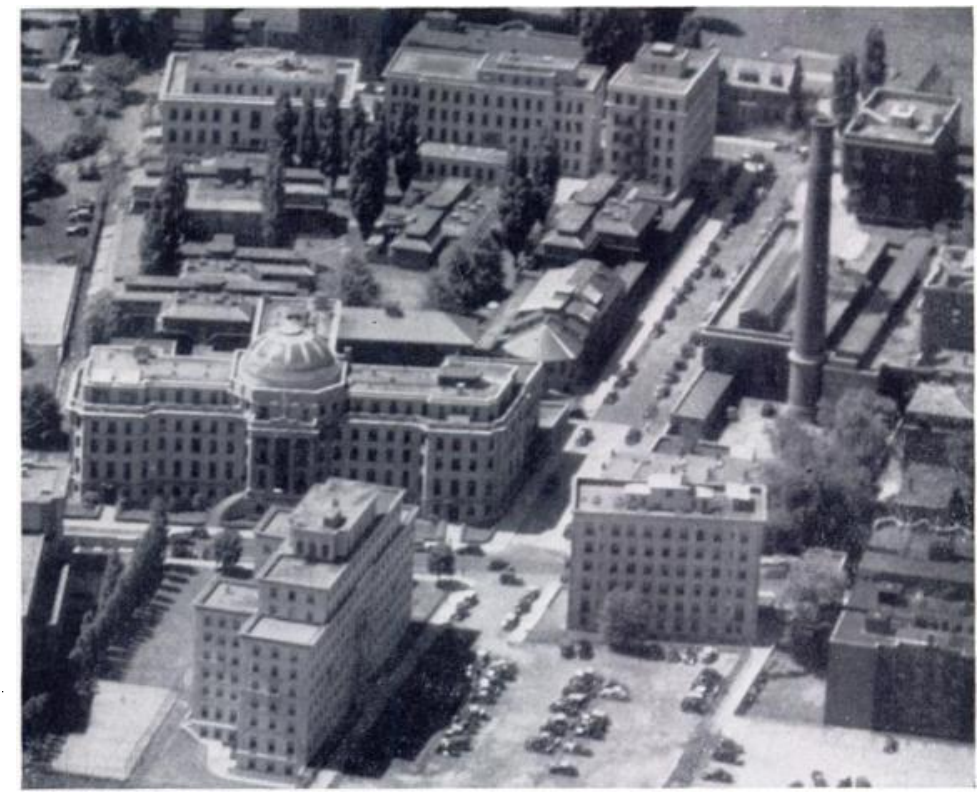

The Children's Hospital of Boston to-day-a general hospital for 385 patients. The Bader buildingincluding a therapeutic pool, laboratory and isolation building - was opened in 1931; other buildings have since been added. Here the clinics of the Harvard Infantile Paralysis Commission function, many clinical and research problems are investigated, and graduate as well as undergraduate teaching is in full swing. Under the present Chief of Staff, Dr William T. Green, appointed in 1946, the service was reorganised, and affiliation resumed with the Massachusetts General Hospital in the resident-training program as well as with the Peter Bent Brigham Hospital. 


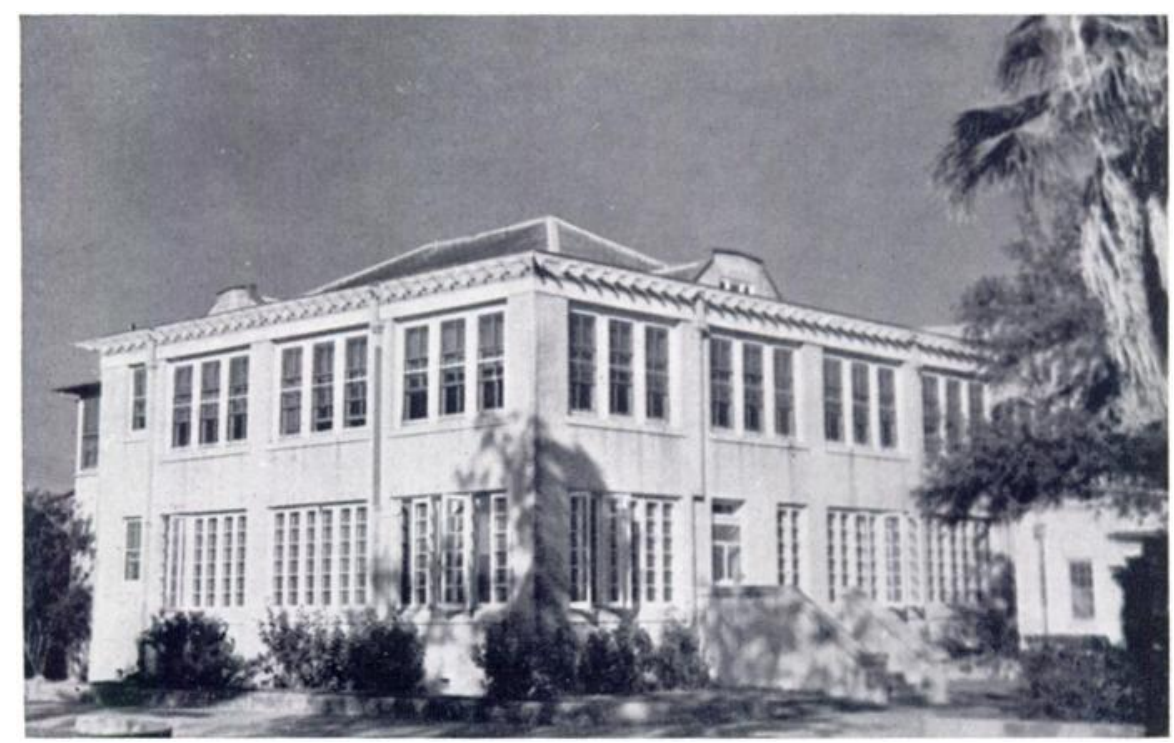

The Children's Hospital of the Lniversity of Texas Medical college, Galveston. Erected in 1915 with funds raised by the Texas Anti-tuberculosis Association, half of its fift $\mathrm{b}$ beds were reserved for cases of tuberculosis. Iater, this provision was set aside and all types of crippled children admitted. It was the first hospital in the State devoted to the orthopaedic care of children. In 1923 the Texas Scottish Rite erected a second hospital at Dallas; there are to-day similar hospitals at Houston, Waco, Fort Worth, Corpus (Christi and other cities-a development typical of all the States; the late Douglas Mc.Murtrie could no longer write as he did in 1912: "From a national standpoint the situation with regard to crippled children's hospitals is most unsatisfactory ... The gravest defect is that immense sections, notably the West and south, are without any provision whatever."

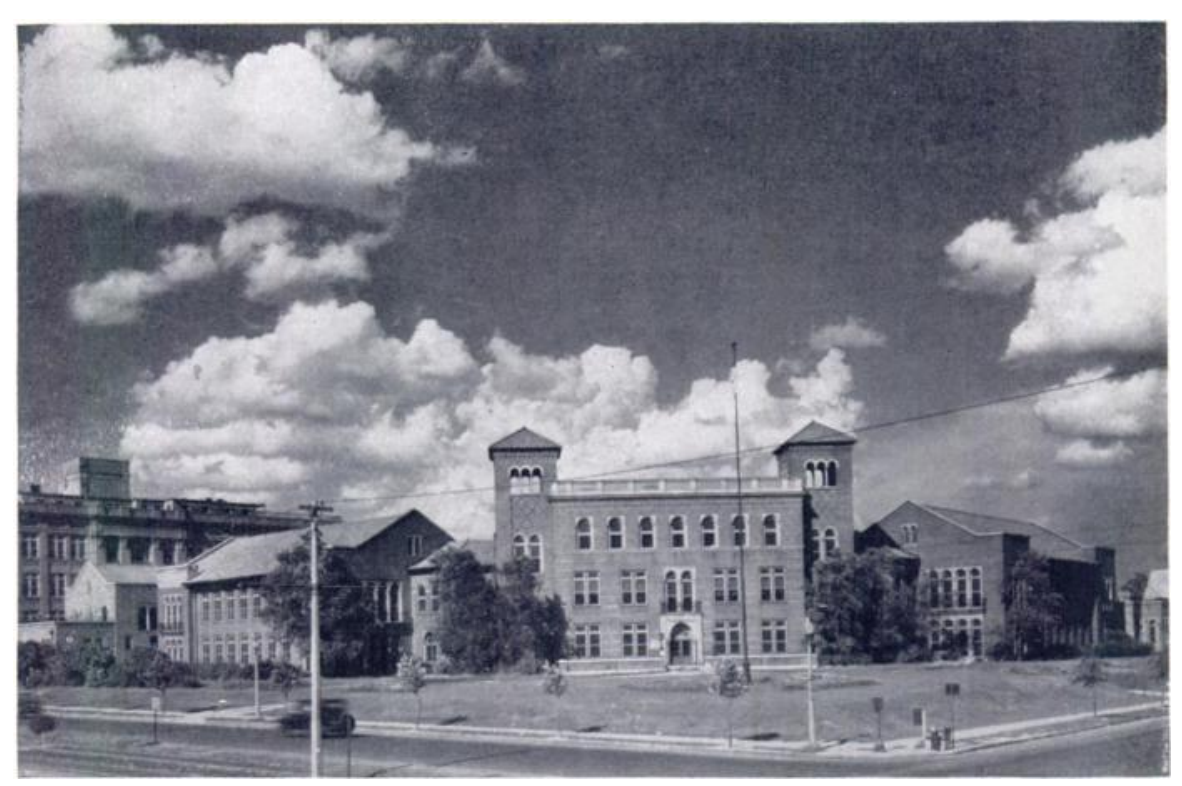

The Shriners' Hospital for Crippled children, st louis, Missouri. Opened in 1924, it is characteristic of the buildings erected by "the Shriners" after I)r Michael Hoke had enlisted their support in the care of crippled children (page 477). Here I)r . Illert key and I)r Le Roy Abbott did their early work with l)r ('rege) as their resident. To-day I)rs Ifecarroll and crego, the heads of the service, are making outstanding contributions to the treatment of congenital hip dislocation, infantile paralysis, cerebral palsy and many other orthopaedic conditions. 
concerned in the problem of the crippled child, and attempts further by subsidizing the publication of books and magazines to awaken the consciousness of the lay communities to his needs." (Edgar Bick 1948).

Meanwhile, amid the ceaseless production of new techniques, new investigations, new knowledge, new goals, new lines of thought, it was but natural that orthopaedic surgeons should decide to come together more frequently than at the yearly convocation of the American Orthopaedic Association. They had much to talk about: exchange of views was bound to add to the fund of knowledge. Many orthopaedic clubs and societies were started. Probably the oldest of them was the Boston Orthopaedic Club (1896); in 1902 the Inter-urban Orthopaedic Club was founded, and the orthopaedic section of the New York Academy of Medicine; in 1910 the Chicago Orthopaedic Society. When Dr Freiberg was president of the Association (1911) he devoted part of his address to the question whether the Association " has responded to all the demands which may rightfully be made upon it." He continued: "At the great convocation of physicians and surgeons which takes place annually in the spring [the meetings of the American Medical Association] there are represented adequately all the specialities of our profession save one: orthopaedic surgery. It is for you to say whether this is as it should be." Thanks to him, the Orthopaedic Section of the American Medical Association was organized the following year. In 1912 the Central States Orthopaedic Club was created under the aegis of Dr John Porter of Chicago; two years later the Western States Orthopaedic Club with Dr Harry Sherman of San Francisco as its president, and in the same year the Philadelphia Orthopaedic Club. Since that time each city with a nucleus of orthopaedic surgeons has organized its orthopaedic "club "; many inter-urban groups, such as the "Robert Jones," have been formed; and at the State Medical Society meetings there are sections devoted to orthopaedic surgery. These meetings have helped to educate by exposition, demonstration and discussion; they have encouraged men to develop new ideas.

In the medical schools orthopaedic surgery made slow but consistent progress. The Association appointed a committee in 1909 to investigate undergraduate instruction in orthopaedic surgery. The committee reported in 1910 that it had received answers to its inquiries from 110 out of 126 colleges; in forty-one, orthopaedic surgery was taught as a separate branch (Group I); in fifty-one, it was combined with general surgery (Group II); the total number of hours allotted to orthopaedic surgery averaged sixty-four in Group I and forty-seven in Group II; there were thirty-five professors in Group I and thirteen in Group II. The committee recommended that orthopaedic surgery be taught as a separate and distinct department in charge of a professor, that a minimum of sixty hours be allotted to the subject, and that instruction be partly didactic, partly clinical. Charles F. Painter (1913) in his paper on the development of orthopaedic teaching in America also favored the didactic lecture, to be followed by a "quiz" and clinical demonstrations. He concluded: "To the teacher and investigator there is no more fruitful field than is offered by this subject."

So the stage was set for an event which, tragic though it was for the world at large, brought recognition, honor and a wealth of new experience to our speciality-the first world war. In the March 1917 issue of the Journal appeared a letter from Dr Joel E. Goldthwait telling of the appointment of committees by the American Orthopaedic Association and the Orthopaedic Section of the American Medical Association to consider " the question of the orthopaedic preparedness of the nation. . . . In this country we need, as in England, a large number of hospitals . . . to which the patients can be sent after the immediate care at the Front has been given, and where they can be kept long enough for the needed reconstruction work to be completed. . . . Such work, of course, involves also the teaching of trades and occupations to those who may be crippled, the lines followed to be similar to those which have been worked out so admirably in England under the guidance of Colonel Robert Jones." In the May 1917 issue appeared an editorial entitled "The Opportunity." It told of the willingness of orthopaedic surgeons to serve and their prompt response to the inquiries of 
the "Committees on Preparedness." The Journal recommended: 1) the appointment of a director of orthopaedic general hospitals; 2) the immediate organization and equipment of two or more such hospitals; and 3) the conservation by the Government of the orthopaedic resources. It pointed out that " the speciality is a small one. In the event of hard fighting the demand, we believe, will be a large one. . . . England has already been seeking our help. We may need every available orthopaedic surgeon for the work he is specially fitted to do. . . . The comfortable transport of the wounded would receive his attention, but probably his first important service may be rendered at a base hospital well back of the line. More than half the injuries of modern warfare are lesions of the bones and joints; some observers have said 75 per cent. In civil life when these cases present themselves, the general surgeon turns to the orthopaedic surgeon-in the terrible wounds of war he should also be available."

Dr David Silver, president of the Association, sent a letter urging attendance at the annual meeting, concluding with the words " Your country needs you."

In the June issue of the Journal an editorial reported that a cable had gone out for twenty trained orthopaedic men to go to England to work under the direction of Robert Jones. Within twenty days, on April 28, twenty-one men had sailed on their way for duty. Dr Joel Goldthwait, the leader of this medical group, has been gracious enough to contribute a brief account of his recollections of these war years. He writes:

Until the first world war, orthopaedic surgery in Great Britain was not a very important speciality, but the large number of disabled veterans presented such a problem for rehabilitation that Sir Robert Jones was turned to in the hope of improving conditions. His results were so striking that the importance of this branch of the medical and surgical profession began to be appreciated and assistance was asked from the United States. At that same time in the United States, orthopaedic surgery was recognized, the Orthopaedic Association was active, but the number of men carefully trained in that profession was not large and the general surgical profession was not friendly to the orthopaedic activities. In Great Britain also the general surgical group was not too co-operative. The need for help was so great that when the United States declared war (April 7, 1917) at once a cablegram came from Great Britain asking for six base hospitals to aid the British and twenty orthopaedic surgeons to serve with Sir Robert Jones. This at once established the fact that the British Government recognized orthopaedic surgery as of importance. In this country the position Great Britain had taken was recognized and immediately it was decided to send the assistance requested.

As chairman of a special committee that had been working for over a year listing the orthopaedic surgeons that would be available in case of war, a message from Washington came to me the day the cable was received, and the next day a conference was held by me in Washington for the situation. Immediately telegrams were sent to twenty of the younger orthopaedic surgeons asking them to enlist and to arrange for transfer to England to serve under Sir Robert Jones. In one day less than three weeks these twenty men sailed with me for England and were assigned to work with Sir Robert Jones upon arrival at Liverpool.

This recognition of the importance of orthopaedic surgery by the Governments of both Great Britain and the United States established the speciality in a way that almost nothing else could have done. Naturally, much of the work was in the field of traumatic surgery with which few of the orthopaedic men had had much experience, but the principle underlying orthopaedic surgery-improving the function of a damaged part as much as possible - applied directly to the war casualties. Both the British Government and our Government recognized the need of these trained specialists and insisted that none of them be removed from their orthopaedic assignments.

After studying the work in England and France, and planning the requirements of our own Army, I returned to the United States and spent nearly two months in

VOL. $32 \mathrm{~B}$, No. 4, NOVEMBER 1950 
Washington helping to perfect the organization of the Orthopaedic Department of the Army.

As the result of this, in October I sailed again for England accompanied by forty-five officers, many of whom had had considerable experience in orthopaedic surgery, the others hurriedly trained in the fundamentals of orthopaedic surgery, and with them, twelve orthopaedically trained nurses and three officers expected to develop the occupational therapy shops. This latter feature had been very much developed in England where "curative workshops" were part of each hospital center. All these doctors and nurses were at first assigned to the British under the direction of Sir Robert Jones. Later, other groups were sent over from the United States and distributed among the hospitals as needed.

As our own organization developed, the officers that had been serving in the British Hospitals under Sir Robert Jones's direction were gradually withdrawn for assignment in the American Hospitals and other officers were sent to fill the gaps.

Splints and surgical supplies-Almost at once, as the military problem was studied, it was obvious that it was necessary for our Service to have proper apparatus for taking care of the wounded, and that no such apparatus was being sent over either with the Hospital Groups or with the Combat Divisions. It was also recognized that proper splints should be applied to the wounded man before he was taken from the ground to be placed on the stretcher. Recognizing the complete lack of such equipment and the necessity of manufacturing it in France, where there was only a meagre supply of raw materials and of labor, it was obvious that the utmost simplicity and economy had to be observed.

By eliminating all non-essentials it was shown that with seven types of splint practically all the needs of the wounded man could be met. Every stretcher carried with it a Thomas' splint for the leg and an arm splint for the arm and shoulder. The system that was followed when the wounded men were placed in the ambulance was: the ambulance delivered to the stretcher-bearers a stretcher equipped with two splints. When the wounded man was delivered at the dressing station the ambulance received another stretcher and another set of splints. This was continued all the way back. By this system the wounded were handled with a minimal degree of pain; and the orthopaedic splinting started on the battlefield was continued until the patient was on his way home.

Since it was necessary for the wounded to be moved from one hospital to another in order to accommodate the new cases that were coming in at the Front, a wounded man had to be under the care of several different surgeons before he reached the Base ports. The unit splint, however, helped to give continuity to the treatment and the results were, in the main, satisfactory.

As the work went on, Dr John Finney, the director of general surgery, realizing that his training as an abdominal surgeon did not qualify him for the treatment of this type of injury, held a conference with me which resulted in an order by the Chief Surgeon of the A.E.F., transferring the responsibility of these cases to the Orthopaedic Department. This led to the assignment of orthopaedic consultants in all of the large battle or hospital areas and while the work naturally had to be performed by the general surgeons, the general handling and the functional restoration were directed by the orthopaedic consultants.

Because of the rapid increase of battle casualties, the Engineering Department was unable to build enough hospitals. As a consequence, in the latter part of the summer General Ireland, the Chief Surgeon, summoned me to his office and stated that it was necessary to have some of the so-called "non-transportable" cases, chiefly the bad femur injuries, sent to the United States. "If not," said the General, " the wounded will have to lie on the battlefield."

It therefore became necessary to reorganize the method of handling severe bone injuries. One week later I personally spent the night on a hospital train carrying 500 of 
these cases to the port of Brest. Each man had been carefully splinted and carried a tag telling how the case should be handled. Since the harbor of Brest had no dockage facilities for large transports, it was necessary to transfer the patients from the hospital train to lighters which took them to transports anchored three miles from shore. That same afternoon the transports sailed for home. Since none of the cases suffered from this method of transportation it was generally adopted and from then on the wounded were moved as rapidly as possible from France to the United States.

While Dr Goldthwait was busy in England and France, the American Orthopaedic Association met in Washington under the presidency of Dr Silver. The attendance was the largest in the history of the Association. The president pointed out the importance of orthopaedic surgery in war work and reported that three members of the Association had already been appointed to the important Committee on standardization for medical and surgical supplies and equipment. The Journal in the editorial columns published three important papers, the first by Colonel Robert Jones, the second by Dr Gallie, and the third, Dr Goldthwait's report as chairman of the Committee on preparedness. Colonel Jones's paper was a reprint of the introduction to his book Notes on Military Orthopaedics. It told about the "curative workshops" - why they had been started and what they were doing. "In the Military Orthopaedic Hospital at Shepherd's Bush alone," he wrote, " out of 800 patients about 500 are employed at some regular work which fosters habits of diligence and self-respect, and converts indolent and often discontented patients into happy men." Gallie wrote "How Canada is Caring for her Crippled Soldiers." He described in some detail the types of war-wounded whom they were treating, the methods employed, and in particular their experience with the amputees. He also wrote of vocational training: "Although the problem was very haltingly dealt with at first, it has now become a national institution." Goldthwait's report included important recommendations on the physical training of the recruit, particularly of his feet, and of the proper types of army shoes. He outlined the organization of the Military Orthopaedic Hospital and told of the medical mission to England. He concluded: "It is quite obvious that the orthopaedic profession is meeting its opportunity, and the recognition of the need of such work by the officials in Washington should be a source of much satisfaction." Orthopaedic surgery in America had at last come into its own. Substantiation is found in the letter of Dr Charles Parker of Chicago (1919) to the editor of the Journal, published in the November issue. It ends with this significant paragraph: " This is truly the era of orthopaedic surgery and the enormous impetus give it by war practice is certain to be reflected in civil practice with results of inestimable value to the multitude of potential cripples constantly repleted from the vast army of citizens engaged in the peaceful pursuits of our normal industrial life."

At the October 1917 meeting of the Boston Orthopaedic Club Dr Brackett, who had been made director of orthopaedics in the Government with the rank of major was the chief speaker. He said in part: "Very early in this war the Department had decided that since a man is taken out of industrial life well and strong and a wage-earner, and is put into service and is there injured, it is the duty of the Government, and therefore of the Army, to consider him as its ward and to replace him in civil life not only repaired to the greatest potential degree through surgical and medical care, but also to put him back into the community so that industrially he is an efficient man." He told of the reorganization of the army medical department into a series of specialities, each to take charge of a particular group of cases. He estimated that the number of orthopaedic beds in France would amount to about 35,000. To take care of this number and to do the work in England and at home, more orthopaedic surgeons were needed. To train men, courses in orthopaedic surgery were to be started in New York and in Boston. In summing up he said: "The men who are to do orthopaedic surgery must have in view one very distinct feature, and that is to restore function. That has to be the fundamental thing. Necessarily it is a long stay, weeks and months perhaps, but

Vol. 32 B, No. 4 , NOVEMBER 1950 
this must never be lost sight of-not only restoring the function surgically and medically but undoing the habit of long invalidism."

The meeting of the American Orthopaedic Association in 1918 was devoted almost wholly to military surgery. Dr John L. Porter, the president, told of the work done by the medical department of the Army under Surgeon-General Gorgas, who had expanded the staff from a few hundred to 20,000 in one year, and of the Orthopaedic Department under Dr Brackett (now promoted to Lieutenant-Colonel) whose personnel comprised 626 commissioned officers. "Every training course, base hospital and fort is supplied with at least one competent orthopaedic officer and assistants. And men of experience in the speciality are on duty abroad." There were stimulating papers by Clarence Starr of Toronto, DeForest Willard and James Rugh of Philadelphia, Sydney Cone and William Baer of Baltimore, Edward Rich of Tacoma, William Erving, George Hawley of Bridgeport and many others. Hawley's paper deserves particular comment since it dealt with a revolutionary method of treating bone infections-the Carrel-Dakin technique. He stated that after watching Carrel's work for several months he was convinced that his method represented one of the most important advances in surgery. "For the first time in the writer's experience it has been possible to definitely sterilize suppurating infections of the bones and joints and see them heal without any evidence of pus and without sinus formation. ... The method is technically difficult and laborious. Each daily dressing is like performing a clean surgical operation at the bedside. . . . Only those who have had the opportunity to study at first hand the principles and have patiently persisted through obstacles and failures can appreciate what Carrel has contributed to surgical science."

Several books of military significance were published. In addition to Robert Jones's Notes on Military Orthopaedics the Army published an excellent Manual of Splints and Appliances and a Medical War Manual (No.4) in Military Orthopaedic Surgery. Douglas McMurtrie, who had helped to found the Red Cross Institution for Crippled and Disabled Men published The Evolution of National Systems of Vocational Re-education for Disabled Soldiers and Sailors. This was issued by the Federal Board for Vocational Education and contained important information on the details of rehabilitation and its history in other countries. Dr Brackett wrote the introduction to a monograph by Mayer on The Orthopaedic Treatment of Gunshot Injuries, in which he welcomed a book " that comes to us at a time when it is needed."

Of great significance were two papers: one by King Manuel of Portugal, representing the British Red Cross, on "The Scheme of Curative Workshops in the Orthopaedic Centres of the United Kingdon"; and the other by Sir Robert Jones on "The Problem of the Disabled"both published during the spring of 1918. The distinguished layman and the great orthopaedic surgeon alike had the same message to deliver: the overwhelming importance of rehabilitation to the economic and moral life of the nation. Those who love beautiful prose should read the concluding paragraphs of Sir Robert Jones's paper. I quote only a few sentences: "Are our memorials to be spiritual or material, living and permanent, dead or cold ? For my part I have no hesitation in saying that cold marble or perennial brass has no re-echoing voice to me. My feeling is that the heroic spirit that sent our beloved dead to their end, should be reflected in an equally heroic effort on our part to make and keep the nation efficient."

In America the theme was ably enunciated by Major Robert W. Lovett (1918) who wrote: "The curative workshop represents the most important and the newest feature of the therapeutic stage of reclamation, and it is a natural sequence to bedside occupation. In the curative workshop the brain is kept interested in mechanical results accomplished and the physical improvement comes on apace."

So the war brought recognition to orthopaedic surgery, and to the orthopaedic surgeon fell that most important phase of treatment: restoration of function and the return of the soldier to normal living. 


\author{
1) BUCKNINSTER BROWN (1819-1891)
}

Son of the distinguished Dr John Ball Brown, one of Boston's earliest orthopaedic surgeons, and wrandson of I)r John Warren, the first Professor of Surerery at Harvard Medical School, he was one of the "founding fathers" who belonged to the older generation. After studying abroad in 1845 and 1846 - in London under John Little, in Paris under Gurin and Bouvier, in (iermany under strohmeyer-he bean practice in Boston and soon devoted himself exclusively to orthopaedic surgery. He was placed in charge of the first ward in New England devoted to orthopacdic surgery at the Samaritan Hospital in 1861 . Bradford credits him as being the first American orthopaedic surgeon to cure a double congenital hip dislocation. It was said of him that he " was an orthopaedist in the best and broadest sense of the word, using all means-operative, mechanical and medicinal. His mechanical ability was great and his surgical dexterity was equally. remarkable." It his death he left a large sum of money to Harvard lniversity to endow an orthopaedic professorship, which is still in existence.

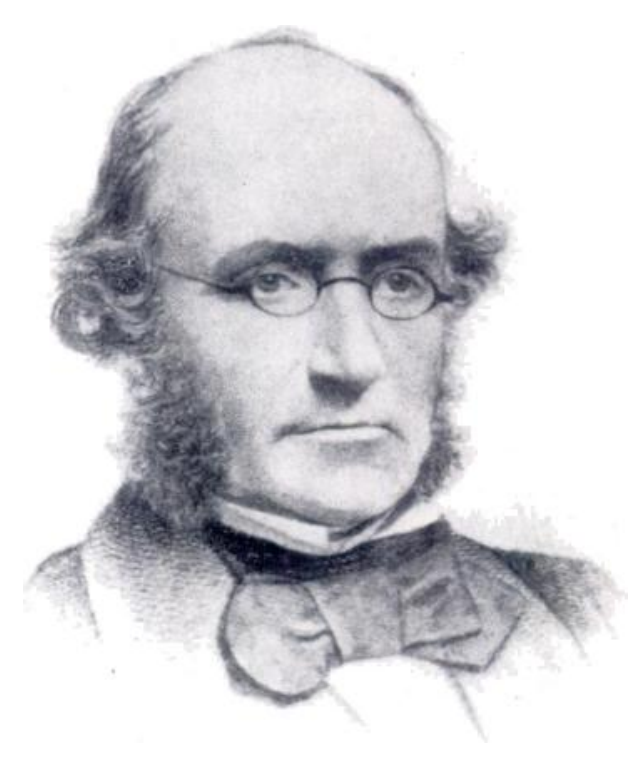

\section{I)r (HARIES FAYETTE TAYLOR (1827-1899)}

( )ne of the founders of the American Medical Association, and frequently termed the father of American orthopaedic surgery. He organized the New York Orthopaedic Dispensary in $1866 \mathrm{to}$ which the hospital was added in 1873. He was the first to devise a brace which gave adequate support to patients with Pott's disease. This he termed " the spinal assistant." At his death in 1899 I)r F. H. Bradford wrote of him: "he was largely influenced to turn his attention to the branch in which he distinguished himself by a humanitarian clesire to attempt a cure in a child suffering from what was regarded at this time as an incurable disease-caries of the spine. To this effort he enlisted himself with all the energy and ingenuity of a fertile and persistent mind, regarding the supposed impossibility of successful treatment as a challenge for strenuous encleavor."

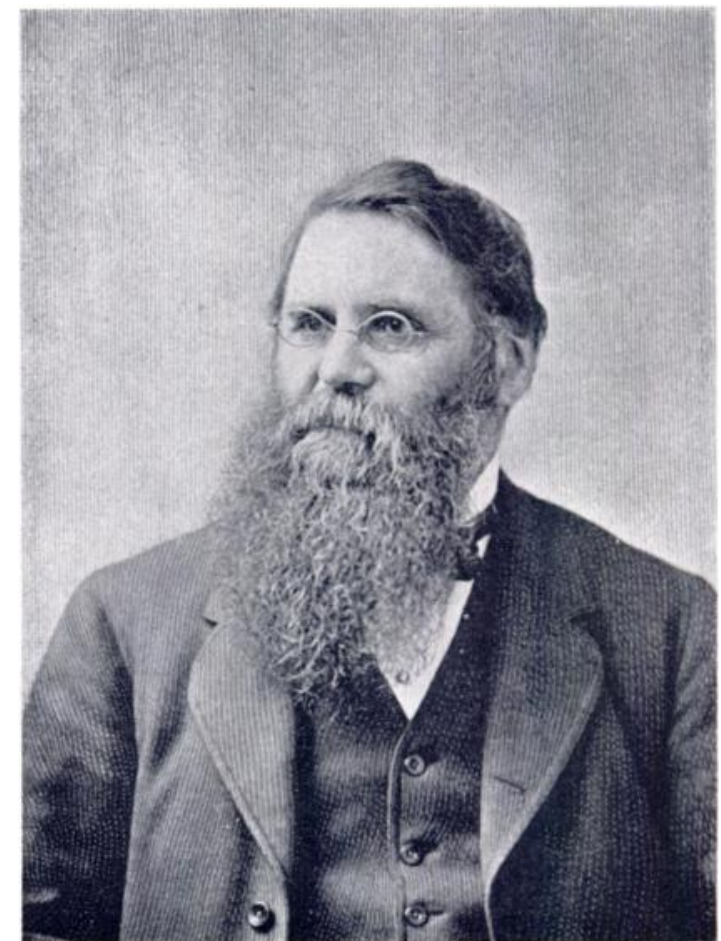



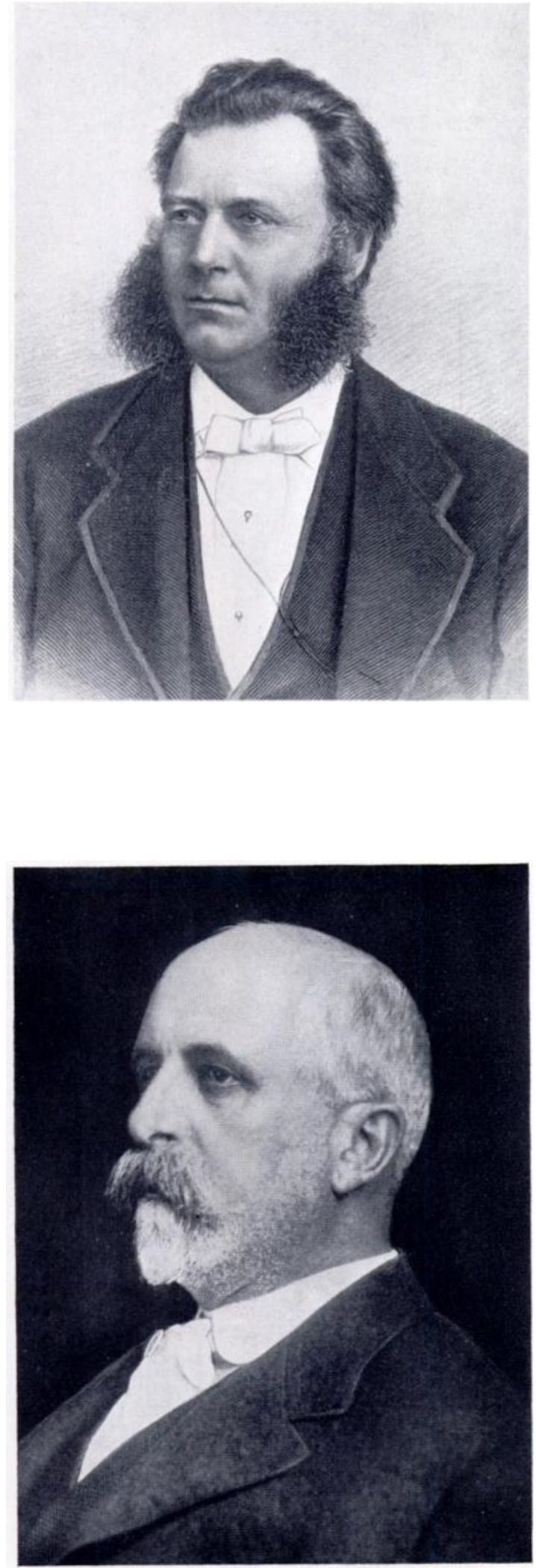

\section{1) I.EWIS A. SAYRE (1820-190(0)}

Appointed visiting surgeon to Bellerue Hospital in 1853, he held the first chair of orthopaedic surgery to be established in the United States (1861) at Bellevue Hospital Medical sichool. He was an impressive teacher, an eminent author and an intrepid surgeon, famed as the first to perform an excision of the hip joint (1854). He was elected to membership in the Amcrican Orthopaedic Association in 1889, an honor conferred on his distinguished son, Reginald H. Sayre, two years before. Though never elected president of the orthopaedic association, he was president of the American Medical Association (1880). He showed medical as well as surgical talent during his six years of service as resident physician of the City of New York. " He advocated compulsory vaccination, intelligent disposal of sewage, sanitary inspection of tenement houses, and quarantine for cholera." (From Cleveland and Winant: Instructional Courses of American Academy Orthopaedic Surgery at Fourteenth Anmual Assembly, January 1947.

\section{I)r VIRGL P. (IIBNEY (1847-1927)}

First president of the American ()rthopaedic Association, re-elected in 1912 an honor accorded no other orthopaedic surgeon. Surgeonin-chief to the Hospital for Ruptured and Crippled from 1887 to 1924 , professor of orthopaedic surgery at the College of Ihysicians and surgeons, of Columbia Iniversity. Though himself inadequately trained as a surgeon, he was a man of vision and sensed the direction which the speciality was bound to take. Stating that orthopaedic surgery was "as yet in it. infancy," he predicted (1891) that orthopaedic surgery would include the treatment of fractures, particularly " how to relicve old intra-capsular fractures of the neck of the femur" and "how to correct the deformities that follow bally united fractures and poorly replaced dislocations."

THF JOURNAL OF BONE ANI JOINT SURGERY 
1) NEWTUN II. SHAFFER (1846-1928)

Surgeon-in-chief of the New York (Orthopaedic Dispensary and Hospital from 1877 to 1898. With Virgil (iibney he called together thirteen other orthopaedic surgeons in 1887 whe voted to organize the American Orthopaedic Association, and in $188 \mathrm{~s}$ he became its second president. Intrained in surgery, he showed mechanical ingenuity and considerable administrative ability. He, together with .1. 13. Judson, bitterly opposed the growing tendency to introluce sursery into orthopaedics. He said:

"To mingle surgery and mechanics is to endanger both." (1891.) A zealot in maintaining his own views of correct treatment, he forbade lor John Ridlon, his junior on the orthopaedic staff of St. luke's Hospital to apply a Thomas hip splint, and thus drew down upon himself the righteous anger of Hugh Owen Thomas who wrote a seathing article condemning " the censor at st. luke's Hospital." Ifter his replacement at the New York (Orthopaedic Hospital by Russell Hibbs, he established the New York State. Reconstruction Home at Haverstraw for the care of crippled children. His personal animosity. to Russell Hibbs and his position of authority in the councils of the American Medical Association resulted in the exclusion of Hibbs from the Issociation for many years.

\section{Dr EDWARI) H. BRALFORD (1SHA-1926)}

One of the most vigorous of the " founding fathers," the third president of the American ()rthopaedic Association (1889), professor of orthopaedic surgery at the Harvard Medical school 1903. He had a mind of unusual maturity and originality. His study of club-teet published sixty years ago might well be used to-day in an orthopaedic instructional course. Besides his great technical contributions, particularly to the treatment of tuberculous coxit is and of congenital hip disease, he introduced the "social point of view " into orthopaedic surgery by helping found the Industrial school for Crippled and I leformed Children in Boston (1894), and established the principle of preventive medicine in orthopaedic urgery by his campaign for correct shoes and adequate seating of school children. His amazing industry is attested by the publication between 1887 and 1902 of 105 original papers, a text-book, and numerous articles on orthopaedic progress in the Boston. Medical and Surgical Journal.
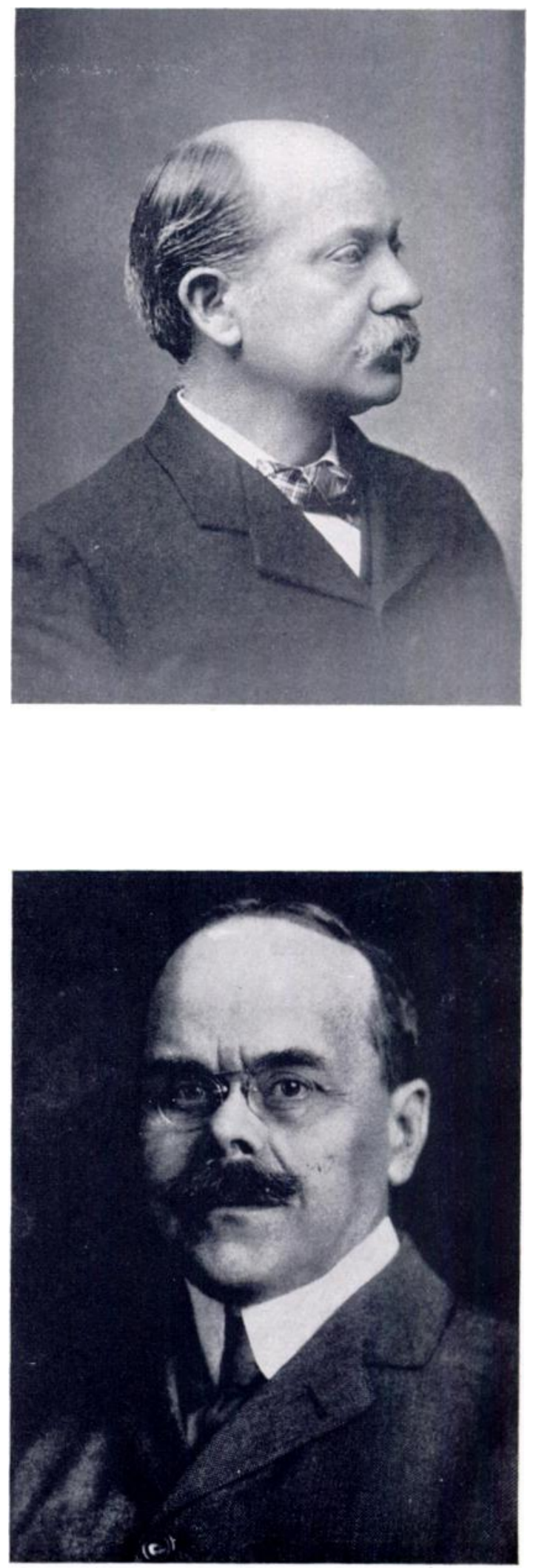


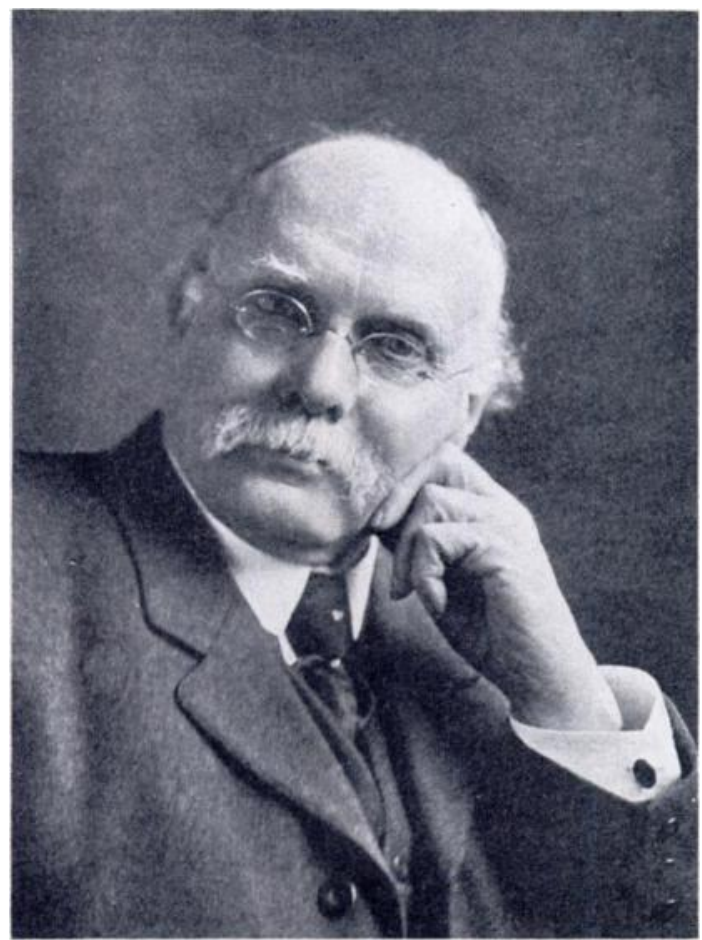

1)r DeForest WillaARI) (1846-1910)

Professor of orthopaedic surgery at the University of Pennsylvania Medical School, a "founding father" of the American Orthopaedic Association, and its fourth president (1890). A man of great physical and mental powers, he developed such surgical dexterity that he could perform six osteotomies for rachitic deformities at one sitting without danger to his patients. He established the first ward for crippled children at the University Hospital and was largely responsible for the endowment of the Widener Nemorial school for Crippled Children, of which he was Surgeon-in-Chief until his death in 1910 .

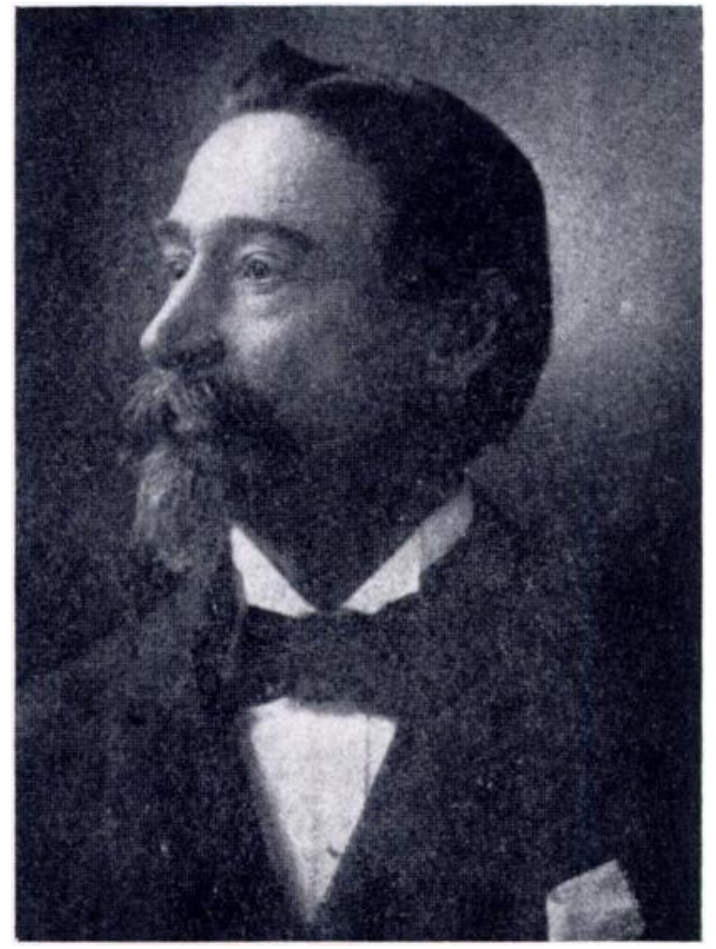

Dr Aaron John Stekle (1835-1917)

A " founding father," professor of orthopaedic surgery in Washington University school of Medicine, St Louis, president of the Association in 1893. Intensely active and enthusiastic, a fine mechanic and an even better surgeon, he was, in the words of Drs Philip Hoffman and Nathaniel Allison, "ideally fitted for the practice and development of orthopaedic surgery, especially. for those pioneer days." Known for his " ready. wit and quickness of repartee, his kindness to patients, and 'especially his love for and tenderness toward children,' he was also widely recognised as 'one of America's best connoisseurs of old prints and engravings.' "' 
D) JoHN RHLON (18ה2-1936)

Professor of orthopaedic surgery in the NorthVestern Iniversity Medical School, Chicago, a "founding father" and president of the American Orthopaedic Association in 1895 . A warm friend of Hugh ()wen Thomas and Robert Jones, he became a staunch supporter of their fixation method of treating tuberculous coxitis as contrasterl to the traction method. In the Association discussions, which were at times quite. acrimonious, he was always in the minority but never wavered in his opinions. He believed in leaving tuberculous abscesses alone--." not one in a hundred will cause trouble." He started practice in New York, but because he could not aet along with l)r Newton shatfer at the st. Luke's Hospital, he moved to Chicago where he became a distinguished teacher and attending orthopaedic surgeon to the St. Luke's, Michael Reese. Misley and Evanston Hospitals. I) uring the first world war he served as major.

\author{
I) ROSAL WHTMAN (1857-1946)
}

Caustic of tongue and brusque of manner, his brilliant intellect, his unusual powers of exposition and his scientific zeal made him one of the outstanding orthopaedic surgeons of all time. Although he is known chiefly for his abduction treatment of fractures of the femoral neck and for his astragalectomy for calcaneus deformity, Whitman's early papers on weak foot, adolescent coxa vara, Morton's toe, and torticollis are important contributions to orthopaedic progress. In his address as president of the American Orthopaedic Association in 1896 he formulated the first modern concept of orthopaedics as " that division of surgery which treats of disabilities and diseases of the locomotive apparatus and of the prevention and treatment of deformities of the framework of the body."
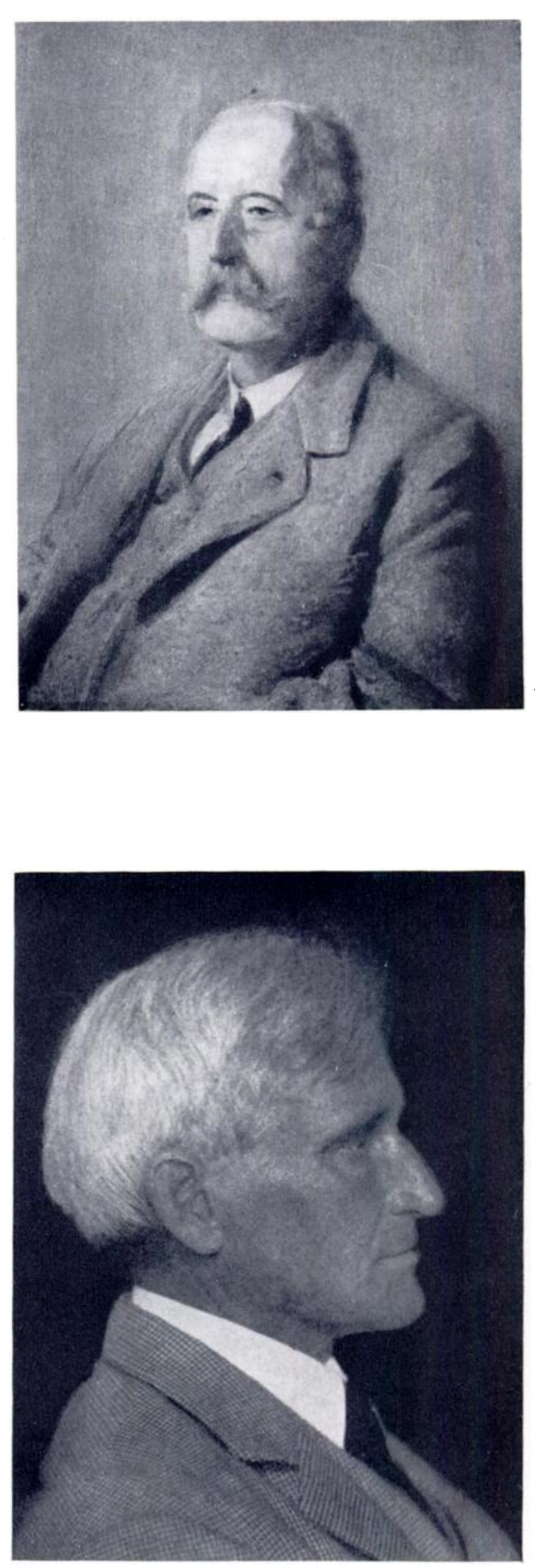

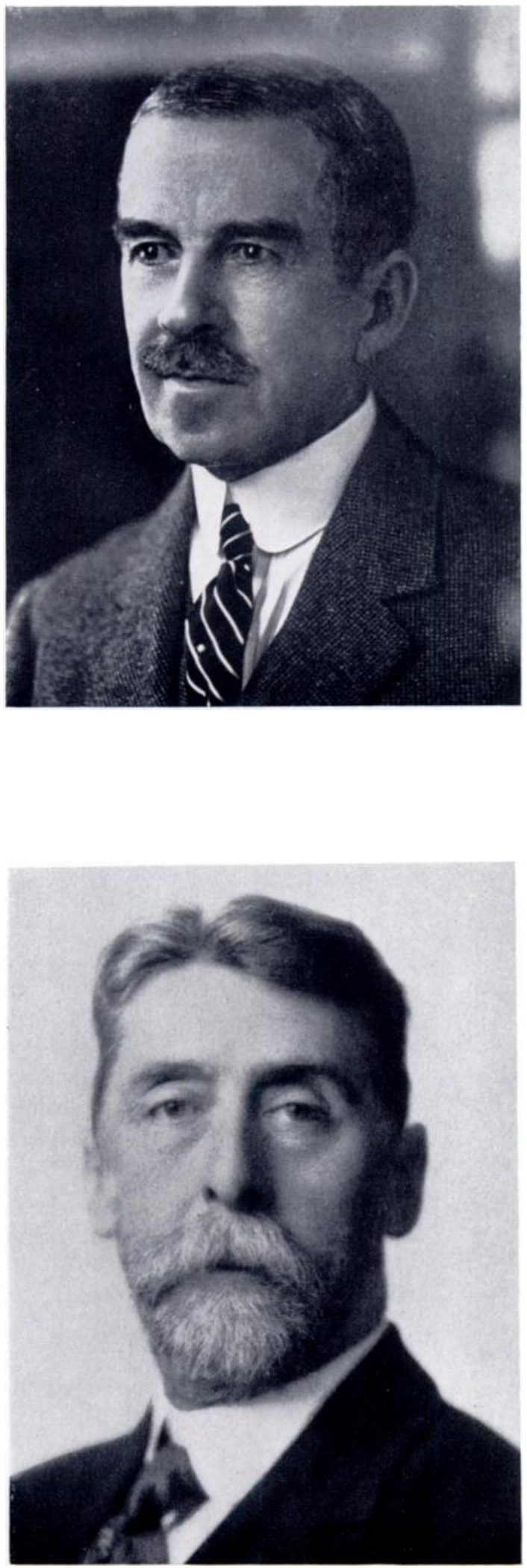

Dr ROBERT W. LOVETT (1859-1924)

One of the founders of the American Orthopaedic Association and president in 1898; professor of orthopaedic surgery at the Harvard Medical School. He combined great clinical gifts with an unusual flair for research, as evidenced by his study of the mechanics of scoliosis. He was a skilful administrator, an eloquent teacher, a fluent writer and an orthopaedic statesman who helped shape the policies and control the personnel of many medical schools besides his own. He was particularly interested in poliomyelitis and in 1916 helped to create the Harvard Infantile Paralysis Commission whose activities he directed for many years. He served as consulting orthopaedic surgeon to the Board of Health of New York City during the 1916 epidemic and developed the program of aid in that city as well as in Massachusetts and Vermont.

\footnotetext{
Dr HARRY M. SHERMAN (1854-1921)
}

Clinical professor of orthopaedic surgery in the medical department of the Iniversity of California. Elected to the American Orthopaedic: Association in 1889, he became one of its most active members and in 1900 was elected president. An original thinker, a brilliant surgeon and an honest seeker after truth, he refused to accept the current methods of treatment. He was one of the first to advocate early operation in tuberculosis of the hip (1893) because of the slow unsatisfactory course of cases treated conservatively. He practised excision of the knee in children and took care to conserve the epiphysial cartilage (1897). He had the courage to report unsatisfactory results with the Lorenz reduction of congenital hip dislocation at a time when other orthopaedic surgeons were lavish in their praise of the method. His presidential address was devoted to the same theme as that of his modern successor, Le Roy Abbott-the place of orthopaedic surgery in the medical school curriculum.

THE JOURNAL OF BONE AND JOINT SLRGERY 
1)r ARTHER J. (ill.teTtE $(1864-1921)$

Elected to the American Orthopaedic Issociation in 1889, he became president in 1901. Professor of orthopaedic surgery in the Mlinnesota State Iniversity, attending orthopaedic surgeon at numerous hospitals, he devoted much of his life to developing state aid for crippled children. Through his efforts the Minnesota State Hospital for Crippled and I)eformed Children was opened in 1897, and he served as its chief surgeon for many years. In his presidential address on "Injuries to the spine" he showed great clinical acumen, refuting the current claim that "it was impossible for a man to have a fracture of the vertebrate or a dislocation without a cord involvement which would be manifest." In the presence of paralysis he considered laminectomy. futile. "Complete. immobilization should be the surgeon's aim."

D) REGINALD H. SIYRE (1539 1929)

Son of Lewis. I. Sayre, he shared his father's enthusiasm for orthopacelic surgery. One of the "founding fathers" of the Issociation, he served as its president in 1904. His address was devoted to the theme of preventice medicine as applied to orthopaedic surgery. "We have been content," he said, " to go on year after year truing to correct all manner of deformities, many of which from their very nature can at best be ameliorated but never cured, and have done but little to teach the medical profession that early diagnosis is the secret of success in the treatment of deformities." That he was an ingenious surgeon is attested by his cure of a club hand (1893) due to congenital absence of the radius by the shift of the ulna to the middle of the carpus. In addition to his orthopaedic attainments he was a noted marksman and for a number of years held the American championship for small arms.
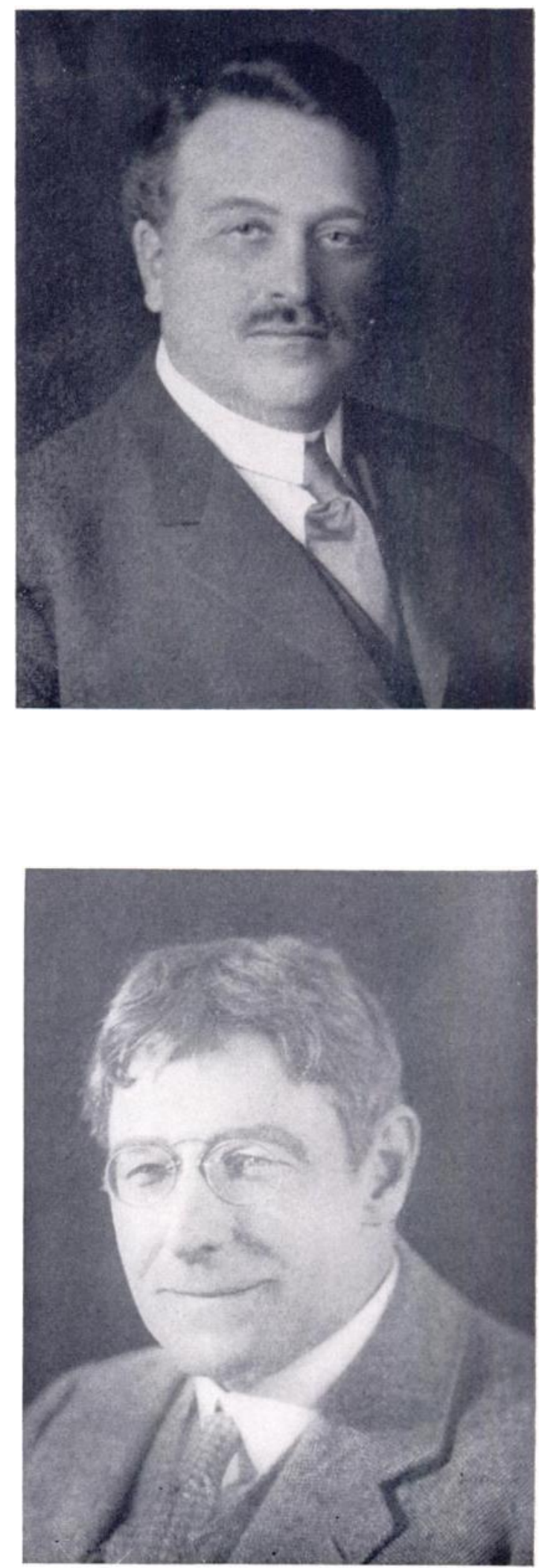


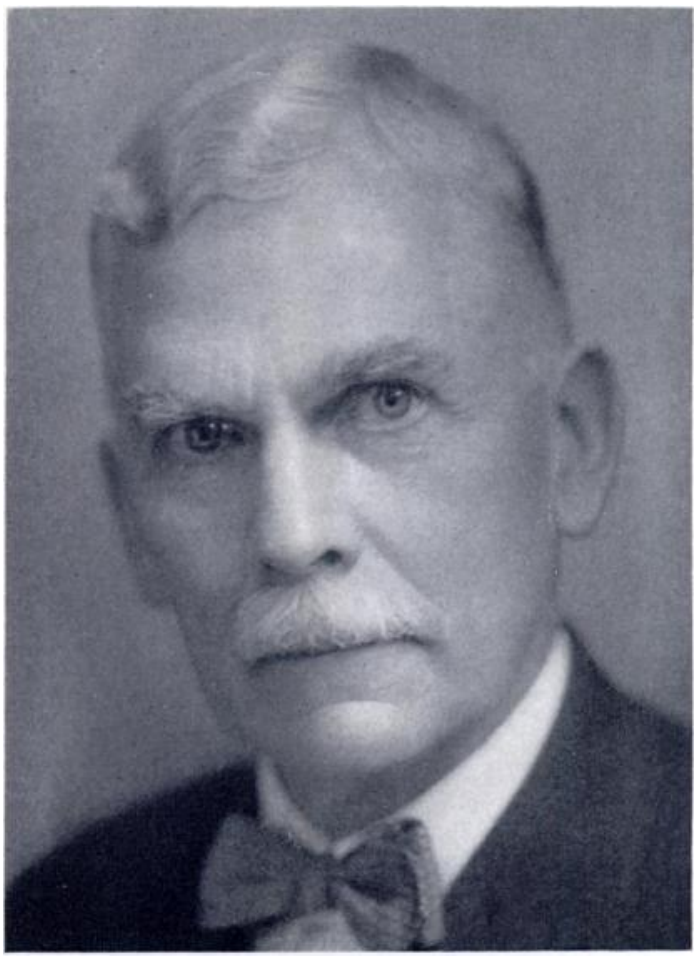

\section{Dr JOEl E. GOLDTHWAT (1866)}

Elected to the American Orthopaedic Association in 1892, he is the oldest living member of the Association. Recognizing early the importance of orthopaedic surgery as a speciality, he raised the necessary funds to equip the first orthopaedic ward at the Massachusetts (ieneral Hospital. His studies of the sacro-iliac and lumbo-sacral joints, and his papers on posture have become classics. Is chairman of the "Preparedness Committee," appointed in 1916, he organized the first group of American orthopaedic surgeons who sailed for England, $A$ pril 28, 1917, just three weeks after the declaration of war, to work under Colonel Robert Jones. He was promoted to the rank of colonel in charge of the overseas division of the l)epartment of Military Orthopaedic Surgery of which colonel F. G. Brackett was the director.

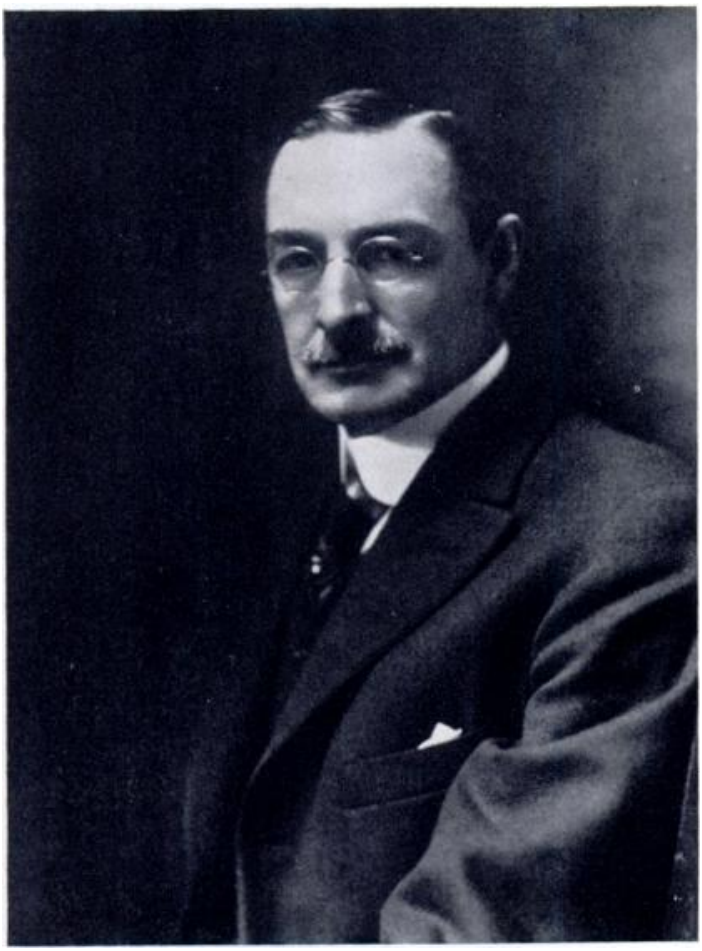

Dr (iWhYYM (i. DAVIS (1857-1918)

Professor of applied anatomy at the university of Pennsylvania until his appointment as professor of orthopaedic surgery in 1910. Educated here and abroad, he combined scholarly knowledge with "originality and inventiveness" (Bruce Gill). Of his many contributions, the most important was the "horizontal transverse section of the foot "-an operation designed to correct and stabilize paralyzed feet (1913). He devised a method of reducing congenitally dislocated hips which was less traumatic than that of Lorenz, and an ingenious operation " to correct external or internal rotation of the lower extremity by suturing the fascia lata to the great trochanter." Dr Frank Dickson, Dr DeForest P. Willard and Dr Bruce (iill received much of their early training under Dr Davis. 
I) FRED H. ALBEE (1S76-1945)

I mechanical genius who invented the motor saw, and devised scores of ingenious bone operations which he performed with the skill of a master craftsman. His outstanding contribution - spine fusion by the tibial graft for l'ott's disease, published in the same year as the Hibbs operation, precipitated a rivalry between the two surgeons which after many years of heated discussion ended happily in the appointment of Mlbee's son as a resident in the New York ()rthopaedic Hospital. His book, Orthopaedic and lieconstruction surgery (1919), is a milestone in orthopacdic progress. Is president of the American Orthopaedic Association in 1929 he led a group of Americans across the waters to hold a joint meeting with the British Orthopaedic Issociation, an occasion of goodwill and friendliness which has done much to cement the bonds between the two associations.

Dr Resselt A. Hibis (1869-1932)

Appointed in 1898 by the directors of the New York Orthopaedic Hospital to replace I)r Newton Shaffer, he represented the new school of orthopaedic surgery as contrasted to the old "strap-and-buckle" period. He disproved shaffer's theory that "mechanics and surgery. could not be mingled."

His concept of early fusion as the most effective treatment of joint tuberculosis has dominated orthopaedic thinking for the past forty years, just as his technique of spine fusionpublished in 1911-has formed the basis for our modern methods of spine surgery.
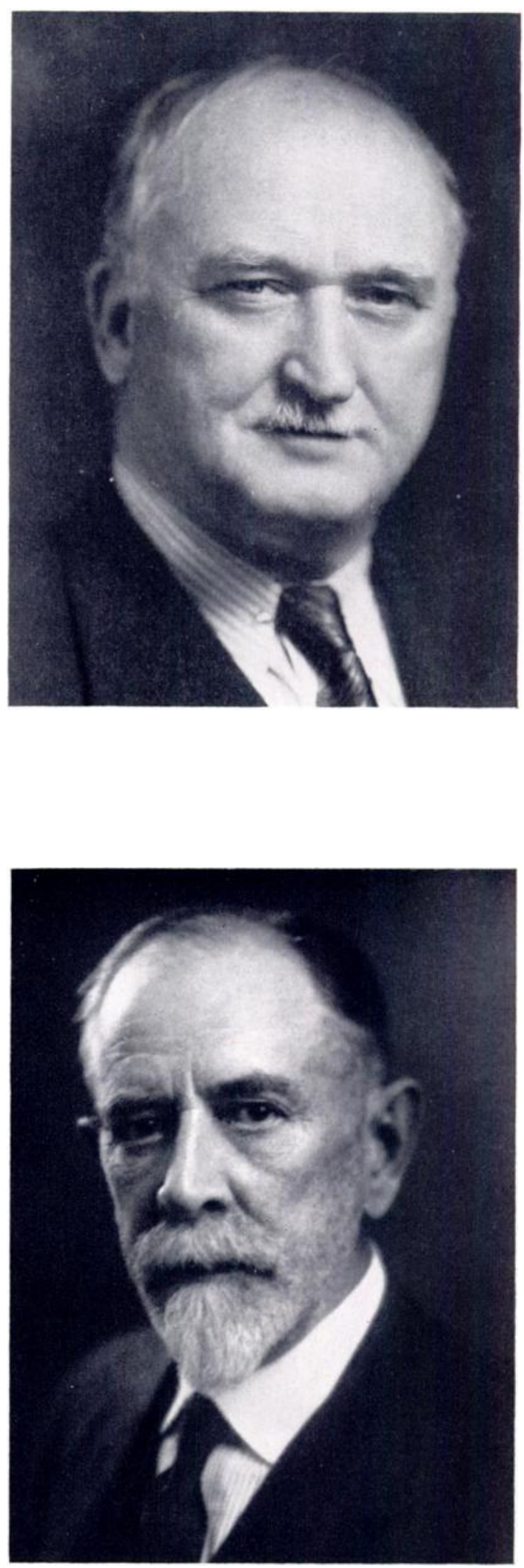


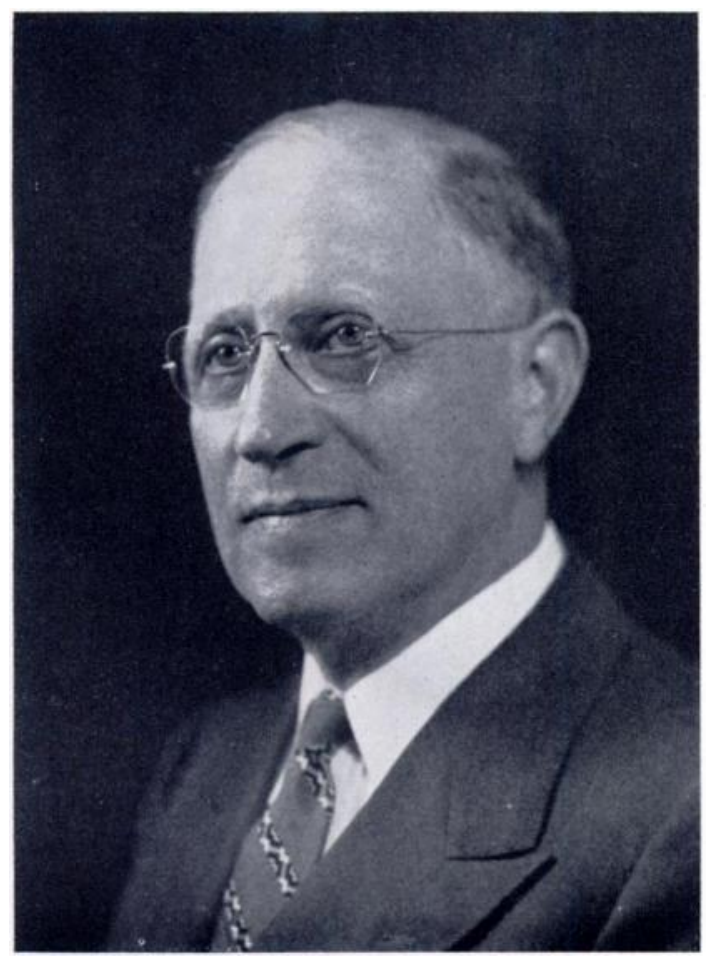

\section{Dr Albert H. Freiberg (1868-19411)}

Organizer of the department of orthopaedic surgery of the College of Medicine of the University of Cincinnati, and its first professor (1902), elected to membership of the American Orthopaedic Association in 1902 and president in 1911. His knowledge of parliamentary law was such that he was called to take the chair in executive sessions of the American Orthopaedic Association when complicated situations were anticipated. A careful, judicious surgeon, he was never swept off his feet by a temporary wave of enthusiasm but ever retained a critical attitude. As chairman of the Association committee to investigate scoliosis, 1914, 1915 and 1916, he showed objectivity and mature powers of judgment. His Robert Jones lecture (1937) on " Orthopaedic Surgery in the Light of its Evolution " showed a grasp of the subject which might well earn him the title of "the philosopher of orthopaedic surgery."

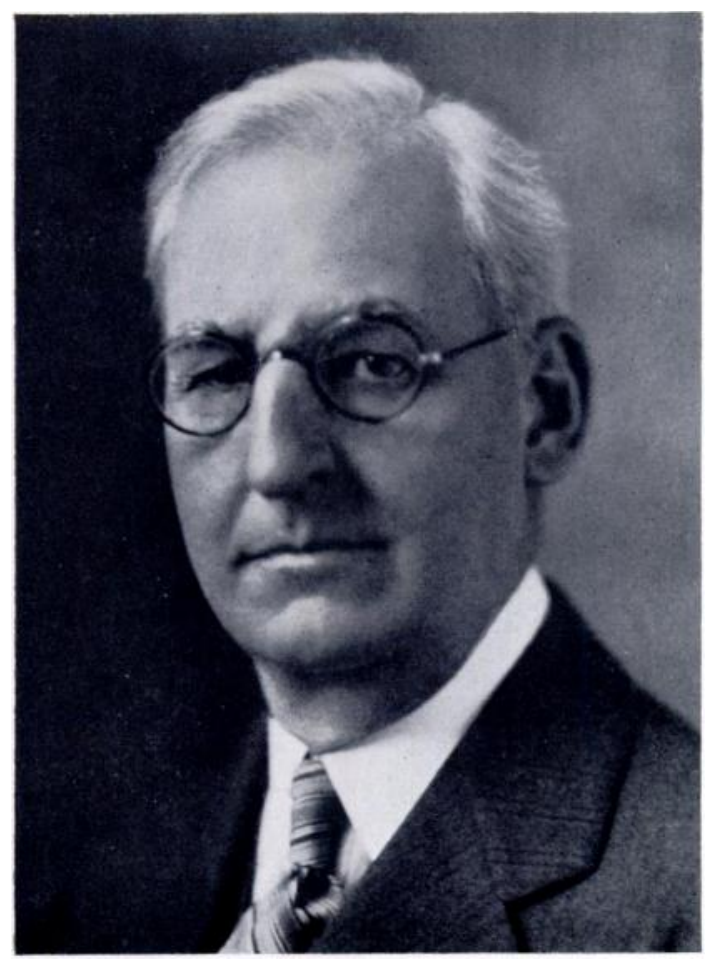

Dr JOHN L. PORTER (1864-1938)

Professor of orthopaedic surgery in the University of Illinois Medical School, president of the American Orthopaedic Association during the first world war (1918). Treasurer of the American Orthopaedic Association for twenty-six years, his annual financial reports were models of clarity and brevity. He had the rare gift of imparting eloquence to a column of figures. $\mathrm{He}$ was a warm supporter of the Journal of Bone and Joint Surgery and a close friend of Dr E. G. Brackett. He helped to found the Central States Orthopaedic Club (1912) and became its first president. His life was characterized by courage, honesty and kindness. " His name will stand at the head of the list," concludes the tribute published in the Journal, "of those who have been pre-eminent in their love for their fellow men." 
Wr MICHALI. HOKE (1574-1944)

l'resiclent of the . Imerican ()rthopacelic Association in 1926. Sion of a noted confederate seneral, he combined the courtesy and culture of a southern aristocrat with a love for humanity and a passionate desire to help the crippled. In 1920 he enlisted the support of " The shriners" -a Masonic order-for the crection and maintenance of hospitals for crippled children. Is the orthopacdic physician of Franklin 1). Roosevelt he was largely instrumental in establishing the IVarm springs foundation. Though his first major contribution to orthopaedic surgery dealt with the operative correction of a severe case of scoliosis, he is best known for his work on the foot: first, his paper on the treatment of severe recurrent talipes equinovarus (1911): second, his stabilization operation for paralyoed foet (1921)

Ior Willis ('. CAMPBEL $(1880-1941$

President of the American Orthopaedic Association in 1931, and president of the American Academy of Orthopaedic Surgeons at its first independent meeting, 1934. Beginning his medical career as a pediatrician, his mechanical talent and innate surgical inclination led him into the orthopacdic field, where he soon became an acknowledged master. Arthroplasty, bone graft ing, the operative treatment of paralytic deformities, the management of fractures and the operative treatment of low back pain all owe much of their growth to his contributions. His clinic in Memphis, Tennessee, became a Mecca for southern patients requiring orthopaedic care and for students wager to work under so gifted a teacher.
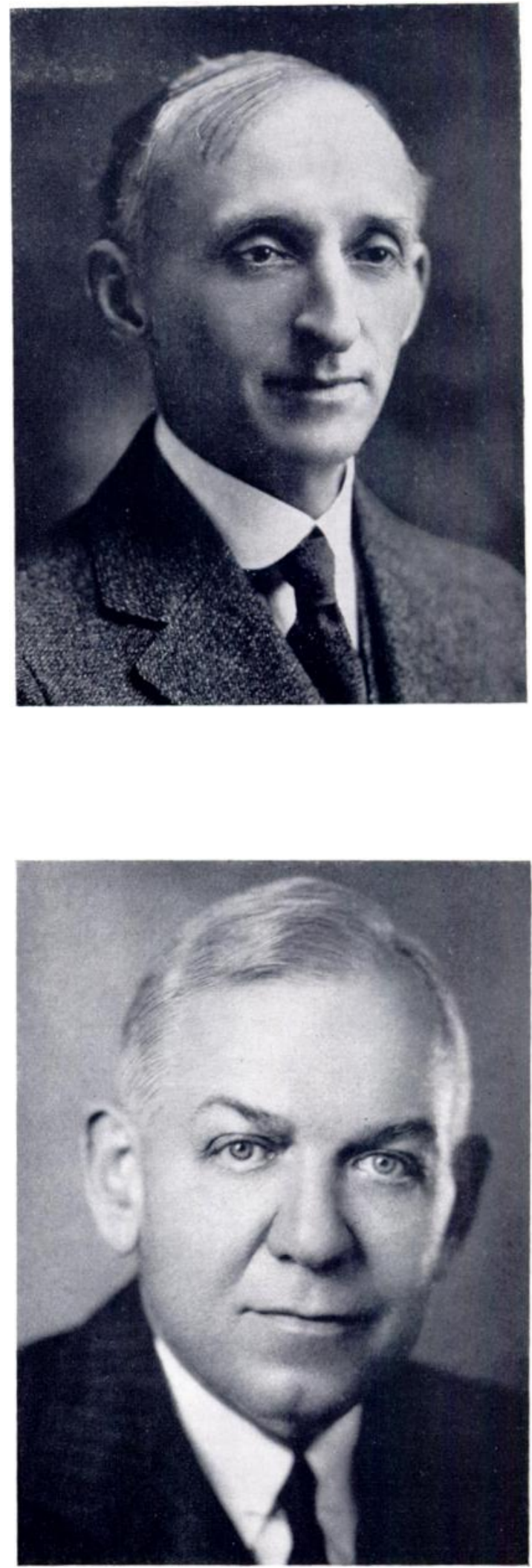


\section{PART IV}

The Years of Maturity

Pathology . . . . . . . . . . . . Henry L. Jaffe

Technical Advances

Arthroplasty

Arthrodesis

Osteotomy of the Femur . . . . . . . . . Henry Milch

Bone Grafting

Surgery of Poliomyelitis

Recurrent Dislocation of the Shoulder . . . . Jesse T. Nicholson

Congenital Dislocation of the Hip

Control of Bone Length . . . . . . . . . . Walter Blount

Back Pain and Sciatica

Scoliosis

Fractures of the Neck of the Femur

Other Fractures

Surgery of Tendons and of the Hand

Biochemical Advances

Scientific Progress .

AARON BODANSKY

Clinical Applications

Osteomyelitis

Tuberculosis . $\quad . \quad . \quad . \quad . \quad . \quad . \quad . \quad . \quad$ Charles Sutro

Arthritis . $\quad . \quad . \quad . \quad . \quad . \quad . \quad . \quad$. Otto Steinbrocker

Cerebral Palsy $\quad . \quad$. $\quad . \quad$. $\quad . \quad$. $\quad$. . . . Winthrop Phelps

Muscle Relaxants . . . . . . . . . . . . Edward Schlesisger

Development of New Societies and of Orthopaedic Education

American Academy of Orthopaedic Surgeons . . . . CARL Badgley

American Society for Surgery of the Hand . . . . . Joseph Boyes

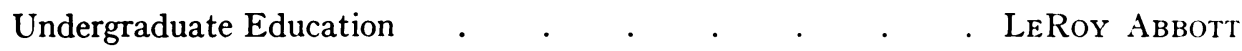

Postgraduate Education. $\quad . \quad$. $\quad . \quad$. . . . . A. R. ShANDS

American Board of Orthopaedic Surgery . . . . . . . Allen F. Voshell

Orthopaedic Research . . . . . . . . VERNE T. INMAN

Public Health Programs for the Orthopaedically Handicapped SAMUEL WISHIK

\section{Lay Societies}

The National Foundation for Infantile Paralysis . . . Dorothy Ducas

The Second World War

- Major-General N.T. Kırk

Veterans' Administration Hospitals .

- Paul Magnuson

Rehabilitation

Committee on Artificial Limbs. . . . . . . . Rufus Aldredgr:

Summary 
In planning this last section your reporter has encountered the difficulty which must be evident to every reader: so much has happened that a mere chronological register of advances in technique-operative, mechanical, diagnostic, sociological and administrative-would fill several volumes. Nor is it advisable to attempt an encyclopaedic account of these thirts years; that would be beyond the function of this paper. It may, however, be of some interest and educational value to trace certain developments of orthopaedic thought and technique: to stress the importance of The American Academy of Orthopaedic Surgeons, of The American Board, of The American Society for Surgery of the Hand and of other orthopaedic groups; to note the advances in educational standards and the extension of orthopaedic surgery to almost all the medical schools; to report some of the significant contributions to pathology, chemistry and biophysics; to read General Norman Kirk's account of the part orthopaedic surgery played in the second world war, and Dr Magnuson's tale of the Veterans' Hospitals. In carrying out this plan, many friends have helped and to all of them I now extend my warm thanks.

It will also be necessary, because of the complexity of the subject, to abandon the narrative style of Parts I and III and adopt instead presentation by topics. Unfortunately. this method of procedure has one obvious disadvantage: many contributions of great importance cannot be referred to. This is a source of great concern for fear that it may cause disappointment to some whose work deserves recording. For such omissions I now express my regrets and my apologies.

In another respect this account is sure to be deficient: it cannot bring out clearly the full educational, sociological, industrial and legislative significance of modern orthopaedic surgery, a development which has been so effectively presented by Sir Harry Platt in his "Evolution and Scope of Modern Orthopaedics." He emphasizes the "varied and humanistic experience which has determined the attitude of the orthopaedic surgeon of to-day towards the art and science of medicine as a whole, and which has made him strive to become something more than a mere specialist in either diagnosis or craftsmanship." It is to be hoped, however, that in the succeeding pages the reader will find more than a mere citation of technical advances, and that he will sense the myriad ramifications of our speciality and its significance not only. in medicine but in the life of the community.

Since progress in orthopaedic thinking is to a great extent predicated upon a more exact knowledge of pathology the first section of Part IV will be deroted to that subject.

\title{
PATHOLOGY
}

\section{Some Recent Advances}

\author{
HeNRY L. JAFFe, NeW YORK
}

A comprehensive discussion of skeletal disease from this point of view is, of course, quite out of the question here. We shall limit ourselves, therefore, to a few disease categories, and attempt to show how the pathologist's conception of them has been moulded and modified in the course of medical evolution during the past thirty-five years.

Hyperparathyroidism-That hypoparathyroidism induced by parathyroprivia leads to a prompt drop in the serum calcium level and to the appearance of tetany was discovered in 1909. This fundamental finding gave the clue to the relation of parathyroid function to calcium (and hence necessarily skeletal) metabolism. Its larger applications in the field of skeletal disease were not fully realized, however, until about 1925. It is true that before that time pathologists already recognized that in cases of so-called generalized osteitis fibrosa cystica of Recklinghausen, and also in some cases of so-called severe osteomalacia, one or more of the parathyroid glands would usually be found to be greatly enlarged. However, the parathyroid enlargement found in these cases, and even its suspected hyperfunctioning, were generally considered to have arisen in response to the skeletal devastation, and it was not realized that hyperfunction of the parathyroids itself instigated the devastation.

vOL. $32 \mathrm{~B}$, NO. 4 , NOYEMBER 1950 
In 1926 a case of Recklinghausen's bone disease was treated for the first time on the supposition that it might be based upon parathyroid hyperfunction, a dramatic improvement being obtained through removal of an enlarged adenomatous parathyroid in this case. The aforementioned clinical advance was concomitant with the development of chemical methods for the preparation of potent parathyroid extracts. Clinical and experimental studies soon proved that with such extracts one could duplicate the clinical (including biochemical) and the pathological aspects of the bone disease hitherto known as Recklinghausen's osteitis fibrosa cystica. Thus it became established that parathyroid hyperfunction was the fundamental disorder and that generalized osteitis fibrosa cystica of Recklinghausen represented merely the extreme skeletal expression of hyperparathyroidism. Soon thereafter it also began to be evident that cases of hyperparathyroidism really fall into two subdivisions. One group, primary hyperparathyroidism, is constituted by cases in which there is no direct explanation or known cause for the parathyroid hyperplasia and hyperfunction. The other group, secondary hyperparathyroidism, is constituted by cases in which there is a direct explanation or known cause for the parathyroid hyperplasia and hyperfunction. Specifically, for practical purposes secondary hyperparathyroidism is hyperparathyroidism appearing in response to chronic renal insufficiency ascribable to any one of several pathologic causes such as congenital polycystic kidneys, congenital ureteral strictures or chronic glomerular nephritis. Thus the changes associated with so-called renal rickets and renal dwarfism of early childhood had come to be recognized: and even in adults chronic renal insufficiency, through its instigation of parathyroid hyperfunction, may be reflected in resorption and fibrosis of the bones, occasionally even reaching a high degree.

Collateral results of delineation of the concept of hyperparathyroidism-The concept of hyperparathyroidism was the entering wedge which brought about the collapse of the former infertile though widely accepted classification of many of the systemic bone diseases under the general vague heading of " fibrous osteodystrophy," modified merely by the descriptive term "hyperostotic" or "hypostotic." For instance, in that system Recklinghausen's disease of bone represented the hypostotic and Paget's disease the hyperostotic form of fibrous osteodystrophy, as though the two disorders were not fundamentally distinct. The finding that patients suffering from primary hyperparathyroidism tended to have distinctive serobiochemical patterns in regard to calcium, inorganic phosphorus and alkaline phosphatase stimulated intensive study of these patterns in regard to these substances in other skeletal disorders. Previously only the serum calcium and inorganic phosphate values had received study, and these only in connection with rickets. The serum biochemical pattern characterizing hyperparathyroidism was soon established as hypercalcemia, hypophosphatemia and an elevated serum phosphatase activity value. The pattern for secondary hyperparathyroidism was established as a tendency toward hypocalcemia, definite hyperphosphatemia, an elevated alkaline phosphatase and an elevated non-protein nitrogen value. Rickets and osteomalacia were found to be characterized by a tendency of the calcium value to be normal or at most slightly below normal, for the phosphate to be definitely below normal and for the alkaline phosphatase to be elevated. Paget's disease was found to be characterized biochemically only by an elevated alkaline phosphatase value, and the condition which is now generally recognized as fibrous dysplasia of bone also only by an elevated alkaline phosphatase value, though one which, even when the disease is very extensive, is not as high as that which is characteristic of advanced Paget's disease. However, along more purely clinical lines, and in the field of tissue pathology, much progress in the understanding of the disorders (other than hyperparathyroidism) has also been made during the past twenty-five years.

Paget's disease-In connection with this disease the most significant advance is the recognition that circumscribed calvarial osteoporosis is part and parcel of the total picture of Paget's disease. Roentgenologists had recognized that in the calvarium, particularly of older persons, large, clear-cut, relatively radiolucent areas may appear, while at the same time the thickness 
of the calvarium in the affected area remained within normal limits. Gross anatomic examination of the calvarium in such cases showed that these radiolucent areas appeared purplish or reddish. Histologic study showed that the tables and diploic bone in these areas were thinned and the osseous tissue tended to present the mosaic tissue pattern of Paget's disease. Systematic study of such cases subsequently showed that these altered calvarial areas eventually, though slowly, became sclerosed and thickened, and came to show also the rather typical roentgenographic and gross anatomic pattern of Paget's disease. Thus circumscribed calvarial osteoporosis was definitely established as an early porotifying phase of Paget's disease of the calvarium.

Rickets and osteomalacia-Almost nothing has been added to what was already known by about 1915 concerning the gross and microscopic pathology of infantile rickets. Its etiology on the other hand was still unknown at that time, although on a vague pragmatic basis codliver oil was sometimes used in its treatment, especially in fishing communities. With the end of the first world war a very intensive campaign of experimental investigation in the field of rickets was undertaken. On the basis of growing knowledge about calcium and phosphorus metabolism, and the discovery of means of inducing rickets experimentally (especially in rats) the first concerted steps toward conquering it were made. The discovery of the value of irradiated ergosterol in the prevention and cure of experimental rickets led to the identification of vitamin $\mathrm{D}$ and then to its chemical synthesis. The wide application of the administration of vitamin $\mathrm{D}$ to infants soon brought about a striking drop in the incidence of this disease. Indeed, a case of full-blown infantile rickets is now a rarity in those parts of the world where it was indigenous and where vitamin $\mathrm{D}$ is now used prophylactically.

Osteomalacia as the strict adult counterpart of vitamin D deficiency rickets of infants was probably always a rare disease. Those instances of osteomalacia which did appear among the adult population can be said in general to have been based on deep-rooted nutritional disorders in the form of deficiencies in mineral and protein intake or absorption, in addition to any vitamin $\mathrm{D}$ deficiency. This general statement is also true for the osteomalacia which sometimes occurred in connection with idiopathic steatorrhoea of adults, coeliac rickets of children, and the rickets or osteomalacia associated with the presence of biliary and pancreatic fistulae.

Although rickets on these various bases has come to be understood and in large measure conquered the past fifteen years have seen a renaissance of interest in the subject. This stems from the discovery that rickets and osteomalacia may arise not only on the basis of a vitamin $\mathrm{D}$ deficiency but also through renal tubular dysfunction (without disease of the glomeruli). In the case of rickets arising through dysfunction of the renal tubules the dysfunction may consist of defective tubular resorption or defective tubular excretion. We are only at the threshold of understanding of the pathologic physiology of these cases, but what we have learned so far does represent progress in that it explains the intractability to vitamin D of certain cases of rickets and osteomalacia which the orthopaedist occasionally encounters.

Fibrous dysplasia-This is another condition which has recently (1937 and 1938) been rescued from the amorphous category of fibrous osteodystrophy. Furthermore in its advanced form it is no longer confused, as it used to be, with generalized osteitis fibrosa cystica of Recklinghausen (the skeletal expression of hyperparathyroidism). As is now being increasingly recognized, what is meant by fibrous dysplasia of bone is the presence in one bone (solitary lesion) or in several or many bones (polyostotic form) of a fibro-osseous replacement tissue sometimes containing islands of hyaline cartilage or areas of cystic softening or both. In association with the bone involvement many patients present cutaneous pigmentation and some few present premature skeletal maturation and even precocious puberty with or without hyperthyroidism. These full-blown cases are some times denoted as instances of "Albright's disease."

The term "fibrous dysplasia of bone" actually denotes only the dysplastic skeletal

VOL. $32 \mathrm{~B}$, No. 4 , NOVEMBER 1950 
changes common to all cases. As applied to the disease complex as a whole, however, it has the value of emphasizing the basic and constant feature of the disease while permitting modifications in accordance with the special features of individual cases. Moreover it is also worth noting in regard to nomenclature that instances of fibrous dysplasia have in the past been designated as focal, unilateral or disseminated " osteitis fibrosa," according to the extensiveness of the bone involvement. Also, they have been denoted as "fibrocystic disease of bone," and sometimes even as a form of Recklinghausen's disease of bone. In regard to fibrous dysplasia of the jaw bones, the terms "fibrous osteoma" and "ossifying fibroma" are the ones which have most often been applied.

Eosinophilic Granuloma of Bone-The concept of eosinophilic granuloma of bone was delineated in 1940. The disorder has come to be recognized as a peculiar inflammatory condition affecting one, several or many bones. Whether single or multiple, the skeletal lesions occupy the foreground of the disease picture. In the cases in which only one bone lesion develops, the lesion heals either spontaneously or under treatment and there is no further trouble. This is true also in most of the cases showing multiple bone lesions.

The delineation of the concept of eosinophilic granuloma of bone opened up a number of questions which have not yet been settled. One of these is the possibility of the identity of cases of multiple eosinophilic granuloma with many of the cases already reported in the literature under the heading of Schüller-Christian disease. In this connection, the further question arises of the actual pathologic nature of Schüller-Christian disease itself, since neither Schüller nor Christian had presented any relevant gross or microscopic pathologic findings. The question also arises whether, and if so how, eosinophilic granuloma is related to LettererSiwe disease. At any rate, whatever the anatomic interrelations among these three conditions may be there does seem to be a need for retaining at least clinical distinctions among the three, especially since eosinophilic granuloma is a relatively innocuous clinical condition.

Giant-cell tumor-This lesion continues to be the " problem child " among the benign tumors of bone. This is true even though, in accordance with more recent knowledge, the term "giant-cell tumor" is generally being used rather strictly. Specifically, it is no longer being made a catch-all for various other tumorous lesions formerly included among the giant-cell tumors, albeit as variants, merely because they contain some multinuclear giant cells. The genuine giant-cell tumor remains a lesion difficult to assay in respect to its clinical behaviour. In general it can be said now, however, that it very frequently recurs after any form of local therapy, and that instances of metastasis from giant-cell tumor are increasingly being recorded. Thus the giant-cell tumor is actually a rather treacherous lesion, in regard to which the term " benign," still often made part of its name, conveys a false conception of its potentialities. Whether a particular giant-cell tumor will recur cannot necessarily be predicted from the histologic pattern of the lesional tissue. Indeed, it has been found that it may recur or even metastasize when the pattern is not in itself such as to create uneasiness. Thus an occasional giant-cell tumor runs a malignant course without presenting, even in its metastases, an obviously malignant histologic pattern. Nevertheless, in most cases of malignant giant-cell tumor the stromal tumor tissue does present a sarcomatous appearance. Sometimes this appearance is already manifest in the original local tumor, and sometimes it does not become so until after repeated local recurrence.

Chondrosarcoma-It is now generally recognized that chondrosarcoma of bone is an entity distinct from osteogenic sarcoma. It is a malignant bone tumor which arises from cartilage and tends to maintain its essentially cartilaginous nature as it continues to grow. It is possible to show, in regard to many chondrosarcomas, that they arise through malignant degeneration of a previously benign cartilage tumor-in particular through malignant degeneration of an enchondroma or an osteochondroma (osteocartilaginous exostosis). The transformation of a benign cartilage tumor into a frank chondrosarcoma is often slow, and even after this the sarcoma often remains only locally invasive for years. On the other hand it is not unusual 
for the transformation to be achieved rather quickly and for the case to run a rapid course, terminating in death within a year or so.

Ewing sarcoma-The Ewing sarcoma is a specific primary malignant tumor of bone. As to pathogenesis, it was originally thought that the tumor cells of the lesion were derived from angio-endothelium in the broadest sense, and hence the lesion was originally designated as "diffuse endothelioma" or "endothelial myeloma" of bone. The present tendency is to favor the interpretation of the tumor as a sarcoma of a primitive form of connective tissue, and specifically of the mesenchymal supporting framework of the bone marrow. This conception of the histogenesis of the tumor cells seems to be superseding the one proposed originally. Osteoid osteoma-The small but painful benign bone lesion known as osteoid osteoma was first defined in 1935. It is a sort of borderline or quasi-tumor. The fact that it is a lesion of self-limited growth, irrespective of its duration, is of course somewhat against its being acceptable as a tumor. On the other hand it clearly does not represent, for instance, a reparative response to an inflammation. At any rate it is now generally accepted as a distinct lesion and one which should not be confused, as it still sometimes is, with a small bone abscess or a focus of chronic sclerosing non-suppurative osteomyelitis.

Tumors developing at sites of damage from noxious agents - In relation to the bones, there have been many clinical and experimental observations of both the immediate and remote harmful effects of the external application of roentgen and radium rays. It has been clearly established that if, for therapeutic purposes, one or more long bones, for instance, of a young child have been irradiated with too large a single dose, or at too frequent intervals, the bone or bones in question may become stunted because of damage to the epiphysial cartilage plate areas. In a child or in an adult (in whom, of course, the plates no longer exist) intensive external radiation is known to induce injury to the other bone elements also. That is, it may damage the periosteum, bone marrow, spongy bone and cortex. The complex of changes which may appear under these conditions is usually termed "radiation osteitis." This involves necrosis and sclerosis of the osseous tissue and fibrosis of the bone marrow. The bones so affected also become brittle and highly susceptible to fractures (which are also slow in uniting) and to infection.

That a sarcoma may develop in a bone which has been heavily irradiated has become increasingly evident as experience accumulates. There is quite likely to be an interval of five years or so between the time of the intensive irradiation and the appearance of the malignant tumor. Sarcoma has been known to develop in a bone which had been heavily irradiated in the treatment of an infection (tuberculosis, for instance), a non-malignant tumorous bone lesion (such as a giant-cell tumor or a bone cyst) and even in an originally sound bone which had been within the field of irradiation. Though the incidence of post-irradiation sarcoma is apparently not high its occurrence cannot be doubted and should be a deterrent to irradiation of benign bone lesions which could be treated by surgery instead. These experiences are in line with the earlier observations on the development of bone sarcomas in persons who, years before, had either ingested or inhaled salts of radium of mesothorium, the salts having lodged in the bones and first induced a radiation osteitis.

Infantile cortical hyperostosis-In 1947 the entity of infantile cortical hyperostosis was delineated. This affection, not particularly rare, appears in infants of about three or four months of age. It sets in with swellings of the soft parts overlying various bones, and these are soon followed by the appearance of an osteoperiostitis of the underlying bone. Very often the mandible is the first bone affected; but a number of other bones may soon become involved. The course is one with remissions and exacerbations, certain of the bones showing recession of the osteoperiostitis while others are developing it. After a period of six months or a year the disease usually comes to a spontaneous arrest.

Infantile cortical hyperostosis seems to be a new disease entity. It is not likely that it had previously been confused with the osteoperiostitis of congenital syphilis and the

Vol. $32 \mathrm{~B}$, No. 4 , NoVEMBER 1950 
subperiosteal new bone formation associated with healing scurvy. The cause of the disease remains an enigma.

Aseptic necrosis of bone-The groundwork for the study of aseptic necrosis of bone was laid in the experimental studies carried out years ago on the fate of bone transplants. These studies helped to develop the concept of "creeping substitution "- that is, of the process by which bone which has been transplanted into a host and died is gradually replaced by new bone. It is through creeping replacement that a bone graft used for instance in fusion of a vertebral column comes to be transformed into host bone.

The concept of aseptic necrosis and creeping substitution soon found its applicability in explaining the basic pathologic alterations taking place in the capital femoral epiphysis in cases of Perthes disease. The immediate change was shown to be an aseptic necrosis of a smaller or larger part of the femoral epiphysis. The later reparative changes were found to be dependent on revascularization and creeping replacement of the dead bone by living bone.

What has remained a mystery, however, in connection with the localized aseptic necrosis has been the manner by which the blood supply to the affected bone area is interrupted. The idea that the blood supply to the part was interrupted through the plugging of the terminal arteries by bland bacterial emboli found many adherents. It has never been proved, however, and has now been largely discarded. All one can say is that in some way trauma plays a part in the evolution of the alterations leading to death of the bone in localized aseptic necrosis such as occurs in the capital femoral epiphysis, the condyle of the femur, the carpal lunate, the head of the second metatarsal bone and other sites.

In connection with infarction of the bone as observed in caisson workers, embolization of terminal arteries by bubbles of nitrogen seems to be the mechanism by which the aseptic necrosis of bone is instigated. Bone infarction, expecially if the infarction extends to an articular bone end, may lead to collapse of the bone end, articular incongruity and the development of osteoarthritis. In this way the painful joints of caisson workers are to be explained. The occasional occurrence of bone infarction in solitary and multiple foci in persons who are neither caisson workers nor high altitude fliers has been noted and requires further investigation.

\section{TECHNICAL ADVANCES}

\section{ARTHROPLASTY}

One of the most intriguing fields of orthopaedic endeavor has been the creation of a new joint to replace one destroyed by disease or accident. Though a first attempt was made by $\mathrm{J}$. Rhea Barton in 1826 the subject did not engage serious surgical consideration in America until the beginning of the twentieth century. Then from the group of general surgeons, represented by $\mathrm{Dr}$ John B. Murphy, and from the orthopaedic group, represented by $\mathrm{Dr}$ William Baer of Baltimore, frontal attacks were made. Murphy used a pedunculated flap of fascia and fat as interposition material. He considered the fat as important as the fascia; he thought the pedicle necessary for vascular supply. Baer (1909) considered the Murphy flap too bulky and after experimentation selected chromicized pig's bladder (Cargile membrane) as the most suitable interposition material. Allison (1915) used fascia impregnated with silver so as to render it more resistant. At a symposium of the American Orthopaedic Association in 1917 Baer presented satisfactory results in 68 per cent of arthroplasties of the hip, knee, elbow, jaw and other joints. Dr Melvin S. Henderson (1918), as the result of a questionnaire, reported that results were best for the jaw (93 per cent), next best for the elbow (76 per cent), then for the hip (57 per cent) and for the knee (15 per cent). The showing was not too encouraging.

Far better were the results of Dr W. Russell MacAusland of Boston, reported in his paper before the International Congress of Surgeons in London in 1923. He used fascia from which the fat had been carefully removed, and sutured this so as to cover one of the two articulating 
surfaces. The elbow proved most amenable to arthroplasty and in thirty-one cases gave 90 per cent or more of painless motion.

A scholarly paper-the first Sir Robert Jones lecture of the Hospital for Joint Diseaseswas delivered by Willis Campbell in 1931. Entitled "The Physiology of Arthroplasty," it presented the objective evidence regarding arthroplasty as seen in animal experiments, in clinical results, in observations after spontaneous new joint formation. (as in pseudarthrosis), in biopsies and autopsies and in roentgenological studies. He considered 60 per cent of his operations successful. In six cases he had the opportunity to examine the newly formed joints months or even years later. In these he found a joint cavity containing fluid; the articular surfaces were covered by a smooth, firm fibrous tissue, which "may in time by functional adaptation be supplanted by cartilage."

An actual demonstration of cartilage, however, was not made until some years later, when by introducing a new principle into arthroplasty Dr M. N. Smith-Petersen of Boston was able to prove at secondary operations that hyaline cartilage actually formed in a man-made joint. The story of Smith-Petersen's work is so fascinating that it should be read in his own words. In his first paper published in this Journal in 1939 after fifteen years of experimentation first with glass moulds, then with pyrex and bakelite, he reported his first twenty-nine cases of vitallium-mould arthroplasty. His original idea was of a two-stage operation: the first for the insertion of the mould, the second, after a joint had been formed, for its removal. Further observation showed that the second operation was unnecessary, but the superiority of the mould to a perishable interposition material such as fascia or chromicized pig's bladder has been well established. To insert the mould Smith-Petersen modified slightly his subperiosteal supra-articular approach, first reported in 1917, and developed an adequate set of tools. He paid meticulous attention to the post-operative care of his patients. By nature a perfectionist, he has worked over each tiny detail of the operation until it actually seems to the observer to be the perfection of bone surgery. In his second important paper on the subject, the Moynihan lecture delivered in 1947 at the University of Leeds, he told of his experiences with more than 500 hips. He considers his operation better than arthrodesis for dealing with malum coxae senilis, rheumatoid arthritis and aseptic necrosis. He has also had much success with congenital dislocations. "This is the first time," he writes in his conclusions, " that the principle of the mould - the principle of guiding the repair of nature for the purpose of recreating a destroyed or damaged structure-has been applied to surgery."

Thus far it has not proven possible to extend this principle to the knee and to other joints where an improved method of arthroplasty is desirable.

Recently at the 1950 session of the American Orthopaedic Association, still another type of arthroplasty was presented - the Jaenichen method of substituting a metal ball for the femoral head. Peterson reported fifteen cases with good results but the method must still be considered in the experimental stage. A similar method of substitution has been demonstrated by McBride at the exhibits of the Academy of Orthopaedic Surgeons. Experimental and clinical investigation has been done at the Columbia College of Physicians and Surgeons on plastic substitutes for the femoral head, and in France an acrylic femoral head has been successfully used in several hundred cases by Drs Jean and Robert Judet, and also by Professor Merle D’Aubigné.

\section{ARTHRODESIS}

One of the procedures that have added greatly to the therapeutic effectiveness of the orthopaedic surgeon is the surgical production of ankylosis of the joints. Originated by Albert of Vienna, who coined the term " arthrodesis," it was first used to fuse a paralyzed shoulder and thus to transfer the action of the thoraco-scapular muscles to the arm. This principle of stabilizing a paralyzed joint was extended later to prevent progress of deformity, as in fusion of the spine for advancing scoliosis, and to act as an internal splint, thus eliminating joint motion and aiding the healing of tuberculosis and severe arthritis.

Vol. 32 B, No. 4, NOVEMBER 1950 
During the period under consideration fusion of all the major joints has been extensively practised. For the ankle and foot it has been used chiefly for paralytic conditions, but also for arthritis, particularly of the traumatic type induced by malunited fractures. The horizontal transverse section of G. G. Davis (1913) was succeeded by the brilliant operation of Hoke (1921) (already referred to) and by the triple arthrodesis of Ryerson (1923). Another principle, the bone block, was introduced by Willis Campbell (1923). The bone block was built up behind the tibia, resting in the talus and calcaneum; it was used in combination with subtalar arthrodesis to prevent dropping of the foot. All these operations, together with the Whitman astragalectomy combined with tendon transplants, have enabled the orthopaedic surgeon to correct practically all paralytic deformities of the feet.

For malunited fractures, with disorganization either of the talo-tibial or subtalar joints, arthrodesis relieves pain with a minimal loss of motion. At the talo-tibial joint the lateral approach of Horwitz, who used the resected fibula as a graft to fuse the tibia to the talus, or the anterior approach, with sliding graft from tibia to talus, gives excellent results. For fractures of the calcaneum involving the subtalar joint the posterior incision of Gallie with the introduction of two tibial grafts is simple and effective.

At the knee the actual enunciation of the principle of fusion for the cure of tuberculosis was first made by Hibbs in 1911, but we have seen that during the 'nineties there were numerous "resections" of the knee with resultant ankylosis and cure of the tuberculosis. Hibbs (1911) utilized the patella as a graft, Albee (1916) a sliding graft from the femur, Milgram (1931) a round graft removed with a special trephine from the adjacent surfaces of the femur and tibia. Bosworth substituted the Smith-Petersen nail for the less efficient nails and wires used by previous surgeons. American orthopaedic surgeons were quick to adopt the idea of Dr Albert Key, as advocated by Charnley at the Quebec meeting of the Association (1948), of utilizing a compression force so as to hold the femur and tibia in intimate contact.

Arthrodesis of the knee has been effective in severe chronic osteoarthritis and even in neurotrophic joints (Cleveland and Smith). For paralyzed knees the operation is used less and less because of the obvious superiority of a light brace which permits flexion in the seated position.

As to the hip, an intense controversy is still raging with regard to the comparative merits of arthrodesis versus arthroplasty in cases of osteoarthritis. Smith-Petersen in a personal communication has informed the author that within the past ten years he has not once been forced to resort to arthrodesis; other competent surgeons, however, prefer the more certain results of arthrodesis to the hazard of arthroplasty, even though arthrodesis unquestionably throws a severe strain on the lumbar spine, which frequently is also the seat of osteoarthritis. In cases of tuberculosis there is no doubt about the indication for arthrodesis. The method of Chandler, as reported by Pease (1948), has given unusually good results in children. In adults iliac grafts, reinforced by the Smith-Petersen nail (Watson-Jones) have been most effective. In paralytic conditions the operation has a place whose importance has thus far not been sufficiently recognized.

No part of the body is fused in modern orthopaedic surgery so frequently as the spine. Although thanks to the diminution in the incidence of tuberculosis the original purpose of the operation published by Hibbs and by Albee in 1911-namely the cure of Pott's diseaseis now seldom invoked, the extension of fusion of the spine to cure painful back and to prevent the advance of scoliosis has made the operation very popular.

At the shoulder fusion is of inestimable benefit in paralytic cases. Although in certain instances transplantation of the trapezius or other muscles may be practised most of the extensive paralyses require arthrodesis. But the operation is indicated only if the trapezius, serratus magnus and other thoraco-scapular muscles are reasonably strong. Great care must be taken to place the arm in a functional position at the end of the operation (Pemberton 1942).

At the wrist, too, both in poliomyelitis and in the complicated lesions of the peripheral 
nerves due to injury, fusion is an important adjuvant. The iliac graft of LeRoy Abbott (1947) is the most effective method.

\section{OSTEOTOMY AT THE UPPER END OF THE FEMUR}

Henry Milch, New York

The purposeful cutting of the upper end of the femur with the object of altering its axial alignment probably dates from 1827. In that year John Rhea Barton of Philadelphia first performed subtrochanteric osteotomy for the correction of a flexion adduction deformity in an ankylosed hip. For many years such anatomical correction of axial alignments presented the only indication for the use of the " directional osteotomy." No further significant progress was made until 1894 when Kirmisson suggested subtrochanteric osteotomy with the object of improving function in cases of congenital dislocation of the hip. After this the physiological implications of subtrochanteric osteotomy in the movable hip began to receive attention. In 1915 Hibbs performed detorsion osteotomy for the correction of anteversion of the femoral neck as had been recommended by Bradford in 1900. In 1918 von Baeyer, and in 1919 Lorenz, independently described a type of upper femoral osteotomy which has since acquired the designation "bifurcation operation." Because of its stabilizing effect on the pelvis this operation early acquired wide popularity. In this country good results were reported by Reich (1925) and later by Galland (1930). But subsequent experience has shown that it frequently resulted in annoying pain, limp and limitation of motion. While the explanation of these unhappy sequelae was not immediately apparent, the operation gradually lost favor and was soon superseded by a somewhat different type of " pelvic support osteotomy " first described by Schanz in 1922. This found a strong supporter in Gaenslen (1935) who considered it more effective than the Lorenz " bifurcation." Schumm also favored it.

Though both the Lorenz and Schanz procedures achieve pelvic stability by displacement of the mechanical axis with effectual exclusion of the femoral neck it was not until 1944, when the concept of the "post-osteotomy angle" was developed (Milch), that the reason for the superiority of the Schanz over the Lorenz procedure became evident. It was found that whenever the "post-osteotomy angle" exceeded the critical value determined by the inclination of the wall of the erect pelvis, stability and pelvic inclination were increased while mobility was correspondingly decreased. It was further found by differential amputation of the " bifurcation spike" that as the spike was made smaller and the Lorenz procedure tended to assume the appearance of the Schanz osteotomy pain, limp and the limitation of motion tended to disappear.

The appreciation of the kinesiological value of upper femoral osteotomy soon led to its application in a number of different conditions. In 1930 Putti began the use of the displacement osteotomy to support both head and neck of the femur by bridging across the fracture line in fractures of the femoral neck (reported in 1937). In 1935 Pauwels employed an abduction type of osteotomy with the object of changing the angular relationship of the fracture line to the axis of the femoral shaft and thereby converting a shearing stress into a compression force. At about the same time McMurray recommended a modified form of Lorenz bifurcation for the purpose of altering the line of weight-bearing in osteoarthritis of the hip. In 1943 Milch reported on the use, during the preceding nine years, of the resection-angulation operation in the treatment of the same condition. This operation, much like that described by Batchelor in England, was designed to effect: 1) release of the pelvis and restoration of hip mobility by resection of the femoral head and neck; and 2) re-establishment of pelvic stability by a Schanz type of osteotomy. It has since been employed in the treatment of a number of different hip affections. In 1947 Irwin again proposed the previously abandoned method of subtrochanteric osteotomy for the purpose of enforcing pelvic inclination and thus of increasing pelvic stability in cases of gluteal paralysis after poliomyelitis.

Recognition must be given here to the work of Trumble (1932), Brittain (1941) and

VOL. $32 \mathrm{~B}$, No. 4 , NOVEMBER 1950 
Bosworth (1942) who recommended various modifications of the subtrochanteric osteotomy for the purpose of accomplishing extra-articular ischio-femoral arthrodesis of the hip joint.

Many excellent techniques for predetermining the exact degree of axial deviation to be obtained and many different methods of fixing the fragments of the femur have been developed. Blount's (1943) modification of the Moore nail, in particular, has greatly simplified postoperative treatment.

\section{BONE GRAFTING}

Originated by a great French surgeon, Ollier, in his famous Traité Experimentale et Clinique (1867), activated by the brilliant contribution of Macewen of Glasgow in his monograph The Growth of Bone (1912), this branch of surgery has reached the peak of its development through the efforts of a group of American surgeons. The story is as exciting as a novel in which ardent rivals, men of blood and brawn, contend for mastery. Even to-day, after forty years of intense effort, all is not yet decided, but orthopaedic surgery has advanced because of the conflicting views.

The tale begins, as already told in Part III, in 1911 when within a few months there appeared two independent papers by two New York orthopaedic surgeons-Fred Albee and Russell Hibbs-each dealing with the application of bone grafting to fuse a diseased spine. Albee used a massive tibial graft which he removed with a motor-driven saw. The graft was placed between the two halves of the split spinous processes. No attention was paid to the intervertebral joints. Hibbs meticulously denuded the laminae of cortical bone, the intervertebral joints of cartilage, and utilized as bone grafts the spinous processes and the tiny bits of bone supplied by the denudation. Albee contemptuously referred to these grafts as " chicken-feed" but we now know that they possess much more osteogenic potentialities than the massive graft on which he was so insistent. Each surgeon was in his own right a master technician. Both achieved a remarkably high percentage of good results, and each kept to his own path, determined to show the other that his method was superior. Albee rapidly extended the use of the graft to fractures, recent, old and ununited, and to many phases of reconstruction surgery. Hibbs applied his method, with slight modifications, to fuse the hip, the knee and other joints. Albee developed the technique of the inlay bone graft with the finesse of a cabinet-maker. He favored the inlay because it appealed to his boyhood knowledge of tree grafting. He had noted how accurately the scion (graft) was fitted into its new bed so that each layer of the bark-alburnum, heartwood and heart-contacted the corresponding layer of the host. The same laws of growth must, he thought, hold true in bone grafting. Certainly his method worked; in 1930 he could report 89 per cent of cures in 754 cases. But Phemister of Chicago was able in 1931 to demonstrate by animal experiments and by clinical observations that the coaptation of the layers of the bone graft to the host was not essential. He found that in selected cases of non-union the inlay method was an unnecessary refinement and that healing could be secured by the simple expedient of wrapping osteoperiosteal grafts about the site of non-union or by applying two whole-thickness " splint grafts " after removal of the exuberant bone. In twenty-four cases of non-union treated by this method healing occurred in all.

Meanwhile Willis Campbell (1924) and Melvin Henderson (1928) had independently perfected the technique of the onlay graft. Albee disapproved of this type of graft because it did not correspond to his insistence on the coaptation of the layers of graft and host; because the onlay graft would add to the thickness of the recipient bone and thus cause undue strain on the skin suture; and because screws were necessary to secure the graft, and screws, he thought, diminished the strength of the graft because of the holes drilled for their insertion. Though proven wrong on all three counts, he continued to champion his method to the very end. The onlay graft, however, had come to stay, and in the hands of competent surgeons gave an even higher percentage of cures than the inlay; the Campbell Clinic (1942) for instance, was able to report over 93 per cent of cures in 511 cases of non-union (Boyd). Thanks to the work of 
Venable, Stuck and Beach (1937) it was proven that screws of inert alloys such as vitallium in no way interfere with bone healing. This fact led to a further development: Harold Boyd's dual onlay bone graft-one of the most effective methods of treating congenital pseudarthrosis of the tibia and other types of non-union close to a joint. Boyd did not hesitate to use homologous grafts even though Albee insisted on the superiority of autogenous bone.

The success of the homologous graft was in part responsible for another important contribution - the use of refrigerated bone, first advocated by Alberto Inclan of Havana (1940). He preserved the bone in citrated blood or saline at a temperature of 37 to 40 degrees Farenheit. Of forty-three cases in which he was able to check the final result 73 per cent were successful. By using modern refrigeration with temperatures of minus 25 degrees Centigrade (Bush), or by immersing the bone in merthiolate solution, " bone-banks " have been established in many hospitals. Though some surgeons still prefer the autogenous graft-and the experimental work still shows it to be somewhat more reliable-the bone-bank is a boon to many patients.

A new idea in the technique of repairing large defects of the tibia and femur was presented by Flanagan and Burem (1947). Their purpose was the "reconstruction of the normal architecture of tubular bone at the site of the defect " by apposing two massive grafts each comprising one-half the circumference of the affected bone-the half-cylinder grafts first described by Hey Groves. Of twenty-one cases sixteen were successful, a high percentage considering the extreme difficulty of the reconstruction problem.

Of the recent contributions the most significant is that of LeRoy Abbott and his co-workers (1947). As the result of intensive animal experimentation and clinical studies he was able to show that the cortical graft such as Albee used possessed " strength but little osteogenetic power." On the other hand cancellous bone, because of its loose structure and the presence of numerous endosteal cells, possesses a high osteogenetic power and permits of early and thorough revascularization. Cortical bone may be used to advantage with cancellous bone which furnishes the osteogenetic medium. Cancellous bone possesses a high degree of vitality in the presence of infection, particularly if penicillin is employed before and after the operation.

\section{SURGERY OF POLIOMYELITIS AND OTHER FORMS OF FLACCID PARALYSIS}

Although orthopaedic interest had attached to the treatment of poliomyelitis from the earliest days of the Association, and important articles had been published by Goldthwait, Bradford, Dana and Townsend, Whitman, G. G. Davis and others, it was not until the extensive epidemic of 1916 and its pathetic harvest of crippled bodies that orthopaedic surgeons began to note the numerical increase of paralyzed patients in their clinics and in their office practice. At this time appeared Dr Robert Lovett's spring balance test for muscle strength which has added considerably to the accuracy of our methods of examination. He developed a series of exercises for paralytic cases which, with the aid of his physical therapist, Miss Wilhelmina Wright, have formed the basis of the system of so-called " muscle education." The publication in Surgery, Gynecology and Obstetrics of three articles dealing with the anatomy, physiology and surgery of tendons-a summary of the monograph by Biesalski and Mayer-stimulated more precise attention to the technique of that most valuable adjuvant in the correction of paralytic deformities-the transplantation of strong tendons to replace those of paralyzed muscles.

The operative treatment of poliomyelitis may be divided into:

1. The release or correction of contractures.

2. The stabilization of joints.

3. The re-establishment of muscle balance by tendon or fascial transplants.

To the first group belong such operations as: the lengthening of the Achilles tendon, best done by an open operation; the correction of knee flexion contracture by lengthening of the hamstring tendons or capsulotomy or osteotomy of the femur; correction of genu recurvatum by the ingenious operation of Gill (construction of a powerful posterior check ligament); the

Vol. 32 B, No. 4, NOVEmber 1950 
release of flexion contracture of the hip by the Soutter or Campbell methods; correction of fixed obliquity of the pelvis (Mayer) by division of the tight quadratus femoris or other tight abductors or adductors and application of a push-pull device; the improvement of paralytic scoliosis by the turnbuckle plaster (Hibbs and Risser); and release of tight posterior capsule of the carpo-metacarpal joint of the thumb.

The second group, stabilization of joints, includes the following:

At the foot-The astragalectomy of Whitman for calcaneus; the G. G. Davis horizontal transverse section of the foot for cavus; the Hoke stabilization; the Ryerson triple arthrodesis; and, from across the waters, the Naughton Dunn and Lambrinudi operations. In flail foot pantalar arthrodesis may be indicated; occasionally the tenodesis of Gallie is effective. At the knee-The bone block operations for recurvatum of Campbell, Mayer and Milgram, or in rare instances fusion to eliminate the necessity of a brace. At the hip-Fusion for recurrent paralytic dislocation or for extensive paralysis of hip muscles with intact abdominal muscles; fusion of the spine; arthrodesis of the shoulder for extensive paralysis with good thoraco-scapular muscles: At the wrist-Fusion to stabilize the hand for the better function of the fingers: In the hand-Bone graft for paralyzed opposing muscles of the thumb.

To the third group belong the transplants of tendon and occasionally of fascia. Silk ligaments (Bartow and Plummer) and silk tendons (Lange) are no longer used. In all these operations certain rules must be observed. These are given in the section dealing with surgery of tendons.

The following are the more important tendon transplants:

At the foot-Shift of the peroneus longus to replace a paralyzed tibialis anterior alone (Peabody) or with the peroneus brevis to overcome drop foot; shift of the tibialis anterior alone or with extensor longus hallucis, to the outer side of the foot for varus; shift of the peronei and the tibialis posterior, or the flexor longus hallucis, to the insertion of the Achilles tendon for paralysis of the triceps surae; transplantation of the tibialis anterior to the Achilles tendon through the interosseous membrane (Peabody); transplantation of the tibialis posterior through the interosseous membrane to the outer side of the foot for equinovarus. Both these latter operations require particular care to avoid adhesion of the tendon as it passes through the interosseous membrane.

At the knee-Transplantation of the biceps femoris, usually with one of the inner hamstrings (preferably the sartorius) to the patella, for paralyzed quadriceps.

At the hip-The Ober or Mayer transplants of fascia to strengthen a weak gluteus maximus through the action of the erector spinae; the T. C. Thompson transplant of the abdominal muscles to strengthen the abductors; and the Telson forward shift of the gluteus maximus to aid abduction.

For paralysis of the abdominal muscles-The fascial transplants of Lowman, or the Mayer modification of his method by attaching the fascial grafts to the rib above and to the ilium or Poupart's ligament below.

At the shoulder-The trapezius transplant (Mayer) and the triceps-biceps transplant (Ober) for weakness of abduction; the teres major transplant for paralysis of the serratus magnus; the L'Episcopo shift of the latissimus dorsi and teres major to the posterior surface of the humerus for weakness of the external rotators (usually combined with division of pectoralis major and subscapularis for internal rotation contracture).

At the elbow-For paralysis of the biceps and brachialis anterior the upward shift of the muscles springing from the medial condyle of the humerus and the coronoid process of the ulna (Steindler). This operation when correctly performed gives amazingly good power of elbow flexion. Attachment of the muscles is best made into the bone rather than by the original suture to the intermuscular septum.

At the wrist-Transplantation of the flexors carpi radialis and ulnaris, usually with the palmaris longus and the pronator radii teres, to the extensors of the wrist and fingers for drop 
wrist and paralyzed finger extensors; transplantation of the extensors carpi radialis and ulnaris to the flexors of the fingers; the Bunnell operation for paralysis of the opposing muscles of the thumb (transplantation through a pulley at the level of the pisiform bone of a flexor tendon to the dorsum of the proximal phalanx of the thumb). This operation has been modified by J. C. Thompson and others, but the original Bunnell technique gives almost perfect restitution of function; the Bunnell operation for paralyzed interossei by transplanting the flexor sublimis digitorum to the tendons of the interossei (a delicate, exquisite operation); transplantation of extensor indicis proprius for paralysis of extensors of thumb or other fingers; and replacement of the pinching muscle (first dorsal interosseous) by one of several tendons.

This section, though dealing chiefly with the surgical treatment of poliomyelitis, would be incomplete without mention of the name Sister Elizabeth Kenny. When nursing in " the bush " of Australia many years ago she came face to face with the practical problem of treating fresh cases of paralysis. Far from any doctor, she was forced to use her own initiative and, remembering that as a little girl she had seen her mother relieve painful muscles by hot moist applications, she tried the same method on the paralyzed children. They liked it. The tender, sore muscles were soothed by the moist heat and by her skilful fingers. Muscle power happened to return. Thus encouraged, she began to treat more cases and soon established a local reputation which eventually extended to the entire continent and involved Nurse Kenny in a heated controversy with the Australian Medical Association. Though a medical investigating committee declared against the Kenny treatment, she, nothing daunted, came to America armed with such strong letters of recommendation that $\mathrm{Mr}$ Basil O'Connor, president of the National Association for Infantile Paralysis, felt impelled to give her a chance. His idea was to run two parallel wards in the Minneapolis General Hospital, one for the Kenny treatment, the other for the rather vague and uncertain "current treatment." Within a week, however, Sister Kenny had all the patients; for the parents insisted that their paralyzed children be treated by her. So she ran the two wards. She demonstrated to the satisfaction of Drs Cole and Pohl, who were there to observe her, that every case of acute infantile paralysis showed definite spastic components; that this spasm could usually be relieved by the moist packs; and that as the spasm receded the opposing muscles in many cases regained power. Even respiratory paralysis was treated by hot packs without the use of the Drinker respirator and without tracheotomy, and some very severe cases recovered. The National Foundation was sufficiently impressed to set up instructional courses; physical therapists from every state came to Minneapolis to study the Kenny treatment. Doctors came too. Some, like Hibbs of Texas, became advocates; others like McCarroll of St Louis, bitter opponents. He and Albert Key maintained that whatever was good in the Kenny technique had been used before; that whatever was new was invalid. They accused Nurse Kenny of wishful thinking, incorrect observations and misrepresentation.

Despite the fact that moist heat had been used in the Children's Hospital of Boston in the early years of the century, and that isolated observations of spasticity in poliomyelitis had been noted, Sister Kenny must be given credit first for emphasizing the great value of moist heat as an important phase of treatment, secondly for starting treatment at once instead of waiting till tenderness had disappeared, and thirdly for insisting on the presence of spasticity in the paralyzed muscles. Above all she stimulated interest in the treatment of the acute stage of the disease. Though rejected by most orthopaedic surgeons, her method was accepted and practised in some of the foremost pediatric clinics and in the municipal isolation hospitals. She preached much that in this writer's opinion was unsound, but she had a natural talent for nursing, a compelling personality which attracted even the youngest of her patients, great patience and untiring energy. She thought nothing of spending the entire night applying Kenny packs to a sick child. Her method of muscle re-education, though open to theoretical criticism, gave good practical results in many children who were made to concentrate much more effectively by Kenny than by reciting sing-song verses as in some orthopaedic clinics.

VOL. $32 \mathrm{~B}$, No. 4, NOVEMBER 1950 
Opinion still remains divided. Dr Pohl's (1947) article in this Journal and his monograph, The Kenny Concept of Infantile Paralysis (1943) are a good defence of the method; the report of the orthopaedic investigating committee condemned it. It is, however, still being used very extensively. It has stimulated research such as that of Plato Schwartz, and the use of pharmaceutical relaxants such as curare (Ransohoff) which have apparently been helpful. Careful unbiased observation over many years should be the method of reaching a final conclusion.

\section{REGURRENT DISLOGATION OF THE SHOULDER}

Jesse T. Nicholson, Philadelphia, Pennsylvania

In the past twenty-five years the operative treatment of recurrent dislocation of the shoulder has been, with a single exception, intracapsular. The previously devised extraarticular procedures denoted surgeons' reverence for joint space and their fear of initiating a pyoarthritis. Due to the prolonged insistence upon extra-articular trials of capsular reefing, bone blocks, muscle transplants, tendon shortening and tendon lengthening, the intra-articular pathology was disregarded. It was Bankart in 1923 and Hill and Sacks in 1940 who recalled the forgotten intra-articular pathology. The latter authors revealed by roentgen films the depressed defect in the posterior surface of the humeral head. This finding had been described as early as 1861 by Flower. Again in 1890 Broca and Hartman described the defect and, in addition, the torn anterior joint capsule, the stripping of periosteum from the neck of the scapula and "Bankart's lesion," the torn glenoid labrum. A few pertinent observations have recently been made. Fahey and De Cosola found, among fifty shoulder dislocations produced at autopsy, capsular tears from the neck of the humerus in 80 per cent and various types of glenoid labrum tears in the remaining 20 per cent. De Palma, Bennett and Callery revealed in cadaver dissections that sulci in the capsule between the gleno-humeral ligaments frequently communicated with the space between the subscapularis and the glenoid neck, and that there were frequently detachments of the glenoid labrum. Grant substantiated the latter finding. Gallie and LeMesurier pointed to variation in the shape of the glenoid in dry anatomical specimens. They suggested that anatomical variations were further substantiated by the frequency of bilateral involvement and by the occurrence of recurrent dislocations in two pairs of twins and three pairs of brothers.

Although Bankart described his operation in 1923 it remained practically unnoticed. For the great majority of surgeons, the intra-articular repair of recurrent dislocations began with Nicola's (1929) operation. This ingenious procedure, based upon the conversion of the long biceps tendon into a ligamentum teres for the humeral head, was relatively easily mastered. It was effective in a majority of subjects but owing to recurrences in those subjected to severe physical strain it began to lose its popularity prior to World War II. Bankart published his results in 1938, but it was Bost and Inman reporting their success with the Bankart operation in 1942 that sponsored its reception in America. A few years later surgeons reported failure to find the "Bankart lesion " in every case. The Magnuson-Stack procedure of transplanting the tendon attachment of the subscapularis muscle to the greater tuberosity to check external rotation was utilized after its publication in 1943. From England, however, came a surge of enthusiasm, based upon experience among military personnel, for the PuttiPlatt procedure. Putti reputedly was doing the operation in 1923 and Platt independently developed it in 1925 but in either case their procedure was described by an associate (Osmond-Clarke 1948). The operation was technically easier than the Bankart. Although the exposure of the joint was the same the result of the operation did not depend upon finding a torn labrum glenoidale. The principle of the Putti-Platt operation was to sew the distal part of the divided subscapularis muscle to the labrum, periosteum and deep capsule in front of the neck of the scapula. The capsule was then sewn over it and the proximal part of the subscapularis sewn over all. This not only reinforced the anterior capsule but advantageously limited the 
external rotation of the shoulder. Adams, in reviewing the three procedures, found recurrences after operation: Nicola, fifty-nine cases-twenty-one recurrences; Bankart, eighteen casesone recurrence; Putti-Platt, thirty-seven cases-two recurrences. The average range of external rotation of the shoulder was eleven degrees less following the Putti-Platt as compared with the Bankart operation.

A few in America and a majority in the Scandinavian countries have developed enthusiasm for an anterior bone block on the rim of the glenoid-the Hybbinette-Eden operation. Ivar Palmer emphasized the effectiveness of the bone block in preventing the depressed defect in the posterior humeral head from slipping over the glenoid rim when the shoulder is externally rotated. He reported in 128 cases a post-operative recurrence in eight. This was better than that reported by Arno V. Hellens with twenty-five recurrences in 166 post-operative cases. Little information was given by the authors as to the limitation of shoulder motion after the bone block procedure.

Gallie and Le Mesurier reported upon the use of a fascia lata transplant through drill holes in the neck of the scapula, humeral head and coracoid. This reinforced the anterior ligament and checked the external rotation about twenty-five degrees. Though this method has had little recognition beyond Toronto since 1926, the authors have acquired 175 postoperative results with but seven recurrences of dislocation.

It is to be presumed that the effectiveness of the Hybbinette-Eden operation is based, as in the Putti-Platt and Gallie operations, upon checking the shoulder motion before it reaches its unstable position of external rotation, extension and abduction. These effective results obtained with such great effort on the part of the surgeon are similar to what Hippocrates accomplished two thousand years ago quite simply by applying a cautery to the axillary region.

\section{CONGENITAL DISLOGATION OF THE HIP}

The importance of this topic in orthopaedic surgery is indicated by the large number of articles and by the symposia of the American Orthopaedic Association devoted to it. Its historical development is of particular interest because of the swings of the pendulum, first toward the side of " bloodless reduction," then to open operation, then back to the closed method, then to open operation, finally to a combination of the two. At each swing the momentum was so great as to carry most orthopaedic surgeons off their feet; only a few rugged individualists managed to keep their balance. Only recently, largely through the courageous exposition by Bruce Gill of the heavy percentage of poor end-results, by the pathological and embryological studies of Vernon L. Hart and Carl Badgley, by the differentiation of types of displacement by McCarroll and Crego, and by improved operative techniques (Colonna, Howorth, Gill, McCarroll and Crego) has light begun to dawn.

When the manipulative correction of congenital dislocation was first reported by Paci in 1887 a wave of enthusiasm swept through the orthopaedic ranks. This was a real triumph for the new speciality: but not for long. Soon both Hoffa and Lorenz condemned the closed reduction and urged open operation. Lorenz claimed excellent results in a series of 100 cases. Hoffa also was pleased with his results, but there is presumptive evidence of wishful thinking on his part as shown by the remark of a famous contemporary surgeon: "Before operation Hoffa's patients walk like ducks; after operation they walk like operated ducks." Within three years Lorenz switched to the closed method and urged it strongly in his address before the American Orthopaedic Association in 1896. Bradford in his exhaustive paper of 1900 stated that both the open and closed methods lacked precision; he favored the open operation which gave six good results out of nine, whereas all his closed reductions redislocated. This he attributed to anteversion, and suggested a rotation osteotomy of the femur as a cure. But later, like Lorenz, he returned to the closed method and developed a special " reduction table" which Lange of Munich admired so much that he took one home with him after his American trip of 1910.

VOL. $32 \mathrm{~B}$, No. 4 , NovenBer 1950 
Sherman was not satisfied with the results of closed reduction. G. G. Davis considered the Lorenz method too traumatic and developed his own technique (1906) by posterior pressure on the trochanter. Most surgeons adhered to the Lorenz technique, but in 1920 a bombshell was dropped by Herbert P. Galloway of Winnipeg who stated that the closed method was "blind, irrational and deplorably uncertain in results." He advised open operation in all cases. In his first series of thirty-eight hips he secured good results in twentysix; in his second, published in 1926-also thirty-eight hips-he secured thirty-three good repositions. In 1926 Farrell, von Lackum and Smith, reporting the series at the New York Orthopaedic Hospital, found that by the closed method of Hibbs only 39 per cent remained reduced. Because of anteversion, rotation osteotomies were done in thirty-five patients.

At the symposium of 1935 Freiberg urged earlier recognition and greater proficiencythat is, gentleness-in reduction. The indication for open operation was the failure of the closed method. Steele Stewart gave a beautiful embryological demonstration. "The pathology of congenital deformity is," he said, " sown in heredity, develops in embryo and fruits under the trade winds of use." The open operation is necessary to obliterate the fold of the capsule which prevents satisfactory replacement. He, too, stressed the importance of anteversion. Wallace Cole and Fred Kidner both favored the open operation. Farrell and Howorth in a comparative series reported $\mathbf{4 2}$ per cent successes by the closed reduction, 77 per cent by the open. Four papers (Dickson, Gill, Phemister and Compere, Ober) were devoted to the construction of a " shelf " to deepen the aplastic acetabulum, or to support a dislocated head. Of these, Gill's was unusually instructive both because of his refined surgical technique and his careful analysis of the types of pathology which require variations in the operative procedure. Gill concluded with the optimistic statement: " Judicious combination of closed and open methods should give almost 100 per cent successful results in young children."

Gill's paper the following year was one of the most thorough and convincing in the literature. His treatment may be summarized as: reduction in infants by simple abduction; in young children (two to three years) by gentle manipulation; removal of plaster in four months; if redislocation occurs, deepen acetabulum by shelf operation preferably without opening the capsule. He praised Putti's educational program for the early recognition of congenital dislocation as the most important recent development in the treatment of the condition.

In 1936 Kleinberg wrote an excellent short paper on the inadequacy of the acetabulum, and coined the phrase "acetabular index" to indicate the degree of obliquity of the roof. Ponseti's article (1946) on pathomechanics of the hip after shelf operations brought out clearly the importance of the comparative length of the horizontal distance between the mid-line of the body and the replaced head-the longer the distance, the less favorable the supporting action of the femur and its abduction mechanism.

Of particular significance is the symposium of 1948. In this, as in his paper of 1943, Gill stressed the inherent difficulties which face the orthopaedic surgeon. "The form and the degree of the dysplasia of the various structures of the hip joint which is present at birth, and the ability or inability of resumption and continuation of normal growth after reduction, are the essential factors that determine the end-result." After a careful follow-up of 105 cases he concluded that one could expect the following: 25 per cent perfect results after closed reduction -35 per cent if during the first three years of life; 15 per cent more of satisfactory resultsor 20 per cent in children under four years of age; failure in 60 per cent-or in 45 per cent in the younger group. Open operations and shelves are helpful, but perfect results are found only in " cases amenable to bloodless reduction."

Similar end-results were reported by Bost and his associates, except that they found a much higher percentage of perfect repositions in children treated during the first two years. Even as early as in the third year, the percentage of perfect anatomical and functional cures dropped sharply. As an overall figure, they estimated $\mathbf{7 4}$ per cent as functionally satisfactory. 
In 52 per cent of their cases, however, they found aseptic necrosis: this was as low as 12 per cent in infants whose hips were reduced by simple abduction, but as high as $\mathbf{7 4}$ per cent when manipulation was necessary.

The most encouraging statistics come from the Shriners' Hospital for Crippled Children, St Louis, where in a series of seventy-eight cases of posterior dislocation with a follow-up period of one to fifteen years, Crego and Schwartzman secured forty-eight normal or " near normal " hips, twenty-four satisfactory, and only six failures. In their work they have never used forcible manipulation nor the Lorenz " frog " position for immobilization. All cases were treated by preliminary traction, usually skeletal, until the femoral heads could be reduced by gentle pressure. If a "stable seating" in abduction and internal rotation was impossiblewhich occurred in twenty-five of the seventy-eight cases-open reduction with removal of the redundant part of the capsule was undertaken. This was supplemented by a " shelf " in forty cases with good results, even in children under five years of age. If careful analysis by $\mathrm{X}$-ray studies showed excessive anteversion, a derotational osteotomy was done (sixty-seven operations) the upper fragment being held in internal rotation by incorporating a threaded wire in the plaster. Failure to correct anteversion results, they believe, in redislocation into an anterior position.

McCarroll working in the same hospital reported on primary anterior dislocation which in a series of 111 congenital dislocations "was encountered in twenty-five hips." These are much more difficult to treat: in five a successful closed reduction was accomplished with good result, in twelve a massive anterior shelf, and in four a superior shelf gave eight fair results and two good; there were seven results classed as poor.

It is evident that despite progress, orthopaedic surgery still has much to learn about the treatment of this congenital deformity.

\title{
CONTROL OF BONE LENGTH
}

\author{
Walter Blount, Milivaukee, Wisconsin
}

[Equalization of leg length has appealed to the orthopaedic imagination for many years. As early as 1903 Codivilla reported his ingenious method of lengthening a femur by osteotomy and skeletal traction applied by a nail through the os calcis. Since then many papers have appeared dealing with this topic-among others, those of R. T. Taylor (1916), Calvé (1918), Putti (1921), Abbott (1927) and Warren White. A new principle introduced by Phemister has recently been modified ingeniously by Walter Blount, the author of this section. His report on "Control of Bone Growth by Epiphysial Stapling" has created great interest. The operation is being carried out in many clinics and in due course we may expect further clarification by follow-up studies-L. M. ?

Before 1932 adjustment of the length of bones was by osteotomy and one-stage shortening of the long bone or lengthening of the short bone by the traction procedures of Putti, Abbott and others. Recently the use of sliding internal fixation by McCarroll's technique has renewed interest in femoral lengthening. In general, bone lengthening is a hazardous procedure, painful to both the patient and the surgeon. As pointed out by Warren White, leg shortening is a much more direct approach to the problem but has the constant objection of shortening the good limb. The hazard of non-union and infection is not as great as with bone lengthening but the operation is one of considerable magnitude.

In 1932 Phemister reported the arrest of longitudinal growth of bone by a new method. He curetted and grafted one epiphysis of the long bone at a time calculated to be suitable according to growth charts. The operation was of less magnitude and it did not carry as much risk of complication as the previous operations. Failure to stop growth on one side of the bone occasionally resulted in angular deformity. Mistakes in calculation of the expected growth resulted in inadequate or excessive correction, although these errors have been diminished by the accurate studies of Abbott (1927) and Green (1947).

vol. $32 \mathrm{~B}$, No. 4, Novenber 1950 
Stimulation of growth by sympathectomy has long been popular in Canada (Harris). It is unpredictable but is usually insufficient to be of practical value unless there is definite clinical evidence of circulatory embarrassment. Stimulation of growth by juxta-epiphysial bone operations of various types usually achieves so little increase in length that it is not practical. If osteotomy or osteoclasis is indicated for another reason (angular deformity) it may be counted on to stimulate some temporary increased rate of growth, particularly if it is repeated. Recently Pease has implanted various foreign materials in the metaphysis, and advocates the use of ivory screws to stimulate growth.

While looking for a method of stimulating growth in 1945, Haas discovered that growth of an epiphysial plate could be retarded by encircling it with a wire loop. This proved feasible in laboratory animals and in children. Growth was held back mechanically. When the wire loop broke or was removed growth was resumed at about the normal rate. The implications were tremendous. If the method could be made practical it would be unnecessary to compute the anticipated growth accurately. Temporary retardation was vastly superior to permanent arrest.

Stimulated by Haas, in 1949 Blount and Clarke reported their work in the practical use of rigid staples of the type which had been popularized by Burns. They proved that three stainless steel staples on either side of the bone would almost completely stop the growth of an epiphysial plate in an eight-year-old child. They proved also that upon removal of these staples two or three years later, bone growth would be resumed at about the normal rate. Simultaneously, Barr and his co-workers experimented with roentgen ray retardation of epiphysial growth but discarded it as impractical.

\title{
LOW BACK PAIN AND SGIATICA
}

\author{
Joseph Barr, Boston, Massachusetts
}

[From the layman's point of view no orthopaedic problem concerns him more realistically than backache. To a group of Boston's orthopaedic surgeons-Goldthwait, Painter, Osgood, Bucholz and Swaim-we are indebted for studies which transformed this vast limbo known as "lumbago" into a field of anatomically based differential diagnoses. To their early pioneer work no one has made a more significant recent contribution than another Boston surgeon, Joseph Barr, the author of this section-L. M.]

"As a rule, it [sciatica] is an obstinate affection, lasting for months or even, with slight remissions, for years. Relapses are not uncommon, and the disease may be relieved in one nerve only to appear in the other. In the severer forms, the patient is bedridden, and such cases prove among the most distressing and trying which the physician is called upon to treat."-Osler.

Although there are still large gaps in our knowledge of the causes and cure of low back and sciatic pain it is comforting to know that now in most cases, we can arrive at an accurate diagnosis and prescribe adequate treatment. Fifty years ago the uncommon causes of symptoms were well known and carefully described. Tumors, tuberculosis, syphilis, gout were recognised as etiologic agents, but there was little knowledge of the common causes such as disk lesions, mechanical instability and spondylolisthesis. Treatment fifty years ago was empiricfantastically so-leeches, cupping, purging and acupuncture were commonly used for sciatica, which was thought to be a primary neuritis.

It is easy to single out certain major contributors who have revolutionized our concepts of diagnosis and treatment but let us here pay tribute to the many others who have also contributed their modest bit. The discovery of the Roentgen ray gave little immediate help in diagnosis as the early apparatus was not sufficiently powerful to penetrate the heavy structures of the low back. Better X-ray tubes and the invention of the Bucky diaphragm made it possible to obtain films of fair diagnostic quality by 1920 , and of good quality by 1935 . The development of contrast myelography added another important laboratory diagnostic aid. 
Pioneer work in directing attention to the lumbo-sacral spine and its articular facets was contributed by Goldthwait, Hibbs and Putti. They pointed out the possibility of mechanical strain and arthritis of these structures producing low back and sciatic pain. Other investigators laid stress on the role of the sacro-iliac joints, articulating transverse processes, tight fascial structures, tender trigger points and spasm of the pyriformis as etiologic factors. Almost all authors felt that the common syndrome of low back pain and sciatica was due to mechanical strain with secondary " reflex" pain. There was little agreement on the location of the exact structures involved or on proper methods of treatment.

Practical techniques of spine fusion developed by Hibbs and Albee in 1911 were first used for tuberculosis and scoliosis, but were soon applied to the treatment of lumbo-sacral strain. Sacro-iliac arthrodesis, fascial stripping, fasciotomy, pyriformis section, excision of articulating transverse processes were other operative approaches to the problem in common use between 1920 and 1935. Non-operative techniques were too numerous to mention. The lack of agreement on methods of treatment obviously stemmed from ignorance of etiology and failure to appreciate the fact that there is a natural tendency to spontaneous remission of symptoms. Nevertheless these pioneers have shown that mechanical strain is a factor to be reckoned with, and that stabilization by fusion is a potent therapeutic weapon.

The recognition of the etiologic role of intervertebral disk lesions has occurred within the past twenty years. The neurologist, neurosurgeon, roentgenologist and orthopaedic surgeon as well as the suffering patient share an intense interest in this relatively new concept. Schmorl's fundamental studies on the intervertebral disk, confirmed by Beadle, Mauric, Keyes and Compere and others focused attention on this structure. Clinical case reports by Elsberg, Kocher, Middleton and Teacher, Goldthwait, Dandy, Bucy, Alajouanine and Petit-Dutaillis suggested that disk lesions occasionally produced nerve root compression. In 1934 Mixter and Barr reported a series of nineteen cases as "Rupture of the Intervertebral Disk with Involvement of the Spinal Canal." Their series included cervical as well as lumbar lesions. In 1937 forty cases of proven disk protrusions including only lumbar lesions were reported from the Massachusetts General Hospital. It was pointed out that the symptoms and signs of a disk lesion are indistinguishable from so-called lumbo-sacral or sacro-iliac strain. A recognizable clinical syndrome was described and local nerve root pressure due to disk protrusion was established as a cause of backache and sciatica. "It is not excessively rare and should be thought of in every case of back strain and sciatica."

There was at first considerable scepticism regarding the significance of disk protrusions but the concept gained ground rapidly. Thousands of cases proven by operation have been reported by many different clinics. Friberg, Hirsch and others have shown that degenerative disk change normally occurs with increasing age and may be accompanied by mechanical instability of the spine. This is an important concept and is subject to demonstrable proof as shown by examination of spine specimens removed at autopsy, and in the living, by X-ray examination with the spine flexed and extended. It is becoming evident that backache is often associated with the mechanical instability of a degenerative disk lesion.

There have been marked technical advances in the operative treatment of disk lesions. Careful analysis of the clinical findings supplemented by diagnostic myelography permits accurate localization of the lesion in most cases. Special instruments and highly perfected surgical skill in exposure and technique have made the operation for removal of a protruded disk a very precise one. In most cases dramatic relief of sciatic pain may be confidently expected after excision of the protruded disk fragment.

End-result studies, however, show that backache and other residual symptoms and signs may be found in some of these cases. Surgical fusion of the vertebrae adjacent to the involved disk has been proposed as a method of overcoming these residual symptoms and some surgeons perform fusion as a routine measure. Others oppose this, reserving fusion for patients not satisfactorily relieved by simple removal of the protruded disk.

Vol. $32 \mathrm{~B}$, No. 4 , November 1950

$\mathrm{E}$ 
This quick backward glance over a few of the advances made in the solution of the problems of low back and sciatic pain should be heartening to all who deal with them. Scientific inquiry yields its fruits to the curious, intelligent, diligent student. The "backtrees" are still laden.

\section{IDIOPATHIC SCOLIOSIS}

Reference has already been made in Part III to the treatment by E. G. Abbott (1917). His papers demonstrated the roentgenological correction of severe rotary curvature, but the method had to be abandoned because the forces used were so great as to cause extensive decubiti and secondary malformations worse than the pre-existing scoliosis. In 1914 Hibbs performed the first fusion operation for scoliosis and in 1924 was able to report the results in fifty-nine cases. Correction was usually secured by traction and application of plaster-of-paris corsets, in some instances by the "wedging " or turnbuckle jackets. He concluded that "we have in fusion a means of preventing the progress of deformity of scoliosis in cases in which it is caused by muscle unbalance." In 1922 Kleinberg modified the Hibbs technique by adding a strong beef-bone graft and in 1927 Armitage Whitman utilized portions of the resected prominent ribs as reinforcement of the fusion area. Proof of the efficacy of fusion was demonstrated by Alan de Forest Smith (1923) who in nine reoperations on spines fused by the Hibbs method found the laminae united by a solid sheet of bone.

In 1931 appeared a paper by Hibbs, Risser and Ferguson, significant for six reasons: 1) the mathematical determination by measurements on the X-ray film of the angle of curvature; 2) the perfected use of the hinged anterior-posterior turnbuckle jacket as developed by Risser; 3) an improved operative technique by which the area to be fused was accurately determined by means of markers; 4 ) the performance of the operation through a large window cut in the plaster; 5 ) the reduction of mortality in a series of 427 operations to $\mathbf{1 \cdot 6}$ per cent; 6) proof that fusion can prevent advance of the curve, and in some cases maintain the correction secured by the turnbuckle plaster corset. The repercussions of this article were so great that for more than a decade the Hibbs-Risser-Ferguson method dominated the treatment of scoliosis. The report of the Research Committee of the American Orthopaedic Association in 1941 concluded as follows:

1. Practically none of the patients with scoliosis are cured, if correction of lateral deviation is a criterion.

2. In approximately 60 per cent of those treated by exercises the deformity increased and in $\mathbf{4 0}$ per cent it remained unchanged.

3. Correction without fusion resulted in complete loss of correction after support was discontinued, in the majority of instances.

4. Correction by the turnbuckle jacket and subsequent fusion has yielded better results in this series than have other types of treatment.

The results in 69 per cent of the cases were rated as fair or poor, and 31 per cent good or excellent.

The high percentage of poor results caused some careful students to begin to have their doubts about the wisdom of the method. They reconsidered Steindler's teaching (1929) that the " treatment of scoliosis is not only a problem of orthopaedic surgery, but also of orthopaedic reconstruction," that maintenance of correction is not necessarily " best solved by totally abolishing the mobility of the spine, in other words, by operative fusion." Steindler's emphasis on " compensation" began to take on added meaning when follow-up studies of cases fused in correction by the development of extreme counter curves above and below the fused area could not compensate- that is, assume the upright posture-without a pseudarthrosis in the fusion area or by a gradual giving-way of the fusion.

This more critical attitude was well expressed in 1949 by a member of the New York Orthopaedic Hospital Staff, Dr Wm. H. von Lackum. He conceded that the follow-up of 
operative cases had revealed many instances of what he euphemistically called " substandard results." These were due, he thought, to excessive correction, since the maximum amount of compensatory adjustment of the secondary curves amounted to only twenty degrees. Therefore any correction beyond this degree caused a lack of compensation.

In the same year (1949) Dr John Cobb presented a unique paper (not yet published) backed up by an exhibit at the Chicago meeting of the American Academy of Orthopaedic Surgeons, in which on the basis of more than 3,000 cases observed over a period of four or five years he concluded that the vast majority of scolioses do not progress beyond a certain fixed point which can be determined by systematic roentgenographic examination; that in this large group-95 per cent of the idiopathic cases-no treatment is necessary other than a rest period after school hours and good general hygiene; that braces and spinal exercises have no demonstrable beneficial effect; that in the 5 per cent of cases which show a tendency to advance beyond the mild stage fusion can be successfully used after correction in the turnbuckle jacket. Cobb advised a one-stage operation with the use of banked-bone, and a long post-operative recumbency period until the callus had become thoroughly organized (six to nine months). His demonstration of results was most convincing.

Another significant contribution was by Blount and Schmidt who at the 1948 meeting of the Academy exhibited a turnbuckle extension brace which could be applied before operation; and after operation, during the period of maximum correctibility of the curve, it could be adjusted so as to secure a gratifying degree of improvement. Their results have not yet been published in final form.

Papers dealing with the theory of scoliosis by Farkas (1941) and by Arkin (1949) add to the fascination of this problem, which, though still unsolved, has unquestionably shown signs of yielding to the steady attack of progressive orthopaedic surgeons.

\section{FRAGTURES OF THE NECK OF THE FEMUR}

[In preparing this and the following section I have been greatly helped by my office associate, Dr Barnard Kleiger, associate attending surgeon of the Hospital for Joint Diseases.]

During the early years of the American Orthopaedic Association fractures were scarcely mentioned. The first indications of orthopaedic interest were in 1892 when John Ridlon in conjunction with Robert Jones reported twelve cases of fracture of the femoral neck treated by the Thomas hip-splint, and in 1893 when Whitman published the first of his two papers dealing with fracture of the neck of the femur in children. In 1894 Ansel Cook wrote a brief article on "Fixation in the Treatment of Fractures into Joints." In 1897 appeared additional papers by Ridlon and Whitman and a contribution by Newton Shaffer entitled "On the Mechanical Treatment of Ununited Fractures of the Neck of the Femur with Traction Apparatus Producing Abduction of the Thigh and Direct Lateral Pressure Over the Trochanter Margin." The ideas of Ridlon and Shaffer have passed into oblivion but Whitman formulated the germ of an important principle. Though unable to treat any one of the ten cases observed, since in none had the diagnosis been made at the time of injury, he wrote that reduction in such fractures could " best be accomplished by abducting the leg its full limit; thus by leverage of the rim of the acetabulum and by downward pressure on the trochanter with extension of the limb, one might hope to rectify the deformity, at least in part." This idea, elaborated in his paper of 1902 dealing with adult femoral neck fractures, dominated the thinking both of general surgeons and orthopaedists, until 1932 when Dr Guy Leadbetter made an important modification of the method of reduction by flexing the thigh before abducting. He, like Whitman, continued to use the plaster-of-paris spica as the best means of fixation. In 1938 he was able to report 71 per cent of unions in fifty-nine patients treated by this method.

The importance of Whitman's contribution cannot be overestimated: he demonstrated

vol. 32 B, No. 4, NOVEMBER 1950 
that the orthopaedic surgeon could secure better results in the treatment of this difficult fracture than the general surgeon, and thus created the entering wedge which gradually has shifted the responsibility for fracture treatment from the general to the orthopaedic surgeon.

Smith-Petersen in 1931 revolutionized the treatment of femoral neck fractures when he introduced the three-flanged nail for internal fixation of the fracture after open reduction. Subsequent improvements in roentgen control of closed reduction and accurate insertion of a nail of the proper length permitted elimination of a hip arthrotomy for open reduction. Among the many workers each of whom contributed something to the development of this operation were White, Wescott, Plummer, Sloat and Peterson, King, O'Meara, Cox and Cotton.

Subsequently the Smith-Petersen nail was modified by Johansson of Sweden to include a central cannula. This permitted more accurate insertion of the nail over a guide wire. Many other appliances have since been devised for internal fixation of femoral neck fractures but none have replaced the Smith-Petersen nail in popularity. Among these are the threaded steel wires proposed by Moore (1934) and by Telson and Ransohoff (1935). These were modified by Knowles (1936) who added a fixed head instead of threaded nuts. Gaenslen in 1935 advocated the use of several spikes to fix the femoral head. Compression bolts and lag screws were devised by Melville Henderson, Henry, Lippmann and others.

Internal fixation immobilized the fracture adequately and permitted bone healing to take place as demonstrated by Kulowski and Luck in 1941. Though the fracture healed, however, the follow-up study of Boyd and George in 1946 indicated that other dangers lurk in the path of a good result. These authors reported a follow-up study of 300 cases treated by internal fixation; 285 with the Smith-Petersen nail and fifteen with Knowles pins. Though $86 \cdot 5$ per cent of these cases united, yet they had only $\mathbf{4 3 . 6}$ per cent of good results without articular change; 19 per cent fair results with moderate articular change due to aseptic necrosis or moderate arthritis and 28.1 per cent poor results due to non-union, aseptic necrosis or severe arthritic change. The mortality rate was $9 \cdot 3$ per cent. These complications in the course of healing have been the subject of extensive studies by Phemister and Sherman who have found that they are caused by circulatory disturbances resulting in aseptic necrosis.

A report by the Fracture Committee of the American Academy of Orthopaedic Surgeons in 1941 also pointed out these dangers. Of 241 cases collected from various clinics throughout the country 144 had been treated by Smith-Petersen nails, eighty-three by wires and fourteen by miscellaneous methods of internal fixation. Union occurred in $\mathbf{7 0} \cdot \mathbf{l}$ per cent of the total number of cases. Further analysis showed that $\mathbf{7 2 \cdot 9}$ per cent of those fixed with a SmithPetersen nail united, $62 \cdot 7$ of those with wires and $85 \cdot 7$ per cent of those with miscellaneous apparatus. Of those that united with a Smith-Petersen nail, 73.4 per cent developed no arthritic change, $\mathbf{2} \cdot \mathbf{9}$ per cent Grade I arthritis, $\mathbf{4} \cdot \mathbf{7}$ per cent Grade II, $4 \cdot 7$ per cent Grade III and 14.3 per cent Grade IV. When wires were used, 71.2 per cent had no arthritic change, 9.6 per cent Grade I, 3.8 per cent Grade II, 1.9 per cent Grade III and 13.5 per cent Grade IV. The conclusion of this committee presents a timely and important warning. "In the hands of experienced surgeons the end-results obtained in fractures of the neck of the femur have been greatly improved by the use of internal fixation. When employed by the inexperienced or untrained the outcome is often deplorable and the end-results inferior to those seen following non-operative means."

These statistics do not adequately picture the advantages of internal fixation which free the patient from a long period of immobilization in plaster-of-paris and consequent stiffness of the knee as well as of the fractured hip.

\section{OTHER FRACTURES}

The physiological process of callus formation has been studied by Phemister, Key, Potts, Haldeman, Urist and McLean, Clay Ray Murray and others. In addition to the well-known facts regarding the invasion of the haematoma by capillaries, resulting in fibroplasia, 
chondrification and eventually ossification, much has been learned about the causes of the initial fall and subsequent rise in the $p \mathrm{H}$ of the tissue fluids at the site of fracture, the influence of phosphatase, the nature of calcification and the local necrosis of the bone ends. Moot points are: 1) the origin of the osteoblastic cells-some maintaining with Macewen that they emanate from the bone, others from the periosteum, others from the endosteum, still others from a metaplasia of the surrounding connective tissue cells; 2) the influence of foreign bodies, such as metal plates, or the Küntscher nail on the production of callus; 3 ) the causes of non-union or delayed union.

The ideals of treatment remain to-day exactly as they were outlined by Sir Robert Jones many years ago-the restoration of function by the simplest, quickest and least dangerous method. Closed reduction and immobilization, either in a splint, as used by Hugh Owen Thomas and Robert Jones, or in plaster-of-paris, is probably the method of choice in the majority of cases. Most orthopaedic surgeons find it advisable to reduce the fracture as soon as possible, but a strong advocate of delay has been found in John R. Moore of Philadelphia. His method, which has been characterized as "the set 'em on Tuesday," has in his expert hands given excellent results in over 7,000 cases. His weekly clinic at the Temple University Orthopaedic Department, when he reduces and immobilizes fifty or sixty fractures in a morning is unique. It must be emphasized that he does not tolerate any delay when there are peripheral nerve or vascular complications, and that every fracture is given a preliminary immobilization in plaster-of-paris.

For fractures of the femur and some fractures of the humerus traction still retains its importance. The modern technique of so-called balanced traction was introduced by a general surgeon, Dr Joseph Blake, during the first world war. It represented a considerable improvement over the method of Bardenheuer of Cologne which had until then dominated the German, and even the American schools. Skin traction by adhesive strips has been largely replaced by skeletal traction; for the original Steinman pin has been substituted the Kirschner wire which rarely causes the persistent sinuses seen rather frequently when the Steinman nail was used. During the war traction by a Kirschner wire through the tibia was one of the accepted methods of treating fractures of the femur in military hospitals. A word must also be said about the ingenious traction method of Russell of Australia, which with slight modifications is most effective for femoral fractures with a tendency to anterior angulation. John Dunlop of Pasadena has demonstrated the value of traction in the transcondylar type of elbow fracture which cannot be held by the usual position of flexion advocated by Sir Robert Jones.

There are certain fractures which almost always require open reduction: these are the fractures of the patella and of the olecranon process with wide separation of the fragments. The latter can best be held by a screw, the former by an encircling suture if the fragments are of equal size and not comminuted; by resection of the distal fragment if it is small and comminuted. The patellar tendon is then reattached to the main proximal fragment. Occasionally, in very extensive comminution, the entire patella has to be removed.

The greatest strides in fracture treatment have occurred as the direct result of improved methods of internal fixation. The use of the metal bone-plate so vigorously championed in England by that most meticulous of surgeons, Sir Arbuthnot Lane, found equally ardent American champions first in Sherman of Pittsburgh, then in Clay Ray Murray of the College of Physicians and Surgeons in New York. The method has benefited greatly by technical advances in metallurgy. Through the researches of Venable and Stuck (1937) it was shown that the electrolytic currents set up by the implantation of the ordinary steel screws, resulting in bone absorption, could be completely eliminated by the use of inert metals such as an alloy of cobalt, chromium and molybdenum, known as vitallium. Later work by Key indicated that an equally inert alloy was the so-called 18/8 SMo steel (16 to 20 per cent chromium, 14 per cent nickel, $2 \cdot 4$ per cent molybdenum). This steel has the advantage that it can be

Vol. $32 \mathrm{~B}$, No. 4, NOVEMBer 1950 
" cold-rolled," whereas vitallium must be cast. Further technical improvements resulted through the exact studies of Leonard Peterson (1947) of the Surgeon-General's office. Carried on in conjunction with an engineer, J. G. Collison, he was able to demonstrate that many screws did not hold because of the inaccuracy of their insertion. He devised a drill point of such a diameter as to permit the screw to grip the threads in the bone with maximum efficiency: A cruciate head to the screw, special guide to secure verticality and other aids to accurate insertion have greatly facilitated the technique of bone-plating.

The skilful work of William Darrach and Clay Ray Murray, and more recently of their successor at the Presbyterian Hospital, Dr H. L. McLaughlin, must also be stressed. Murray laid down precise rules which when followed gave a high percentage of healing with little stiffness of the adjacent joints: minimal trauma, careful aseptic technique, accurate length of screws, in oblique fractures the use of an additional screw so placed as to transfix the cortices of both fragments and thereby prevent rotation, early mobilization.

A contribution of great significance has recently been made by Dr Eggers (1948) of Galveston, Texas-the so-called " contact splint." This is based on the correct physiological premise that some necrosis of the fractured bone ends invariably occurs. To maintain contact of living bone to living bone, thus avoiding the danger of delayed union or pseudarthrosis, Eggers's plate has slots so placed that muscular contraction or body-weight will cause the fragments to remain in close approximation, despite the absorption due to necrosis. He has corroborated his clinical observations with a series of experiments on the healing of fractures of the rat's skull, so exquisitely performed that he was given an award for his exhibit at the meeting of the American Academy of Orthopaedic Surgeons in 1949. Eggers's work is in a way similar to Key's observation, subsequently elaborated by Charnley of England, on the beneficial effect of pressure in the healing of arthrodesed knees.

A form of intramedullary splinting was used in this country before World War II by Rush, but it never attracted attention until near the end of the war. Another type of intramedullary nail designed by a German surgeon, Küntscher, and very extensively used by Böhler of Vienna, was introduced into America by a number of German war prisoners and American soldiers operated on by this method in German hospitals. Soeur of Belgium (1946) helped to popularize the method by his thorough description in the Journal of Bone and Joint Surgery. The original nail of trefoil section has been modified by Hansen-Street who used a diamond-shaped nail. Whether this is better is still a moot question, but it is certain that the nail, whatever its shape, must be strong enough to resist lateral bending forces equivalent to the body-weight. Böhler, who at one time used the nail for almost all fractures, now with rare exceptions confines its use to the femur. It may be introduced " blind " through a small proximal incision above the trochanter, or by the open method, exposing the site of the fracture. The method is being employed much more extensively in this country, and with adequate experience in the technique the reported results are gratifying. All these methods of internal splinting have been rendered safer by the antibiotics.

An ingenious method of combining fixation with freedom of joint motion has been independently devised by three men-Haynes, Stader and Roger Anderson. They employ a splint which can be attached to the fractured bone by means of long pins which transfix one or both cortices. After manipulating the fragments into alignment the splint is " locked," thereby fixing the bone. Though good results are reported, the method was not accepted by the Surgeon-General's office, largely because of the danger of infection along the path of the pins, and the difficulty of application in the hands of any but the most experienced.

The use of bone grafts in fractures has already been described in the section dealing with bone grafting and the treatment of infected compound fractures in the section on osteomyelitis.

The necessity of thorough after-treatment emphasized by Sir Robert Jones more than thirty years ago is as true to-day as then. Every " fracture patient " must begin to use his muscles at the earliest possible moment. Every fracture service requires an experienced 
physical therapist who will from the very outset work on the functional rehabilitation of the fractured limb. When healing has occurred strengthening of the muscles can be greatly aided by the De Lorme (1945) system of heavy resistance exercises.

\section{SURGERY OF TENDONS AND OF THE HAND}

Although Nicoladoni performed the first tendon transplantation in 1882 his contribution - like penicillin and many another good idea-lay dormant for many years. Then at the beginning of the twentieth century two orthopaedic surgeons in Germany, Vulpius and Lange, revived Nicoladoni's principle of replacing the tendon of a paralyzed muscle by shifting a strong tendon to take its place. Vulpius sutured tendon to tendon; Lange thought this method inadequate since the paralyzed tendon would stretch, and advocated instead a direct bony attachment. Since in many instances the transplanted tendons were too short to reach their destination he lengthened them with strands of strong silk soaked in paraffin and sublimate of mercury. His experience with this technique was the topic of his address before the American Orthopaedic Association in 1910, at which time he had already performed many hundred " silk tendon plastics." It was the author's good fortune to spend a year in Lange's clinic in Munich (1912-1913) where somewhat to his surprise he found that the results of the transplants were far from satisfactory. Lange was sufficiently objective to concede that something was wrong: he thought the difficulty was due to the formation of adhesions and therefore assigned as a research topic the problem of preventing post-operative adhesions. Together with Dr Carl Henze of New Haven the author performed an extensive series of animal experiments which proved conclusively that the one effective method of avoiding adhesions was the conservation of the normal gliding mechanism of the tendons (1914). This led a few years later (1916) to the publication with Professor Biesalski of Berlin of the monograph Die Physiologische Sehnenverpflanzung (The Physiological Method of Tendon Transplantation) which may be in part responsible for some of our advances in tendon surgery. A summary of the method was published in Surgery, Gynecology and Obstetrics in 1916.

In January of 1918 there appeared in the same journal a modest article by Dr Sterling Bunnell on the "Repair of Tendons in the Fingers." The significance of this contribution should be emphasized for it contained the germ of Bunnell's concept which was later elaborated into one of the most important surgical monographs of the century, Surgery of the Hand. He stressed in this paper four points: 1) an atraumatic technique; 2) lateral placement of the incisions with an L-shaped prolongation in the creases of the finger; 3) preservation of the pulleys; and 4) due regard for the gliding mechanism. Shortly thereafter the author met Dr Bunnell and worked with him; and the friendship then begun has ripened with the years. Bunnell's work combined with the anatomical-physiological observations of Biesalski and Mayer, and the practical teachings of Robert Jones, resulted in the formation of certain rules which apply to all types of tendon operations. The author has formulated these as follows:

" Since gliding is an essential function of the tendon, the operator must avoid damage to the gliding mechanism. An atraumatic technique must be cultivated. Never grasp the gliding surface of the tendon with mouse-tooth forceps, never allow the tendon to dry in the air, never wrap it in a piece of gauze even though the gauze be moistened, since any one of these procedures will damage the smooth surface cells. Grasp the tendon only where an adhesion is desirable, for instance, where it is to become attached to a bone; or where it is possible to remove that part of the tendon which has been traumatized by the clamp. Plan the operation so that the tendon will be exposed to the air for a minimal length of time and while it is exposed moisten it every minute or two with warm saline. The gliding pathway must be conserved. Do not damage the paratenon or the sheath. Wherever possible conserve the normal relationship between tendon and sheath. If the sheath has been destroyed strive to construct a new sheath which will replace the old. Avoid infection even of the mildest type by rigid

VOL. $32 \mathrm{~B}$, No. 4, NOVEMBER 1950 
asepsis, for even a mild infection which does not produce suppuration may cause enough fibrosis to prevent gliding. Always restore the normal tension to the tendon operated on, for excessive tension produces muscle degeneration. Never forget that a transplanted tendon must obey the same mechanical rules as the normal tendon. Unless the line of traction is mechanically correct the tendon cannot do its work. Usually the course of a transplanted tendon should be straight, but if a sharp change of direction is necessary construct a pulley similar to that of the omohyoid muscle (Bunnell) or utilize the pulley action of the tendon sheath. Be careful to avoid injury to the main blood vessel of the tendon which is usually found running in the lower muscle fibres. The smaller vessels running in the mesotenon may, however, be divided with impunity. Always mobilize stiff joints before attempting a tendon operation since otherwise it will be impossible for the tendon to function. Repair divided nerves before suturing a tendon and replace dense scars by suitable skin transplants."

The most useful tendon transplants for the operative treatment of the residual paralyses of poliomyelitis have already been listed. These include important contributions by Frank Ober, Arthur Steindler, H. B. L'Episcopo, Charles Peabody, Schwartzman and Crego, and Charles Irwin. Ober (1935) has devised transplants of the long head of the triceps and of the biceps to strengthen a weak deltoid; he has also utilized the erector spinae muscle to reinforce a paralyzed gluteus maximus by running a fascial graft from the back muscles to the trochanter. Steindler's (1919) upward shift of the muscles springing from the medial condyle of the humerus to strengthen the weak elbow flexors has helped to restore function to many paralyzed arms. L'Episcopo's (1934) shift of the tendons of the latissimus dorsi and teres major to the posterior surface of the humerus, devised chiefly for obstetrical paralysis, gives excellent results. Charles Peabody (1938) made an exhaustive follow-up study of end-results and contributed a number of original ideas, such as the transfer of the tibialis anterior through the interosseous membrane to strengthen a weak Achilles tendon. Schwartzman and Crego (1948) studied 134 transplants of the hamstrings for quadriceps paralysis and concluded that the operation is of value, particularly if a medial muscle (the semitendinosus) is transplanted together with the biceps. Charles Irwin has divided the paralytic deformities of the thumb into a number of groups, for each of which an appropriate operation has been devised. In this he has been much helped by the previous work of Ney (1921), Lyle (1923), Steindler (1930), Royle (1938) and particularly Bunnell (1924 and 1938).

Meanwhile in paralyses due to trauma, particularly injuries of the radial nerve, successful results were secured by tendon transplants. One of the first papers, " Army Experiences with Tendon Transference," by Charles L. Starr (1922) was delivered before the British Orthopaedic Association. He reported fifty-two cases with excellent results in twenty-nine, good in fifteen, fair in seven, failure in one. Billington (1922) also found the operation most satisfactory. Twenty-four years later Altman and Trott (1946), using slight modifications of the same technique, working under the able direction of Dr Harry Blair, were able to report good results in all their twenty-eight cases.

In the surgery of the traumatized hand significant papers were written by Harmer (192: and 1926), Auchincloss (1929), Garlock (1926), Koch and Mason (1933). The latter authors have given us a thorough report not only of the repair of tendons but also of the nerves of the hand.

Gratifying though these experiments have been, the culmination of surgery of the hand has been secured by Bunnell and his group of co-workers. Developing the essential concept of atraumatic technique first enunciated in his paper of 1918, Bunnell has applied this to every tissue of the hand-skin, fascia, tendons, muscles, nerves, bones and ligaments. $\mathrm{He}$ was the first to stress the importance of suture of the digital nerves, and suture of the motor branch of the median to the intrinsic thumb muscles; to develop adequate operations for paralysis of the opposing muscles of the thumb, for paralysis of the interossei, for restoration of " pinch." He has perfected the reconstruction of the thumb by pollicization of the index 
finger. He has perfected the technique of tendon suture by one idea after another, the most recent being the so-called " pull-out stitch." He has applied bone grafts with the skill of an Albee, he has rivalled Gillies in the finesse of his skin grafts. He has devised scores of braces. so simple and inexpensive that they can be made by any mechanic with some wire and strips: of felt. He has summarized his experiences in a book which the British tendon surgeon Furlong called his " bible," which is, as Boyes phrased it, "the vade mecum of all hand surgeons." It is significant of Bunnell's modesty that he himself is dissatisfied with the book and is now engaged in preparing a third edition so as to eliminate the many faults which he has noted in the first two editions. Best of all, his work has inspired a group of younger men to try to improve upon his methods: Littler, Luckey and MacPherson, Lott Howard, Boyes, Walter Graham and others are not content simply to follow in the master's footsteps but have already. made notable contributions to aid in solving that most difficult of orthopaedic problems-the restoration of function to the crippled hand.

\title{
ADVANCES IN BIOCHEMISTRY AND RELATED FIELDS
}

The preceding sections have dealt almost altogether with advances in operative technique. The percentage of aseptic wound healing has been increased by the use first of the sulpha drugs, more recently by the antibiotics, but the influence of these biochemical developments has not been of paramount importance. Now we wish to review several fields of orthopaedic endeavor in which pharmacology, biochemistry, biophysics and other related sciences have been of much more significance. I refer particularly to osteomyelitis, tuberculosis, arthritis and abnormal neuromuscular disturbances such as cerebral palsy. Before considering them in detail, it will be helpful to take a general view of certain phases of scientific advance as seen through the eyes of a biochemist.

\section{Scientific Progress}

\author{
Aaron Bodansky, New York
}

Rapid advances in the chemistry of enzymes, vitamins and hormones have been made in the United States and Canada, particularly in the second quarter of this century. Spectacular developments in the field of antibiotics occurred in the 'forties.

Enzymes - The crystallization of highly purified urease by Sumner in 1926 must be noted, because it marked a new stage in enzyme research (the crystallization of this and other enzymes has so far not had wide clinical application).

Robison's work on yeast phosphatase was followed by his important studies on the role of alkaline phosphatase in bone formation. Kay noted increases of plasma alkaline phosphatase in bone disease. Development of improved analytical methods for the determination of alkaline phosphatase by Bodansky, and by King and Armstrong, permitted clinical studies on an adequate scale. Bodansky and Jaffe used this determination in studies of hyperparathyroidism, rickets, Paget's bone tumors and other bone diseases. Better evaluation of therapy in these diseases was likewise promoted by the use of this test.

After the demonstration of acid phosphatase in the prostate gland by Kutschner and Wolbergsin 1935, Guttman and his associates carried these studies forward to the demonstration of acid phosphatase in the serum of patients suffering from prostatic carcinoma with metastases to the bones. Huggins and his associates confirmed these findings and applied them in the now well-known treatment of prostatic carcinoma.

Vitamins-The existence of vitamin D and its role in calcium and phosphorus metabolism and the prevention of rickets in experimental animals was demonstrated by McCollum and associates. The effects of direct ultra-violet radiation in the prevention and cure of rickets and in the preparation of anti-rachitic substances were announced by Hess and Steenbock almost simultaneously.

vol. $32 \mathrm{~B}$, No. 4, NOVEMBER 1950 
Hormones-The development of purified insulin preparation by Banting, Best, Macleod and Collip has affected profoundly the treatment and course of diabetes, and has prevented or mitigated many of its complications. The development of purified parathormone by Collip permitted the production of experimental chronic hyperparathyroidism which was proven by Jaffe and Bodansky to be the experimental equivalent or analogue of clinical von Recklinghausen disease (osteitis fibrosa cystica). Chemical studies of the latter, including determinations of serum calcium, phosphorus and particularly of alkaline phosphatase activity, were performed by Bodansky and Jaffe before and after parathyroidectomy. More extended studies of the condition were carried on by Guttman and associates, Albright and associates and others. Such determinations have become standard aids in the treatment of clinical hyperparathyroidism.

Active research in the isolation, synthesis and study of the metabolic effects of female and male sex hormones has been carried on by many American investigators. The most striking demonstration of their relationship to bone pathology has been made in the control of prostatic cancer and of its metastases to the bone: orchidectomy and administration of female sex hormone by Huggins causes a remission of symptoms with the healing of bone lesions and the reduction of the acid phosphatase activity of the serum.

More recently ACTH was developed in the Armour Laboratories and cortisone was developed by Kendall and associates. The effectiveness of these substances in the treatment of rheumatoid arthritis and other conditions has been the subject of active research.

Chemotherapy and antibiotics-After the introduction of therapy by sulfonamides developed abroad, other derivatives were produced in this country. Their very wide application has been to some extent superseded by the more recent developments in the field of antibiotics. Dubos was one of the earliest American workers in this field. Selman Waxman has been among the foremost contributors; his many years of work in soil microbiology were appropriately climaxed by the preparation of streptomycin and other antibiotics.

\section{Clinical Applications OSTEOMYELITIS}

No other field of orthopaedic surgery except arthritis owes as much to the recent advances in chemistry and bacteriology as does the treatment of osteomyelitis. We must of course differentiate in our thinking between: 1) acute haematogenous osteomyelitis-a generalized septicaemia with local bone manifestations; 2) chronic osteomyelitis-a sequel of the acute; and 3) localized traumatic osteomyelitis, with which the two world wars has made us all too familiar. The writings of Wilensky gave an excellent concept of the pathological process but did not help solve the therapeutic problem. Acute osteomyelitis was, until the advent of the sulfonamides (1935), a dread disease, particularly in children, with an estimated mortality irrespective of the method of treatment of 25 per cent. To-day, thanks to the antibiotics, the mortality is approximately 3 per cent.

We have already told in Part III of the treatment of infected gunshot fractures by Carrel during the first world war. Hawley of Bridgeport, who studied the method thoroughly, considered it one of the great surgical advances. He saw hundreds of infected compound fractures converted into healthy granulating wounds. He stressed the difficulty of carrying out the Carrel technique, which required daily dressings each the equivalent of a full-fledged operation. Meticulous débridement and the exposure of every portion of the wound to the action of the chlorine solution were essential to success. Probably for this reason, rather than because of an error in principle, the method lost popularity and was replaced by one directly opposed to it - the closed plaster treatment of Winnett Orr. Orr said "Leave the wound alone. Each time you touch it you stir up trouble." After débridement he packed the wound wide open with vaseline gauze, applied a closed plaster-of-paris dressing and allowed healing to occur undisturbed by the surgeon. The stench from the plasters was almost unbearable, but 
healing occurred in a high percentage of patients. In 1935 this method was adopted by Trueta of Barcelona who, by adding sulfonamides to the dressing, increased its efficacy. Albee added bacteriophage but without any appreciable improvement.

An interesting phase of treatment was the use of maggots, introduced by Baer of Baltimore. Discovered accidentally, through contamination of a wound by the larvae of the blowfly, it unquestionably aided healing. Buchman used it for more than ten years with gratifying results and has stated, in a personal communication, that the beneficial action of the maggots was due to a combination of "subminimal physical irritation to produce granulations rapidly, enzymatic digestion of necrotic tissues, chemical inhibition of bacterial growths, bactericidal action and biological stimulation of tissue growth."

Attempts to improve therapy by bacteriophage (d'Herelle and MacNeil), antistreptococcus serum and staphylococcus toxoid proved unavailing, but in 1935 occurred a great discovery by Domagk - the therapeutic effect of the sulfonamides. Though this followed the work of Fleming, who in 1929 had observed the antibiotic effects of cultures of the fungus penicillin, it was the opening wedge in the therapeutic campaign. Soon the literature was flooded with reports of successful cases: Mitchell, Key, Hoyt, Davis and Van Beuren, Lennox Baker, Shands, Bick, Schnabel and Kuhn, Wilson and McKeever all wrote of the amazing effects of the "magic powder." Cases of acute osteomyelitis were cured without operation; in others no surgery was necessary other than incising a subperiosteal abscess.

Dickson, Diveley and Kiene (1941) reported twenty-two cases of subacute and chronic osteomyelitis in which they had secured good results with primary closure under sulfathiazole medication. Bick (1941) in his paper sounded a warning note with this concluding sentence: "In the treatment of haematogenous osteomyelitis sulfone chemotherapy is not a substitute for surgical judgment, operative technique or meticulous after-care." Some patients moreover were sensitive to the sulfa drugs, or failed to respond favorably. It was therefore not surprising that with the advent of the antibiotics, the first enthusiasm for the sulfonamides abated. Fleming's work in England had gone unnoticed for more than ten years when a group of Oxford investigators under Florey (1940) reviewed the study of penicillin, confirmed its therapeutic effect and developed purified penicillin suitable for clinical use.

In the United States the significance of penicillin was at once appreciated and its study was placed under control of the Committee on Medical Research of the Office of Scientific Research and Development. Thanks to the intensive work of numerous civilian investigators the clinical application of the antibiotic was perfected and the difficulties in manufacturing it in sufficiently large quantities for practical use were overcome. Brilliant results were soon reported: Herrell Nichols and Heilman of the Mayo Clinic (1944) gave a review of three years of experimental and clinical work; Kirby and Hepp (1944) observed remarkable results in osteomyelitis of the facial bones; Compere, Schnute and Cutell (1945) cured twelve cases of acute haematogenous osteomyelitis with only minor operative procedures. As soon as it was made available to the army, a complete change occurred in the treatment of gunshot fractures. Under the influence of penicillin primary or delayed primary closure became the rule. By 1945 Colonel Mather Cleveland was able to report that 93 per cent of the compound fractures were healed by the time the patients left the hospitals. Buchman, aided by the bacteriological studies of Blair, achieved a high percentage of primary unions in cases of chronic osteomyelitis with discharging sinuses by the use of penicillin before, during and after thorough "saucerization" and immediate suture. The percentage of primary unions after extensive bone-grafting operations was greatly increased even in those in which there had been a preceding infection.

Even to penicillin, however, many pathogens were not susceptible. In streptomycin, discovered by Waksman in 1943, another powerful antibiotic was made available, which controlled many bacteria resistant to penicillin. Aureomycin was added, which in the hands of Buchman is giving even better results than penicillin in the cure of chronic osteomyelitis

VOL. $32 \mathrm{~B}$, No. 4 , NOVEMBER 1950 
with discharging sinuses. Other antibiotics are at present under investigation and they may prove superior to those now employed.

In preparing this section I have been greatly helped by my colleague at the Joint Disease Hospital, Dr Joseph Buchman, who has devoted twenty years of productive clinical research to the solution of the therapeutic problem.

\section{SKELETAL TUBERCULOSIS}

\section{Charles Sutro, New York}

In summarizing the modes of therapy for tuberculosis of the skeletal system, one may state definitely that the only new ray of hope has been the discovery of streptomycin. But even this ray is rather dim for the more this antibiotic has been used for skeletal tuberculosis, the more evident it has become that it is not a cure-all. In fact a recent survey of the Veterans' Administration has disclosed that the use of streptomycin per se (without local surgical intervention) in the "closed " type of skeletal tuberculosis is of no demonstrable value. Its combined use with local surgery, however, is of considerable efficacy. It aids in temporarily "sterilizing" the osseous or joint lesions. Its most effective use is in mixed infections. According to Bosworth the sinuses heal rapidly in 83 per cent of the ninety-five patients observed.

It is of interest that there are still two schools of thought regarding treatment of skeletal tuberculosis. Bosworth and his group sponsor early surgical intervention irrespective of the age of the patient. Sorrel on the other hand favors long periods of conservative therapy followed by elective surgical intervention. He does not advocate surgical intervention in children before puberty.

In reviewing the literature one is struck with the change in the interpretation of "rest." Several authors, Gill, Kestler and others, have emphasized that prolonged bed rest is not physiologically sound. Severe stunting of growth, due to premature closure of the distal epiphysial plate of the femur and of the upper end of the tibia, is an unfortunate sequel of protracted immobilization for tuberculosis of the bones of the hip. For this reason many authors advocate procedures especially for tuberculosis of the hip which would "by-pass", the tuberculous lesion and permit early weight-bearing. This has been accomplished by osteotomy or by fusion (Hibbs, Chandler, Farkas, Milch, Bosworth, Brittain, Trumble).

Tuberculosis of the vertebral column-Here also there are two schools with divergent opinions as to treatment. Sorrel of Berck-Plage advocates conservative therapy with surgical intervention only in specially selected patients. Mayer and his group also advocate conservative therapy in children for tuberculosis of the vertebral column although strongly in favor of fusion for patients who are beyond the adolescent period. On the other hand Bosworth adrocates early surgical arthrodesis of the involved vertebral column for children as well as adults. He does not advocate laminectomy for Pott's paraplegia, but Garceau believes emphatically that laminectomy is indicated in paraplegia when conservative therapy for three or four months fails to give signs of recovery.

\section{ARTHRITIS}

\section{A New Approach}

\section{Otto Steinbrocker, New York}

A number of advances in our knowledge of arthritis and related disorders had gradually accumulated before the epochal announcement of cortisone and ACTH. Amongst the arthritic diseases, the greatest progress had been made in infective arthritis. The sulfonamides and the antibiotics had given us mastery over suppurative, gonorrhoeal and many other forms of 
joint infection. Streptomycin had become a potent weapon in some forms of tuberculous arthritis. Light on the evolution of degenerative arthropathy was provided by the work of Bauer and his co-workers. Numerous contributions have been made to the understanding of the clinical picture, mechanism and treatment of lesions of the soft tissues and supportive structures beyond the scope of this limited presentation. The use of procaine and related substances in their diagnosis and treatment has been an inportant forward step. The recognition of the somatizations in musculoskeletal disorders has been a useful development.

Of all the joint diseases, with the possible exception of rheumatic fever, rheumatoid arthritis has been the object of the most extensive clinical and investigative efforts. Although not the most common arthropathy it has been on the whole the most serious and crippling. Important strides have been made in our knowledge of its pathologic basis as a generalized disease which may involve other systems, such as the cardiovascular, central nervous and visceral, as well as the muscles, peripheral nerves and joints. The clinical characteristics of rheumatoid arthritis have been well defined and the need for more exact therapeutic criteria in the evaluation of therapeutic agents has been emphasized. For some time the concept of a general or focal infection in the etiology of rheumatoid disease has been minimized, although the frequency of positive streptococcus agglutinations and, more recently, of positive sheep cell agglutinations in high titre in active rheumatoid disease constitute provocative evidence. Chrysotherapy has been the most widely adrocated therapeutic measure although its ultimate contribution to the arrest of the disease has remained controversial, if not extremely doubtful.

Though casual references to the hormones in rheumatoid arthritis and other musculoskeletal diseases had appeared in the literature their significance was not appreciated until Selye made his remarkable experimental and clinical contribution. He noted that the experimental injection of large doses of desoxycorticosterone into rats with intact adrenals produced arthritis and related rheumatic and vascular lesions in some of the animals. In adrenalectomized rats treated in the same way the articular and extra-articular lesions appeared more frequently and in greater degree. Similar lesions were produced in the heart and joints of rats injected with a crude anterior pituitary preparation, but in adrenalectomized rats these effects did not appear. Selye deduced that the lesions were brought about, therefore, via the adrenal glands.

From his observations on the lesions produced in adrenal glands of rats by such varied harmful agents as exposure to cold, drug poisons, infections and emotional disturbances, Selye conceived the theory of "The General Adaptation Syndrome." The experimental disorders thus produced he termed "The Diseases of Adaptation." Rheumatoid arthritis, rheumatic fever and the collagen diseases were regarded by him as "diseases of adaptation" brought about by insufficiency or imbalance of the adrenal secretions with minerolo-corticoids overshadowing glucocorticoid secretion. These original and provocative investigative and theoretical contributions, monumental in scope, remain to be confirmed to a great extent. Their consistency with the collateral, independent clinical application of ACTH and cortisone to rheumatic diseases now to be discussed must depend on further observations, but Selye's work has already added concepts and terms which are part of the current medical language and thought.

The historic advent of cortisone and ACTH with their remarkable reversal of the rheumatoid process has made a tremendous impact on clinical thought and investigation in the rheumatic diseases as well as in almost every field of medicine. The original report of Hench, Kendall, Slocumb and Polley in April 1949 on the effects of cortisone and ACTH in rheumatoid arthritis has been substantially confirmed by other observers.

It is generally agreed that these compounds produce the most uniform and rapid suppressive effect on rheumatoid activity of any treatment yet available. They do not, however, cure the disease, for when the substance is withheld the symptoms return within days or weeks or sometimes months. When administration of the compound is resumed,

vol. $32 \mathrm{~B}$, No. 4, NovenBer 1950 
control of the symptoms again occurs usually with the same effectiveness. Interrupted administration is preferred on the assumption that the rest periods may favor less potent side-effects and fewer long-range complications from the widespread action of ACTH and cortisone. Even in the early short periods of administration, however, undesirable side reactions may occur by virtue of the varied physiologic functions of these potent hormones.

Although the exact site and manner of their action is not clear at this time it is obvious that they influence or block cellular infiltration and other inflammatory reactions, inhibit fibroblastic proliferation and stimulate filtration through the body membranes and other tissues. They exert powerful antipyretic and analgesic action. Salutary effects on the blood picture, sedimentation rate and some chemical constituents of the blood, such as the albumin and globulin, are consistently produced. These actions of the new hormones appear to account for their anti-rheumatoid effect.

Unfortunately, to provide these benefits the compounds must be administered in doses which are apt to produce in some patients hyperadrenalism or other metabolic abnormalities. These may be transient or persistent. Undesirable side-effects that may arise include rounding of the face and body, hypertension, acne, cutaneous striae, electrolyte disturbances with edema of the extremities or other parts, sodium retention and hypopotassemia, glycosuria with or without hyperglycemia, menstrual disorders, emotional disturbances, cardiac arhythmias and others such as those seen in the Cushing syndrome. Undoubtedly the nature and complete range of complications arising from the widespread use of ACTH and cortisone remain to be explored, so that the contra-indications and hazards must be regarded as incompletely determined at this early stage of their introduction.

In musculoskeletal disorders ACTH and cortisone appear to be equally effective. They have given the most impressive results in our hands in rheumatoid arthritis, acute gout and in reflex dystrophy (the shoulder-hand syndrome). They have also demonstrated definite promise as palliative agents or aids to mobility in rheumatic fever, periarthritis of the shoulder, malum coxae senilis and other forms of severe degenerative arthritis and in the collagen diseases. Our experience in a limited number of cases receiving these substances after manipulation of ankylosed joints or after surgery suggests that they may help to improve functional post-operative results.

It is desirable to begin the administration of these drugs in a hospital where base-line tests can be conducted as a safeguard. The patient is then continued on the smallest dose which will maintain suppression of the symptoms. The size of the maintenance dose varies with the type of disease and its severity. At present ACTH and cortisone are given parenterally but recently the more convenient oral route has been found to be effective. The use of fractions of ACTH by the sublingual method is now under investigation.

The undesirable side-effects of ACTH and cortisone have led to an intensive search for substances providing their benefits without these reactions. A diligent therapeutic study is being made of intermediate or modified steroids produced in the course of the complicated synthesis of cortisone, as well as other substances which might produce similar physiologic responses. Unfortunately, so far these efforts have not been fruitful. Amongst the compounds which have been tried for these purposes are pregnenolone, acetoxy-pregnenolone, desoxy-corticosterone (DOCA) with ascorbic acid, adenosine-5-monophosphate testosterone, progesterone, hydroxy-phenyl cinchominic acid and others.

The experimental observations and theories of Selye, the isolation, synthesis of adrenal compounds by Kendall and others, the isolation, purification and fractionation of ACTH, and the clinical application of these hormones by Hench, Slocomb and Polley to arthritis and other diseases, have altered and enlarged our understanding of specific and general disease processes and added greatly to our therapeutic efficiency. New and limitless pathways of investigation have been opened which directly or indirectly should stimulate further important contributions to progress in arthritis and other diseases. 


\section{CEREBRAL PALSY}

Winthrop M. Phelps, Baltimore, Maryland

In the field of cerebral palsy there has been marked advance both in diagnosis and treatment especially within the past twenty-five years. The condition was first described by Little in 1862 and the prognosis then was reported as hopeless except in mild cases, and it was thought that practically all were mentally affected. Hence the condition was neglected for many years. However, interest in the disease increased between 1910 and 1920 when infantile paralysis became more widespread. Many of these children were brought to infantile paralysis clinics, since the families knowing that their children had been paralyzed since infancy thought they might fit into this category. It became evident at this time that all of these children were not mentally defective and there were different types of cerebral palsy and all of these children were not " spastic."

Investigations started at that time have shown that cerebral palsy is a group of conditions with brain involvement of one sort or another and that the patients can be classified into specific types depending on the motor characteristics of the part of the brain involved. It was determined that the true spastics resulted from damage to the cortex of the brain or the pyramidal system. A second type of brain involvement resulted in athetosis in which were found changes in the various parts of the basal ganglia. A third type showed ataxia in which the cerebellum was the part of the brain chiefly involved. The rigidities, a fourth type, were seen to differ from the spastics in absence of stretch reflex on examination. This condition is usually the result of diffuse brain damage, from cerebral anoxia for example. A fifth type was congenital tremor.

Until 1920 most of these cases were considered to be the result of birth injury, but subsequent statistical studies of birth injury as such can only account for less than half of the total cases. Other etiological factors which have been found to produce cerebral palsy are mid-line defective development, vertex hemorrhage in prematures as a result of rapid birth and pressure changes from intra-uterine to air pressure. Kernicterus resulting from erythroblastosis associated with $\mathrm{Rh}$ factor difficulties is a definite, although not large, etiological factor.

In the birth injury group there have been found two types, those with cortical hemorrhage resulting from pressure of forceps and subsequent subdural hemorrhage, and excessive traction usually in breech deliveries resulting in damage to the basal ganglia. There is also a post-natal group of cases resulting from intercurrent infections with high temperatures, occasionally severe convulsive episodes or the violence of paroxysms of coughing in pertussis contracted under three months of age. The after-effects of encephalitis in infancy and early childhood also can result in cerebral palsy. Further statistical studies show that the instances of mental deficiency, directly due to cerebral palsy, is only about 30 to 35 per cent and therefore the majority of these children are not mentally defective.

Advances in the treatment of these children have been made in five fields.

1. Physiotherapy, occupational therapy and speech therapy. In these fields of therapy special methods of re-education for the establishment of fundamental cortical patterns of motion have been developed, chiefly in the physiotherapy field for the legs, in the occupational therapy field for the development of the normal use of the arms and in the speech field for the development of the usually automatic reflex of the diaphragm, larynx, tongue and lips.

2. There has been marked advance made in the construction of special types of braces and apparatus which can be used specifically to facilitate the development of usually normal automatic patterns.

3. There is definite promise being shown in drug therapy, but only as an adjunct to the previously mentioned methods, in facilitating motion and eliminating unwanted involuntary motions.

vol. 32 B, No. 4, November 1950 
4. In the field of surgery the types of orthopaedic operative procedures are gradually becoming clearly defined and those which are effective in cerebral palsy are being developed and classified as to their usefulness. In the field of neurological surgery advances in surgery on the cortex, basal ganglia and lateral columns of the cord have been made.

5. Finally, special educational methods for teaching these children have been developed which would take into consideration the sensory difficulties in sight and hearing as well as the motor aspects of the condition in bringing about more rapid development in the field of learning.

Special training facilities for doctors and therapists who are interested in cerebral palsy are being developed more widely and schools and training centers are being established specifically for these children. Statistical surveys of the number of cases show that the yearly increment is essentially constant as opposed to epidemic diseases and there are about six new cases a year in every 100,000 population of which four are mentally normal and definitely capable of a considerable degree of reclamation.

\section{MUSGLE RELAXANTS IN ORTHOPAEDIC SURGERY}

\section{Edward B. Schlesinger, New York}

The operative management of abnormal neuromuscular mechanisms and their sequelae has always been less than satisfactory. Growing emphasis upon the dynamics of the muscles has imposed new lines of investigation upon traditional orthopaedics. Attempts to influence abnormalities of posture and movement by the use of drugs represent the renaissance of an old and well documented concept-new only in its endowment of Sherringtonian principles and standardized alkaloids.

Burman, actively interested in the treatment of dyskinetic phenomena, in 1938 published the first of a series of reports upon the use of curare and later erythroidine in clinical practice. His findings renewed interest in this therapeutic approach in America, but widespread acceptance awaited the availability of a reliable preparation of curare. The impetus for the development of such a standard alkaloid was largely due to the efforts of Bennett, who thoroughly understood its potential usefulness and subsequently explored it in a series of clinical studies. Since chronicity is a common denomination of most of the states under discussion, aqueous solutions of curare with high initial levels and rapid dissolution of effect betray impractical aspects in clinical use. The inevitable step was the preparation of a long-acting suspension, described in 1946, which tended to obviate the potential toxicity of high early levels inherent in aqueous solutions and also to prolong the desired therapeutic effect.

The use of aqueous and long-acting suspensions of curare, such as tubocurarine, to aid in dissipating the muscular spasm associated with acute skeletal trauma has become the most secure niche for the muscle relaxant group generally. In the treatment of " acute low back" and cervical spine syndromes it may replace less specific traditional medication, and has proven efficacious in the potentiation of traction effect. In general, the search for efficient oral preparations has been unrewarding.

The synthesis of myanesin by Berger and Bradley in Britain in 1946 drew interest to the alpha substituted esters of glycerol, described years before and completely neglected. A 10 per cent solution necessitating rather potent solubilizing agents was proffered to the medical profession in Britain as a substitute for curare, particularly in anesthesia practice. Although its hemolytic properties and transient efficiency militated against its enthusiastic adoption, Stephen and Chandy of Montreal called attention to its interesting effects in ameliorating clinical dyskinetic phenomena. The group involved in the study of muscle relaxants at the Neurological Institute in New York were able to prepare a 2 per cent solution which reproduced the desired effects of the higher concentrations, but was less apt to cause serious hemolysis and phlebitis. This preparation, known as tolserol and lissephen in this 
country, has attracted much interest because of its unusual properties. By the intravenous route it is a specific, rapidly acting muscle relaxant whose chief site of action seems to be the bulbo-reticular substance and the synapses of the fairly long pathways mediating control of motor function. Its evanescent effects upon tremor, rigidity, spasticity, muscle spasm and involuntary movement are quite dramatic. The ephemeral nature of its therapeutic action narrows its clinical application to the treatment of reversible states such as muscular spasm and to the amelioration of other mechanisms for short periods of time. As a means of allowing evaluation of contractures or complicated dystonic mechanisms preparatory to definitive treatment, the intravenous preparation serves admirably. Its use as an adjuvant to traction, and as a means of determining the response of the "acute low back" with radicular pain to conservative treatment have been described.

More isolated examples of its occasional usefulness consist in maintaining limb rest after hip-pinning in patients with Parkinson's syndrome, and in dissolving adductor spasticity to allow cystoscopy or abdominal examination. Several oral preparations both in the form of tablet and elixir have been used extensively and described enthusiastically in the American literature. Unfortunately the drug is inefficient by mouth and even in large doses cannot reproduce the best effects obtained by the intravenous route.

Present day pharmacological research, unfortunately or otherwise, depends largely for the vigor of its pursuit upon the attentions of the drug industry. It can be said that the preliminary forays in the field of muscle relaxants have given impetus to their efforts and augurs well for the near future.

In summary, it may be said that in this field of investigation the last decade is chiefly notable for the reintroduction of the idea of attempting to ameliorate neuromuscular mechanisms by physiological rather than purely surgical means, and in giving therapeutic dignity to the concept of muscle relaxants.

We have now completed our topical review of advances in orthopaedic surgery. Your reporter is keenly aware of serious omissions, but limitations of space and time make it impossible to consider such important subjects as the stiff painful shoulder, internal derangements of the knee, slipped femoral epiphyses, the bone dystrophies, neoplasms and the surgery of peripheral nerves. To secure a well-rounded concept of orthopaedic surgery in this country, other phases of development besides the technical must be described.

THE DEVELOPMENT OF NEW SOGIETIES AND OF ORTHOPAEDIC EDUCATION

The significance of the American Orthopaedic Association has already been emphasized in the preceding parts of this paper. It is now time to consider the role of other orthopaedic organizations. Of these, the most important is the American Academy of Orthopaedic Surgeons. An account of its history has been contributed by one of the organizers and a past president of the Academy.

\title{
The American Academy of Orthopaedic Surgeons
}

\author{
Carl E. Baigley, Ann Arbor, Michigan
}

The development of the American Academy of Orthopaedic Surgeons is not an isolated incident in the history of orthopaedics. Rather, it was the natural result among other normal factors of the great stimulus given to surgery in general, and orthopaedic surgery in particular, by the brilliant results achieved and popularized in World War I. An ever expanding growth of orthopaedic surgery, hitherto confined to university clinics and large medical centers and cities, spread by popular demand into the larger hospitals and clinics throughout the country. Capable, well-trained men were attracted in ever increasing numbers into the speciality of orthopaedic surgery.

vol. 32 B, No. 4, NOVEMber 1950 
The American Orthopaedic Association, composed by constitution and inheritance of a restricted membership, had for years by custom as a courtesy held annual meetings at the home of the current president. A constantly increasing attendance each year of well-qualified younger orthopaedic surgeons or guests demonstrated to the members of the American Orthopaedic Association the obvious need for the formation of a new organization constituted on a much larger scale. The concept was expressed by some to maintain the American Orthopaedic Association in a capacity somewhat analogous to the Senate and to develop a much larger membership in the new organization akin to the House of Representatives. There was, however, no official act by the American Orthopaedic Association itself.

The Academy historian, Philip Lewin, states: "On October 11, 1931, Willis Campbell unofficially initiated a meeting of a few members of the American Orthopaedic Association at the Congress Hotel in Chicago for the purpose of discussing a matter of vital importance to the development of American Orthopaedic Surgery." Campbell, among others, was fully cognizant of the need for an annual gathering of all interested in orthopaedic surgery. He had been much impressed with the increasing size and evolution of the Clinical Orthopaedic Society which, outgrowing its original purpose of a travel club visiting clinics annually throughout the Mid-West, had developed into an organization of such size and scientific caliber that scientific programs were required to replace the clinical demonstrations.

At this historical 1931 meeting and at several meetings the following year, Campbell launched a program for the development of a national organization for orthopaedic surgeons in the form of an academy whose primary object, as expressed in its constitution, "shall be for the advancement of orthopaedic surgery in all of its phases." Particularly, recognizing the broad scope and appeal of orthopaedic surgery and its dependence upon the allied sciences, one of the purposes of the meeting was to allow attendance as guests of any member of the medical or allied professions.

On January 13, 1933, at a regular annual meeting of the Clinical Orthopaedic Society in Chicago, through the instigation of Campbell and his selected committee, a formal organization meeting of The American Academy of Orthopaedic Surgeons was held. The members of the Clinical Orthopaedic Society properly qualified by training thus became the nucleus for the newly formed American Academy of Orthopaedic Surgeons. Officers of the new organization were duly nominated and elected with E. W. Ryerson as president of the organization meeting, and Willis Campbell President Elect. During the ensuing year a constitution was established. Membership in the organization was restricted to individuals who had received adequate training in orthopaedic surgery and had practised orthopaedic surgery exclusively at least three years subsequent to his period of training. In 1937, for the first time, does it appear in the articles of the by-laws that the applicant must be certified by the American Board of Orthopaedic Surgeons.

The 1934 meeting of the Academy of Orthopaedic Surgeons proved the need of such an organization. To a large enthusiastic attendance was presented a most stimulating program. The first invited foreign guest of the Academy was the late Naughton Dunn who in 1934 distinguished himself by his wit and humor as well as by his scientific contribution.

The growth of the Academy continued apace, attracting not only orthopaedic surgeons but many other interested guests. At first there was a retention of the old custom of the Clinical Orthopaedic Society, from which the Academy emerged, to hold a day for clinical presentation. The meetings were held in large cities with suitable clinical and hotel facilities. The increasing attendance at the annual meeting soon restricted the location to a few large cities, chiefly Chicago, where ample facilities for hotel accommodations could be obtained. Commercial firms, quick to recognise the value of exhibits, helped to meet the financial costs of the Academy by renting space. Scientific exhibits became of increasing importance and supplemented the scientific papers. An audio-visual program was initiated at the 1939 meeting in Memphis which has developed into such an important part of the annual meeting that 
1,700 members and guests sitting in two halls of the Waldorf-Astoria in 1950 viewed this part of the program.

In 1942, through the interest of J. E. M. Thomson and a favorable executive committee, the Instructional Courses of the Academy were begun. The success of this feature of the meetings has led to its continuation. The organization and the functioning of this complicated portion of the program, although open to minor criticism, have in general been most satisfactory. Little time has been lost from the regular scientific program as Saturday, Sunday and Monday mornings have been utilized for this portion of the program. The seventh volume of the Instructional Course lectures has just come from the press, a valuable addition to any orthopaedic library.

In 1943 there was a combined meeting of the American Academy of Orthopaedic Surgeons and the Clinical Orthopaedic Society, celebrating a decade of existence for the Academy.

As the Academy has grown in importance and become truly " big business," it became obvious that there was a need for a central office for the affairs of the Academy. Such an office has been established in Chicago and now serves not only the Academy but the American Orthopaedic Association, The American Board of Orthopaedic Surgeons and the Clinical Orthopaedic Society. It has a complete addressograph file for these organizations. Its services are available to others on a " cost plus" basis.

The American Academy of Orthopaedic Surgeons has now grown to the size where it is inevitable that normal expectancy of future growth will make it physically impossible to continue its meetings with the physical facilities of hotels. Restriction of attendance has been suggested but the obvious evidence of its success on the broad principle expressed in the constitution of the Academy, "The object of the Academy shall be the advancement of orthopaedic surgery in all of its phases," shows the need and dependence of the orthopaedic surgeon on his medical confrères and the allied sciences. Future meetings may by necessity have to be held in locations with suitable auditorium accommodation.

\section{The American Society for Surgery of the Hand}

Joseph Boyes, Los Angeles, California

In the fall of 1945, when World War II was drawing to a close, there had been set up in the United States Army Hospitals a system of treatment of casualties of the hand wholly different from anything seen in previous wars-nine army hospitals had been established as centers where injuries of the hand were treated as an entity. This deliberate plan of concentrating the treatment of injuries of a specific anatomical region rather than classifying them on the basis of a surgical speciality had been established by the Surgeon-General of the United States Army, Major-General Norman Kirk.

Early in the war years, because of his long familiarity with problems of hand injuries and especially reconstructive surgery of the hand, Sterling Bunnell had been asked to visit the various army hospitals and make recommendations for treatment of the increasing number of hand injuries. As a result this type of injury was assigned to nine army centers and these hospitals were staffed with men whose enthusiasm, set free from the traditional views of tissue surgery and stimulated by frequent visits from Dr Bunnell and later other consultants, led them into the fascinating field of reconstructive surgery of the hand. The results were outstanding and the new procedures developed and the new ideas generated by this group showed that here was a new field of surgical endeavor well able to keep a man's full faculties exercised. Here was a field where plastic surgery, neurosurgery and orthopaedic surgery would be combined and a knowledge of anatomy in its finest details essential; where a delicate touch and extremely fine skill were required; and where all the imagination a man possessed could be utilized to help him restore to the wounded the function of this most essential part.

When it became apparent, with the end of the war and subsequent demilitarization of

Vol. $32 \mathrm{~B}$, No. 4 , NOVEMBER 1950 
the country, that these centers would be closed and the staff returned to civilian life, some means was sought to keep alive the spirit of the group and further the common interest in problems of surgery of the hand. A correspondence club was considered but it was decided to make a more closely knit organization; and thus the American Society for Surgery of the Hand was organized. In 1945 a small nucleus met to discuss the problem and to invite into the proposed small organization those surgeons throughout the country who were known to have been interested in and to have contributed to the development of this field of surgery. The organization began on a small scale and has grown slowly. The present membership is sixty-two. Annual meetings have been held and the topics discussed have apparently been of great interest to the profession as a whole, for the meetings have been attended by as many as nine hundred.

The establishment of an organization such as this has settled the question of where surgery of the hand belongs in the realm of surgical specialities. The aim of the hand surgeon is not to treat a tendon injury, a fracture, a nerve injury, or to replace skin on a burned part, but to restore function to the extremity as a whole; not only to enable the hand with sensation to grasp objects, but to enable the individual to place that essential organ in its most useful position by means of a functioning arm and shoulder. Truthfully the hand, as Bunnell says, "starts at the opposite cerebral cortex" and does not start at the wrist, which is palmistry. The modern concept of reconstructive surgery of the hand and the rational approach to the problems of treatment which the Society is attempting to promulgate are but the extended ideas first felt by the group under the stimulus of Bunnell's teaching and as exemplified in his textbook, the vade-mecum of every hand surgeon.

\title{
The Place of Orthopaedic Surgery in the Teaching Program of the University Medical Schools
}

\author{
LeRoy Abbott, San Francisco, California
}

In 1947 I was able to secure data concerning the status of orthopaedic surgery in fifty-three of our medical schools. In seventeen of these schools orthopaedic surgery had acquired major status with a certain measure of control over the amount and distribution of budgets, appointments and promotions on their staffs, and representation on the executive advisory committees of the deans of their respective schools. Thirty-six were subdepartments of surgery; that is, in approximately one-third of our medical schools the orthopaedic divisions have autonomy.

In 70 per cent of the schools fractures, osteomyelitis, joint infections and bone tumors were treated exclusively on the orthopaedic service. In the remaining schools the treatment of these conditions was divided between orthopaedic surgery and general surgery, while in a small percentage they were treated on the general surgical service. In 20 per cent, amputations were cared for exclusively on the orthopaedic service; in 8 per cent, on the surgical service; and in 72 per cent the treatment was divided between the two services. Acute surgery of tendons and the treatment of infection of the hand were assigned in varying proportions in the different medical schools to both orthopaedic and general surgical services. The teaching of the subjects of fractures, osteomyelitis, joint infections, bone tumours, amputations, surgery of the tendons and of the hand was divided between the two divisions of surgery in about the same proportion as the treatment of these conditions.

In reply to the question: "Do you have facilities for complete training in orthopaedic surgery including fractures, children's orthopaedic surgery and fundamental sciences?" forty-one indicated that they had all the necessary facilities and ten were lacking in some particulars.

During the past year, the Division of Orthopaedic Surgery of the University of California Medical School has enjoyed the status of a major division of surgery. With this independence 
and authority to control our future development, integration of our teaching with other divisions of surgery for the benefit of the undergraduate and postgraduate student is to be desired. We will then fulfil the obligation which will justify the newly acquired autonomy. As Carl Badgley, my former associate at the University of Michigan, so well expressed it: "Our aim should be first, to train doctors; second, to train surgeons; and then to train orthopaedic surgeons."

\title{
Postgraduate Education in Orthopaedic Surgery after World War II
}

\author{
A. R. Shands, Jr., Wilmington, Delaware
}

During the latter years of World War II it became evident to the American Academy of Orthopaedic Surgeons and the American Orthopaedic Association that due to the increased interest of the military physicians in orthopaedic surgery there would be a very large demand for orthopaedic training when peace-time conditions once more existed. With this thought in mind these two organizations appointed a six-man Joint Committee on Postgraduate Training with Dr Ralph K. Ghormley of the Mayo Clinic as chairman. The objective of this Committee was to increase facilities for orthopaedic training in order to provide for the medical veteran desiring to become a qualified orthopaedic surgeon. The author of this article upon discharge from the service became the seventh member of this Committee and was made its secretary.

The first work of the Committee was to review the approved training services in the United States and the services in the larger hospitals which had no formal training. After this review, those services with formal approved training which were considered eligible were asked to increase the number of their residents, and those hospitals without approved training which had the necessary facilities and staff were asked to start a formal training service and apply for approval. The Council on Medical Education and Hospitals of the American Medical Association agreed to give temporary approval to all new orthopaedic services established to meet this emergency which were approved by the American Board of Orthopaedic Surgery and the Committee on Postgraduate Training. In the first two years the number of training services was increased from approximately seventy-nine to 238 and the number of residencies from 253 to 726 . These have now increased to 257 services and 779 residencies. Realizing that the sudden expansion of orthopaedic training services might not be best for orthopaedic surgery as a whole and might result in some poorly trained specialists, the Postgraduate Training Committee with the sponsorship and approval of the Council on Medical Education and Hospitals of the American Medical Association reviewed the training afforded by these services in 1949. This was done by twenty-eight carefully selected orthopaedic surgeons. The reports of these surgeons resulted in the changing of the type of approval of approximately 20 per cent of these services.

With this expansion of the training services approved training was given for the first time in the Veterans' Administration Hospitals and in the larger hospitals of the Army and Navy. Some of these government services are now among the best in the country. Most of the new services were awarded training only for adult and fracture work but many were allowed credit for children's orthopaedics and basic science as well.

\section{The American Board of Orthopaedic Surgery}

\author{
Allen F. Voshell, Baltimore, Maryland
}

(President of the Board)

The tendency of an increasing number of physicians to limit their practice to a special branch of medicine has made it essential that the various recognized specialities organize qualifying boards to certify applicants who prove themselves competent. Recognizing this need, three major orthopaedic groups-the American Orthopaedic Association, the Section

vol. $32 \mathrm{~B}$, No. 4 , NOVEMBer 1950 


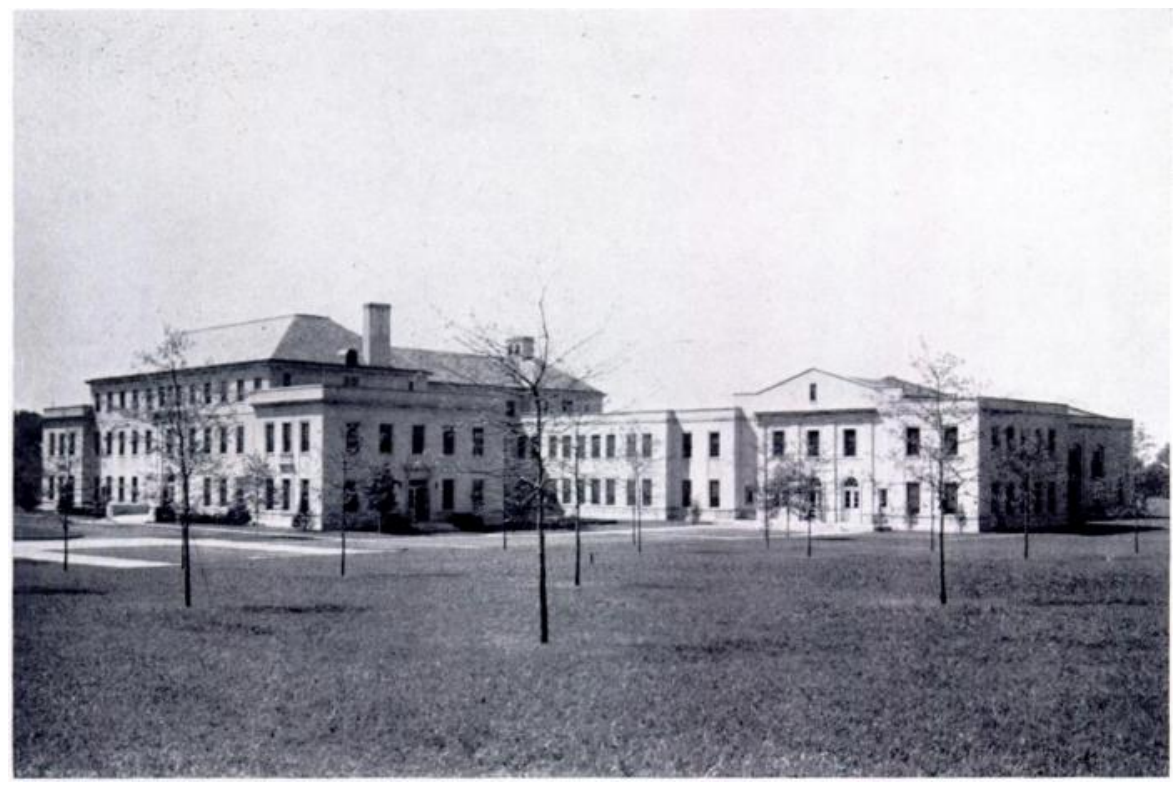

The Alfred I. Du Pont Institute, Wilmington, Delaware. Opened in July 1940 by the Nemours Foundation, it represents one of the most carefully planned and well organized private philanthropies for crippled children. Dr A. R. Shands, the Medical Director, spent two years of study and visited over 100 institutions in Europe and the United States before submitting building plans for the Institute. The bed capacity is eighty-five. There are schoolrooms, an auditorium, indoor and outdoor pools, a physical therapy department and playrooms. There is a fourteen-bed research ward, and laboratories for research in biochemistry, bacteriology and pathology. There are a library with 6,000 volumes and a museum for bone specimens. The Institute has had the following four-point program : 1) Hospitalization of the crippled child; 2) education of the crippled child; 3 ) research on problems related to the crippled child; and 4) postgraduate training of the workers in the field of crippled children.

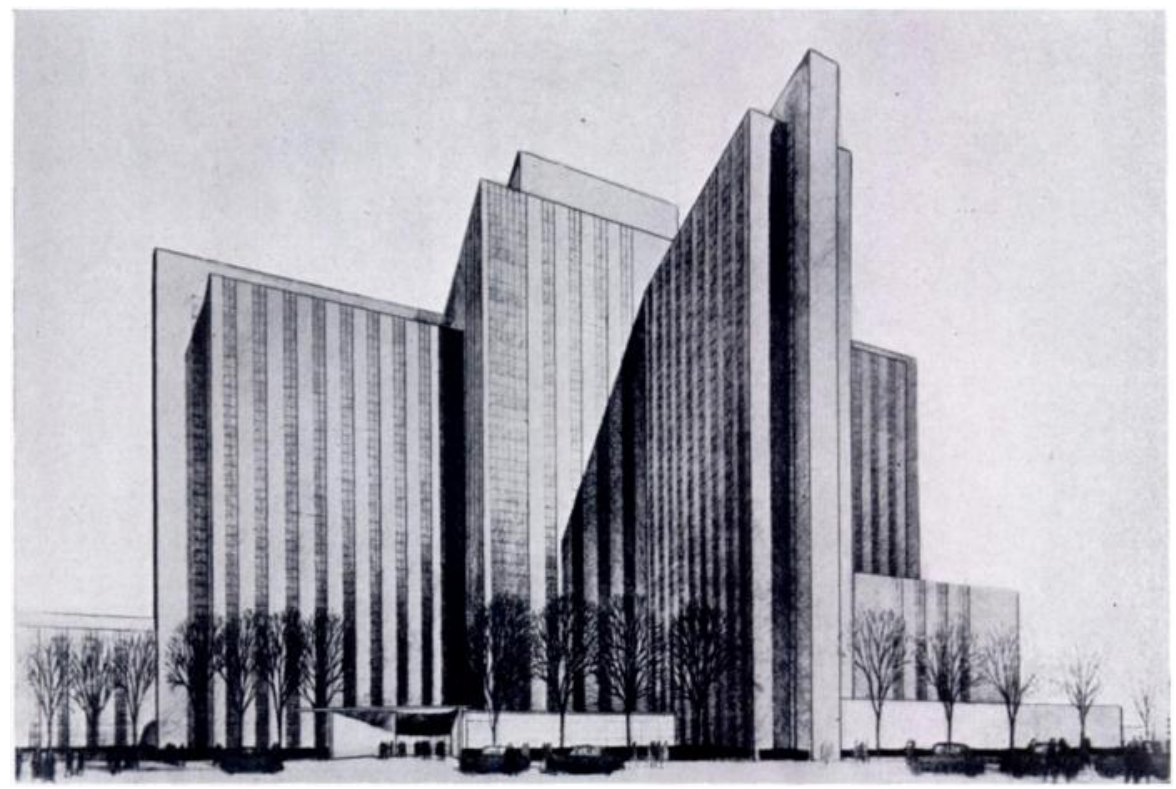

Veterans' Administration Research Hospital now under construction on Chicago's lake front, adjacent to North-Western University. Medical School campus. This beautiful building is typical of the progressive spirit and the accomplishment of the 'eterans' Administration under the able direction first of cieneral Hawley, and now under his successor, Dr Paul Magnuson. 
on Orthopaedic Surgery of the American Medical Association and the American Academy of Orthopaedic Surgeons-united in organizing a certifying Board. This Board was incorporated in the year 1934 as the American Board of Orthopaedic Surgery, Inc., and is officially approved by the Advisory Board of Medical Specialities and by the Council on Medical Education and Hospitals of the American Medical Association.

It is the purpose of the Board to raise the qualifications and standards for the practice of orthopaedic surgery and to certify those surgeons who voluntarily comply with its requirements. The following facts are pertinent results of the Board's activities and principles:

1. Certification by the Board forms a criterion by which interested lay and professional groups may judge the qualifications of an orthopaedic surgeon and will be a reliable guide in the choice of consultants.

2. Board certification has been made a requirement for staff appointments in hospitals and a pre-requisite for recognition as a specialist in orthopaedic surgery by other organizations, though this is not a purpose of the Board nor was it initiated by it.

3. Certification by the American Board of Orthopaedic Surgery is one of the essential requirements for membership in the American Orthopaedic Association and the American Academy of Orthopaedic Surgeons.

4. Qualification of applicants for certification by the Board indirectly results in improved teaching of orthopaedics in medical schools and better care of patients on orthopaedic services of hospitals that have approved resident training programs.

During the past sixteen years improvements in the training of orthopaedic surgeons have been many, with perhaps the stress placed upon the basic sciences as an important phase of modern orthopaedics, and the need for some fundamental general surgical experience preliminary to specialized orthopaedic training. The equivalent of six months in the basic sciences with emphasis upon anatomy and pathology has been a requirement of the Board for five years, but a year of general surgical experience has just been instituted and from now on will be required. A system of examining candidates to evaluate their capabilities has been evolved and it seems to merit the statement that it is fair and essentially accurate, particularly since two examinations are made of eligible candidates, one early in his training and the other after two years of specialized practice. About one thousand orthopaedic surgeons have been certified to date in the United States and Canada and there are about three hundred more in training or in process for certification.

\section{Orthopaedic Research}

\section{Verne T. Inman, San Francisco, California}

[The clinical progress of orthopaedic surgery is largely dependent on research. This is being conducted in so many fields and by so many different men that it is impossible even to list them. It is, however, important to cite a single instance of what is being done and the work that is being conducted at the University of California is given as an example of the type of study which is adding greatly to the sum total of our knowledge-L. M.]

It is our feeling that the research activities of the Division of Orthopaedic Surgery are of equal importance to the practice of clinical surgery and instruction. It is the research that distinguishes the university from a mere trade school. The fields of research should extend beyond clinical investigation and include studies of a fundamental nature. In fact, the clinical activity should be the end-result of new ideas originating from such fundamental investigations.

With these concepts the Division of Orthopaedic Surgery has sponsored a Biomechanics Group. This group is co-operating in investigations in the fields pertaining to the locomotor system.

An investigation of the mechanics of motion involves problems which can only be attacked

vol. $32 \mathrm{~B}$, No. 4 , NOVEMBer 1950 
and quantitatively analyzed by individuals who are familiar with engineering technique and methods. Since these problems lie within the field of the engineers we have sought their close co-operation and assistance. Within the Biomechanics Group, the work has been divided into two general fields. One involves the study of the mechanics of the human body and the other is restricted to medical and biological problems. Those dealing with the kinematics and kinetics are placed under the supervision of engineers, the medical group acting as consultants and advisers. Those problems which are fundamentally medical in nature are supervised by medical personnel and assistance is sought from the engineers when indicated.

The extent of our interest in the fundamental problems is indicated by a list of the projects which at the present time are being actively pursued:

A. Fundamental studies of locomotion under the direction of engineers.

1. Displacement patterns of the various segments of the body in all planes of space during locomotion.

2. Angular acceleration of the various segments of the lower extremity.

3. Recording of floor reactions using force plates.

4. Calculations of moments about the joints of the inferior extremity.

5. Electromyographic studies to determine the activity of the various muscle groups and individual muscles during locomotion.

B. Studies under the supervision of the medical personnel.

1. Fundamental studies on the dynamics of muscular contraction.

2. Studies on electromyography in an attempt to correlate the electrical activity with mechanical activity of muscle.

3. Studies on the chemistry of muscle and the contractile unit.

4. Studies on atrophy and hypertrophy of muscle.

C. Fundamental studies on pain.

1. The innervation of the deeper tissues by staining with methylene blue to determine the type of nerves and their distribution.

2. Study of thresholds to pain in normal subjects.

3. Study of the extent of the radiation of pain from experimental irritative skeletal lesions.

4. Clinical study of pain in amputees.

5. Study of the vascular supplies to stumps of amputees.

6. Electrophysiological studies on the small fibres of mammalian nerves.

We have at the present time approximately twenty-seven full-time research personnel sponsored by private funds and grants from the National Foundation for Infantile Paralysis and Advisory Committee on Artificial Limbs. No departmental funds from the University of California are being utilized.

\title{
PUBLIC HEALTH PROGRAMS FOR THE ORTHOPAEDICALLY HANDICAPPED
}

\author{
Samuel Wishik, New York \\ Director, Bureau of Child Health, New York Department of Health
}

The twentieth century was well advanced before there was appreciable assumption by government of responsibility for crippled children other than in institutional care. On the national level some programs for maternity and infancy hygiene which were established by the Shepard-Towner Act of 1921 gave a small amount of service to crippled children. The specific federal legislation that launched a nation-wide program for meeting the problem on more than a token basis was the Social Security Act of 1935. This Act, under Title V, Part 2, authorized an annual appropriation of $\$ 2,850,000$ for grants to the states to extend and 
improve services to crippled children, especially in rural areas and areas suffering from economic distress. Each state was granted $\$ 20,000$ plus an additional amount determined by the number of crippled children in need of service, the cost of care and the financial need of the state. The amount granted had to be matched dollar for dollar with state or local funds. In 1939 the total annual amount for the program was increased to $\$ 3,870,000$ with $\$ 1,000,000$ of it not requiring state matching. In 1946 the annual appropriation authorized was raised to $\$ 7,500,000$ with half requiring matching and in 1950 this was doubled to $\$ 15,000,000$.

The first funds under the Social Security Act were passed to some of the states in February 1936. By 1939 every state had received approval of a plan and grants of funds. A variety of administrative patterns developed. The official state agencies administering the plans were health departments, welfare departments, education departments or separate special commissions. The trend over the years has been to shift more and more to health departments. The administrative variety resulted from the different activities that existed at the time the Act was passed, particularly the tradition of Welfare Departments giving institutional care to the mentally and physically handicapped.

At both the federal and state levels committees of orthopaedic surgeons and other professional and lay persons help advise on the policies of the programs. The Children's Bureau maintains a staff of consultants in the fields of orthopaedics, physical therapy, pediatrics, public health nursing, social work, nutrition, hospital planning and administrative methods to give assistance to the state agencies which in turn offer similar consultation to the local personnel working in the program.

One of the outstanding developments under the state programs has been the itinerant clinics conducted by a professional team composed of an orthopaedic surgeon and some or all of the following: public health nurse, medical social worker, pediatrician, physical therapy technician and vocational rehabilitation worker. The clinics are held in areas which do not otherwise have access to specialized services. Consultation on diagnosis and recommended treatment is given to the local physicians and assistance is given to other local professional persons in meeting the total needs of the crippled child. When hospital care is necessary the program pays for it if the work is done by qualified specialists in hospitals which meet acceptable standards in facilities, personnel and practices. Diagnostic services are available to all but a means test is usually applied to determine eligibility for treatment services. Approximately 25 per cent of the children seen in the clinics are referred for hospital care. Convalescent care in institutions or in foster-homes is furnished when needed. In 1947, 485,000 handicapped children under twenty-one years of age were listed on the state registers.

Just about the turn of the century first steps were taken to bring special education to crippled children. Minnesota started education in the state institution for crippled children. In New York City the public school system sent teachers into children's orthopaedic hospitals and into the homes of home-bound children. This practice spread slowly until at present there is hardly an institution for crippled children that does not give education along with medical care.

In the first twenty years of the century public departments of education in large cities built and maintained special residential schools for handicapped children. More recently the trend has been towards day-time education rather than full-time residence. Special day schools exist in Newark, Chicago, Baltimore and a number of other cities. Special schools may provide wide corridors, easily accessible and wide exits, elevators, ramps, special auditorium and gymnasium facilities, treatment rooms, treatment swimming pool, rest rooms, lunch rooms, industrial training rooms and special equipment such as wheel chairs or adjustable benches and desks. Children are transported from all parts of the city to the centralized school. Transportation under such a program becomes an extremely expensive and difficult problem.

The more recent trend in most parts of the country is away from the separate special school and to the special classes in certain of the regular schools. This pattern offers the

vol. $32 \mathrm{~B}$, No. 4 , NOVEMBer 1950 
advantages of giving schooling closer to the child's home and also greater opportunity for the handicapped children to mingle with the normal groups. The first special classes were established in Chicago and New York City just about 1900. By 1914 Cleveland, Detroit, Baltimore and Philadelphia also had such classes. The history of day-school classes for crippled children in the United States shows a gradual transition from private to public responsibility. In various cities, private schools and such organizations as the Association for the Aid to Crippled Children sponsored such special classes during the early 1900's. Special classes are usually located on the ground floor level. They have fewer pupils per teacher and may have attendants to assist with the children. Physical therapy and occupational therapy under medical direction are given in some of the classes. It is estimated that education in a special class is four to six times as costly as for the regular program. Although transportation is less expensive than that in the special school it is still a large item. When the number of children is small, departments of education usually contract for their transportation. For larger groups, special buses have been constructed and are operated by the school system.

It is the generally held belief in the United States that handicapped children should receive their education in as regular an environment as possible and that they should not be separated from other children unless definite advantage accrues from such separation. Therefore, when a child no longer needs special instruction, treatment or handling he is transferred to a regular class despite the persistence of a handicap. The most recent trend is towards the so-called divided program in which a child spends most of his day in a regular class and goes to the special class in the same school only during those hours when he needs and receives special care. In any event, the decision concerning placement must depend to a large degree on the medical diagnosis and recommendation.

State support of local school systems in giving special education to handicapped children did not begin until 1915. In that year Ohio and shortly thereafter New York and other states first granted supplements over and beyond the usual grant for education. In 1914, 3000 children attended special classes in the United States. By 1948 the number of children in special classes had grown to 30,000 and 1,469 school systems were giving some type of special education to about 440,000 children with various kinds of handicap. It is recognized that such children should start their education earlier in life and should be able to continue it longer than the normal child. Twenty-four states now permit modification of the usual minimum or maximum educational age levels.

At the federal level the United States Office of Education in the Federal Security Agency gives consultations to state departments of education and helps to set standards for the education of crippled children. As yet, however, no federal grants of funds have been made available to the states for educational purposes.

This report on the public health aspects of orthopaedic care in the United States has thus far been largely limited to children. But much can be said about public health services to adults. In 1917 Congress passed the Smith-Hughes Act establishing a federal agency to administer grants for vocational education. In 1918, under the impetus of World War I, the Soldiers' Rehabilitation Act was passed to offer retraining to disabled veterans after their discharge from the armed forces. Placing the rehabilitation of returning soldiers under a civilian agency established the framework for a program of vocational rehabilitation of civilians. Emphasis was still given to industrial injuries but by 1920 the National Vocational Rehabilitation Act was passed along broader lines. Allotments were made to states on the basis of population. The Social Security Act of 1935 established a permanent rehabilitation agency not requiring periodic renewals, increased the grants and increased the amount to be used by the federal administering agency. In 1939 the Social Security Act was amended to authorize appropriations of $\$ 3,500,000$ a year for grants to the states, set a minimum allotment for any state at $\$ 20,000$ and authorized $\$ 150,000$ a year for federal administration. In 1939 under government reorganization the Board of Vocational Education 
was placed in the United States Office of education in the Federal Security Agency. In 1925 the National Civilian Rehabilitation Conference was organized and its name was changed in 1927 to the National Rehabilitation Association. It is a professional organization of rehabilitation workers whose objective is the promotion of measures that will improve the condition of the disabled. It publishes a bi-monthly periodical, The National Rehabilitation Neros.

Twelve states had rehabilitation legislation on their statute books when the 1920 federal law was passed. During the next year nineteen additional states adopted rehabilitation laws. Within two years after the passage of the Act, two-thirds of the states had accepted federal aid and had established state boards for vocational education. It was not until 1940, however, that the last state participated in the program. Under the federal program a disabled person is defined as any person who by reason of a defect whether congenital or acquired by accident, injury or disease is or may be expected to be totally or partially incapacitated for remunerative occupation. No means test or statement of financial eligibility and no age limit exist at the federal level. Training may be secured in schools and colleges, public or private, from tutors

- or correspondence courses or by supervised experience in business establishments.

In 1922 interpretation of the Act was revised to permit expenditure for orthopaedic appliances when the appliance was essential to the vocational rehabilitation of the individual but not merely for physical reconstruction or restoration of the individual alone. In 1926 this was further liberalized. In 1943, this time because of the manpower shortage during World War II, vocational rehabilitation was expanded considerably. Physical restoration was permitted in order to render a disabled or handicapped person more employable. Approximately $\$ 2 n, 000,000$ a year were made available for grants to the states as needed. By agreement with the United States Children's Bureau, the Crippled Children's Services in the states offer medical correction to most of the patients under twenty one years of age, the State Vocational Rehabilitation Agencies to those over twenty-one. Vocational counselling is usually available by sixteen years of age, though earlier services are offered in some areas. The 1943 Act accelerated the program tremendously. From 1920 to $1943,210,000$ persons had received some type of vocational rehabilitation service. In the next five years the number was 219,000 . The average cost of vocational rehabilitation has been $\$ 300$ to $\$ 500$ per case which is less than the cost of maintaining a dependent person for a single year.

The disabled unemployable citizen becomes a drain upon society. Failure to prevent disability and failure to offer full potential rehabilitation are extravagances which no community can afford. The orthopaedic surgeon holds the key position as a party to the co-operative efforts of individual clinicians and teachers and the combined resources of voluntary groups, institutions and government.

\title{
LAY SOCIETIES
}

Most orthopaedic surgeons are much more keenly aware of the lay societies active in the cause of the crippled than they are of governmental agencies. Particularly prominent among these lay groups, and of great constructive help in the fight against poliomyelitis is the National Foundation for Infantile Paralysis. As an example worthy of being followed, a section is being devoted to this society.

\section{The National Foundation for Infantile Paralysis}

\author{
Miss Dorothy Ducas \\ Public Relations Director of the Foundation
}

This is a non-profit membership corporation supported by the American people through the March of Dimes each January. It was founded in 1938 to "lead, direct and unify " the fight against poliomyelitis. At present the national Foundation has 2,822 Chapters manned by volunteers in the United States, Alaska, Hawaii and Puerto Rico. Each Chapter is prepared to spring into instant action to assist infantile paralysis patients in the locality.

vol. $32 \mathrm{~B}$, No. 4 , NOVEMBER 1950 
The organization has three basic aims:

1. To maintain nation-wide systematic aid in regular and epidemic outbreaks of poliomyelitis.

2. To encourage through scholarships, fellowships, and assistance to schools and professional organizations the recruiting of additional scientists, physicians, nurses, physical therapists and other professional workers in the poliomyelitis field.

3. To support intensive scientific research with the object of discovering a preventive, a specific cure and improved treatment of the disease.

The National Foundation's continuous search for a medical preventive, and for methods of ameliorating the crippling after-effects of poliomyelitis, together with its vast epidemic aid program, constitute the most comprehensive attack on a single disease ever made by a private agency.

Half of the money raised by the March of Dimes goes to the national headquarters of the organization for its program of scientific research, education and emergency aid in epidemics. The other half is retained by the county Chapters for care and treatment of local poliomyelitis patients who need financial help and, in emergencies, is used also to supplement national epidemic aid. The Chapters work with hospitals and recognized health and welfare agencies, rendering financial aid where needed, regardless of the age, race or creed of patients.

In less than thirteen years since it was founded by the late President Roosevelt the National Foundation has made grants and appropriations totalling some $\$ 28,500,000$ for research, education and non-epidemic medical care. In the same period about $\$ 94,200,000$ has been spent for epidemic aid and patient care.

Research sponsored by the March of Dimes has uncovered the fact that infection with poliomyelitis is not a rare occurrence. Approximately 80 per cent of the people in the United States have been infected by one or more of the polio viruses by the age of fifteen. However, only a small percentage of these developed clinical symptoms; the majority are seldom aware that they have been infected. It has been learned that specific antibodies exist in the blood of adults conferring a measure of immunity to the paralytic disease, but immunity to one of the viruses does not provide immunity to the others. National Foundation research grantees are now determining exactly how many different types of virus can cause human poliomyelitis, with a view to attempting a combined preventive vaccine or serum against all types. At the same time the search for a drug to prevent paralytic poliomyelitis continues. It is known to-day that nerve cells, once invaded by the virus, are not always destroyed. Many may recover. Thus it is reasonable to believe that paralysis and death can be decreased if an agent can be produced that can destroy the virus within the nerve cell.

Among the foremost accomplishments in the research field are those which have led to a substantial reduction in the death-rate from bulbar poliomyelitis, in the development and improvement in the techniques of orthopaedic surgery and more widespread use of physical therapy. More than 2,000 physical therapists have been trained in recent years in approved schools under National Foundation scholarships.

Research in muscle and joint action has brought about the development of electronic instruments for testing and strengthening weakened muscles and has enabled engineers to create new and greatly improved prosthetic devices of all types. Recent studies also have shown that strenuous physical activity during the pre-paralytic stages of infection can increase the amount and extent of involvement, as can chilling. Thus widespread dissemination to the public of the precaution to avoid over-fatigue and chilling has been undertaken for the last three years.

Because of greater knowledge of the nature of infantile paralysis and because of improved techniques and prompt medical attention, extensive deformity and distortion, once relatively common, have been substantially reduced, while possibilities in the field of mental and physical rehabilitation are being explored and expanded. 


\title{
ORTHOPAEDIC SURGERY IN THE SECOND WORLD WAR
}

\author{
Major-General Norman T. KIRK * \\ Surgeon-General, United States Army
}

The excellent medical service rendered to the American Army in World War II can to no little extent be attributed to the consultant service of the Medical Corps. Consultants in surgery and its specialities, including orthopaedic surgery, and in medicine were established in the office of the Surgeon-General; in the nine service commands in the Zone of Interior; in each overseas theatre and in each Army.

The members of the American Orthopaedic Association and of the Academy not in the military service, acting individually or as members of the Orthopaedic Panel of the National Research Council, were of great assistance in the evaluation of the professional qualifications of the Reserve component concerning the training of the individual officer in orthopaedic or traumatic surgery and in other ways. This information or Board certification was of great value in determining the officer's MOS number and his initial duty assignment. The orthopaedic consultant not only advised regarding specialized care of the sick and wounded in the command to which he was attached but controlled the assignment, relief or reassignment of those medical officers carrying the orthopaedic MOS number, and in addition recommended his up or down grading according to the officer's ability.

The orthopaedic work load was a stupendous one. There were never enough medical officers trained in this speciality available to meet the needs. Twenty per cent of all wounded sustained compound fractures and there were 598,000 wounded in the American Army. Yet 375,000 of these wounded were returned to duty overseas and more than 70,000 in the Zone of Interior. In addition there were thousands of musculoskeletal injuries incurred in accidents during training, transport and in combat requiring specialized care. Statistics are not available to me regarding the number of arthrotomies performed for intra-articular derangements, backs examined for pain or feet treated for sprain.

The fixation-traction splint for immobilization of the lower extremity developed by Thomas and introduced into World War I by Sir Robert Jones continued to be the life-saving splint in the second world war. We in America for various reasons prefer the Keller modification-the Army hinged half-ring splint-for transportation of fractures of the lower extremity from combat or the site of trauma to hospital and for suspension when skeletal traction is used in definitive care. As recorded in history, the Thomas splint alone reduced the mortality rate from 50 per cent to 15 per cent during transportation of gunshot fractures of the femur from the aid station to the casualty clearing station in the British Army in World War I.

As in World War I all wounds were thoroughly debrided, left open and drained with a light vaseline gauze pack. Plasma, whole blood and the antibiotics were of great assistance to the surgeon in the prevention of shock, the resuscitation of the patient and the prevention and control of infection in the wounded. After débridement, compound fractures were immobilized in well-padded plaster encasements for transfer to the orthopaedic service of a general hospital in the theatre. Air lift played an important role in this transportation in many theatres. On the third to fifth day after initial surgery and after the patient's arrival in the general hospital the plaster casing was removed from the fractured extremity. If the wound looked clean, cultures were not taken but closure by layers was accomplished where possible or a split-thickness skin graft was performed. Dependent drainage was established if the wound was through deep muscle tissues. If the wound looked " dirty" - if it contained

* As a member of the American Orthopaedic Association, Major-General Kirk had made notable contributions to bone-graft surgery and to the treatment of fractures before being called to take medical charge of the army. It is the first time in our history that an orthopaedic surgeon has been called to fill such a high military post : it is a source of pride to our speciality that he was called and that he acquitted himself so admirably-I. M.

VOL. $32 \mathrm{~B}$, No. 4 , NOVEMBER 1950 
dead tissue because of insufficient initial débridement-it was further débrided and placed back in plaster.

Skeletal traction with suspension from a Balkan frame was the method of choice in fractures of long bones. The compound fracture was thus converted into a simple one and with the aid of penicillin parenterally 86 to 90 per cent of the wounds healed by primary union. When the fracture became firm with proper length and alignment a plaster encasement was applied and the patient was ready for transfer to the Zone of Interior for definitive care and rehabilitation. The cast was removed on arrival and suspension traction continued until consolidation occurred while joints were being mobilized and muscles redeveloped. Internal fixation of fractures, particularly in the shaft of the femur, with metal plates and screws was done in certain cases at the time of "reparative" surgery, when the wound was healed. The end-results as seen in the General Hospital orthopaedic wards in the Zone of Interior were not as good as those following skeletal traction.

The hanging cast which gives excellent results in simple fractures of the humerus was not satisfactory in the open gunshot wound until after the wound had healed. Tendons and nerves healed better if their suture was delayed for some two to three weeks after healing of the wound. The guillotine or open circular amputation, popularized in the first world war, proved to be the operation of choice when amputation was necessitated because of trauma or for the control of infection. The open end of the stump, early in the war, was dusted with sulphonamides; later only vaseline gauze was used. Skin traction to the stump by sterile stockinet glued with " ace adherent" assisted in healing and gave ideal results if continued without interruption.

Centers were set up here at home in the sixty-five General Hospitals to give specialized care to the sick and wounded as they arrived from overseas theatres. Every General Hospital became an orthopaedic center with an orthopaedic section as part of the surgical service except in a few hospitals which treated medical or psychiatric patients only. Each of some 400 overseas hospitals and hospitals here at home had its orthopaedic section. There were in operation five amputation centers, fifteen neurosurgical, nine plastic, two vascular, five thoracic, two blind, three deafness, two arthritic centers and others. The orthopaedic surgeon played his part well in the team along with the neuro-surgeon, the urologist, the ward officer, the plastic surgeon, the nurse, the dietician and the ward man in the surgical care and rehabilitation of the 1,400 paraplegic patients.

Upon my personal request, Dr Sterling Bunnell of San Francisco became a civilian consultant and for two years taught the surgery of the crippled hand. A center in each service command was established at his request for this purpose. Medical officers known to him and others as skilled or interested in this type of surgery were transferred to these centers as were the more difficult hand cases. He estimated that 20,000 severe hand injuries occurred during the war years. A new or almost new orthopaedic speciality was born.

Infected wounds with chronic osteomyelitis were the exception rather than the rule in comparing patients of the two wars. Bone-grafting operations were possible two to three months after healing of the wound and the removal of all scar tissue rather than waiting six months or more, and the incidence of post-operative infection was minimal. This can be attributed to better and earlier initial surgery by well-trained surgeons, rapid evacuation, early closure of wounds, antibiotics, plasma and whole blood.

Eight thousand major amputations were treated in the five amputation centers; stumps were revised and concomitant wounds treated. Prostheses were fitted from the orthopaedic shop of the hospital after the stump had been prepared for fitting. With the aid of the Physical Therapy Department the patient was taught the use of the prosthesis and was rehabilitated with the aid of occupational therapy before discharge. All of this was the responsibility of the chief of the Amputation Service. Under the auspices of the National Research Council a prosthetic research project was initially set up by the Army in 1945 in which the Veterans' 
Administration later shared. This project still continues. Some $\$ 15,000,000$ has been expended to improve the prosthesis for the military and civilian amputee as well. Considerable improvement has been developed, particularly in the upper extremity prosthesis. The Navy and Army have each carried on their own research and development projects. The Army has developed a new hook and hand covered with a skin-appearing plastic along with an ingenious lever device which permits delivery of greater power than heretofore obtainable.

Orthopaedic surgery as we know it to-day had its birth in World War I and we might say became of age in the second world war. Many young men returned to civilian life from the Army well trained in bone and joint surgery by the able orthopaedic consultants and chiefs of orthopaedic services who served so well in the Medical Corps of the Army in World War II.

\title{
THE VETERANS' ADMINISTRATION HOSPITALS
}

\section{A Review of their Contribution to Orthopaedic Surgery since 1946}

\author{
Paul Magnuson, Chicago, Illinois
}

In the old days of the Veterans' Administration Medical Department specialists were created by edict: the manager of a hospital assigned a man to a speciality in which a specialist was needed. This did not involve particular consideration of such man's previous training or interest in that speciality, and certainly did not conform to any pattern that we now consider as adequate training.

On the introduction of the new medical program of the Veterans' Administration General Paul R. Hawley, then Chief Medical Director, called into consultation top bracket men in all the specialities of medicine and surgery. Dr Ralph Ghormley was the first Chief Consultant in orthopaedic surgery and he was succeeded by Dr Rex Diveley. This group was headed by Dr Elliott Cutler and each member was asked to recommend consultants in his own speciality in the different geographical branches of the Veterans' Administration. These men were known as branch consultants in their particular speciality. They in turn were asked to recommend individuals in their speciality to oversee that speciality in the various Veterans' Administration Hospitals, at that time numbering about 105 .

In addition to these consultants the approved Medical Schools of the country were asked to staff, as far as possible from their faculties of Medicine, hospitals located in their immediate vicinity, and in this case the Professor of Orthopaedic Surgery was usually made Chief Consultant to that hospital in that speciality. He in turn was asked to staff that hospital with his junior men and establish residency training in orthopaedic surgery. This was done promptly and so effectively and the cases admitted to the hospital were distributed so well, according to the various specialities, that no conflict arose among the specialities.

Orthopaedic surgery was considered a speciality of surgery and in no case as far as I know was there any conflict between the Chief of Orthopaedic Surgery and anyone else as to the distribution of cases. All bone and joint work was referred to the orthopaedic department, and the residents in general surgery, on orders from this office, were rotated for a six months' tour of duty through the orthopaedic department. The residents in orthopaedic surgery were given a year in general surgery before being admitted to residency in orthopaedic surgery. This was done by me, over some protest, because I have had a sincere feeling all my professional life that trying to make a specialist out of a man who has just finished his internship is a very short-sighted policy for the speciality involved. We are all surgeons and surgical principles should be thoroughly understood from every standpoint before a man specializes. We should all be diagnosticians and if it were possible I would have every surgeon, be he orthopaedic or other, have a year's internship or junior residency in internal medicine before he took up any speciality.

With this background of supervision by the top orthopaedic surgeons of the country, there has been developed in the Veterans' Administration the finest and broadest training in 
orthopaedic surgery that anybody could devise at this time. In the Veterans' Administration we can give only adult orthopaedic surgery. We have an agreement with the medical schools that after a year or two years of service as a resident in orthopaedic surgery in the Veterans' Administration a man may go to an orthopaedic hospital for a year's work for his training in children's orthopaedic surgery, and during that one year he will be paid by the Veterans' Administration. This arrangement provides two years of adult orthopaedic surgery with the Veterans' Administration and one year of children's orthopaedic surgery at a children's hospital under the supervision of the Professor of Orthopaedic Surgery in a medical school. Through the earnest and constant efforts of the teachers of orthopaedic surgery and the collaboration of the Academy of Orthopaedic Surgeons and the American Board of Orthopaedic Surgery this has worked out to the great advantage of the young men interested in this speciality. At this time, some five years after the start of the program, a number of the men have finished their residencies in the Veterans' Administration or elsewhere and are serving as Chiefs of Orthopaedic Surgery in our various hospitals.

In our smaller institutions of 200 to 300 beds we cannot carry on our residency training program but by agreement with the American Board of Orthopaedic Surgery young men may go to these smaller hospitals as ward surgeons in orthopaedic surgery, where they really act as chiefs of that speciality, for two years of practice in their speciality in order to complete their Board requirements. The Veterans' Administration has agreed to see that a Board Certified Consultant in orthopaedic surgery attends that hospital at least once a month to look over the young men's work and make an estimate of their honesty, the quality of their work in surgery and their judgment. In other words, they are these young men's sponsors for the two years of practice. All this is on a completely voluntary basis and it has nothing to do with the Military; it is run on the basis of the free, independent practice of medicine. We have no authority to hold any man anywhere.

We have taken the highest standards set by the medical profession as our own and we require the maintenance of these standards. There is no effort to send out orders from Washington as to how cases shall be treated, except to constantly call attention to the standards that have been set. This has offered a magnificent training to many young men, at the same time paying them a stipend: if they are veterans, $\$ 3,300$ a year which does not include their board and room. When they become ward officers they become full-time employees of the Veterans' Administration at a grade which is determined by a Professional Standards Board and their previous record is one of the things that affects the grade under which they are employed. They are free to resign on the day after they are employed; they do not hold a commission; and they are allowed to consult with the doctors in their community if they are called, and to accept a fee for that service, but they cannot practice medicine in an office of their own or accept remuneration other than consultation fees.

In order to give the orthopaedic surgeon what he needed in the way of apparatus it was found necessary to establish brace shops in many of our hospitals. These brace shops are under the control of the Chief of Orthopaedic Surgery. Bracemakers have been trained in large numbers to satisfy the needs of the profession. In addition to this, thirty centers have been established for services to amputees. These centers are under the control of orthopaedic surgeons who have had special experience and have taken courses offered in various types of artificial limb making, fitting and design. The amputee is assigned to the Department of Orthopaedic Surgery. The Army, the American Academy of Orthopaedic Surgeons and the Veterans' Administration are collaborating in the preparation of an atlas of braces which is now nearing completion. This will cover the making, fitting and taking of molds for brace fittings. It will include specifications of materials and information as to where the bracemaker may purchase these materials from suppliers; and will serve as a means of bringing the bracemaker and the orthopaedic surgeon to an understanding so that they can both talk the same language from a thoroughly indexed catalog. So far as we know, this has never been 
done and will be of great assistance to all concerned in the making and fitting of braces of the right kind to the disabled patient.

In addition to this the Veterans' Administration furnishes research laboratories to which the orthopaedic surgeons have free access and the help of many scientists in allied branches, such as chemistry, psychology and pathology. Many outstanding reports have come from these research laboratories which also act as a great stimulus for the young men who want to know why as well as how.

\section{REHABILITATION}

\section{Howard Rusk, New York}

[Rehabilitation owes more to Sir Robert Jones than to any other orthopaedic surgeon. It was his warm sympathy for the disabled and his amazing practicality which started the great movement in England during the first world war. To quote his own words, already cited in this paper, "My feeling is that the heroic spirit that sent our beloved dead to their end, should be reflected in an equally heroic effort on our part to make and keep the nation efficient."

At this time, we must not forget the name of that remarkable man, Konrad Biesalski, who in 1914 inaugurated a program for Germany's war cripples similar to Sir Robert Jones's in England. During the interval between the two world wars rehabilitation flagged, but during the second world war it sprang into new life, in England largely under the inspiration of our distinguished editor, Sir Reginald Watson-Jones; in America under the guidance of Dr Howard Rusk, who by virtue of his achievements has been made the first Professor of Rehabilitation in America at the New York University Medical School-L. M.]

Without doubt much of the present growth of interest in extending rehabilitation opportunities and services to the handicapped has resulted both directly and indirectly from war. Such advances, however, are not entirely due to the impetus of war, for the growth of rehabilitation opportunities and services to the handicapped is a part of a total pattern of an expanding national and community consciousness of social welfare which is reflected in similar advances in all education, health and social services.

Immediately after World War I, as to-day, there was a developing interest in increasing rehabilitation opportunities for the physically disabled. Unfortunately much of this interest died in the years between the wars. From it, however, did come some pioneer institutions and some needed legislation such as the Federal-State vocational rehabilitation programs. Even before this workmen's compensation laws enacted in several states prior to 1920 had given official recognition to the growing belief in the responsibility of society for the welfare of injured workmen and revealed the necessity for further legislation designed to restore to disabled persons the earning power lost as a result of industrial accidents.

World War I created a problem of national importance in that the large number of disabled veterans had a clear moral claim upon the nation and the government in whose behalf they had sustained their injuries. In recognition of their needs Congress passed the Smith-Sears Soldiers' Rehabilitation Act of June 1918. This was followed in 1920 by the Fess-Kenyon Act providing for " the vocational rehabilitation of persons disabled in industry or otherwise and their return to civil employment." The primary feature of both of these acts was the provision of vocational counselling and training for the disabled person. No provision was made for physical restoration or reducing the physical disabilities of the trainees. Such restrictions made it impossible for the state vocational rehabilitation programs operating under the Federal Office of Vocational Rehabilitation to give adequate service to their clients. Until medical services were made a part of the program by the Barden-La Follette Amendment of 1943 , in twenty-three years only 210,000 persons were rehabilitated, although over a million persons were in need of such aid at any given time during that period.

Under the Walsh-Clark-Rankin Act of March 1943 disabled veterans of World War II were provided with vocational counselling, vocational training and subsistence payments while undergoing such training. The medical and physical rehabilitation aspects of the

VOL. $32 \mathrm{~B}$, NO. 4 , NOVEMBER 1950 
veterans' program are provided by the Physical Medicine Rehabilitation Services established in all Veterans' Administration hospitals. Under these programs the disabled veteran is receiving the full advantages of all modern techniques and methods of rehabilitation.

Although the focus of attention has been centered on the disabled veterans, the extent of disability among our civilian population is far greater. There were 20,500 amputations during World War II among military personnel, but over 120,000 civilians suffered major amputations during the same period. Some 265,000 men were permanently disabled as a result of combat injuries during the war, but $1,250,000$ civilians were permanently disabled by disease and accidents in the same period. There are some $23,000,000$ persons in the United States who are handicapped to some extent by disease, accident, maladjustment or war. Not all of these would need rehabilitation, but it is estimated that over 2,000,000 persons need such services if they are to be employable. Through the efforts of the Baruch Committee on Physical Medicine and Rehabilitation, the National Foundation for Infantile Paralysis, the National Society for Crippled Children and Adults, and other voluntary and public agencies, increasing attention is being devoted to the provision of rehabilitation-the third phase of medicine which takes the patient from the bed to the job. One of the most significant recent developments is the increase in training in physical medicine and rehabilitation given to both undergraduate and postgraduate students. The American Board of Physical Medicine and Rehabilitation has been granted speciality status and a section on Physical Medicine and Rehabilitation has been created in the American Medical Association.

With the growing incidence of chronic disease and its resultant physical disability, it can be expected that the prevalence of physical disability in this nation will increase rather than decrease in the future. A thousand years ago the average length of life was twenty-five years; at the turn of the century it was forty-nine; to-day it is sixty-six and five-tenths. In 1900 one person in twenty-five was sixty-five years of age or older; it is estimated that in 1980 the ratio will be one in ten.

Lacking specific measures for the cure of many of the chronic diseases, medicine must look to rehabilitation to teach those afflicted with chronic disability to live and to work as effectively as possible with what they have left. Until medicine finds the specific answers to the problems of the diseases of the heart and circulation, rheumatic fever and arthritis, cerebral palsy, multiple sclerosis, poliomyelitis and other crippling diseases, it must utilize the techniques of physical rehabilitation, vocational guidance, psychology, social service and other ancillary specialities of rehabilitation to teach the disabled to live within the limits of their disabilities but to the hilt of their capabilities.

THE COMMITTEE ON ARTIFICIAL LIMBS OF THE NATIONAL RESEARGH GOUNGIL

\section{Rufus Aldredge, New Orleans, Louisiana}

During World War II, at the request of the Surgeon-General of the Army, the Committee on Prosthetic Devices was set up by the National Research Council to study artificial limbs and to carry out research work to the end of improving prostheses in general. The Committee was composed of several orthopaedic surgeons and several physicists, engineers and other scientists, who immediately set to work to reach some common point of agreement as to what needed to be done in completing the great task ahead. Together they visited the various war-time amputation centers, inspecting the amputation problems first hand from the aspects of the requirements of the patient, of the individual amputation stumps, as well as the prosthetic needs and shortcomings with a view to proceeding with research and development to eventually improve the prosthetic appliance.

After some time and effort the committee decided that the best approach would be to develop contracts with various universities, industries and individuals throughout the country 
who would work on special problems. As a result, many different groups of men throughout the country became interested and carried out research and development work in the various phases of the amputation problem with regard to the prosthesis.

Early in 1946 a group of orthopaedic surgeons, engineers and physicists were sent to Europe to visit the various leading European Centers in an effort to determine if any new or improved methods regarding amputations and artificial limbs were being used which were not already known about. Of outstanding interest to the research effort reported by the European Commission was the development of the cineplastic method for upper extremity amputations and the suction socket prosthesis for the lower extremity amputations, particularly amputations above the knee. The Committee on Artificial Limbs immediately set to work with research and development projects on the suction socket prosthesis and the cineplastic method and as a result, after four years of trial, there has been great improvement in the cineplastic prosthesis, and the suction socket prosthesis for above the knee amputations has been tested and proved to be a great advance.

There have been many other contributions to the entire problem of amputations and artificial limbs, including basic and fundamental research work on anatomy, physiology and function of the normal muscles of the extremities, as well as those of amputated extremities. The results of this work have been used by all of the research and developmental workers as a basis upon which to guide their research problems in artificial limbs.

The work of the original committee is still under way in co-operation with the Veterans' Administration, and the new and improved products which have been developed by the individual researchers have been thoroughly tested on selected amputee subjects before their release for general use. Some of the newly developed prosthetic aids are still under testing and development at various centers throughout the country.

\section{SUMMARY}

In the welter of details contained in the preceding pages the reader has, I trust, perceived certain broad shining pathways leading towards our orthopaedic lode-star, the adequate treatment of all the crippled and disabled of our community-adults and children, rich and poor. These are, as I see them, four in number: first, the emergence of our speciality from a tiny beginning, against the opposition of general surgery, to the position of an accepted branch of surgery secure in the support of all the branches of medical science. Second, the development not only of technical skill but of a humanitarian spirit which has resulted in the adequate care of the crippled child and, to a lesser degree, of the crippled adult. Third, the growth of educational facilities for undergraduate and postgraduate instruction and for research. Finally, the integration of orthopaedic surgery with all those progressive elements in the community which aim to democratize our efforts on behalf of the disabled.

This paper could not have been written without the co-operation of many friends to whom I gratefully acknowledge my indebtedness. My thanks are due particularly to the following:

For contributions: Dr LeRoy Abbott, Dr Rufus Aldredge, Dr Carl Badgley, Dr Joseph Barr, Dr Harry C. Blair, Dr Walter P. Blount, Dr Aaron Bodansky, Dr Joseph A. Boyes, Dr Jospeh Buchman, Dr Michael Burman, Dr John Cobb, Dr Edward L. Compere, Miss Dorothy Ducas, Dr G. W. N. Eggers, Dr Jospeh Freiberg, Dr Ralph Ghormley, Dr H. Bruce Gill, Dr Joel E. Goldthwait, Dr William T. Green, Dr Verne T. Inman, Dr Henry Jaffe, Dr Abel Kenin, Dr Norman Kirk, Dr Hiram Kite, Dr Barmard Kleiger, Dr H. R. McCarroll, Dr Henry Milch, Dr J. T. Nicholson, Dr Robert G. Packard, Dr Charles W. Peabody, Dr Winthrop Phelps, Dr Howard Rusk, Dr A. R. Shands, Dr John A. Siegling, Dr Otto Steinbrocker, Dr Arthur Steindler, Dr Charles Sutro, Dr Vernon P. Thompson, Dr Allen F. Voshell, Dr Samuel M. Wishik.

For the loan or donation of photographs: Mrs Fred Albee, Dr Rodney F. Atsatt, Miss Florence Daland, Dr G. W. N. Eggers, Dr Jospeh Freiberg, Dr William Green, Dr Samuel Kleinberg, Dr H. R. McCarroll, Dr Paul Magnuson, Dr Jesse T. Nicholson, Dr Edwin W. Ryerson, Dr A. R. Shands, Dr Alan DeForest Smith, Dr James Speed.

To my son-in-law, Lloyd McKean, for his symbolic drawing of the growth of American Orthopaedic Surgery.

For help in preparation of the manuscript: Miss Amelia Mater, Mrs Esther Ney.

For advice and encouragement: Dr William Rogers and Miss Florence Daland.

vol. $32 \mathrm{~B}$, No. 4 , NOVEMBer 1950 


\section{REFERENCES}

\section{Part I}

Brackett, E. G., (1891): Atrophy in Joint Disease. Transactions of the American Orthopedic Association, 4,61 .

Brackett, E. G. (1897): Gluteal Bursitis. Transactions of the American Orthopedic Association, 10, 123. BRADFORD, E. H. (1889): Treatment of Club-foot. Transactions of the American Orthopedic Association, $1,89$.

Bradford, E. H. (1895): Slipping Patella. Transactions of the American Orthopedic Association, 8, 228. BradFord, E. H. $(1894,1900,1902)$ : Congenital Dislocation of the Hip Joint. Transactions of the American Orthopedic Association, 7, 88; 13, 124 ; and 15, 284.

Bradford, E. H. (1902): Shoe Deformities. Transactions of the American Orthopedic Association, 15, 321. Bradford, E. H., and Stone, J. S. (1899): The Seating of School Children. Transactions of the American Orthopedic Association, 12, 170.

Bryant, J. D. (1891): Ten Cases of Excision of the Knee Joint for Disease, and their Lessons. Transactions of the American Orthopedic Association, 4, 314.

Brown, D. (1894): A Case of Ankylosis of the Jaw in a Child. Transactions of the American Orthopedic Association, 7, 306.

DANE, J. (1902): Remarks on Arthrodesis of the Ankle for Infantile Paralysis. Transactions of the American Orthopedic Association, 15, 29.

DAvis, G. G. (1900): An Operation for Ununited Intracapsular Fracture of the Neck of the Femur. Transactions of the American Orthopedic Association. 13, 134.

Foster, C. C. (1891): Extension in Bed in the Treatment of Caries of the Spine. Transactions of the American Orthopedic Association, 4, 258.

Gibney, V. P. (1894): The Correction of the Deformity of Hip-Disease. Transactions of the American Orthopedic Association, 7, 190.

Gillette, A. J. (1898): An Operation for Ununited Fracture of the Neck of the Femur. Transactions of the American Orthopedic Association, 11, 241.

Goldthwait, J. E. (1892): Joint Lesions due to Spinal Disease. Transactions of the American Orthopedic Association, 5, 84.

Goldthwait, J. E. (1894): Anterior Transverse Arch Proven by Frozen Section. Transactions of the American Orthopedic Association, 7, 82.

Goldthwait, J.E. (1895): Tendon Transplantation in the Treatment of Paralytic Deformities. Transactions of the American Orthopedic Association, 8, 20.

Goldthwait, J. E. (1900): Knee-joint Surgery for Non-tubercular Conditions. Boston Medical and Surgical Journal, 143, 286.

HADRA, B. E. (1891): Wiring the Spinous Processes in Pott's Disease. Transactions of the American Orthopedic Association, 4, 206.

Hodgen, H. (1892): Peripheral Neuritis and Scapular Brace. Transactions of the American Orthopedic Association, 5, 148.

Jones, C. N. D. (1889): Etiology and Pathology of Rachitic Deformity. Transactions of the American Orthopedic Association, 1, 242.

Judson, A. B. (1891): President's Address: Orthopedic Surgery as a Speciality. Transactions of the American Orthopedic Association, 4, 1.

Keтch, S. (1897): President's Address: Summary of Papers of its First Ten Years. Transactions of the American Orthopedic Association, 10, 1.

Lorenz, A. (1894): The operative Treatment of Congenital Dislocation of the Hip Joint. Transactions of the American Orthopedic Association, 7, 99.

Lorenz, A. (1896): Cure of Congenital Luxation of the Hip by Bloodless Reduction and Weighting. Transactions of the American Orthopedic Association, 9, 254.

Lovert, R. W. (1897): Spondylolisthesis with Description of a Case. Transactions of the American Orthopedic Association, 10, 20.

Lovetr, R. W. (1897): Late Excision of the Hip. Transactions of the American Orthopedic Association, $10,55$.

Lovetr, R. W. (1898) : President's Address: Pathology in its Relation to Orthopedic Surgery. Transactions of the American Orthopedic Association, 11, 1.

Lovert, R. W. (1900): The Mechanics of Lateral Curvature of the Spine. Transactions of the American Orthopedic Association, 13, 251. 
I.ovetr, R. W., and Cotron, F. J. (1898): Some Practical Points in the Anatomy of the Foot. Transactions of the American Orthopedic Association, 11, 298.

Lovett, R. W., and Goldthwait, J. E. (1889): The Abscesses of Hip Disease. Transactions of the American Orthopedic Association, 2, 82.

McKenzie, B. E. (1901): Neurosis as seen in Orthopedic Practice. Transactions of the American Orthøpedic Association, 14, 24.

Moore, J. E. (1892): A Report of Six Cases of Excision of the Knee Joint. Transactions of the American Orthopedic Association, 5, 140.

Moore, J. E. (1895): Pigeon-toe. Transactions of the American Orthopedic Association, 8, 254.

Nichols, E. H. (1898): Tuberculosis of Bones and Joints. Transactions of the American Orthopedic Association, 11, 353.

PAckard, G. B. (1898): Observations upon Tubercular Joint Disease in Colorado. Transactions of the American Orthopedic Association, 11, 164.

PARK, R. (1895): On the Deformities and Malformations Resulting from Acute Infections in Bone. Transactions of the American Orthopedic Association, 8, 102.

Phelps, A. M. (1894): President's Address: The Influence of Surgical Bacteriology and Modern Pathology upon Orthopedic Surgery. Transactions of the American Orthopedic Association, 7, 31.

Plimpton, W. O. (1895): Excision of Knee as an Orthopedic Procedure. Transactions of the American Orthopedic Association, 8, 187.

SAYRE, R. H. (1889): Excision of the Hip Joint. Transactions of the American Orthopedic Association, 2, 153.

SAYRE, R. H. (1893): A Contribution to the Study of Club-hand. Transactions of the American Orthopedic Association, 6, 208.

Sherman, H. M. (1893): The Question of Excision of the Hip Joint for Tubercular Disease and the Results of the Operation. Transactions of the American Orthopedic Association, 6, 120.

Sherman, H. M. (1900): President's Address: Transactions of the American Orthopedic Association, $13,1$. Steele, A. J. (1893): President's Address: The Embodiment of an Idea. Transactions of the American Orthopedic Association, 6, 7.

Steele, A. J. (1898): Hallux Valgus Extremus. Transactions of the American Orthopedic Association, $11,17$. TAYLOR, H. L. (1894): Infantile Scorbutus and its Relation to Orthopedic Practice. Transactions of the American Orthopedic Association, 7, 129.

TAYLOR, H. L. (1899): Enlargement of Tibial Tubercles. Transactions of the American Orthopedic Association, 12, 138.

Tномson, C. E. (1901): Operative Case of Intracapsular Fracture of the Hip. Transactions of the American Orthopedic Association, 14, 361.

Townsend, W. R. (1889): Acute Arthritis of Infants. Transactions of the American Orthopedic Association, 2, 260.

Townsend, W. R. (1900): Tendon Transplantation in the Treatment of Deformities of the Hand. Transactions of the American Orthopedic Association, 13, 193.

VANCE, AP M. (1889): Femoral Osteotomy for the Correction of Deformity Resulting from Hip-joint Disease. Transactions of the American Orthopedic Association, 1, 149.

Weigel, L. A. (1899): The Diagnostic Value of Radiography in Orthopedic and General Surgery. Transactions of the American Orthopedic Association, 12, 76.

Whitman, R. (1889): Observations on Seventy-five Cases of Flat-foot with Particular Reference to the Treatment. Transactions of the American Orthopedic Association, 1, 122.

Whitman, R. (1894): Observations on Bending of the Neck of the Femur in Adolescence. Transactions of the American Orthopedic Association, 7, 270.

Whitman, R. (1895): A Study of the Weak Foot. Transactions of the American Orthopedic Association, 8, 42. Whitman, R. (1896): President's Address: A Definition of the Scope of Orthopedic Surgery. Transactions of the American Orthopedic Association, 9, 1.

Whitman, R. (1897): Further Observations on Fracture of the Neck of the Femur in Childhood. Transactions of the American Orthopedic Association, 10, 216.

Whitman, R. (1898): Observations on Morton's Painful Affection of the Fourth Metatarso-phalangeal Articulation. Transactions of the American Orthopedic Association, 11, 34.

Willard, De F. (1889): Osteotomy for Anterior Curvatures of the Leg. Transactions of the American Orthopedic Association, 1, 138.

Willard, DE F. (1893): Operative Treatment of Knee-Joint Disease. Transactions of the American Orthopedic Association, 6, 23.

Willard, De F. (1900): President's Address: Transactions of the American Orthopedic Association, $3,1$. Wilson, H. A. (1902): President's Address: The Advance of Orthopedic Surgery. Transactions of the American Orthopedic Association, 15, 1.

vol. 32 B, No. 4, NOVEMBer 1950 


\section{Part III}

Аввотт, E. G. (1917): Scoliosis. American Journal of Orthopedic Surgery, 15, 26; 15, 108; 15, 172; 15, 243; 15,362 .

Albee, F. (1911): Transplantation of a Portion of the Tibia into the Spine for Pott's Disease. Journal of the American Medical Association, 57, 885.

Albee, F. (1913): An Experimental Study of Bone Growth and the Spinal Bone Transplant. Journal of the American Medical Association, 60, 1044.

AlBeE, F. (1914): The Inlay Bone Graft Growth in Fresh Fractures. New York Medical Journal, 99, 1020. Albee, F. (1916): A Statistical Study of 539 Cases of Pott's Disease treated by the Bone Graft. American Journal of Orthopedic Surgery, 14, 134

Allison, N. (1905): A Study of the Anatomy of Congenital Dislocation of the Hip after Manipulative Reduction. American Journal of Orthopedic Surgery, 3, 157.

Allison, N. (1915) : Tuberculosis of the Hip. American Journal of Orthopedic Surgery, 12, 623.

Allison, N., and Brooks, B. (1918): Arthroplasty: Experimental and Clinical Methods. American Journal of Orthopedic Surgery, 16, 83.

Allison, N., and Moody, E. F. (1915): Osteochondritis Deformans Juvenilis (Perthes Disease). American Journal of Orthopedic Surgery, 13, 197.

Allison, N., and SchwaB, S. I. (1910): Muscle Group Isolation and Nerve Anastomosis in the Treatment of the Paralysis of the Extremities. American Journal of Orthopedic Surgery, 8, 95.

ARNOLD, E. H. (1916): Fixation of the Sacrum. American Journal of Orthopedic Surgery, 14, 574.

BAer, W. S. (1909): A Preliminary Report of the Use of Animal Membrane in Producing Mobility in Ankylosed Joints. American Journal of Orthopedic Surgery, 7, 1.

BaER, W. S. (1918): Arthroplasty with the Aid of Animal Membrane. American Journal of Orthopedic Surgery, 16, 94.

BAKER, E. M. (1918): Opportunities for Social Service in an Orthopaedic Clinic. American Journal of Orthopedic Surgery, 16, 34.

BARRIE, G. (1918): Hemorrhagic Osteomyelitis and Sarcoma in Bone. American Journal of Orthopedic Surgery, 16, 392 .

BArtow, B., and Plummer, W. W. (1911, 1913, 1916): The Use of Intra-articular Silk Ligaments for Fixation of Loose Joints in the Residual Paralysis of Anterior Poliomyelitis. American Journal of Orthopedic Surgery, 9, 65; 10, 499; 14, 594.

Blanchard, W. (1906): The Exceptional Rachitic Distortions of the Legs. American Journal of Orthopedic Surgery, 4, 207.

Blanchard, W., and Parker, C. A. (1915): A Resection of the Transverse Process of the Fifth Lumbar Vertebra for the Relief of Painful Back. American Journal of Orthopedic Surgery, 13, 250.

BLodgetr, W. E. (1905) : Congenital Luxation of the Head of the Radius. American Journal of Orthopedic Surgery, 3, 253.

Brackett, E. G. (1905): President's Address. American Journal of Orthopedic Surgery, 3, 1.

Brackett, E. G. (1910): Study of the Relation Between Clinical Evidence and Pathological Conditions in Spinal Caries. American Journal of Orthopedic Surgery, 8, 362.

Brackett, E. G. (1915): Operative Treatment of Osteoarthritis, American Journal of Orthopedic Surgery, 13, 46.

Brackett, E. G., and Hall, C. L. (1917): Osteochondritis Dissecans. American Journal of Orthopedic Surgery, 15, 79.

BrickNer, W. M. (1912): Abduction Treatment of Shoulder. American Journal of Surgery, 26, 196; American Journal of the Medical Sciences, 149, 351; Medical Record, 87, 15.

Bucholz, C. H. (1914): Further Studies of the So-called " Sciatic Scoliosis." American Journal of Orthopedic Surgery, 12, 90.

Bucholz, C. H. and Osgood, R. B. (1914): A Frame for Standardizing Photographic Records of Scoliosis. American Journal of Orthopaedic Surgery, 12, 77.

Campbell, W. C. (1917): An Analysis of Fifty-one Bone and Joint Affections Treated by Heliotherapy, with Special Reference to Tuberculosis. American Journal of Orthopedic Surgery, 15, 1.

Codivilla, A. (1903): On the Means of Lengthening, in the Lower Limbs, the Muscles and Tissues which are Shortened through Deformity. American Journal of Orthopedic Surgery, 2, 353.

Codman, E. A. (1906): On Stiff and Painful Shoulders. Boston Medical and Surgical Journal, 154, 613.

Codman, E. A. (1934): The Shoulder. Boston: Privately printed.

Coon, C. E. (1911): Dyschondroplasia. American Journal of Orthopedic Surgery, 9, 604.

Cotron, F. J. (1911): Artificial Impact in Hip Fracture. American Journal of Orthopedic Surgery, 8, 680. Cotton, F. J., and Henderson, F. F. (1916): Results of Fracture of the Os Calcis. American Journal of Orthopedic Surgery, 14, 290. 
Davis, G. G. (1905): Multiple Cancellous Exostoses. American Journal of Orthopedic Surgery, 3, 234

Davis, G. G. (1913): The Treatment of Hollow Foot (Pes Cavus). American Journal of Orthopedic Surgery, 11, 23.

Davis, G. G. (1914): The Education of Crippled Children. American Journal of Orthopedic Surgery, $12,1$. Dunlop, J. (1907): Further Studies of the Relaxation of the Sacro-iliac Synchondroses. American Journal of Orthopedic Surgery, 5, 101.

Dunlop, J. (1911) The Adolescent Tibial Tubercle. An Anatomical and Pathological Study. American Journal of Orthopedic Surgery, 9, 313.

Elliotr, G. R. (1905): Rigid Spine. American Journal of Orthopedic Surgery. 3, 303.

Elliott, G. R. (1912): An X-ray Study of Gastro-intestinal Findings in Multiple Arthritis. American Journal of Orthopedic Surgery, 10, 56.

ELY, L. W. (1911): Joint Tuberculosis in Children. American Journal of Orthopedic Surgery, 9, 31.

ELY, L. W. (1912): The Etiology of Chronic Non-tuberculous Arthritis. American Journal of Orthopedic Surgery, 10, 171.

ELY, L. W. (1913): The Pathology of Tabetic Arthropathy: Preliminary Study of Two Cases. American Journal of Orthopedic Surgery, 11, 404.

ERLAcher, P. (1915): Direct and Muscular Neurotization of Paralyzed Muscles. American Journal of Orthopedic Surgery, 3, 22.

FEISS, H. O. $(1906,1907)$ : The Mechanics of Lateral Curvature. American Journal of Orthopedic Surgery, 4,$37 ; 4,323 ; 5,152$.

Fisher, A. L. (1916): Torticollis-A Review. American Journal of Orthopedic Surgery, 14, 669.

Förster, O. (1908): Über eine neue operative Methode der Behandlung spastischer Lähmungen mittels Resektion hinterer Rückenmarkswurzeln. Zeitschrift für Orthopädische Chirurgie, 22, 203.

FreiberG, A. H. (1905): Coxa Vara Adolescentium and Osteoarthritis Deformans Coxae. American Journal of Orthopedic Surgery, 3, 6.

FreiberG, A. H. (1913): Corrective Jackets in the Treatment of Structural Scoliosis with Especial Reference to Mensuration and Record. American Journal of Orthopedic Surgery, 11, 29.

FreiberG, A. H. (1914): Infraction of the Second Metatarsal Bone. Surgery, Gynecology and Obstetrics, 19, 191.

FReiberg, A. H. (1914): Editorial: Scoliosis. American Journal of Orthopedic Surgery, 12, 183.

FreiberG, A. H. (1937): Orthopedic Surgery in the Light of Its Evolution. Journal of Bone and Joint Surgery, 19, 279.

Freiberg, A. H., Silver, D., and Osgood, R. B. (1914): Report of the Committee on the Treatment of Structural Scoliosis to the American Orthopedic Association. American Journal of Orthopedic Surgery, $12,5$. Freiberg, A. H., Silver, D., and Osgood, R. B. (1915): Second Report of the Committee on the Treatment of Structural Scoliosis to the American Orthopedic Association. American Journal of Orthopedic Surgery, $13,6$.

Freiberg, A. H., and Woolley, P. G. (1910): Osteochondritis Dissecans: Concerning its Nature and Relation to Formation of Joint Mice. American Journal of Orthopedic Surgery, 8, 477.

Gaenslen, F. J. (1915): Osteitis Deformans (Paget's Disease). American Journal of Orthopedic Surgery, $13,96$.

Gallie, W. E. (1914): The History of a Bone Graft. American Journal of Orthopedic Surgery, 12, 201.

Gallie, W. E. (1917): How Canada is Caring for her Crippled Soldiers. American Journal of Orthopedic Surgery, 15, 547. (Unsigned Article.)

Gallie, W. E., and Le Mesurier, A. B. (1922): A Clinical and Experimental Study of the Free Transplantation of Fascia and Tendon. Journal of Bone and Joint Surgery, 4, 600.

GeIST, E. S. (1907): Chondrodystrophia Foetalis. American Journal of Orthopedic Surgery, 5, 240.

Gibney, V. P. (1905): A Report of the Adult Ward of the Hospital for the Ruptured and Crippled for the First Two Years Ending March 1, 1905. American Journal of Orthopedic Surgery, 3, 178.

Gillette, A. J. (1909): Editorial. American Journal of Orthopedic Surgery, 6, 723.

Goldthwait, J. E. (1905, 1907, 1911): Anatomic Explanation of Weak or Painful Back. Boston Medical and Surgical Journal, 152, 280. Journal of the American Medical Association, 49, 768. Boston Medical and Surgical Journal, 164, 365.

Goldthwait, J. E. (1909): The Relation of Posture to Human Efficiency and the Influence of Poise Upon the Support and Function of the Viscera. American Journal of Orthopedic Surgery, 7, 371.

Goldrhwait, J. E. (1916): The Opportunity for the Orthopedist in Preventive Medicine through Eductaional Work on Posture. American Journal of Orthopedic Surgery, 14, 443.

HaAs, S. L. (1917): Relation of the Blood Supply to the Longitudinal Growth of Bone. American Journal of Orthopedic Surgery, 15, 157, 305.

Hammond, R. (1911): A Roentgenologic Study of some Brittle Bones. American Journal of Orthopedic Surgery, 9, 615 .

vol. 32 B, No. 4, NOVember 1950 
Hartwell, J. B. (1916): Fractures of the Spine without Paraplegia. American Journal of Orthopedic Surgery, 14, 82.

HAwLEy, G. W. (1917): Bone and Joint Infections Treated by the Carrel Technique. American Journal of Orthopedic Surgery, 15, 586.

HENDERSON, M. S. (1914): Transplantation of Bone in Ununited Fractures. Lancet, 34, 615.

Henderson, M. S. (1917): Osteochondromatosis of the Knee Joint. American Journal of Orthopedic Surgery, 15, 351.

Henderson, M. S. (1918): What are the Real Results of Arthroplasty ? American Journal of Orthopedic Surgery, 16, 30.

HibBs, R. A. (1911): An Operation for Progressive Spinal Deformities. New York Medical Journal, 93, 1013.

Ноке, M. (1903): Lateral Curvature Rib Resection Operation Both Sides. American Journal of Orthopedic Surgery, 1, 168.

Hoke, M. (1911): An Operative Plan for the Correction of Relapsed and Untreated Talipes Equinovarus. American Journal of Orthopedic Surgery, 9, 379.

Hoke, M. (1921): An Operation for Stabilizing Paralytic Feet. Journal of Orthopedic Surgery, N.S. 3, 494. Honeij, J. A. (1917): Bone Changes in Leprosy. American Journal of Roentgenology, 4, 494.

Horwirz, A. E. (1908): Congenital Elevation of the Scapula-Sprengel's Deformity. American Journal of Orthopedic Surgery, 6, 260.

Horwitz, A. E. (1909): Adolescent Rachitis. Etiology and Pathology. American Journal of Orthopedic Surgery, 7, 199.

Hunkin, S. J. (1913): Experience with Foerster's Operation. American Journal of Orthopedic Surgery, $11,207$.

JAEger, C. H. (1908): Gonorrhoeal Exostoses of the Os Calcis. American Journal of Orthopedic Surgery, 5, 304.

Jones, R. (1907): An Operation for Paralytic Calcaneo-cavus. American Journal of Orthopedic Surgery, $5,371$.

Jones, R. (1913): An Orthopedic View of the Treatment of Fractures. American Journal of Orthopedic Surgery, 11, 314.

Jones, R. (1918): The Problem of the Disabled. American Journal of Orthopedic Surgery, 16, 273.

Jones, S. F. (1911): Bilateral Congenital Dislocation of the Lower End of the Ulna. American Journal of Orthopedic Surgery, 9, 199.

LANGE, F. (1910): The Orthopedic Treatment of Spinal Paralysis. American Journal of Orthopedic Surgery, 8, 8.

LANGE, F. (1910): Support for the Spondylitic Spine by Means of Buried Steel Bars, Attached to the Vertebrae. American Journal of Orthopaedic Surgery, 8, 344.

LEGG, A. T. (1908): The Cause of Atrophy in Joint Disease. American Journal of Orthopedic Surgery, 6, 84. Lovetr, R. W. (1906): Intermittent Limping (Myasthenia Angio-Sclerotica). American Journal of Orthopedic Surgery, 4, 120.

Lovetr, R. W. (1918): The Problem of the Reconstruction and Re-education of the Disabled Soldier. Surgery, Gynecology and Obstetrics, 27, 169.

Lovetr, R. W., and Martin, E. G. (1916): The Spring Balance Muscle Test. American Journal of Orthopedic Surgery, 14, 415.

Low, H. C. (1914): A Study of the Scope and Efficiency of a Large Orthopedic Clinic. American Journal of Orthopedic Surgery, 12, 396.

MAYER, L. (1916): The Physiological Method of Tendon Transplantation. Surgery, Gynecology and Obstetrics, 22, 182; 22, 298; 22, 472.

MAYer, L., and Wehner, E. (1914): An Experimental Study of Osteogenesis. American Journal of Orthopedic Surgery, 12, 213.

McMurtrie, D. C. (1911): The Care of Crippled Children in the United States. American Journal of Orthopedic Surgery, 9, 527.

Meisenbach, R. O. (1910): A Consideration of the Chemical and Mechanical Stimulation of Bone with Reference to the Epiphysial and Diaphysial Lines. American Journal of Orthopedic Surgery, 8, 28.

Meisenbach, R. O. (1911): A Pelvi-thoracic Triangle as a Means of Recording Spinal Lateral Curvature. A Scoliometer. American Journal of Orthopedic Surgery, 9, 690.

MURPhy, J. B. (1912): Contribution to the Surgery of Bones, Joints and Tendons. Journal of the American Medical Association, 58, 985.

Nathan, P. W. (1906): Differential Diagnosis of Arthritis. American Journal of the Medical Sciences, 132, 857.

Nathan, P. W., and Strang, W. W. (1909): The Joint Cartilage in its Relation to Joint Pathology. American Journal of Orthopedic Surgery, 7, 85. 
Ober, F. (1916): An Operation for Congenital Equinovarus Deformity. Journal of the American Medical Association, 65, 621 .

ORR, H. W. (1911): Reasons for the State Care of the Crippled and Deformed. American Journal of Orthopedic Surgery, 9, 218.

Osgood, R. B. (1903): The Value of X-ray Negatives in the Study of Orthopedic Pathology. American Journal of Orthopedic Surgery, 2, 390.

OsGood, R. B. (1907): The Comparative Strength of the Adductor and Abductor Groups in the Foot. American Journal of Orthopedic Surgery, 5, 298.

PAINTER, C. F. (1913): The Development of Orthopedic Teaching in America. American Journal of Orthopedic Surgery, 11, 301.

Painter, C. F., and Clarke, J. D. (1908): Myositis Ossificans. American Journal of Orthopedic Surgery, 6, 626 .

Painter, C. F., and Rogers, M. H. (1907): Neoplasms and their Relations to Orthopedic Surgery. American Journal of Orthopedic Surgery, 5, 129.

Pескнам, F. E. (1909): The Treatment of some Types of Rheumatoid Arthritis. American Journal of Orthopedic Surgery, 6, 702.

Peскнам, F. E. (1912): The Abdomen. An important Factor in Chronic Joint Affections. American Journal of Orthopedic Surgery, 10, 80.

Porter, J. L. (1918): Orthopedic Surgery and the War. American Journal of Orthopedic Surgery, 16, 413. Preiser, G. (1912): Static Joint Diseases. American Journal of Orthopedic Surgery, 10, 100.

Ridlon, J. (1907): A Preliminary Report upon Ten Cases of Chronic Joint Disease, Treated by Tuberculin Injections by Wright's Method. American Journal of Orthopedic Surgery, 5, 14.

Rogers, M. H. (1914): Tuberculosis of the Knee Joint in Adults: Prognosis and Treatment. American Journal of Orthopedic Surgery, 12, 589.

Rugh, J. T. (1916): Bone-grafting for Spinal Conditions. American Journal of Orthopedic Surgery, $14,71$. Ryerson, E. W. (1914): Pott's Disease, Albee's Bone Grafting Operation. Results in a Series of Twenty-six Cases Operated more than Six Months Ago. American Journal of Orthopedic Surgery, 12, 259.

SAYRE, R. H. (1904): President's Address. American Journal of Orthopedic Surgery, 2, 1.

SChlatter, C. (1903): Verletzungen des schnabel-formigen Fortsatzes oberen Tibiaepiphyse. Beiträge zur klinischen Chirurgie, 38, 874.

Sever, J. W. (1916): Obstetrical Paralysis-an Orthopedic Problem. American Journal of Orthopedic Surgery, 14, 456.

Silver, D. (1906): An Experimental Study of the Influence of Necrosis, Produced by Sutures, in Tendon Suture and Transplantation. American Journal of Orthopedic Surgery, 4, 218.

Silver, D. (1911): The So-called Benign Cyst of the Bones. American Journal of Orthopedic Surgery, 9, 563. Smith-Petersen, M. N. (1917): A New Supra-articular Subperiosteal Approach to the Hip Joint. American Journal of Orthopedic Surgery, 15, 592.

StarR, C. L. (1918): The Role of Orthopedic Surgery in Modern Warfare. American Journal of Orthopedic Surgery, 16, 415.

Steindler, A. (1915): The Method of Direct Neurotization of Paralyzed Muscles. American Journal of Orthopedic Surgery.

Stern, W. G. (1910): Problems in the Treatment of Club-foot. American Journal of Orthopedic Surgery, 8, 131.

Stern, W. G. (1913): Spontaneous Gangrene and Allied Conditions in Orthopedic Surgery. American Journal of Orthopedic Surgery, 10, 381.

Stoffel, A. (1913): The Treatment of Spastic Contractures. American Journal of Orthopedic Surgery, 10,611 .

Swaim, L. T. (1915): The Mechanically Unfit. A Study of Type Forms in Chronic Invalids. American Journal of Orthopedic Surgery, 13, 280.

TAYLOR, H. L. (1908): Present-day Needs of an Orthopedic Service. American Journal of Orthopedic Surgery, 6, 1.

TAYlor, H. L., and Frieder, W. (1915): Quiet Hip Disease. American Journal of Orthopedic Surgery, 13, 192.

TAYLoR, R. T. (1903): Hip Disease, Considered with Special Reference to Diagnosis and the Combined Treatment. American Journal of Orthopedic Surgery, 1, 143.

TAYLOR, R. T. (1916): Shortening Long Legs and Lengthening Short Legs: A New Surgical Procedure. American Journal of Orthopedic Surgery, 14, 598.

TAYLOR, R. T., and KNORR, E. A. (1907): A Study of Vaccines and the Opsonic Index in Relation to Orthopedic Surgery. American Journal of Orthopedic Surgery, 5, 32.

Tномаs, H. B. (1914): Artificial Ankylosis of Spinal Vertebrae. American Journal of Orthopedic Surgery. 12, 265.

Vol. $32 \mathrm{~B}$, No. 4, NOVEMBER 1950 
Wallace, C. (1907): The Effect of Imperfect Hygiene in the Production of Bone Tuberculosis. American Journal of Orthopedic Surgery, 5, 335.

Whitman, R. (1901): The Operative Treatment of Paralytic Talipes of the Calcaneus Type. American Journal of the Medical Sciences, 122, 593.

Whitman, R. (1902): A New Method of Treatment for Fracture of the Neck of the Femur. Transactions of the American Orthopedic Association, 15, 338.

Wilson, H. A., and Muschlitz, C. H. (1909): The Painful Feet of Raynaud's Disease. American Journal of Orthopedic Surgery, 6, 664 .

\section{Part IV \\ PATHOLOGY}

Albright, F., BAUer, W., Ropes, M., and AUb, J. C. (1929) : Studies of calcium and phosphorus metabolism; effect of parathyroid hormone. Journal of Clinical Investigation, 7, 139.

Albright, F., Butler, A. M., Hampton, A. O., and Smith, P. (1937): Syndrome characterized by osteitis fibrosa disseminata, areas of pigmentation, and endocrine dysfunction. with precocious puberty in females. New England Journal of Medicine, 216, 727.

Albright, F., Burnett, C. H., Parson, W., Reifenstein, E. C., and Roos, A. (1946): Osteomalacia and late rickets. Medicine, 25, 399.

Bakwin, H., Bodansky, O., and Schorr, R. (1940): Refractory rickets. American Journal of Diseases of Children, 59, 560.

Barr, D. P., Bulger, H. A., and Dixon, H. H. (1929): Hyperparathyroidism. Journal of the American Medical Association, 92, 951.

Bodansky, A., and JAFFe, H. L. (1934): Phosphatase studies; serum phosphatase in diseases of bone; interpretation and significance. Archives of Internal Medicine, 54, 88.

Bodansky, A., and Jaffe, H. L. (1934): Phosphatase studies: serum phosphatase as a criterion of the severity and rate of healing of rickets. American Journal of Diseases of Children, 48, 1268.

Caffey, J., and Silverman, W. A. (1945): Infantile cortical hyperostoses: Preliminary report on a new syndrome. American Journal of Roentgenology and Radium Therapy, 54, 1.

Cahan, W. G., Woodard, H. Q., Higinbotham, N. L., Stewart, F. W., and Coley, B. L. (1948): Sarcoma arising in irradiated bone: Report of eleven cases. Cancer, 1, 3.

Castleman, B., and Mallory, T. B. (1935): The pathology of the parathyroid gland in hyperparathyroidism; study of twenty-five cases. American Journal of Pathology, 11, 1.

Castleman, B., and Mallory, T. B. (1937): Parathyroid hyperplasia in chronic renal insufficiency. American Journal of Pathology, 13, 553.

Collip, J. B. (1925): The extraction of a parathyroid hormone which will prevent or control parathyroid tetany and which regulates the level of blood calcium. Journal of Biological Chemistry, 63, 395.

Collip, J. B. (1926): The parathyroid glands. Medicine, 5, 1.

Falconer, M. A., Cope, C. L., and Robb-Smith, A. (1942): Fibrous dysplasia of bone, with endocrine disorders and cutaneous pigmentation (Albright's disease). Quarterly Journal of Medicine, N.S. 11, 121.

GinzleR, A. M., and JAFFE, H. L. (1939): Osseous findings in chronic renal insufficiency in adults. Archives of Pathology, 27, 798.

GreEN, W. T., and FArber, S. (1942): "Eosinophilic or solitary granuloma" of bone. Journal of Bone and Joint Surgery, 24, 499.

Hatcher, C. H. (1945): The development of sarcoma in bone subjected to roentgen or radium irradiation. Journal of Bone and Joint Surgery, 27, 179.

JAFFe, H. L. (1933): Hyperparathyroidism. Archives of Pathology, 16, 63; 236. (This article summarizes and contains the references on experimental work as published in a number of papers between 1930 and 1933.) Jaffe, H. L. (1933): Paget's disease of bone. Archives of Pathology, 15, 83. (This article is a critical discussion of the pathology of the disease, and includes among other questions a consideration of the supposed occurrence of Paget's disease in animals.)

JAFFE, H. L. (1935): Osteoid-osteoma: A benign osteoblastic tumor composed of osteoid and atypical bone. Archives of Surgery, 31, 709.

JAFFE, H. L. (1945): Fibrous dysplasia of bone; a disease entity and specifically not an expression of neurofibromatosis. Journal of Mount Sinai Hospital, 12, 364.

Jaffe, H. L., Lichtenstein, L., and Portis, R. (1940): Giant-cell tumor of bone: its pathologic appearance, grading, supposed variants and treatment. Archives of Pathology, 30, 993.

JAFFe, H. L., and Lichtenstein, L. (1940): Osteoid-osteoma: Further experience with this benign tumor of bone, with special reference to cases showing the lesion in relation to shaft cortices and commonly misclassified as instances of sclerosing non-suppurative osteomyelitis or cortical-bone abscess. Journal of Bone and Joint Surgery, 22, 645.

JAFFe, H. L., and Bodansky, A. (1943): Serum calcium: Clinical and biochemical considerations. Journal of Mount Sinai Hospital, 9, 901. 
JAfFe, H. L., and Lichtenstein, L. (1944): Eosinophilic granuloma of bone: A condition affecting one, several or many bones, but apparently limited to the skeleton, and representing the mildest clinical expression of the peculiar inflammatory histiocytosis also underlying Letterer-Siwe disease and SchüllerChristian disease. Archives of Pathology, 37, 99.

Kahlstrom, S. C., Burton, C. C., and Phemister, D. B. (1939): Bone and joint changes in caisson disease, including infarction and deforming arthritis. Surgery, Gynecology and Obstetrics, 68, 129.

Lichtenstein, L. (1938): Polyostotic fibrous dysplasia. Archives of Surgery, 36, 874.

Lichtenstein, L., and JAFFe, H. L. (1940): Eosinophilic granuloma of Bone. American Journal of Pathology, 16, 595.

Lichtenstein, L., and JAfFe, H. L. (1942): Fibrous dysplasia of bone; a condition affecting one, several or many bones, the graver cases of which may present abnormal pigmentation of skin, premature sexual development, hyperthyroidism or still other extra-skeletal abnormalities. Archives of Pathology, 33, 777. Lichtenstein, L., and Jaffe, H. L. (1947) : Ewing's sarcoma of bone. American Journal of Pathology, $23,43$. Mande, F. (1926): Klinisches und Experimentelles zur Frage der lokalisierten und generalisierten Ostitis fibrosa. Archiv für klinische Chirurgie, 143, 1; 245.

Otani, S., and EhrLich, J. C. (1940): Solitary granuloma of bone simulating primary neoplasm. American Journal of Pathology, 16, 479.

Phemister, D. B. (1926): Radium necrosis of bone. American Journal of Roentgenology, 16, 340.

Phemister, D. B. (1930): Chondrosarcoma of bone. Surgery, Gynecology and Obstetrics, 50, 216.

Phemister, D. B. (1930): Repair of bone in the presence of aseptic necrosis resulting from fractures, transplantations and vascular obstruction. Journal of Bone and Joint Surgery, 12, 769.

Ponseti, I., and Barta, C. K. (1947): Osteoid osteoma. Journal of Bone and Joint Surgery, 29, 767.

Sherman, M. S. (1947): Osteoid osteoma; Review of the literature and report of thirty cases. Journal of Bone and Joint Surgery, 29, 918.

Stout, A. P. (1943): A discussion of the pathology and histogenesis of Ewing's tumor of bone marrow. American Journal of Roentgenology and Radium Therapy, 50, 334.

\section{ARTHROPLASTY}

Allison, N., and Brooks, B. (1915): Ankylosis: an Experimental Study. Journal of the American Medical Association, 64, 391.

Baer, W. S. (1909): A Preliminary Report of the Use of Animal Membrane in Producing Mobility in Ankylosed Joints. American Journal of Orthopedic Surgery, 7, 1.

BaER, W. S. (1918): Arthroplasty with the Aid of Animal Membrane. American Journal of Orthopedic Surgery, 16, $1 ; 16,94 ; 16,171$.

Barton, J. R. (1827): On the Treatment of Ankylosis by the Formation of Artificial Joints. North American Medical and Surgical Journal, 3, 279; 3, 400.

CAmpbell, W. C. (1931): The Physiology of Arthroplasty. Journal of Bone and Joint Surgery, 13, 223. Sir Robert Jones Lecture delivered at the Hospital for Joint Diseases, October 18, 1930.

Henderson, M. S. (1918): What are the Real Results of Arthroplasty ? American Journal of Orthopedic Surgery, 16, 30.

Judet, Jean and Robert (1950): The Use of an Artificial Femoral Head for Arthroplasty of the Hip Joint. Journal of Bone and Joint Surgery, 32-B, 166.

MacAusland, W. R. (1923): Mobilization of Ankylosed Joints. Surgery, Gynecology and Obstetrics, 37, 255. Murphy, J. B. (1905): Ankylosis, Arthroplasty, Clinical and Experimental. Journal of the American Medical Association, 44, 1573; 44, 1671; 44, 1749.

MURPHY, J. B. (1913): Arthroplasty. Annals of Surgery, 57, 593.

Smith-Petersen, M. N. (1939): Arthroplasty of the Hip; A New Method. Journal of Bone and Joint Surgery, 21, 269.

Smith-Petersen, M. N. (1948): Evolution of Mould Arthroplasty of the Hip Joint. Journal of Bone and Joint Surgery, 30-B, 59.

\section{ARTHRODESIS}

Abbott, L. C., Schottstaedt, E. R., Saunders, J. B., and Bost, F. C. (1947): The Evaluation of Cortical and Cancellous Bone as Grafting Material. Journal of Bone and Joint Surgery, 29, 381.

Albee, F. H. (1911): Transplantation of Portion of Tibia into the Spine for Pott's Disease. Journal of the American Medical Association, 57, 885.

Albert, E. (1881): Zentralblatt für Chirurgie, 48, 1881.

BARR, J. S. (1937): Sciatica Caused by Intervertebral-disc Lesions. Journal of Bone and Joint Surgery, $19,323$.

Barr, Joseph S., Freiberg, Joseph A., Colonna, Paul C., and Pemberton, Paul A. (1942): A survey of end-results on stabilization of the paralytic shoulder. Report of the Research Committee of the American Orthopaedic Association. Journal of Bone and Joint Surgery, 24, 699.

Vol. $32 \mathrm{~B}$, No. 4, NOVEMBER 1950 
Bosworth, D. M. (1946): Knee Fusion by the use of a Three-flanged Nail. Journal of Bone and Joint Surgery, 28, 550.

CAmpbell, W. C. (1923): An Operation for the Correction of "Drop-foot." Journal of Bone and Joint Surgery, 5, 815.

Clegveland, M. (1935): Fusion of a Knee Joint in Charcot's Disease. Journal of Bone and Joint Surgery, $17,1031$.

Совв, J. R. (1943): Treatment of Scoliosis. Connecticut State Medical Journal, 7, 467.

Davis, G. (1913): The Treatment of Hollow Foot (Pes Cavus). American Journal of Orthopedic Surgery, 11, 231. Gallie, W. E. (1943): Substragalar Arthrodesis in Fractures of the Os Calcis. Journal of Bone and Joint Surgery, 25, 731.

Hibis, R. A. (1911): An Operation for Progressive Spinal Deformities. New York Medical Journal, 93, 1013. HibBs, R. A. (1911): An Operation for Stiffening of the Knee Joint. Annals of Surgery, 53, 404.

HibBs, R. A. (1926): Twenty Cases of Hip Joint Tuberculosis Treated by an Operation Devised to Eliminate Motion by Fusing the Joint. Journal of Bone and Joint Surgery, 8, 522.

HoKe, M. (1921): An Operation for Stabilizing Paralytic Feet. Journal of Orthopaedic Surgery, 3, 494.

Milgram, J. E. (1931): Rotation Arthrodesis of Knee. Surgery, Gynecology and Obstetrics, 53, 355.

Ryerson, E. W. (1923): Arthrodesing Operations on the Feet. Journal of Bone and Joint Surgery, 5, 453.

WAtson-Jones, R. (1934): Inadequate Immobilization and Non-union of Fractures. British Medical Journal, 1, 936.

Watson-Jones, R. (1938): Arthrodesis of the Osteoarthritic Hip. Journal of the American Medical Association, 110, 278.

Whitman, R. (1901): The Operative Treatment of Paralytic Talipes of the Calcaneus Type. American Journal of the Medical Sciences, 122, 593.

\section{OSTEOTOMY}

BArton, John Rhea (1827): On the treatment of anchyloses by the formation of artificial joints. North American Medical and Surgical Journal, III, 279; IV, 310.

Batchelor, J. S. (1945): Excision of femoral head and neck in ankylosis and osteoarthritis of hips. Proceedings of the Royal Society of Medicine (Section of Orthopaedics), 38, 689.

Blount, W. P. (1943): Blade-Plate internal fixation for high femoral osteotomies. Journal of Bone and Joint Surgery, 25, 319.

Bosworth, D. M. (1942): Femoro-Ischial Transplantation. Journal of Bone and Joint Surgery, 24, 38.

Britrain, H. A. (1942): Architectural Principles in Arthrodesis. Baltimore: Williams \& Wilkins.

Dickson, J. A. (1947): High Geometric Osteetomy. Journal of Bone and Joint Surgery, 29, 1005.

Gaenslen, F. J. (1935): The Schanz subtrochanteric Osteotomy. Journal of Bone and Joint Surgery, $17,76$. Galland, W. I. (1930): The Bifurcation Operation. Surgery, Gynecology and Obstetrics, 50, 90.

HibBs, R. A. (1915): Anteversion of the Neck of the Femur. Journal of the American Medical Association, $65,1801$.

Kırmisson, Ed. (1894): De l'ostéotomie sous-Trochantérienne. Revue d'Orthopédie, le série, 5, 137.

LoRenz, A. (1919): Bifurkation des oberen Femurendes. Wiener klinische Wochenschrift, 32, 997.

McMurRay, T. P. (1935): Osteo-Arthritis of the Hip Joint. British Journal of Surgery, 22, 716.

MiLch, H. (1943): Resection of Femoral Neck with Pelvic Support Osteotomy for Ankylosis of the Hip. Surgery, 13, 55.

MiLCH, H. (1944) : Postosteotomy Angle. Journal of Bone and Joint Surgery, 26, 394.

MiLCH, H. (1947): Osteotomy of the Long Bones. Springfield, Illinois: Charles C. Thomas.

Pauwels, F. (1935): Der Schenkelhalsbruch. Stuttgart: Ferdinand Enke.

Purri, V. (1937): L'ostéotomie Intertrochantérienne. Presse Médicale, 45, 1841.

ReITH, R. S. (1925): The Bifurcation Operation for the Treatment of irreducible dislocations of the hip joint. Journal of Bone and Joint Surgery, 7, 598.

Schanz, A. (1922): Zur Behandlung der veralteten angeborenen Hüftverenkung. Münchener medizinische Wochenschrift, 69, 930 .

Trumble, H. C. (1932) : Fixation of Hip by Extra-articular Bone graft. Australian and New Zealand Journal. of Surgery, 1, 413.

voN BAEYer (1918): Operative Behandlung von nicht reponierbaren angeborenen Hüftverenkungen. Münchener medizinische Wochenschrift, 65, 1218.

\section{BONE GRAFTING}

Abbott, L. C., Schottstaedt, E. R., Saunders, J. B. De C. M., and Bost, F. C. (1947): Evaluation of Cortical and Cancellous Bone as Grafting Material; Clinical and Experimental Study. Journal of Bone and Joint Surgery, 29, 381.

Albee, F. H. (1911): Transplantation of Portion of Tibia into the Spine for Pott's Disease. Journal of the American Medical Association, 57, 885. 
Albee, F. H. (1919): Orthopaedic and Reconstructive Surgery. Philadelphia: W. B. Saunders Co. Albee, F. H. (1930): Principles of Treatment of Non-union of Fracture. Surgery, Gynceology and Obstetrics, 51, 289.

Boyd, H. B. (1941): Congenital Pseudarthrosis. Treatment by Dual Bone Grafts. Journal of Bone and Joint Surgery, 23, 497.

Boyd, H. B. (1943): The Treatment of Difficult and Unusual Non-unisns, with Special Reference to Bridging of Defects. Journal of Bone and Joint Surgery, 25, 535,

CAM PBELL, W. C. (1927): The Onlay Graft in the Treatment of Ununited Fractures of Long Bones. Southern Medical Journal, 20, 107.

Flanagan, J. J., and Burem, H. S. (1947): Reconstruction of Defects of Tibia and Femur with Apposing Massive Grafts from Affected Bone. Journal of Bone and Joint Surgery, 29, 587.

Henderson, M. S. (1928) Massive Bone Graft applied for non-union of the Humerus. Surgery, Gynecology and Obstetrics, 46, 397.

HibBs, R. A. (1911): An Operation for Progressive Spinal Deformities. New York Medical Journal, 93, 1013. InCLAN, A. (1942): The Use of Preserved Bone Graft in Orthopaedic Surgery. Journal of Bone and Joint Surgery, 24, 81.

Macewen, W. (1912): The Growth of Bone. Observations on Osteogenesis. Glasgow: J. Maclehose \& Sons. Ollier, L. (1867): Traité Expérimental et Clinique de la Régénération des os et de la Production Artificielle du Tissu Osseux. Paris: Masson et fils.

Phemister, D. B. (1931): Splint Grafts in the Treatment of Delayed and Non-union of Fractures. Surgery, Gynecology and Obstetrics, 52, 376.

Venable, C. S., Stuck, W. B., and Beach, A. (1937): The Effects on Bone of the Presence of Metals; based upon Electrolysis. Annals of Surgery, 105, 917.

\section{POLIOMYELITIS}

Bartow, B., and Plummer, W. W. (1911, 1912, 1916): The Use of Intra-articular Silk Ligaments for Fixation of Loose Joints in the Residual Paralysis of Anterior Poliomyelitis. American Journal of Orthopedic Surgery, 9, 65; 10, 499; 14, 594.

Biesalski, K., and MAYer, L. (1916): Die physiologische Sehnenverpflanzung. Berlin: J. Springer.

Bunnell, S. $(1918,1922)$ : Repair of Tendons in the Fingers. Surgery, Gynecology and Obstetrics, 26, 103; 35, 88.

Bunnell, S. (1932): Contractures of the Hand from Infections and Injuries. Journal of Bone and Joint Surgery, 14, 27.

BunNell, S. (1938): Opposition of the Thumb. Journal of Bone and Joint Surgery, 20, 269.

Bunnell, S. (1942): Surgery of the Intrinsic Muscles of the Hand other than those producing opposition of the Thumb. Journal of Bone and Joint Surgery, 24, 1.

Cambell, W. C. (1925): Transference of the Crest of the Ilium for Flexion Contracture of the Hip. Southern Medical Journal, 16, 289.

Campbell, W. C. (1936): Repair of the Ligaments of the Knee. Surgery, Gynecology and Obstetrics, $62,964$. Davis, G. G. (1913): Treatment of Hollow Foot (Pes Cavus). American Journal of Orthopedic Surgery, 11, 231.

Dunn, N. (1922): Stabilizing Operations in Paralytic Feet. Proceedings of the Royal Society of Medicine (Section of Orthopaedics), 15, 15.

Gallie, W. E., and Le Mesurier, A. B. (1922): A Clinical and Experimental Study of the Free Transplantation of Fascia and Tendon. Journal of Bone and Joint Surgery, 41, 600.

Gill, A. B. (1931): Operation for Correction of Paralytic Genu Recurvatum. Journal of Bone and Joint Surgery, 13, 49.

Hibbs, R. A., Risser, J. C., and Ferguson, A. B. (1931): Scoliosis Treated by the Fusion Operation. Journal of Bone and Joint Surgery, 13, 91.

Hoke, M. (1921): An Operation for Stabilizing Paralytic Feet. Journal of Orthopaedic Surgery, 3, 494.

Hoke, M. (1931): An Operation for the Correction of Extremely Relaxed Flat Feet. Journal of Bone and Joint Surgery, 13, 773.

Lambrinudi, C. (1932): A Method of Correcting Equinus and Calcaneous Deformities at the Sub-Astragaloid Joint. Proceedings of the Royal Society of Medicine (Section of Orthopaedics), 26, 788.

L'Episcopo, J. B. (1939): Restoration of Muscle Balance in the Treatment of Obstetrical Paralysis. New York Journal of Medicine, 39, 357.

Lovetr, R. W. (1916): The Spring Balance Muscle Test. American Journal of Orthopedic Surgery, $14,415$. McCarroll, H. R. (1944): Evaluation of the Kenny Treatment of Infantile Paralysis: Report of Committee. Journal of the American Medical Association, 125, 446.

MAYer, L. (1916): The Physiological Method of Tendon Transplantation. Surgery, Gynecology and Obstetrics, 22, 182; 298; 472.

vol. 32 B, No. 4, NOVEMBER 1950 
MAYer, L. (1927): Transplantation of the Trapezius for Paralysis of the Abductors of the Arm. Journal of Bone and Joint Surgery, 9, 412.

MAYER, L. (1930): An Operation for the Cure of Paralytic Genu Recurvatum. Journal of Bone and Joint Surgery, 12, 845.

MAYER, L. (1944): Significance of the Iliocostal Fascial Graft in the Treatment of Paralytic Deformities of the Trunk. Journal of Bone and Joint Surgery, 26, 257.

Milgram, J. E. (1931): Rotation Arthrodesis of Knee. Surgery, Gynecology and Obstetrics, 53, 355.

Ober, F. R. (1927): An Operation for the Relief of Paralysis of the Gluteus Maximus Muscle. Journal of the American Medical Association, 88, 1063.

Peabody, C. W. (1938): Tendon Transposition. An End-result Study. Journal of Bone and Joint Surgery, 20, 193.

Pонц, Jонn F. (1943): The Kenny Concept of Infantile Paralysis and its Treatment. St Paul, Minnesota: Bruce Publishing Co.

Poht, John F. (1947): The Peripheral Disease of Poliomyelitis. Journal of Bone and Joint Surgery, 29, 1027. Ryerson, E. W. (1916): Methods of Stabilizing the Flail Foot in Infantile Paralysis. American Journal of Orthopedic Surgery, 14, 387.

Ryerson, E. W. (1923): Arthrodesing Operations on the Feet. Journal of Bone and Joint Surgery, 5, 453. Soutrer, R. (1914): A New Operation for Hip Contractures in Poliomyelitis. Boston Medical and Surgical Journal, 170, 380.

Steindler, A. (1919): Operative Treatment of Paralytic Conditions of the Upper Extremity. Journal of Orthopaedic Surgery, 1, 608.

Thом PSon, T. C. (1945): Quadricepsplasty. Annals of Surgery, 121, 751.

Whitman, R. (1901): The Operative Treatment of Paralytic Talipes of the Calcaneus Type. American Journal of the Medical Sciences, 122, 593.

\section{RECURRENT DISLOCATION OF THE SHOULDER}

Adams, J. C. (1948): Recurrent Dislocation of the Shoulder. Journal of Bone and Joint Surgery, 30-B, 26. Hellens, Arno von (1947): Uber die Habituelle Schulterluxation. Annals Chirurgiae et Gynaecologiae Fenniae, 36, 1.

BAnkart, A. S. Blundell (1923): Recurrent or Habitual Dislocation of the Shoulder Joint. British Medical Journal, ii, 1132.

Bankart, A. S. Blundell (1938): Pathology and Treatment of Recurrent Dislocation of the Shoulder Joint. British Journal of Surgery, 26, 23.

Bost, F. C., and Inman V. T. (1942): The Pathological Changes in Recurrent Dislocation of the Shoulder. Journal of Bone and Joint Surgery, 24, 595.

Broca, A., and Hartmann, H. (1890): Bulletins de la Société Anatomique de Paris, 5me série, 4, 312.

De Palma, A. F., Callery, Gerald, and Bennetr, George A., (1949): Variational Anatomy and Degenerative Lesions of the Shoulder Joint. Instructional Course Lecture, American Academy of Orthopaedic Surgeons, 6, 255.

Fahey, J. J., and De Cosola, Michael (1947): Pathology of the Shoulder after Experimental Dislocation at Autopsy. Scientific Exhibit Meeting of the American Academy of Orthopaedic Surgeons, Chicago.

Flower, W. H. (1861): On the Pathological Changes Produced in the Shoulder Joint by Traumatic Dislocation. Transactions of the Pathological Society, London, 12, 179.

Gallie, W. E., and Le Mesurier, A. B. (1948): Recurring Dislocation of the Shoulder. Journal of Bone and Joint Surgery, 30-B, 9.

Grant, J. C. B. (Gallie and Le Mesurier).

Hill, H. A., and SACHS, M. D. (1940): The Grooved Defect of the Humeral Head, a Frequently Unrecognized Complication of Dislocations of the Shoulder Joint. Radiology, 35, 690.

Magnuson, P. B., and Stack, J. K. (1943) : Recurrent Dislocation of the Shoulder. Journal of the American Medical Association, 123, 889.

Nicola, Toufick (1934): Recurrent Dislocation of the Shoulder. Journal of Bone and Joint Surgery, 16, 663. Osmond-Clarke, H. (1948): Habitual Dislocation of the Shoulder. Journal of Bone and Joint Surgery, 30-B, 19.

Palmer, Ivar, and Widén, Anders (1948): The Bone Block Method for Recurrent Dislocation of the Shoulder Joint. Journal of Bone and Joint Surgery, 30-B, 53.

\section{CONGENITAL DISLOGATION OF THE HIP}

Bost, F. C., Hagey, H., Schotrstaedt, E. R., and Larsen, L. J. (1948): The Results of Treatment of Congenital Dislocation of the Hip in Infancy. Journal of Bone and Joint Surgery, 30-A, 454.

BradFord, E. H. $(1894,1900,1902)$ : Congenital Dislocation of the Hip Joint. Transactions of the American Orthopedic Association, 7, 88; 13, $124 ; 15,284$. 
Cole, W. H. (1935): The Open Treatment of Congenital Dislocation of the Hip; the Operative Technique with some of its Complications. Journal of Bone and Joint Surgery, 17, 18.

Compere, E. L., and Phemister, D. B. (1935): The Tibial Peg Shelf in Congenital Dislocation of the Hip. Journal of Bone and Joint Surgery, 17, 60.

Crego, Jr., C. H., and Schwartzmann, J. R. (1948): Follow-up Study of the Early Treatment of Congenital Dislocation of the Hip. Journal of Bone and Joint Surgery, 30-A, 428.

Davis, G. G. (1907): A method of reduction of Congenital Luxation of the Hip by Manipulation. American Journal of Orthopedic Surgery, 4, 276.

Davis, G. G. (1908): A Case of Double Dislocation of the Hip Replaced by Manipulation. Archives of Pediatrics, 25, 867.

Dickson, F. D. (1935): The Shelf Operation in Treatment of Congenital Dislocation of the Hip. Journal of Bone and Joint Surgery, 17, 43.

Farrell, B. P., and Howarth, M. B. (1935): Open Reduction in Congenital Dislocation of the Hip. Journal of Bone and Joint Surgery, 17, 35.

Farrell, B. P., von Lackum, H. L., and Smith, A. De F. (1926): Congenital Dislocation of the Hip; Report of 310 Cases Treated at New York Orthopaedic Dispensary and Hospital. Journal of Bone and Joint Surgery, 8, 551.

Freiberg, A. H. (1935): Congenital Luxation of Hip; Selection of Cases for Open Reduction. Journal of Bone and Joint Surgery, 17, 1.

Galloway, H. P. H. (1920): The Open Operation for Congenital Dislocation of the Hip. Journal of Orthopaedic Surgery, 2, 390.

Galloway, H. P. H. (1926): The Open Operation for Congenital Dislocation of the Hip; Special Reference to Results. Journal of Bone and Joint Surgery, 8, 539.

Gill, A. B. (1935): Plastic Construction of an Acetabulum in Congenital Dislocation of the Hip-the Shelf Operation. Journal of Bone and Joint Surgery, 17, 48.

GiLl, A. B. (1936): An Evaluation of Present-day Methods of Dealing with Congenital Dislocation of the Hip. Journal of Bone and Joint Surgery, 18, 487.

GiLl, A. B. (1948) : The End-results of the Early Treatment of Congenital Dislocation of Hip, with an Inquiry into the Factors that Determine the Result. Journal of Bone and Joint Surgery, 30-A, 442.

Kidner, F. C. (1935): Comparative Analysis of the Results of Open and Closed Reductions in Congenital Dislocation of the Hip. Journal of Bone and Joint Surgery, 17, 25.

KLeinberg, S., and Lieberman, H. S. (1936): The Acetabular Index in Infants in Relation to Congenital Dislocation of the Hip. Archives of Surgery, 32, 1049.

Lorenz, A. (1896): Cure of Congenital Luxation of the Hip by Bloodless Reduction and Weighting. Transactions of the American Orthopedic Association, 9, 254.

McCarroll, H. R. (1948): Primary Anterior Congenital Dislocation of the Hip. Journal of Bone and Joint Surgery, 30-A, 416.

OвER, F. R. (1935): Shelf Operation to Relieve Persistent Dislocation of Hip; A Report on Results. Journal of Bone and Joint Surgery, 17, 73.

PACI, A. (1888): Studio ed osservazione sulla lussazione iliaca commune congenita e sua cura razionale. Genova.

Ponseri, I. (1946): Pathomechanics of the Hip after the Shelf Operation. Journal of Bone and Joint Surgery, 28, 229.

Stewart, S. F. (1935): The Physiological Treatment of Congenital Dislocation of the Hip. Journal of Bone and Joint Surgery, 17, 11.

\section{CONTROL OF BONE LENGTH}

Аввотт, L. C. (1927) : The operative lengthening of the tibia and fibula. Journal of Bone and Joint Surgery, 9, 128.

Absotr, L. C., and Crego, C. H. (1928): Operative lengthening of the femur. Southern Medical Journal, 21, 823 .

Aвbott, L. C., and Saunders, J. B. (1936): The operative lengthening of the tibia and fibula. Annals of Surgery, 110, 961 .

BARR, J. S., Lingley, J. R., and GALl, E. A. (1943): the effect of roentgen irradiation on epiphysial growth. American Journal of Roentgenology and Radium Therapy, 49, 104.

Bisgard, J. D., and BisGard, M. E. (1935) : Longitudinal growth of long bones. Archives of Surgery, $31,568$. Blount, W. P., and Clarke, G. R. (1949): Control of bone growth by epiphysial stapling. Journal of Bone and Joint Surgery, 31-A, 464.

Brockway, A. (1935): Clinical résumé of forty-six leg-lengthening operations. Journal of Bone and Joint Surgery, 17, 969.

BRooke, J. A. (1927): Shortening of bones of the leg to correct inequality of length. Surgery, Gynecology and Obstetrics, 44, 703.

VOL. 32 B, No. 4 , NOVEMBER 195( 
Calvé, J., and Galland, M. (1918): A new procedure for compensatory shortening of the unaffected femur. American Journal of Orthopedic Surgery, 16, 211.

Codivilla, A. (1905): On the means of lengthening, in the lower limbs, the muscles and tissues which are shortened through deformity. American Journal of Orthopedic Surgery, 2, 353.

Green, Wm. T., and ANderson, Margaret (1947): Experiences with epiphysial arrest in correcting discrepancies in length of the lower extremities in infantile paralysis. Journal of Bone and Joint Surgery, 29, 659.

HAAS, S. L. (1945): Retardation of bone growth by a wire loop. Journal of Bone and Joint Surgery, 27, 25. HAAS, S. L. (1948) : Mechanical Retardation of bone growth. Journal of Bone and Joint Surgery, 30-A, 506. Haboush, E. J., and Finkelstein, H. (1932): Leg lengthening with new stabilizing apparatus. Journal of Bone and Joint Surgery, 14, 807.

HARRIS, R. I. (1930): The effect of lumbar sympathectomy on the growth of legs shortened from anterior poliomyelitis. A preliminary report. Journal of Bone and Joint Surgery, 12, 859.

Magnuson, P. B. (1908): Lengthening shortened bones of the leg by operation. Pennsylvania University Medical Bulletin, 21, 103.

Magnuson, P. B. (1913): Surgery, Gynecology and Obstetrics, 17, 63.

Phemister, D. B. (1933): Operative arrestment of longitudinal growth of bones in the treatment of deformities. Journal of Bone and Joint Surgery, 15, 1.

Putri, V. (1921): The operative lengthening of the femur. Journal of the American Medical Association, 77, 934.

Shands, A. R. (1917): Shortening of the long leg. International Journal of Surgery, 30, 273.

Stinchfield, Allan J., Reidy, John, and Barr, Jos. (1949): Prediction of unequal growth of the lower extremities in anterior poliomyelitis. Journal of Bone and Joint Surgery, 31-A, 478.

Straub, L. R., Thompson, T. C., and Wilson, P. D. (1945): The results of epiphyseodesis and femoral shortening in relation to equalization of limb length. Journal of Bone and Joint Surgery, 27, 254.

TAYLOR, R. T. (1916): Shortening long legs and lengthening short legs. American Journal of Orthopedic Surgery, 14, 598.

Whire, J. W. (1935): Femoral shortening for equalization of leg length. Journal of Bone and Joint Surgery, 17, 597.

White, J. W., and Stubbins, S. G. (1944): Growth arrest for equalizing leg lengths. Journal of the American Medical Association, 126, 1146.

Wirson, P. D., and Thompson, T. C. (1939): A clinical consideration of the methods of equalizing leg length. Annals of Surgery, 110, 992.

WU, Y. K., and MiLTNER, L. J. (1937): A procedure for stimulation of longitudinal growth of bone. Journal of Bone and Joint Surgery, 19, 909.

\section{BAGK PAIN AND Sciatica}

AlbeE, R. H. (1911): Transplantation of portion of the tibia into the spine for Pott's disease. Journal of the American Medical Association, 57, 885.

BARR, J. S. (1937): " Sciatica" caused by Intervertebral-disc lesions. A report of forty cases of rupture of the intervertebral disc occurring in the low lumbar spine and causing pressure on the cauda equina. Journal of Bone and Joint Surgery, 19, 323.

Beadle, O. A. (1931): The Intervertebral Discs. Observations on their normal and morbid anatomy in relation to certain spinal deformities. Medical Research Council, Special Report series No. 161, London.

Bucy, P. C. (1930): Chondroma of intervertebral disk. Journal of the American Medical Association, 94, 1552. DANDY, W. E. (1929): Loose cartilage from intervertebral disk simulating tumor of the spinal cord. Archives of Surgery, 19, 660 .

FRIBERG, S. (1941): Low back and sciatic pain caused by intervertebral disc herniation. Acta Chirurgica Scandinavica, Supplement 64.

Goldthwait, J. E. (1907): The Pelvic Articulations. Journal of the American Medical Association, 49, 768. Goldthwait, J. E. (1911): The lumbo-sacral articulation; an explanation of many cases of "lumbago," " sciatica," and paraplegia. Boston Medical and Surgical Journal, 164, 365.

HibBs, R. A. (1911): An operation for progressive spinal deformities. New York Medical Journal, $93,1013$. HibBs, R. A., and SwiFT, W. E. (1929): Developmental abnormalities at the lumbo-sacral juncture causing pain and disability; report of 147 patients treated by the spine fusion operation. Surgery, Gynecology and Obstetrics, 48, 604.

Hirsch, C. (1948): Instability in Degeneration of lumbar disk; anatomic study. Nordisk Medicin, 38, 1252. Keyes, D. C., and Compere, E. L. (1932): The Normal and Pathological Physiology of the Nucleus Pulposus of the Intervertebral Disc. Journal of Bone and Joint Surgery, 14, 897.

Kocher, Theodor (1896): Die Verletzungen der Wirbelsäule zugleich als Beitrag zur Physiologie des menschlichen Rückenmarks. Mitteilungen aus den Grenzgebieten der Medizin und Chirurgie, 1, 415.

Mauric, G. J. J. (1933): Le disque intervertébral. Paris: Masson et Cie. 
Middleton, G. S., and Teacher, J. H. (1911): Glasgow Medical Journal, N.S. 76, 1.

Mixter, W. J., and BARR, J. S. (1934): Rupture of the Intervertebral disc with involvement of the spinal canal. New England Journal of Medicine, 211, 210.

Osler, W., and MicCrae, T. (1920): The Principles and Practice of Medicine. Ninth edition. New York and London: D. Appleton \& Company, 1057.

Petit-Dutaillis, D., and Alajouanine, T. (1928): Syndrome unilatéral de la queue de cheval laminectome exploratrice et ablation d'un fibrome du disque intervertébral. Bulletins et Mémoires de la Société Nationale de Chirurgie, 54, 1452.

Putri, V. (1927) : New Concepts in the Pathogenesis of Sciatic Pain. Lancet, ii, 53.

Schmort, Georg (1927): Verhandlungen der Deutschen Orthopädischen Gesellschaft, 21, 3.

Schmorl, Georg (1927): Verhandlungen der Deutschen Pathologischen Gesellschaft, 22, 250.

SchmoRL, Georg (1929): Fortschritte auf dem Gebiete der Röntgenstrahlen, 40, 629.

Schmorl, Georg (1931): Archiv für Orthopädie, Mechanotherapie und Unfallchirurgie, 29, 389.

\section{SCOLIOSIS}

Аввотт, E. G. (1917) : Scoliosis. American Journal of Orthopedic Surgery, 15, 26; 108; 172; $243 ; 362$.

Arkis, Alvin M. (1949): The mechanism of the structural changes in Scoliosis. Journal of Bone and Joint Surgery, 31-A, 519.

Совв, J. R. (1943): Treatment of scoliosis. Connecticut State Medical Journal, 7, 467.

Farkas, A. (1941): Phỵsiological Scoliosis. Journal of Bone and Joint Surgery, 23, 607.

Farkas, A. (1943): Paralytic Scoliosis. Journal of Bone and Joint Surgery, 25, 581.

Hibis, R. A. (1924): A report of fifty-nine cases of Scoliosis treated by the fusion operation. Journal of Bone and Joint Surgery, 6, 3.

Hibbs, R. A., Risser, J. C., and Ferguson, A. B. (1931) : Scoliosis treated by the fusion operation. Journal of Bone and Joint Surgery, 13, 91.

Howarth, M. B. (1943) : Evolution of spinal fusion. Annals of Surgery, 117, 278

KLEINBerg, S. (1922): The operative treatment of scoliosis. Archives of Surgery, 5, 631.

Kleminerg, S. (1926): Scoliosis. New York: P. B. Hoeber.

Kleinberg, S. (1929): Beef-bone grafting for scoliosis. American Journal of Surgery, 6, 803.

Kleinberg, S. (1929): The results of spine fusion for Scoliosis. Journal of Bone and Joint Surgery, $11,66$. von I ackum, Wm. H., and Miller, J. P. (1949): Critical observations of the results in the operative treatment of Scoliosis. Journal of Bone and Joint Surgery, 31-A, 102.

Outland, Tom, and Corx, Oscar (1947): The use of Parallel Grafts and of two-stage and three-stage interlocking grafts in the treatment of idiopathic Scoliosis. Journal of Bone and Joint Surgery, 29, 163.

Report of Research Committee, American Orthopedic Association (1941): End-result study of the treatment of idiopathic Scoliosis. Journal of Bone and Joint Surgery, 23, 963.

Swith, A. DE F. (1923): A study of autopsy specimens of fused spines. Journal of Bone and Joint Surgery, $5,507$.

Smith, A. de F., Butte, F. L., and Fergeson, A. B. (1938): Treatment of scoliosis by the wedging jacket and spine fusion. A review of 265 cases. Journal of Bone and Joint Surgery, 20, 825.

Steinder, A. (1929): Diseases and Deformities of the Spine and Thorax. St Louis: C. V. Mosby Company, 244. Whitman, A. (1927): A variation in the operative treatment of structural scoliosis. Journal of the American Nedical Association, 89, 2159.

FRACTURES OF THE NECK OF THE FEMUR

Boyd, H. B., and George, I. L. (1947): Journal of Bone and Joint Surgery, 29, 13. Соок, A. (i. (1894): Transactions of the American Orthopedic Association, 7, 348.

Cotton, F. J. (1934): Journal of Bone and Joint Surgery, 16, 105.

Cox, W. J. (1936): Journal of Bone and Joint Surgery, 18, 134

Fracture Committee of the American Academy of Orthopaedic Surgeons (1939): Treatment of fractures of the neck of the femur by internal fixation. Journal of Bone and Joint Surgery, 21, 483.

Fracture Committee of the American Academy of Orthopaedic Surgeons (1941): Treatment of fractures of the neck of the femur by internal fixation. Journal of Bone and Joint Surgery, 23, 386.

GaEnslen, F. J. (1935): Journal of Bone and Joint Surgery, 17, 739.

HARRIS, R. I. (1938): Experiences with internal fixation in fresh fractures of the neck of the femur. Journal of Bone and Joint Surgery, 20, 114.

Henderson, M. S. (1936): Proceedings of the Staff Meetings of the Mayo Clinic, 11, 573.

Henderson, M. S. (1937): Archives of Surgery, 35, 419.

Henderson, M. S. (1938): Annals of Surgery, 107, 132.

HENRY, M. O. (1931): Journal of Bone and Joint Surgery, 13, 530.

HenRY, M. O. (1934): Journal of Bone and Joint Surgery, 16, 168.

Henry, M. O. (1938): Journal of Bone and Joint Surgery, 20, 400.

vol. $32 \mathrm{~B}$, No. 4 , NOVEMBER 1950 
Johansson, S. (1932): Acta Orthopaedica Scandinavica, 3, 362.

King, D., Leef, E., and Terwilliger, C. K. (1940): Journal of Bone and Joint Surgery, 22, 168.

KNowles, F. L. (1936): Fractures of the neck of the femur. Wisconsin Medical Journal, 35, 106.

Kulowski, J., and Luck, J. V. (1941): Journal of Bone and Joint Surgery, 23, 17.

LEADBETter, G. W. (1933): A treatment for fracture of the neck of the femur. Journal of Bone and Join Surgery, 15, 931.

LeADbetter, G. W. (1938): Closed reduction of fractures of the neck of the femur. Journal of Bone an Joint Surgery, 20, 108.

LippmanN, R. K. (1939): Experiences with the corkscrew bolt. Journal of Bone and Joint Surgery, 21, 73: Moore, A. T. (1934): Skeletal fixation of fracture of the hip. Journal of the South Carolina Medice Association, 30, 199.

MOoRE, A. T. (1937): Extra-articular fixation of hip with adjustable nails. Surgery, Gynecology an Obstetrics, 64, 420.

O'Meara, J. W. (1935): Journal of Bone and Joint Surgery, 17, 928.

Plummer, W. W. (1938): Comments on internal fixation in fresh fractures of the neck of the femur. Journe of Bone and Joint Surgery, 20, 97.

Ridlon, J. (1897): Transactions of the American Orthopedic Association, 10, 186.

Ridlon, J., and Jones, R. (1892): Annals of Surgery, 16, 60.

Ridlon, J., and Jones, R. (1892): Medical Recorder.

ShAFFer, N. M. (1897): Transactions of the American Orthopedic Association, 10, 176.

Sherman, M. S., and Phemister, D. B. (1947): Journal of Bone and Joint Surgery, 29, 19.

SHERMAN, W. O. (1926): Operative treatment of fractures of the shaft of the femur with maximum fixatior Journal of Bone and Joint Surgery, 8, 494.

Sloat, J. I., and Peterson, L. T. (1939): Journal of Bone and Joint Surgery, 21, 1041.

Smith-Petersen, M. N., Cave, E. F., and Vangorder, G. W. (1931): Intracapsular fractures of the nec of the femur. Archives of Surgery, 23, 715.

SPEED, K. (1935): The Unsolved Fracture. Surgery, Gynecology and Obstetrics, 60, 341.

Telson, D., and Ransohoff, N. (1935): Fixation of the neck of the femur with steel wires. Journal c Bone and Joint Surgery, 17, 727.

Westcort, H. H. (1934): A method for the internal fixation of transcervical fractures of the femur. Journ: of Bone and Joint Surgery, 16, 372.

Whiте, J. W. (1935) : An instrument facilitating use of the flanged nail in treatment of fractures of the hi] Journal of Bone and Joint Surgery, 17, 1065.

Whitman, R. (1893): Medical Record, 43, 59.

Whitman, R. (1897): Transactions of the American Orthopedic Association, 10, 216.

Whitman, R. (1902): A new method of treatment for fractures of the neck of the femur. Annals of Surger! 36, 746.

Whitman, R. (1945): Journal of Bone and Joint Surgery, 27, 334.

WISE, R. A. (1941): Journal of Bone and Joint Surgery, 23, 941.

\section{OTHER FRACTURES}

Anderson, R., McKibiin, W. B., and Burgess, E. (1943): Intertrochanteric fractures. Journal of Bor and Joint Surgery, 25, 153.

Bardenheuer, B., and Graessner, R. (1909): Die Technik der Extensionsverbände. Stuttgart: Ferdinan Enke.

Blake, J. A. (1917): Suspension with Extension in the treatment of Fractures of the Limbs. America Journal of Orthopedic Surgery, 15, 644.

BöHLER, L. (1945) : Die Technik der Knochenbruchbehandlung im Frieden und im Kriege. Vienna: Wilhelı Maudrich.

Charnley, J. C. (1948): Positive Pressure in Arthrodesis of the Knee Joint. Journal of Bone and Joir Surgery, 30-B, 478.

De Lorme, T. L. (1945): Restoration of Muscle Power by Heavy-resistance Exercises. Journal of Bor: and Joint Surgery, 27, 645.

Dunlop, J. (1939): Transcondylar Fractures of the Humerus in Childhood. Journal of Bone and Joir Surgery, 21, 59.

EgGers, G. W. N. (1948): Internal Contact Splint. Journal of Bone and Joint Surgery, 30-A, 41.

Gaenslen, F. J. (1936): The Role of Physical Therapy in Orthopaedic Surgery. Journal of Bone an Joint Surgery, 18, 559.

Haldeman, K. O. (1932): The Role of Periosteum in the Healing of Fractures. Archives of Surgery, 24, 441 Haldeman, K. O., and Moore, J. M. (1934): Influence of a local Excess of Calcium and Phosphorus on th Healing of Fractures. Archives of Surgery, 29, 385. 
HAYNES, H. H. (1939): Treating Fractures by Skeletal Fixation of the Individual Bone. Southern Medical Journal, 32, 720.

HAYNES, H. H. (1943): Skeletal Fixation of Fractures. American Journal of Surgery, N.S. 59, 25.

Jones, R. (1913): An Orthopedic View of the Treatment of Fractures. American Journal of Orthopedic Surgery, 11, 314.

KEY, J. A. (1932): Southern Medical Journal, 25, 909.

KEY, J. A. (1934): The Effect of a local Calcium Depot on Osteogenesis and Healing of Fractures. Journal of Bone and Joint Surgery, 16, 176.

KEY, J. A. (1941): Stainless Steel and Vitallium in Internal Fixation of Bone. Archives of Surgery, 43, 615. Key, J. A. (1946) : Electrolytic Absorption of Bone due to the use of Stainless Steels of different composition for Internal Fixation. Surgery, Gynecology and Obstetrics, 82, 319.

KEY, J. A. (1947) : Journal of Bone and Joint Surgery, 29, 1.

Küntscher, G. (1940): Die Marknagelung von Knochenbrüchen. Archiv für Kilinische Chirurgie, $200,443$. LANE, W. A. (1893): On the Advantages of the steel screw in treatment of ununited fractures. Lancet, ii, 1500. LANE, W. A. (1894): A method of treating simple oblique fractures of the tibia and fibula more efficient than those in common use. Transactions of the Clinical Society of London, 27, 167.

LANE, W. A. (1900): The Operative Treatment of Simple Fractures. Lancet, i, 1489.

LANE, W. A. (1914): The Operative Treatment of Fractures. Second edition. London: The Medical Publishing Company Limited.

Macewen, Wm. (1912): The Growth of Bone. Glasgow: J. Maclehose \& Sons.

Mclaughlin, H. L., Gaston, S. R., Neer, C. S., and Craig, F. S. (1949): Open Reduction and Internal Fixation of Fractures of the long bones. Journal of Bone and Joint Surgery, 31-A, 94.

Mazet, R. (1943): The Use and Abuse of the Anatomic Splint in the Treatment of Fractures of the lower Extremity. Journal of Bone and Joint Surgery, 25, 839.

Moore, J. R. (1944): Delayed Reduction of Fractures. Journal of Bone and Joint Surgery, 26, 151.

MurRay, C. R. (1933): The Exact Role of Physical Therapy in the Treatment of Fractures. Surgery, Gynecology and Obstetrics, 56, 479.

MURRay, C. R. (1941): The Timing of the Fracture-healing Process. Journal of Bone and Joint Surgery, 23, 598 .

MURray, C. R. (1944): Journal of Bone and Joint Surgery, 26, 307.

Peterson, L. T. (1947) : Fixation of Bones by Plates and Screws. Journal of Bone and Joint Surgery, $29,335$. Phemister, D. B. (1935): Bone Growth and Repair. Annals of Surgery, 102, 261.

Potrs, W. J. (1933): The Role of the Haematoma in fracture healing. Surgery, Gynecology and Obstetrics, 57, 318.

Rush, L. V., and Rush, H. L. (1939): A Technique for Longitudinal Pin Fixation of certain Fractures of the Ulna and of the Femur. Journal of Bone and Joint Surgery, 21, 619.

Russell, R. H. (1924): Fracture of the Femur. British Journal of Surgery, 11, 491.

ShaAr, C. M., Kreuz, F. P. Jr., and Jones, D. T. (1944): End-results of treatment of Fresh Fractures by the use of the Stader apparatus. Journal of Bone and Joint Surgery, 26, 471.

Sherman, W. O. (1926): Operative Treatment of Fractures of the Shaft of the Femur with maximum fixation. Journal of Bone and Joint Surgery, 8, 494.

SOEUR, R. (1946) : Intramedullary pinning of Diaphysial fractures. Journal of Bone and Joint Surgery, 28, 309. Stader, O. (1937): Preliminary announcement of a new method of treating fractures. North American Veterinarian, 18, 37.

Steinmann, F. (1911): Zeitschrift für Orthopädische Chirurgie, 29, 96.

Street, D. M., Hansen, H. H., and Brewer, B. J. (1947): The Medullary Nail. Archives of Surgery, 55, 423. Tномаs, H. O. $(1886,1890)$ : Contributions to Surgery and Medicine. London: K. L. Lewis. Part 6Principles of the treatment of fractures and dislocations. Part 7-Fractures, dislocations, deformities and diseases of the lower extremities.

URIST, MI. R., and MCLean, F. C. (1941): Calcification and Ossification I: Calcification in the callus in healing fractures in normal rats. Journal of Bone and Joint Surgery, 23, 1.

Urist. M. R., and McLean, F. C. (1941): Calcification and Ossification II : Control of calcification in the fracture callus in rachitic rats. Journal of Bone and Joint Surgery, 23, 283.

URIST, M. R. (1942): Calcification and Ossification III: The role of local transfer of bone salt in the calcification of the fracture callus. Journal of Bone and Joint Surgery, 24, 47.

URIST, M. R., and Johnson, R. W. (1943): Calcification and Ossification IV. The healing of fractures in man under clinical conditions. Journal of Bone and Joint Surgery, 25, 375.

Venable, C. S., Stuck, W. G., and BeAch, A. (1937): The Effects on bone of the presence of metals; based upon Electrolysis. Annals of Surgery, 105, 917.

Venable, C. S., and Stuck, W. G. (1938): Electrolysis Controlling Factor in the use of metals in treating fractures. Journal of the American Nedical Association, 111, 1349.

vol. $32 \mathrm{~B}$, No. 4, NOVEMBer 1950 
Venable, C. S., and Stuck, W. G. (1948): Results of recent studies and experiments concerning metals used in the Internal Fixation of fractures. Journal of Bone and Joint Surgery, 30-A, 247.

\section{SURGERY OF TENDONS AND OF THE HAND}

Altman, H., and Trott, R. H. (1946) : Muscle Transplantation for Paralysis of the Radial Nerve. Journal of Bone and Joint Surgery, 28, 440.

Auchinloss, H. (1929): Tendon Transplantation. Annals of Surgery, 89, 145.

Biesalski, K., and Mayer, L. (1916): Die physiologische Sehnenverpflanzung. Berlin: J. Springer.

Billington, R. W. (1922): Tendon Transplantation for Musculospiral (radial) Nerve Injury. Journal of Bone and Joint Surgery, 4, 538.

Bunnell, S. (1918): Repair of Tendons in the Fingers. Surgery, Gynecology and Obstetrics, $26,103$.

Bunnell, S. (1922): Repair of Tendons in the Fingers. Surgery, Gynecology and Obstetrics, 35, 88.

Bunnell, S. (1938): Opposition of the Thumb. Journal of Bone and Joint Surgery, 20, 269.

Bunnell, S. (1944): Surgery of the Hand. Philadelphia: J. B. Lippincott Company.

GarLock, J. H. (1926): Repair of Wounds of the Flexor Tendons of the Hand. Annals of Surgery, 83, 111. HARMER, T. W. $(1917,1926)$ : Tendon Suture. Boston Medical and Surgical Journal, 177, 808; 194, 739.

Henze, C., and MaYer, L. (1916): Experimentelle Untersuchungen über Sehnenverpflanzungen und seidene Sehnen. Zeitschrift für Orthopädische Chirurgie, 35, 867.

IRwin, C. E. (1942): Transplants to Thumb to Restore Function of Opposition : End-results. Southern Medical Journal, 35, 257.

Jones, R. (1908): On Arthrodesis and Tendon Transplantation. British Medical Journal, i, 728.

Koch, S. L., and Mason, M. L. (1933): Division of the Nerves and Tendons of the Hand. Surgery, Gynecology and Obstetrics, 56, 1.

LANGE, Professor F. (1910): The Orthopedic Treatment of Spinal Paralysis. American Journal of Orthopedic Surgery, 8, 8.

L'Episcopo, J. B. (1939): Restoration of Muscle Balance in the Treatment of Obstetrical Paralysis. New York Journal of Medicine, 39, 357.

LyLE, H. H. M. (1923) : The Disabilities of the Hand and their Physiological Treatment. Annals of Surgery, 78, 816.

MAYER, L. (1916): Physiological Method of Tendon Transplantation. Surgery, Gynecology and Obstetrics, 22,$182 ; 298 ; 472$.

MAYER, L. (1940): Reconstruction of Extensor Digitorum Communis Sheath. Bulletin of the Hospital for Joint Diseases, 1, 39.

Nicoladoni, K. (1882): Über Sehnentransplantation. Archiv für klinische Chirurgie, 24, 660.

ОвеR, F. R. (1932): An Operation to Relieve Paralysis of the Deltoid IIuscle. Journal of the American Medical Association, 99, 2182.

PeABody, C.W.(1938): Tendon Transposition. An End-result Study. Journal of Bone and Joint Surgery, $20,193$. Royle, N. D. (1938): An Operation for Paralysis of Intrinsic Muscles of the Thumb. Journal of the American Medical Association, 111, 612.

Schwartzmann, J. R., and Crego, Jr., C. H. (1948): Hamstring-tendon Transplantation for the Relief of Quadriceps Femoris Paralysis in Residual Poliomyelitis; Follow-up Study of 134 cases. Journal of Bone and Joint Surgery, 30-A, 541.

StARR, C. L. (1922): Army Experiences with Tendon Transference. Journal of Bone and Joint Surgery, 4, 3. Steindler, A. (1919): Operative Treatment of Paralytic Conditions of the Upper Extremity. Journal of Orthopedic Surgery, 1, 608.

Steindler, A. (1930): Flexor Plasty of the Thumb in Thenar Palsy. Surgery, Gynecology and Obstetrics, 50, 1005.

Steinder, A. (1939): Tendon Transplantation in the Upper Extremity. American Journal of Surgery, N.S. 44, 260.

VulpiUs, O. (1897): Zur Casuistik der Sehnentransplantation. Münchener medizinische Wochenschrift, 44, 409.

\section{BIOCHEMISTRY}

Banting, F. G., and Best, C. H. (1922): Journal of Laboratory and Clinical Medicine, 7, 464.

Bodansky, A. (1931): Proceedings of the Society for Experimental Biology and Medicine, 28, 760.

Bodansky, A. (1933): Journal of Biological Chemistry, 101, 93.

Bodansky, A., and JAfFe, H. L. (1934): Archives of Internal Medicine, 54, 88. American Journal of Diseases of Children, 48, 1268.

Collip, J. B. (1925): Journal of Biological Chemistry, 63, 395.

Gurtman (1938): Journal of Clinical Medicine, 17, 473.

Hess (1924): Transactions of the American Pediatric Society, 36.

Huggins, C., and Clark, P. J. (1940): Journal of Experimental Medicine, 72, 747. 
Huggins, C., and Hodges, C. V. (1941): Cancer Research, 1, 293.

Huggins, C., Scott, W. W., and Hodges, C. V. (1941): Journal of Urology, 46, 997.

Huggins, C., Stevens, R. E., and Hodges, C. V. (1941): Archives of Surgery, 43, 209.

KAY, H. D. (1930) : Journal of Biological Chemistry, 89, 249.

King, E. J., and Armstrong, A. R. (1934): Canadian Medical Association Journal, N.S. 31, 376.

McCollum, E. V., Simmonds, N., Shipley, P. G., and PARK, E. A. (1922): Journal of Biological Chemistry, 50, 5.

Recklinghausen, F. von (1930): Proceedings of the Society for Experimental Biology and Medicine, 27, 708; 710; 795 .

Recklinghausen, F. von (1930): Journal of Biological Chemistry, 88, 629.

Recklinghausen, F. von (1930): Journal of Experimental Medicine, 52, 669.

Recklinghausen, F. von (1931): Archives of Pathology, 11, 207.

Robison, R. (1932): The Significance of Phosphoric Esters in Metabolism. New York: The New York University Press.

STEENBock (1924): Science (Sept. 5).

\section{OSTEOMYELITIS}

Albee, F. H., and Patterson, M. B. (1930): The Bacteriophage in Surgery. Annals of Surgery, $91,855$. BAER, W. S. (1931): The Treatment of Chronic Osteomyelitis with the Maggot. Journal of Bone and Joint Surgery, 13, 438.

BICK, E. M. (1941): Sulfone Chemotherapy in Hematogenous Osteomyelitis. Surgery, Gynecology and Obstetrics, 72, 995.

Buchman, J. (1945): Penicillin in the Treatment of Chronic Osteomyelitis. Archives of Surgery, $51,81$.

Chain, E., Florey, H. W., et al. (1940): Penicillin as a Chemotherapeutic Agent. Lancet, ii, 226.

Cleveland, M., and Grove, J. A. (1945): Delayed Primary Closure of Wounds with Compound Fractures. Journal of Bone and Joint Surgery, 27, 452.

Compere, E. L., Schnute, W. J., and Cattell, L. M. (1945): The Use of Penicillin in the Treatment of Acute Hematogenous Osteomyelitis in Children. Annals of Surgery, 122, 954.

Dickson, F. D., Diveley, R. L., and Kiene, R. (1941): The Use of Sulfathiazole in the Treatment of Subacute and Chronic Osteomyelitis. Journal of Bone and Joint Surgery, 23, 516.

Doмagk, G. (1935): Ein Beitrag zur Chemotherapie der bakteriellen Infektionen. Deutsche Medizinische Wochenschrift, 61, 250.

Fleming, A. (1929): On the Antibacterial Action of Cultures of a Penicillium with Special Reference to their Use in the Isolation of B. Influenzae. British Journal of Experimental Pathology, 10, 226.

Herrell, W. E., Nichols, D. R., and Heilman, D. H. (1944): Penicillin: its Usefulness, Limitations, Diffusion and Detection, with Analysis of 150 Cases in which it was Employed. Journal of the American Medical Association, 125, 1003.

Kirby, W. M. M., and HePp, V. E. (1944): Treatment of Osteomyelitis of the Facial Bones with Penicillin. Journal of the American Medical Association, 125, 1019.

MacNeal, P. S. (1940): The Use of Asparagin Bacteriophage in the Treatment of Acute Hematogenous Osteomyelitis. Surgery, Gynecology and Obstetrics, 71, 766.

ORR, H. W. (1927): The Treatment of Acute Osteomyelitis by Drainage and Rest. Journal of Bone and Joint Surgery, 9, 733.

Trueta, J. (1939): Treatment of War Wounds and Fractures. London: Hamish Hamilton Ltd.

Trueta, J. (1943): The Principles and Practice of War Surgery, with Reference to the Biological Method of the Treatment of War Wounds and Fractures. St Louis: C. V. Mosby Company.

Waksman, S. A. (1943): Production and activity of streptothricin. Journal of Bacteriology, 46, 299.

\section{TUBERCULOSIS}

Bosworth, D. M., and Green, L. A. (1946): Experience with arthrodesis for tuberculosis of the hip. Quarterly Bulletin of the Sea View Hospital, 8, 39.

Bosworth, D. M., and Levine, J. (1949): Tuberculosis of the Spine. An analysis of cases treated surgically. Journal of Bone and Joint Surgery, 31-A, 267.

Brittain H. A. (1941): Ischiofemoral Arthrodesis. British Journal of Surgery, 29, 93.

Chandere, Fremont, A., and Fox, T. A. (1949): Amputation for Discrepancy of Limb Length in tuberculosis of the Hip. Journal of Bone and Joint Surgery, 31-A, 420.

FARKAS, A. (1939): A New Operative treatment of tuberculous coxitis in children. Journal of Bone and Joint Surgery, 21, 323.

GILL, G. G. (1944): The cause of discrepancy in length of the limbs following tuberculosis of the hip in children. Journal of Bone and Joint Surgery, 26, 272.

Hibss, R. A. (1930): The treatment of tuberculosis of the joints of the lower extremities by operative fusion. Journal of Bone and Joint Surgery, 12, 749.

vol. $32 \mathrm{~B}$, No. 4 , NOVEMBER 1950 
Kestler, O. C. (1947): Early epiphysial growth arrest about the knee joint following various infectious lesions of the hip. Bulletin of the Hospital for Joint Diseases, 8, 94.

Trumble, H. C. (1937): Fixation of the hip joint by means of extra-articular bone graft: Late results. British Journal of Surgery, 24, 728.

\section{ARTHRITIS}

Albright, F. (1947): Annals of Internal Medicine, 27, 861.

Bagganstoss, A. H., and Rosenberg, E. F. (1944): Archives of Pathology, 37, 54.

Bennett, G. A., Waine, H., and Bauer, W. (1942): Changes in the Knee Joint at Various Ages. New York: The Commonwealth Fund.

Bickel, W. H., Young, H. H., Pfuetze, K. H., and Norley, T. (1948) : Journal of the American Medical Association, 137, 682.

Boland, E. W. (1947): Annals of the Rheumatic Diseases, 6, 195.

Bunim, J. J., McEwen, C., Sokoloff, S., and Wilens, S. (1950) : American Journal of the Medical Sciences, 219, 174.

Carlisle, J. M., Gibson, A., and Schmatolla, E. (1950): Cortisone. Postgraduate Medicine, 8, 113.

Cecil, R. L. (1940): Proceedings of the Staff Meetings of the Mayo Clinic, 15, 556.

Copeman, W. S. C., and Ackerman, W. W. (1944): Quarterly Journal of Medicine, N.S. 13, 37.

Forsham, P. H., Thorn, G. W., Prunty, F. T. G., and Hills, A. G. (1948) : Journal of Clinical Endocrinology, 8, 15.

Freund, H. A., Steiner, G., Leichtentritr, B., and Price, A. E. (1942): American Journal of Pathology, 18, 865.

Gibson, H. J., Kersley, G. D., and Desmarais, M. H. L. (1946): Annals of the Rheumatic Diseases, 5, 666. Hench, P. S., Bauer, W., Boland, E. W., Crain, D. C., Freyberg, R. H., Graham, W., Holbrook, W. P., Lockie, L. M., McEwen, C., Rosenberg, E. F., and Stecher, R. M. (1948) : Ninth Rheumatism Review. Annals of Internal Medicine, 28, 31.

Hench, P. S. (1949): Annals of the Rheumatic Diseases, 8, 90.

Hench, P. S., Kendall, E. C., Slocumb, C. H., and Polley, H. F. (1950): Archives of Internal Medicine, 85, 545.

Hench, P. S., and Rosenberg, E. F. (1944): Archives of Internal Medicine, 73, 293.

Kendall, E. C. (1949): Proceedings of the Staff Meetings of the Mayo Clinic, 24, 298.

LI, C. H. (1948): Transactions Conference on Metabolic Aspects of Convalescence. New York: Josiah Macy, Jr., Foundation.

Ludwig, A. O., Short, C. L., and Bauer, W. (1943): New England Journal of Medicine, 228, 306.

MeYer, K. (1947): Physiological Reviews, 27, 335.

RAGAN, C. (1948): Annals of the Rheumatic Diseases, 7, 35

Ralli, E. P. (1949): Transactions Conference on Adrenal Cortex. New York: Josiah Macy, Jr., Foundation. Reichstein, T. (1936): Acta Helvetica Chemica, 19, 1107.

Rose, H. M., Ragan, C., Pearce, E., and Lipman, M. O. (1948) : Proceedings of the Society for Experimental Biology and Medicine, 68, 1.

Selye, H, (1946): Journal of Clinical Endocrinology, 6, 117.

Short, C. L., and BAUER, W. (1942): New England Journal of Medicine, 227, 442.

SLocumb, C. H. (1943): Clinics, 2, 169.

SteCher, R. M. (1941): American Journal of the Medical Sciences, 201, 801.

Steinbrocker, O., Spitzer, N., and Friedman, H. H. (1948): Annals of Internal Medicine, 29, 22.

Steinbrocker, O., Traeger, C. H., and Batterman, R. C. (1949): Journal of the American Medical Association, 140, 659 .

\section{GEREBRAL PALSY}

Chandler, F. A. (1933): Re-establishment of normal leverage of the patella in knee flexion deformity in spastic paralysis. Surgery, Gynecology and Obstetrics, 57, 523.

Collier, James (1924): The Pathogenesis of Cerebral Diplegia. Brain, 47, 1.

Davidian, Hagop (1938): Athetosis (Review of the literature with clinical report of a case). Alienist and Neurologist, 36, 339.

Durham, H. A. (1938): A Procedure for the correction of internal rotation of the thigh in spastic paralysis. Journal of Bone and Joint Surgery, 20, 339.

Freud, Sigmund (1897): Die Infantile Cerebrallähmung. Vienna: Alfred Hölder.

GreEN, W. T. (1942): Tendon Transplantation of the Flexor Carpi Ulnaris for pronation-flexion deformity of the wrist. Surgery, Gynecology and Obstetrics, 75, 337.

Green, Wm. T., and McDermotr, Leo J. (1942): Operative treatment of cerebral palsy of spastic type. Journal of the American Medical Association, 118, 434.

McCarroll, H. R., and Schwartzmann, J. R. (1943): Spastic Paralysis and allied disorders. Journal of Bone and Joint Surgery, 25, 745. 
Phelps, W. M. (1938): The care and treatment of cerebral palsies. Journal of the American Medical Association, 111, 1.

Phelps, Winthrop Morgan (1946) Recent significant trends in the care of cerebral palsy. Lectures on Regional Orthopedic Surgery and Fundamental Orthopedic Problems. (Reprint from Southern Medical Journal, 39, 132.)

Schwartz, Ph., and Fink, Lotte (1926) : Morphologie und Entstehung der geburtstraumatischen Blutungen in Gehirn und Schädel des Neugeborenen. Zeitschrift für Kinderheilkunde, 40, 427.

Stoffel, Adolf (1913): The treatment of spastic contractures. American Journal of Orthopedic Surgery, 10,611 .

\section{MUSGLE RELAXANTS}

Bennett, A. E. (1941): Clinical investigations with curare in organic neurologic disorders. American Journal of the Medical Sciences, 202, 102.

Berger, F. M., and Bradley, W. (1946): The pharmacological properties of A:B Dihydroxy(2-Methylphenoxy)-propane (myanesin). British Journal of Pharmacology, 1, 265.

Berger, F. M., and Schwartz, R. P. (1948): Oral "Myanesin" in treatment of spastic and hyperkinetic disorders. Journal of the American Medical Association, 137, 772.

Burman, M. S. (1938): Curare therapy for the release of muscle spasm and rigidity in spastic paralysis and dystonia musculorum deformans. Journal of Bone and Joint Surgery, 20, 754.

Burman, M. S. (1939): Therapeutic use of curare and erythroidine hydrochloride for spastic and dystonic states. Archives of Neurology and Psychiatry, 41, 307.

Schlesinger, E. B. (1946): Recent advances in the use of curare in clinical practice. Bulletin of the New York Academy of Medicine, 22, 520.

Schlesinger, E. B., and Ragan, C. (1946): “ Muscle spasm " in acute low back pain and similar syndromes. A new method of treatment with curare (d-tubocurarine in oil and wax). American Journal of Medicine, 1,621. Schlesinger, E. B., Drew, A. L., and Wood, B. (1948): Clinical studies in the use of myanesin. American Journal of Medicine, 4, 365 .

Schlesinger, E. B., and Stinchfield, F. S. (1950): Journal of Bone and Joint Surgery (in press).

Stephen, C. R., and Chandy, J. (1947): Clinical and experimental studies with myanesin. Canadian Medical Association Journal, 57, 463.

\section{ADMINISTRATION}

Bick, E. M. (1948) : Source Book of Orthopaedics. Baltimore: The Williams and Wilkins Company. Frampton, Merle E., and Rowell, Hugh Grant (1938): Education of the Handicapped. Yonkers, N.Y.: The World Book Company.

KeEsecker, Ward W. (1929): Digest of Legislation for Education of Crippled Children. Bulletin No. 5 of the United States Office of Education. Washington, D.C.: Government Printing Office.

MacDonald, Mary E. (1944): Federal Grants for Vocational Rehabilitation. Chicago, Illinois: University: of Chicago Press.

McMurtrie, Douglas C. (1916): A Study of the Character and Present Status of Provision for Crippled Children in the United States. American Journal for Care of Crippled, item 2, p. 38.

Shands, Jr., A. R., (1942): Directory of Hospitals and Convalescent Institutions engaged in work for crippled children. Elyria, Ohio: The National Society for Crippled Children in the United States of America. Solenberger, Edith Reeves (1914): Care and Education of Crippled Children in the United States. New York: Survey Associates.

White House Conference on Child Health and Protection (1930): New York and London: The Century Co., 1933.

Vol. IV A-Organization for the Care of Handicapped Children-Committee on National, State and Local Organization for the Handicapped. Section IV-The Handicapped: Prevention; Maintenance Protection.

Vol. IV B-The Handicapped Child-Committee on Physically and Mentally Handicapped. Section IV-The Handicapped: Prevention; Maintenance; Protection.

Public School Classes for the Crippled Children (1918): Bulletin No. 10 of the United States Office of Education. Washington, D.C.: Government Printing Office.

A Digest of Federal and State Legislation Affecting Crippled Children and the Physically Handicapped (1938): Elyria, Ohio: National Society for Crippled Children.

The National Health Survey 1935-36 (1938): The Prevalence and Causes of Orthopedic Impairments. National Institute of Health, U.S. Public Health Service, Washington, D.C.

Twenty-fourth Annual Report of the Secretary of Labor, 1936: pp. 109-137.

Twenty-fifth Annual Report of the Secretary of Labor, 1937: pp. 98-127.

Economic Security Act Hearings before the Committee on Finance, U.S. Senate 74th Congress-First Session on S1130, Part 6 (1935): Washington, D.C.: United States Government Printing Office.

VOL. 32 B, NO. 4, NOVEMBER 1950 